DEPARTAMENTO DE INGENIERÍA GEOLÓGICA Y MINERA ETS DE INGENIEROS DE MINAS Y ENERGÍA UNIVERSIDAD POLITÉCNICA DE MADRID

\title{
Modeling and Risk Assessment of Fault- Induced Mine Water Inrush
}

\author{
Doctoral Thesis
}

Author: Zhou Qinglong

\section{Directed by: \\ Dr. Arturo Hidalgo López \\ Dr. Juan Herrera Herbert}

Programa de Doctorado en Investigación, Modelización y Análisis del Riesgo en Medio Ambiente por la Universidad Politécnica de Madrid,

DIMARMA (RD 99/2011) 


\begin{abstract}
In underground mining, water inrush is a common hydrogeological hazard and is a deadly killer. Over the recent decades countless water inrush accidents have occurred in the main coal producing countries (China, India, Poland, Russia, etc.) and have killed thousands of miners. Among all the occurred water accidents fault-induced water inrushes account for a large proportion, this brings the urgency of researching the mechanisms and assessing the risk of fault-induced water inrush. This thesis concerns the fault-induced water inrush from three perspectives, the mechanism, the risk assessment and the post-disaster measure.
\end{abstract}

To research the mechanisms of fault-induced water inrush, a computational model of a typical underground stope with a hidden fault was established for quantitatively assessing the magnitude of the stress concentration of the stress fields of the fault-tip. The numerical simulation was performed using the extended finite element method and fracture mechanics, and the simulation results suggested that the stress concentration at fault tip caused by fluid pressure, in-situ stresses and mining-induced stresses plays a key role in inducing fault reactivation and thus further inducing water inrush.

To achieve the risk assessment of fault-induced water inrush, two methodologies were introduced into the research, the adaptive neuro-fuzzy inference system (ANFIS) and the rock engineering systems (RES). The former methodology was introduced for predicting the probability of water inrush caused by a specific fault and the later one was introduced for mapping the fault-induced water inrush risk for a whole coalfield. By means of these two methodologies, two quantitative risk assessment models (ANFIS model and RES model) were established and corresponding case studies were also elaborately implemented by using these two established models. The final assessment results showed that the ANFIS model is highly accurate in the prediction of water inrush cause by a specific fault and RES model can clearly get a water inrush safety map for a whole coalfield. 
For fault-induced water inrushes, the most important post-disaster measure is to quickly recognize the inrush sources, accurately identifying which aquifer or which water body is directly related to the inrush accident is the key step of controlling the accident and reducing casualties and economic losses. In this thesis, BP (back propagation) neural network was proposed to identify the water-inrush sources, according to the case studies conducted in Jiaozuo mine area, the results showed that the proposed method in this thesis is an effective and accurate method in recognizing the water-inrush sources. 


\section{Resumen}

En minería subterránea o de interior, las irrupciones súbitas de agua a las labores mineras constituyen un riesgo que se hace muy común en algunas zonas con graves consecuencias en muchas ocasiones mortales. En las últimas décadas se han registrado innumerables accidentes por avenidas de agua en los principales países productores de carbón (China, India, Polonia, Rusia, etc.) que han provocado la muerte a miles de mineros según los registros oficiales. De entre todos los accidentes provocados por el agua, los producidos por inundaciones de las labores desde fallas geológicas representan en estos países una alta proporción, lo que trae consigo una urgencia por investigar los mecanismos de éste tipo de fenómenos y la necesidad de evaluar el riesgo por inundación inducida por fallas. Esta tesis doctoral aborda la incursión súbita de aguas inducida por fallas desde tres perspectivas: su mecanismo, la evaluación del riesgo y las medidas posteriores al desastre.

Para investigar los mecanismos de entrada de aguas inducidos por fallas, se estableció un modelo computacional de una capa subterránea típica de carbón con una falla oculta con el fin de evaluar cuantitativamente la magnitud de la concentración de esfuerzos de los campos tensionales de la falla. La simulación numérica se realizó utilizando el método de elementos finitos extendidos y la mecánica de la fractura, y los resultados de la simulación sugirieron que la concentración de esfuerzos en la punta de la falla causada por la presión del fluido, tensiones in situ y tensiones inducidas por la actividad minera juegan un papel clave en la inducción de la reactivación de fallas y favoreciendo la intrusión de aguas.

Para conseguir la evaluación del riesgo de inundación inducida por fallas, se introdujeron dos metodologías en las investigaciones llevadas a cabo: el sistema de inferencia adaptativa neurofuzzy (adaptive neuro-fuzzy inference system - ANFIS) y los sistemas de ingeniería de rocas (rock engineering systems - RES). La primera metodología fue introducida para predecir la probabilidad de una irrupción de aguas causada por una falla específica y la segunda fue introducida para cartografiar el riesgo de irrupción de agua inducida por la falla para toda una cuenca. Mediante estas dos metodologías se establecieron dos modelos cuantitativos de evaluación del riesgo (modelo ANFIS y modelo RES) y los correspondientes estudios de casos fueron elaborados utilizando estos 
dos modelos establecidos. Los resultados de la evaluación final mostraron que el modelo ANFIS es muy preciso en la predicción de la causa de la irrupción de aguas por una falla específica y el modelo RES puede obtener claramente un mapa de seguridad de la inundación de agua para toda una cuenca minera.

Para inundaciones de labores mineras inducidas a partir de fallas, la medida más importante después de ocurrido el desastre es reconocer rápidamente las fuentes de entrada. Identificar con precisión qué acuífero o qué cuerpo de agua está directamente relacionado con el accidente de entrada es el paso clave para controlar el accidente y reducir las bajas así como las pérdidas económicas. En esta tesis, se propone el uso de la red neural de retropropagación (back propagation - BP) para identificar las fuentes de inundación de agua. Según los estudios de casos realizados en el área minera de Jiaozuo, los resultados mostraron que el método propuesto en esta tesis es un método eficaz y preciso para reconocer las fuentes y el origen de las irrupciones de aguas. 


\section{摘要}

在地下采掘活动中, 突水是一个常见而致命的水文地质灾害。在过去的几十年, 在主要的产煤国（中国、印度、波兰、俄罗斯, 等) 发生了无以计数的地下突水 事故, 导致了成千上万的矿工伤亡。在这些已经发生的突水事故中, 断层导致的 突水占了相当大的比例, 因此研究断层致突的机理和对断层致突进行有效的风险 评价近年逐渐变成一个函待解决的难题。基于此背景, 这篇论文从发生机理, 风 险评价和灾后措施三个方面对断层突水进行相关研究。

为了对断层致突的机理进行模拟研究, 本论文建立了一个典型的含隐伏断层的地 下采场计算模型, 目的在于对断层尖端的应力集中场进行定量分析。该计算模型 的模拟在本论文中通过扩展有限元和断裂力学得以实现。模拟结果表明: 在地下 开采活动中, 由渗透压力, 地应力和采动应力联合导致的断层尖端的应力集中是 导致隐伏断层活化从而引发突水的关键因素。

为了实现对断层突水的风险评价, 本论文引入了两种新颖的系统研究方法, 自适 应神经模糊推理系统和岩石工程系统。前者用于预测单个断层致突的风险性, 后 者用于对整个矿区的断层致突风险进行风险分区。文中首先基于这两种系统研究 方法建立了相应的断层致突风险评价模型, 并应用建立的模型进行了相对应的实 例研究验证。最终的评价结果表明, 自适应神经模糊推理系统在预测单个断层致 突的风险性方面有很高的精确性, 岩石工程系统能对整个矿区的断层致突风险性 进行清晰的风险分区。

对断层致突的灾后研究方面, 本文重点研究了如何实现水源的快速识别。在突水 灾害发生后, 快速且准确的识别哪一个含水层或者哪一个地表水体直接与突水事 故相关联在控制灾害、减少伤亡与最小化经济损失方面起着至关重要的作用。在 本文中, 应用反传神经网络进行水源识别的模型被提出, 应用该模型对文献报道 
的关于中国焦作矿区的地下水文数据进行验证计算, 结果表明提出的模型能有效 且精确的进行快速的水源识别。 


\section{Acronyms}

AT Aquifuge thickness

AHP Analytic hierarchy process

ANFIS Adaptive neuro-fuzzy inference system

ANN Artificial neural network

BN Bayesian network

BP Back-propagation

CA Clustering analysis

DACS Dip angle of coal seam

DZ Damage zone

DWF Distance to working face

DOF Degree of freedom

ESQ Expert semi-quantitative

FEM Finite element method

FIS Fuzzy inference system

FZ Fracture zone

FT Fault throw

FNN Fuzzt neural network

MH Mining height

PCA Principal component analysis

PUM Partition of unity method

RES Rock engineering systems

RFPA Rock failure process analysis system

RBF Radial basis function

SIFs Stress intensity factors

WP Water pressure

XFEM Extended finite element method 


\section{Table of contents}

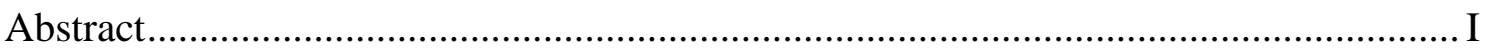

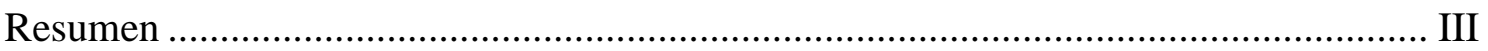

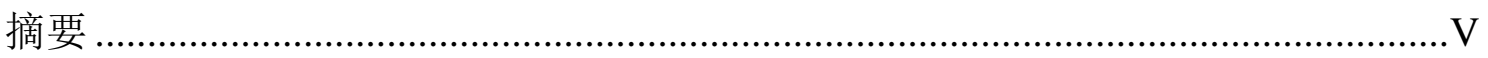

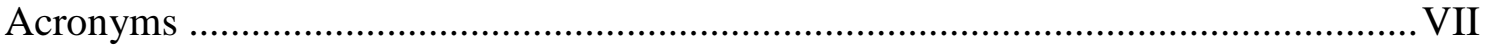

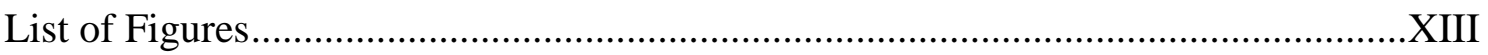

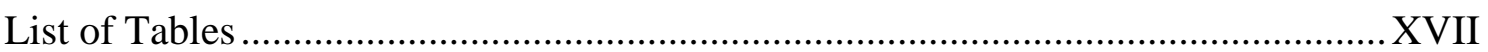

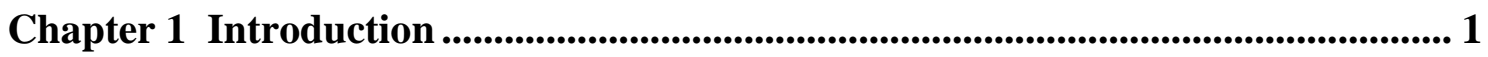

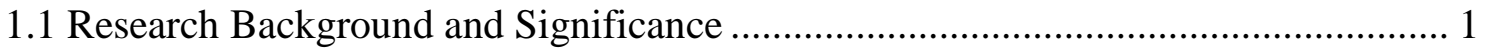

1.1.1 General overview of the problem and risks of water inrushes in top coal

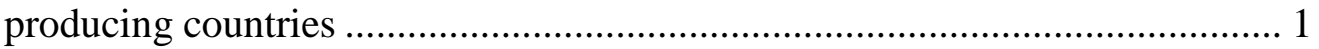

1.1.2 Description of the situation regarding water inrush problems in China.. 5

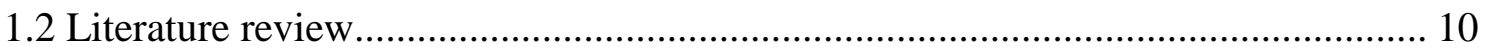

1.2.1 Research about mechanisms of water inrush....................................... 10

1.2.2 Researches about the risk assessment of water inrush ......................... 15

1.2.3 Research on the recognition of water-inrush sources ........................... 19

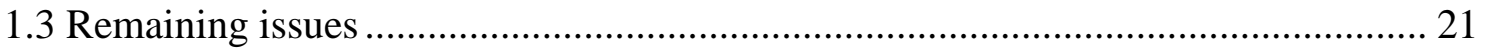

Chapter 2 Research Objectives, Methods and Thesis Organization ........................ 25

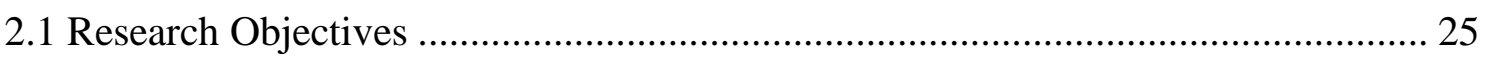

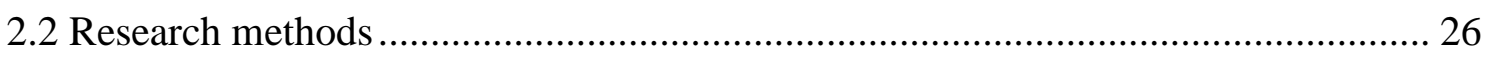

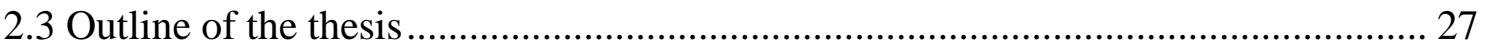

Chapter 3 Theories and Fundamentals of the Applied Methods ............................ 31

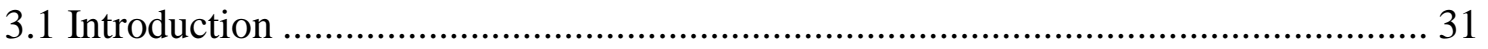

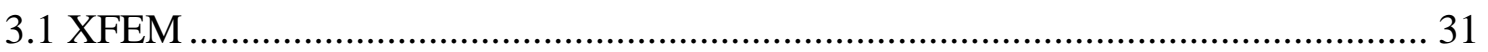

3.1.1 Brief introduction of XFEM ........................................................ 31

3.1.2 The basic formulation of XFEM ...................................................... 32

3.1.3 The Governing Equations of XFEM …............................................ 36

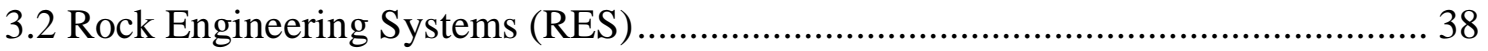




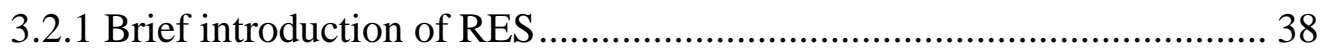

3.2.2 Interaction matrix and its coding methods ......................................... 39

3.2.3 More details about the ESQ coding method ........................................ 42

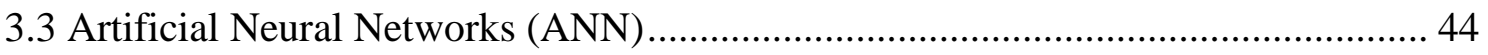

3.3.1 Brief introduction of ANN ............................................................. 44

3.3.2 The structure of biological neuron and neural network....................... 44

3.3.3 Artificial neuron and artificial neural network ................................... 46

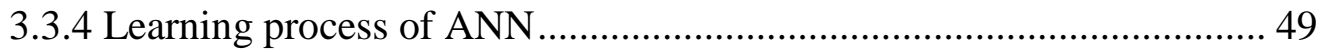

Chapter 4 Modeling and Analysis of Fault-Induced Water Inrush with XFEM .. 51

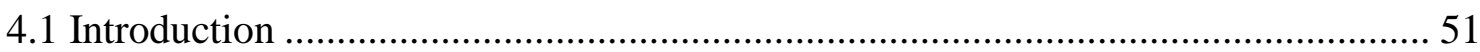

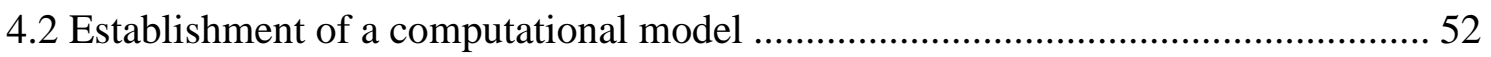

4.2.1 Water-conducting property of fault .................................................... 52

4.2.2 Establishment of a fault-induced water inrush model .......................... 53

4.2.3 Brief description of computational fracture mechanics....................... 54

4.3 Formulation of XFEM with consideration of surface loading ................................ 55

4.3.1 Principle of virtual work when considering fluid pressure.................... 55

4.3.2 Governing equations when considering surface loading ..................... 56

4.4 Fracture criterion and stress intensity factors (SIFs) for mixed mode crack............ 58

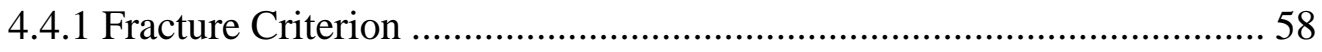

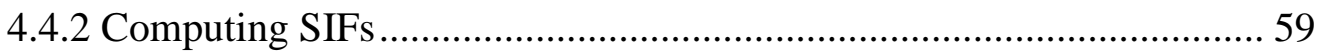

4.5 Numerical implementation and computational results ......................................... 61

4.5.1 How the associated factors affect the fault's stress fields .................... 63

4.5.2 Whether the advancing of mining face could result in fault activation. 67

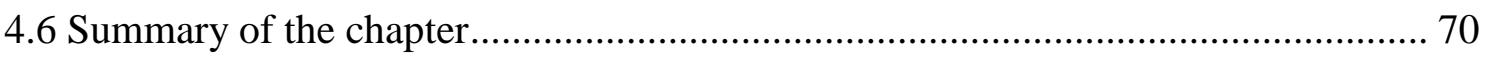

Chapter 5 Risk Assessment of Fault-Induced Water Inrush: Application to a Specific Fault........................................................................................................................................... 71

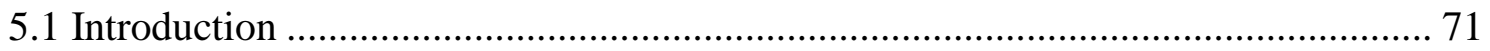

5.2 Two typical fault-induced inrushes in underground mining ................................. 71

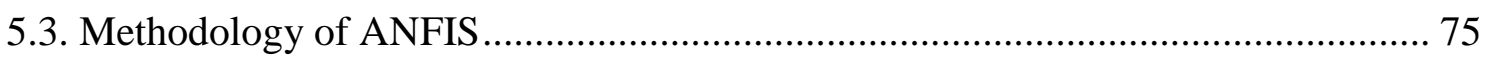

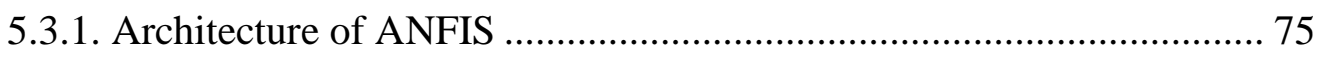

5.3.2 Hybrid learning rule of ANFIS........................................................ 78

5.4. Risk assessment of fault-induced water inrush with ANFIS .................................. 79 


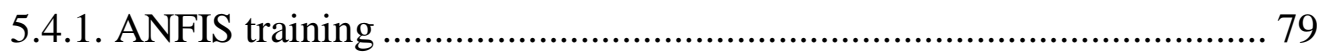

5.4.2. Using the trained rules to infer water inrush index ............................. 84

5.4.3. Using the water inrush index to predict the inrush risk....................... 88

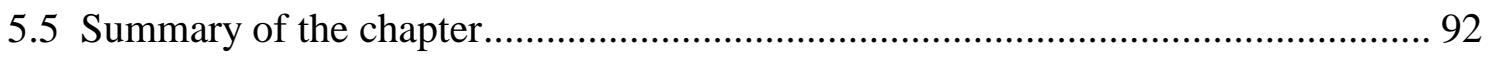

\section{Chapter 6 Risk Assessment of Fault-Induced Water Inrush: Application to a Whole}

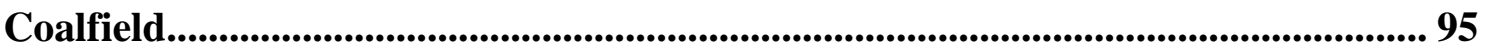

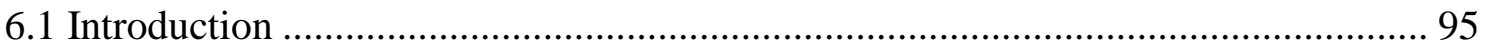

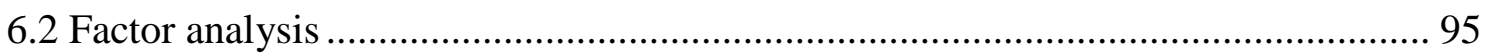

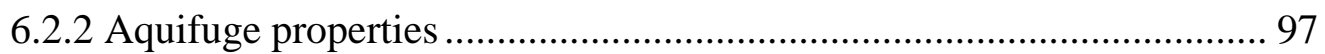

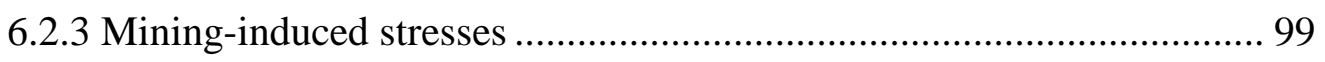

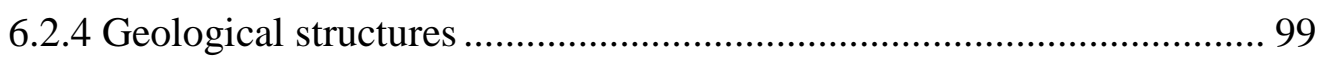

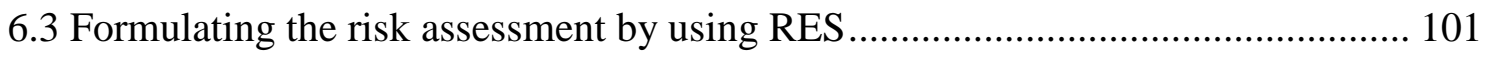

6.3.1 Formulating the interaction matrix ................................................. 101

6.3.2 Interaction matrix coding and C-E plot ............................................. 102

6.3.3 Computing water inrush index ..................................................... 105

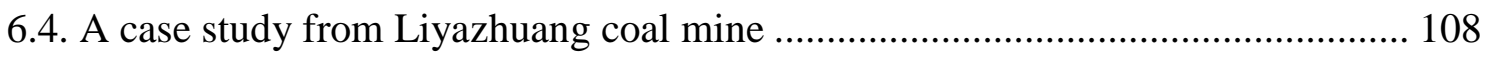

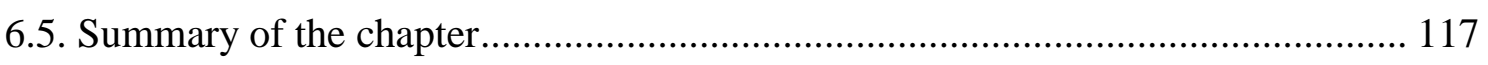

Chapter 7 Solving the Problem of Identifying Water Sources Rapidly After an

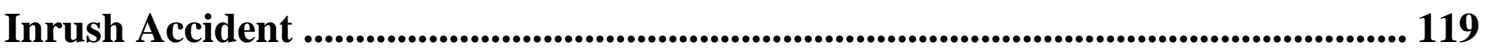

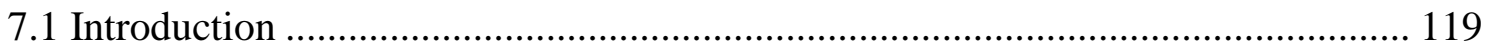

7.2 The basis of using hydrochemical characteristics to identify water sources.......... 119

7.3 The limitations of traditional used methodologies ................................................ 120

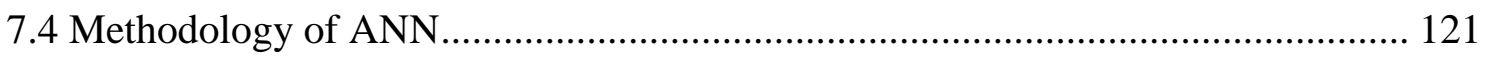

7.4.1 Back propagation neural network................................................. 121

7.4.2 Detailed algorithm ......................................................................... 122

7.5. A case study from Jiaozuo mine area ................................................................ 124

7.5.1 The establishing and training of ANN.............................................. 124

7.5.2 The testing and forecasting processes ........................................... 128

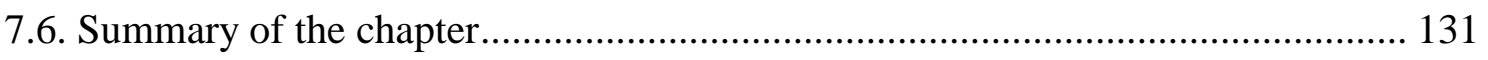

Chapter 8 Conclusions and recommendations for future work........................... 133

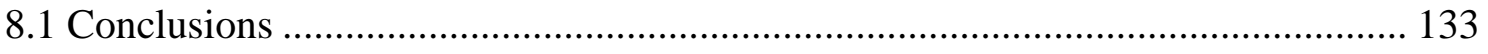


8.2 Recommendations for future work...

References. 


\section{List of Figures}

Fig. 1.1 Using fracture mechanics to analyze the fault-induced water inrush model, this figure is modified from Chen (2011).

Fig. 1.2 Observing borehole layout and observation section of the water-conducting fracture zone in the underlying strata for inclined coal seam in Huainan coal mines, Anhui Province. (Zhang, 2005)

Fig. 1.3 The profile of the water-conducting fracture zone varied with the change of the dip angle of coal seam (Miao et al., 2011)

Fig. 1.4 A BN topology nstructure of floor water-inrush hazard assessment (Dong et al. 2012).

Fig. 3.1 Elements and nodes enrichment scheme for quadrilateral elements crossed by a crack, squares show the crack tip enrichment, and circles are related to the heaviside enrichment.

Fig. 3.2 Location coordinates system at the crack tip.

Fig. 3.3 Location coordinates system at the crack tip.

Fig. 3.4 Simple binary interaction matrix.

Fig. 3.5 Interaction matrix of generic underground excavations. (An example for showing how to construct an interaction matrix in practical projects).

Fig. 3.6 Coding methods for interaction matrix (Hudson and Harrison, 1992).

Fig. 3.7 Summations of coding values in the row and column through each parameter to establish the cause and effect co-ordinates.

Fig. 3.8 Cause-Effect plot: parameter interaction intensity and dominance.

Fig. 3.9 Illustration of a biological neuron with the components (Modified form David, 2005).

Fig. 3.10 The structure of an artificial neuron.

Fig. 3.11 A typical ANN with three layers.

Fig. 4.1 Typical structural elements of a fault zone, generally it consists of two parts: damage zone (DZ) and fault core (FC), fault gouge and fault breccia are structure elements within the fault core and sets of fractures are subsidiary structures in damage zones.

Fig. 4.2 A simplified stope model of coal mining. 
Fig. 4.3 A solid domain $\Omega$ with a crack $\Gamma_{c}$ subjected to a pair of internal pressures $\left(\boldsymbol{p}^{+}\right.$and $\left.\boldsymbol{p}^{-}\right)$on crack surfaces.

Fig. 4.4 Computational mesh generated based on the established model shown in Figure 4.2.

Fig. 4.5 Von-Mises stress contours of the whole computational domain.

Fig. 4.6 The whole process of how a fault-induced water inrush accident caused in a mine face.

Fig. 4.7 How the variation of the mining depth affects the stress field of the fault tip.

Fig. 4.8 How the variation of the fluid pressure impacts on the stress field of the fault tip.

Fig. 4.9 How the variation of the fault dip impacts on the stress field of the fault tip.

Fig. 4.10 How the variation of the fault length impacts on the stress field of the fault tip.

Fig. 4.11 The advancing process of a mining face from right to left.

Fig. 4.12 How the advancing of the mining face influences the stress field of the fault tip.

Fig. 5.1 A small fault is connected to an aquifer but not to a coal seam.

Fig. 5.2 The coal seam and the aquifer are connected by a large fault.

Fig. 5.3 A typical ANFIS model with two inputs and one output.

Fig. 5.4 ANFIS structure used for the assessment of water inrush index.

Fig. 5.5 The initial FIS rules before training and after training.

Fig. 5.6 The training results of the ANFIS.

Fig. 5.7 The shape of the membership functions after training (for parameters WP, MH and AT).

Fig. 5.8 The shape of the membership functions after training (for parameters FT, DACS and DWF).

Fig. 5.9 The inference process and result of the water inrush index for 31503 working face in Huatai coal mine by using the 13 trained rules.

Fig. 5.10 The inference process and result of the water inrush index for 51302 working face in Liangzhuang coal mine by using the trained rules.

Fig. 5.11 The inference process and result of the water inrush index for 6194 working face in Panxi coal mine by using the 13 trained rules. 
Fig. 5.12 The inference process and result of the water inrush index for 9602 working face in Baizhuang coal mine by using the 13 trained rules.

Fig. 5.13 The inference process and result of the water inrush index for 61106 working face in Huahen coal mine by using the 13 trained rules.

Fig. 5.14 The assessment result of 31503 working face in Huatai coal mine.

Fig. 5.15 The assessment result of 51302 working face in Liangzhuang coal mine.

Fig. 5.16 The assessment result of 6194 working face in Panxi coal mine.

Fig. 5.17 The assessment result of 9602 working face in Baizhuang coal mine.

Fig. 5.18 The assessment result of 61106 working face in Huahen coal mine.

Fig. 6.1 The constructed interaction matrix of the water inrush system.

Fig. 6.2 Parameter interaction intensity and dominance.

Fig. 6.3 The histogram of parameter interactive intensity.

Fig. 6.4 The water output contour map of the Carboniferous Limestone aquifer in Liyazhuang coal mine.

Fig. 6.5 The two-dimensional fault traces of Liyazhuang coal mine

Fig. 6.6 The final calculation results of the FD and I+E based on the two-dimensional fault traces.

Fig. 6.7 The distribution of surface water bodies in Liyazhuang coal mine.

Fig. 6.8 The water inrush risk contour map of Liyazhuang coal mine.

Fig. 7.1 The structure of BP neural network and its algorithm in detail.

Fig. 7.2 BP neural network model of water sources recognition.

Fig. 7.3 Neural network training performance. 



\section{List of Tables}

Table 1.1 Selected historical inrush accidents in Great Britain (Vutukuri and Singh, 1995)

Table 1.2 Inrush and inundation accidents of top coal producting countries for the past decades (Detlef, 2012)

Table 1.3 Statistics of severe inrush incidents from 2000 to 2011 in China (Zhang, 2013).

Table 1.4 Selected water inrush accidents occurred in China in recent years.

Table 5.1 Real water inrush cases used for ANFIS training (reported by Shi (2015)).

Table 5.2 Geological data of the five working faces used for predicting.

Table 5.3 Predicting results of the five testing working faces.

Table 6.1 Classification of mine hydrogeological complexity.

Table 6.2 Empirical and critical value of $\mathrm{I}_{\mathrm{t}}$ in several mining areas (Meng et al., 2012).

Table 6.3 Suggested classification of fault distribution complexity in Xuzhuang and Yaoqiao mines (Xu et al., 1996).

Table 6.4 ESQ coding value suggested by Hudson (1992)

Table 6.5 The results of the interaction matrix coding corresponding to Figure 6.1 using the ESQ coding system

Table 6.6 The weighted coefficients of the selected parameters

Table 6.7 Suggested rating values of the selected parameters

Table 6.8 Surveyed geological data for the 12 boreholes

Table 6.9 The proportion of each lithology in the aquifuge

Table 6.10 Lithology type of aquifuge and its resistance to water pressure (Meng et al., 2012)

Table 6.11 The evaluation results of the 12 boreholes

Table 7.1 The training sample sets and their vector representation.

Table 7.2 The testing results with samples randomly selected from training samples. 
Table 7.3 The remaining sample sets and their vector representations.

Table 7.4 The forecasting results of neural network with 4 remaining samples. 


\section{Chapter 1 Introduction}

\subsection{Research Background and Significance}

\subsubsection{General overview of the problem and risks of water inrushes in top coal producing countries}

In the process of mining and excavating, complex hydrogeological conditions often lead to serious water inrush incidents, in which a significant amount of water suddenly invades into an underground working space, flooding tunnels, shafts or even a whole working face. Just as all other geological hazards in mines such as gas outbursts, dust explosion, roof caving or mine fire, water inrush in underground usually cause heavy casualties in human lives and high economic losses. Since the beginning of coal mining history, water hazards in mines are undoubtedly a serious safety problem. According to Vutukuri and Singh's study (1995), we now can see how serious were the water inrush problems in Great Britain in the period from 1815 to 1985 (see Table 1.1).

There are a lot of reasons leading to water inrush accidents in mines. For example, a working or heading face suddenly connects to surface water bodies (rivers, lakes, reservoirs); a working face connects to an underground aquifer; water from other strata or from old abandoned mined areas enter into a new working area; cleaning an old shaft or building a new shaft accidentally encounter a confined aquifer in the sinking operation; failure of underground dams and seals. Among all these above reasons, the most common one is that a working face connects to an underground aquifer.

In recent decades, as a large number of coal mines closed down in most of the western developed countries (United Kingdom, Germany, France, Spain, etc.), coal production gradually shifted from developed countries to developing countries (China, India, Russia, Poland, etc.). Although there are still some inrush incidents reported in developed countries like United Stated and Australia (EDI, 2010; Francis et al., 2004; Szwedzicki, 2004), currently most of the inrush accidents have mainly occurred in developing 
countries. According to published statistics, it is estimated that 10,000 people or more have been killed in mine water inundation accidents in China and India in recent years (Detlef, 2012; Przemysław, 2011; Zhang, 2005). In addition, informations on accidents reported by Detlef (See Table 1.2) even suggests that inrush accidents in developing countries have a higher mortality rate than in developed countries.

In countries like Poland, Russia or South Africa, although there are not so many references published to describe their situations regarding water inrush issues, some of the accidents reported recently from those contries also suggest that in a certain degree they also face the same problem in their mines. Examples can be found in the accidents reported as the water inrush into a decommissioned mine shaft in the Upper Silesian Coal Basin in Poland (Krzysztof et al., 2016), water and muddy materials inrush occurred at the level of +192 in Aikhal Kimberlite mine in Russia (Kurlenya et al., 2013), water inrush produced into the mine workings of the Zapadnaya mine in the Eastern Donbas Region of Russia (Mokhov, 2007) or the massive inrush of water occurred at shaft No. 4 in the West Driefontein mine in South Africa (Musa et al., 2012). 
Table 1.1

Selected historical water inrush accidents in Great Britain (Vutukuri and Singh, 1995)

\begin{tabular}{|c|c|c|}
\hline Year & Mines & Fatalities \\
\hline 1815 & Heaton Colliery, Northumberland, England & 90 \\
\hline 1837 & Workington Colliery. W Cumberland. England & 27 \\
\hline 1883 & Diamond Mine, Braidwood. & 69 \\
\hline 1885 & No. 1 Slope. Nanticoke, Pa. A (anthracite) & 26 \\
\hline 1895 & Audley Colliery, N. Staffordshire, England. & 77 \\
\hline 1889 & White Ash Mine. Golden. & 10 \\
\hline 1891 & Spring Mountain Mine. Jeansville. & 9 \\
\hline 1892 & Lytle Mine. Minersville. & 10 \\
\hline 1898 & Williams Mine. Middleport. & 6 \\
\hline 1901 & Donibdstle, Scot. & 8 \\
\hline 1908 & Rochbum, Scot. & 3 \\
\hline 1912 & Superba-Lemont Mines, Evans Station. & 18 \\
\hline 1917 & Wilkeson Mine. Wilkeson. & 6 \\
\hline 1918 & Stanrigg-Arbuckle, Lanarkshire, Scotland & 19 \\
\hline 1923 & Redding Colliery. Falkirk. Stirlingshire, Scot. & 40 \\
\hline 1925 & Montagu Colliery, Northumberland, Eng. & 38 \\
\hline 1927 & Carbonado Mine. Carbonado. Col & 7 \\
\hline 1950 & Knockshinnoch Colliery, Ayrshire. Scot. & 13 \\
\hline 1952 & Holmes Slope, Forrestville. & 5 \\
\hline 1954 & Newton Chickli Colliery, M.P, India & 62 \\
\hline 1958 & Central Bowrah, Jharia, India & 23 \\
\hline 1959 & River Slope. Port Griffith. Pa. & 12 \\
\hline 1960 & Dhamua main, M.P., India & 16 \\
\hline 1970 & Karanpum Colliery, Bihar, India & 3 \\
\hline 1973 & Lofthouse Colliery. Northumberland, England & 7 \\
\hline 1975 & Silvewara Colliery, Nagpur, M.P., India & 10 \\
\hline 1975 & Chasnala Colliery, Jharia, India & 375 \\
\hline 1977 & Porter Tunnel Mine. Tover City. & 9 \\
\hline 1978 & Moss No. 3. Dante. Va. & 4 \\
\hline 1979 & Mine No. 1. Poteau, Okla. & 1 \\
\hline
\end{tabular}




\begin{tabular}{llr}
\hline 1981 & Harlan No. 5. Grays Knob, Ky. & 3 \\
1983 & Hurrilladih Colliery, Jharia, India & 19 \\
1985 & Lykens No. o, Lykens. & 1 \\
\hline
\end{tabular}

Table 1.2

Inrush and inundation accidents in main coal producing countries in the last decades

(Detlef, 2012)

\begin{tabular}{lcccc}
\hline \multicolumn{1}{c}{ Category } & China & United States & India & Australia \\
\hline Flooding & $8(196)$ & $24(0)$ & $1(200)$ & $3(0)$ \\
Intersecting well & - & $45(0)$ & - & $2(0)$ \\
Intersection mine void & $11(143)$ & $38(0)$ & $3(47)$ & $1(0)$ \\
Strata water & $5(103)$ & $19(0)$ & - & $1(0)$ \\
Dam failure/levee breach & $1(172)$ & $9(0)$ & - & 0 \\
Leaking/failing but seal & - & $7(0)$ & - & 0 \\
Mine fill inrush & - & $1(0)$ & - & 0 \\
Pump failure & $1(23)$ & $1(0)$ & $1(17)$ & 0 \\
Unknown & $120(1536)$ & $19(0)$ & $>\mathbf{5 ( 2 6 4 )}$ & $\mathbf{7 ( 0 )}$ \\
Total & $>\mathbf{1 4 6}(>\mathbf{2 1 7 3 )}$ & $\mathbf{1 6 3 ( 0 )}$ & & 0 \\
\hline
\end{tabular}

Notes: fatality numbers in brackets 


\subsubsection{Description of the situation regarding water inrush problems in China}

According to information reported from the "Coalfield Geological Central Bureau of China” (2000), water-threatening coalfields are distributed in more than ten provinces in China, including most of the late Paleozoic Coalfields and several Mesozoic and Cenozoic Coalfields in North and South China. According to statistics, among the 624 Chinese state-owned mines, up to 285 of them, totaling in terms of coal reserves $250 \times 10^{8}$ tons, are threatened by serious water issues. From these, 272 mines are actually considered as very dangerous regarding water hazards. Water inrush accidents have frequently occurred in more than 70 mines, such as Jingxing, Xingtai, Handan, Fengfeng and Kailuan coal mines in the Hebai Province; Anyang, Hebi, Jiaozuo, Pingdingshan, Xinmi and Yuxi coal mines in the Henan Province; Huoxian and Xuan Gang coal mines in the Shanxi Province; the Weibei coal mine in the Shaanxi Province; Xuzhou and Datun coal mines in the Jiangsu Province and Huainan and Huaibei coal mines in Anhui Province.

Table 1.3 lists the statistics results from a preliminary survey made from 2000 to 2011. As it can be seen, just in a short period of these 12 years a total number of 601 severe inrush disasters occurred, resulting in 3216 deaths. To see the importance of the problem, between the years 2003 and 2005, more than 1000 miners were killed. From 2005 to 2011, despite there was a downward trend in the number of fatalities, there was still a large number of inrush incidents happening every year. Despite the actions taken by authorities, water inrush accidents still occur frequently in China every year. Table 1.4 is a list of some of the more serious accidents occurred in China form 2011 to 2015. 
Table 1.3

Statistics of severe inrush incidents from 2000 to 2011 in China (Zhang, 2013)

\begin{tabular}{lcc}
\hline Year & Number of incidents & Fatalities \\
\hline 2000 & 9 & 98 \\
2001 & 38 & 176 \\
2002 & 93 & 387 \\
2003 & 92 & 424 \\
2004 & 61 & 254 \\
2005 & 104 & 593 \\
2006 & 38 & 267 \\
2007 & 63 & 255 \\
2008 & 49 & 263 \\
2009 & 21 & 125 \\
2010 & 18 & 169 \\
2011 & 15 & 115 \\
Total & 601 & 3216 \\
\hline
\end{tabular}


Table 1.4

Main water inrush accidents occurred in China in recent years.

\begin{tabular}{cllc}
\hline No. & \multicolumn{1}{c}{ Locations } & Dates & Miners killed \\
\hline 1 & Houyang coal mine, Fujian Province & Jun.30, 2015 & 3 \\
2 & Zenjiagou coal mine, Hubei Province & Jun.21, 2015 & 3 \\
3 & Wutongzhuang coal mine, Jiangxi Province & Jul.27, 2014 & 0 \\
4 & Guohua coal mine, Chongqing City & Sep.16, 2012 & 3 \\
5 & Dayugou coal mine, Henan Province & Dec.22, 2013 & 7 \\
6 & Junyuan No.2 coal mine, Heilongjiang Province & May.02, 2012 & 13 \\
7 & Anzhishun coal mine, Heilongjiang Province & Aug.14, 2014 & 16 \\
8 & Qiyishanfu coal mine, Shanxi Province & Apr.13, 2012 & 11 \\
9 & Changfu coal mine, Inner Mongolia Autonomous Region & Aug.19, 2011 & 6 \\
10 & Yunyu coal mine, Shanxi Province & Jun.21, 2015 & 4 \\
11 & Jiangjiawan coal mine, Shanxi Province & Apr.19, 2015 & 21 \\
12 & Changfeng coal mine, Heilongjiang Province & Apr.05, 2015 & 6 \\
13 & Jiayi coal mine, Heilongjiang Province & Sep.22, 2012 & 6 \\
14 & Zhuxianzhuang coal mine, Anhui Province & Jan.30, 2015 & 7 \\
15 & Taoyuan coal mine,Anhui City & Feb.03, 2013 & 1 \\
\hline
\end{tabular}

In North and South China, the severity of mine water hazards is almost on a par. The main difference is in the inrush sources. In North China, water inrushes are mainly caused by underlying aquifers: Ordovician Limestone aquifers, Carboniferous Limestone aquifers and Cambrian Limestone aquifers are three of the most important underlying aquifers which are highly related to the major part of inrush events. The higher aquifer pressure existing in North China (generally in the range of 2 3.2 MPa), makes the water inrush in the North China area generally occur suddenly and in a large scale, generating also much more damages. In South China, the large amount of precipitation makes the surface water bodies (rivers, lakes, reservoirs, rivulets, etc.) to be well developed and therefore mine water inrushes are not only caused by underlying aquifers, surface water bodies are also 
the sources for most of water hazards, but due to the lower aquifer pressure, water inrushes in South China generally occur in slow motion, which makes it easier to control.

Another aspect that can be concluded from water inrush accidents in China is that despite there is a wide variety of passageways (faults, karst caves, karst collapse columns, fractures, unblocked boreholes etc.) leading to inrushes, in fact most of the accidents were actually caused by geological faults. A study conducted by Bu (2009) found that up to $79.5 \%$ of inrush events that occurred in working faces were directly associated with geological faults; a second main passageways was the karst collapse columns. Inrushes caused by collapse columns often came with huge volums of water and huge damages. Inrushes caused by karst caves or underground-river conduits usually have happened in Southwest China, where the landscape is mostly a mountain topography.

Water hazards in Chinese mines can be attributed to many reasons. Almost $80 \%$ of the coalfields in China are seriously threatened by rainstorms, surface water bodies, underground aquifers and strata water as potential inrush passageways. Most coalfields are distributed in regions where frequent tectonic movements have modified and changed the complete development of faults and fractures. In some coalfields, the faults and fractures are even criss-crossed, forming a reticulate structure with good water conductivity providing a favorable passageways for water inrush. Of course, not all the reasons can be attributted to objective or natural conditions, human factors are also a reason why water hazars are difficult to be effectively controlled. In China the mine management level, production technology and disaster prevention and governance capacities are still relatively poor when compared to those existing in other developed countries, especially in the case of those non-state-owned small coal mines. Moreover, in many mines the hydrogeological survey is not enough and the reliability of detailed hydrogeological data is very low. Sometimes those pieces of information obtained from detailed geological survey are even not consistent with the actual geological conditions.

China still has the most rapid economic development in the world, and the massive production and consumption of mineral resources to support the sustained economic development will not change in the short term. In the coming decades China will still be the largest producer and consumer of mineral resources, so there is no doubt that in the furture more problems on mine water inrush will appear in China. This can be explained 
specifically by the following two points. First of all, as most of the mineral resources located in shallow underground have been mined, in the coming decades mining depth will continue to increase. For example, the average mining depth in 2004 was of $422 \mathrm{~m}$, but in 2006 such depth already reached 455 m, especially in the Eastern part of North China, where the average mining depth already reached $647 \mathrm{~m}$ and with an annual growth rate of $10 \sim 20 \mathrm{~m}$ (Hu, 2010). To date, 33 mines in China have already reached more than $1000 \mathrm{~m}$ depth. In deep underground mining, the water pressure tends to rise higher and the hydrogeological conditions should be much more complex. Secondly, drived by interests and maximum production, in the past decades low quality mineral resources in shallow depths with good geological conditions have been mined in priority, so in the future, if the government intends to mine those residual resources, complex hydrogeological conditions will be faced even in shallow underground operations.

To summarize, mine water hazards in China have always been a very serious problem, and it will even become a much more serious issue in the coming decades, both for engineers and researchers who engage in the management or research of mine safety. More studies are need to be conducted to improve the prevention and control of water hazards in mines, this is also the objective of this thesis. 


\subsection{Literature review}

\subsubsection{Research about mechanisms of water inrush}

Understanding the mechanisms of water inrush is of a vital importance to enable the adoption of effective preventive measures in the control of water inrushes (Mironenko and Strelsky, 1993). In previous studies, Finite Element Method (FEM) and direct mathematical analysis were two of the main methods widely used to research the inrush mechanisms.

In a study conducted in Russia (Odintsev and Miletenko, 2015), the water inrush in mining works was considered as a consequence of spontaneous hydrofracturing of surrounding rocks. By using the FEM to simulate an established hydrofracture model, the authors discovered that the water inrush actually would occur when the fracture grows under the coupled actions of underground water pressure and the mining-induced stresses. Moreover, they even proposed that the fracture growth mainly reflect in two ways, the critical extension of rocks at the fracture tip and the fracture opening along the fracture length. With the use of simulation softwares such as RFPA, COMSOL multiphysics, FLAC (both of them are FEM-based simulation softwares), researchers from China (Li et al., 2009; Huang et al., 2012; Wu et al., 2004; Wang and Park, 2003) also obtained similar results to the above mentioned, but the difference was that their researches mainly focused on the mechanisms of fault-induced water inrushes. They found that for water conducting faults and non-conducting faults, they may eventually generate passageways for a water inrush at different positions, but the mechanisms of forming the passageway is the same. It is the extension of the fault under natural and mining-induced stresses, and they also noticed that the geologic feature of a fault plays a big role in the influence of passageways forming. For example, the bigger the dip angle, the less prone to water inrush, the larger the fault throw, and more the danger of a water inrush.

Several studies (Liu and Hu, 2007; Zhu and Wei, 2011; Motyka and Bosch, 1985) considered the fracturing evolution of faults in the process of water inrush with complicate models. In their researches, the coupled solid-liqud models were established to simulate and to understand the complex hydro-mechanical behavior of water inrush. More complex coupled stress-damage-flow models can also be seen from the previous 
researches (Lu et al., 2015; Li et al., 2011). According to Lu's work, with the advancing of working faces, on the one hand the fault (fracture) develop progressively in the floor and, on the other hand, the deepest fractured zone appears under both sides of the minedout area, and he also believed that there are three stages for the fracturing evolution of a fault: the quiet period, the active period and the eventual eruptive period. From Li's point of view, the mining-induced stresses will lead to the stress concentration within the region adjacent to the fault and cause fault activation, considering the rock damage conditions, he classified the floor into three zones, the mining-induced fracutred zone, the intact zone and the fault reactivation zone, and the princple for assessing whether a water inrush will occur is to see whether the mining-induced fracutred zone is connected with the fault reactivation zone. For measuring the water pressure resistance of the fracture zone, a field measurement was conducted by Liang (2015).

Using the traditional mathematical analysis method, to be more specifically, using the principles of strata mechanics to determine the criterion of judging whether a water inrush will occur through a fault or not, can be seen in Shi's work (Shi and Singh, 2001). His research reached the following conclusions: a yield zone will be formed if the vertical strata pressure greater than the coal seam compressive strength, and actually such zone is a water-conducting zone; based on the distribution of vertical strata pressure on coal seam, a peak stress line can be drawed and only the floor strata located in the rear of such stress line has the possibility of being broken by the aquifer pressure and then lead to a water inrush. 


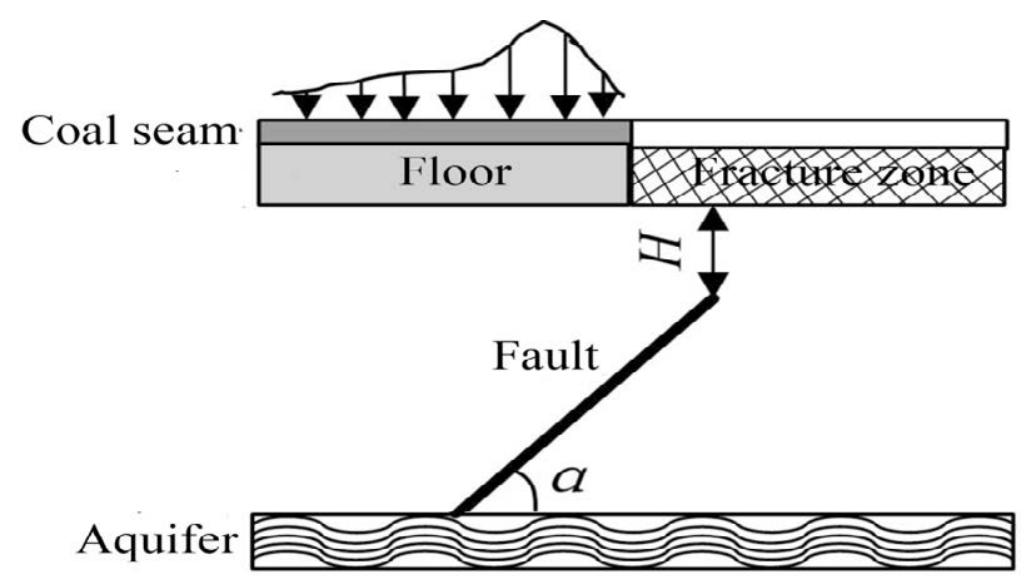

(a) Simplied geological model of fault-induced water inrush

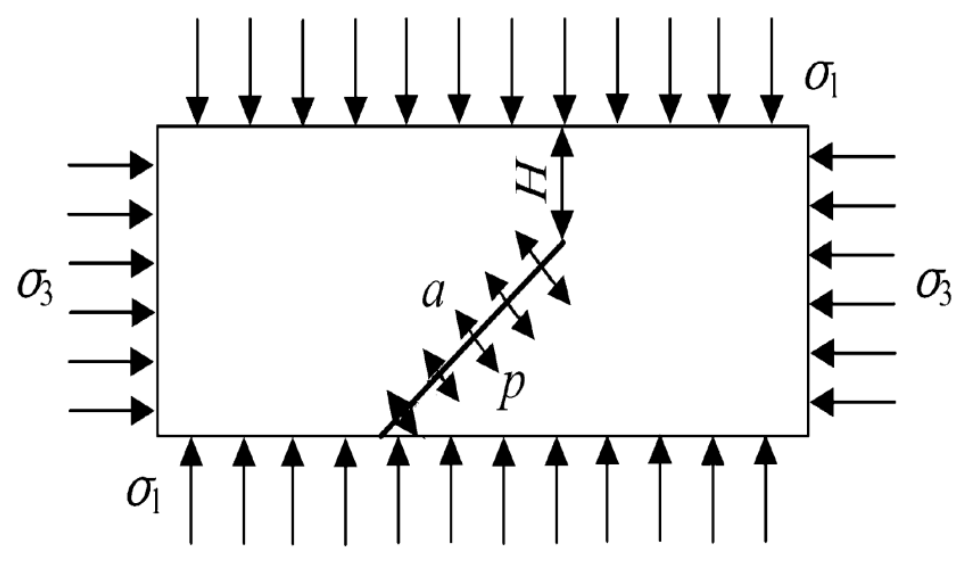

(b) Computing mechanical model with regards to model A

Figure 1.1. Using fracture mechanics to analyze the fault-induced water inrush model, this figure is modified from Chen (2011).

With the establishment of a fracture mechanical model (Figure 1.1), Professor Chen (Chen et al., 2011) proposed that the mechanism of fault-induced water inrush is due to fault activation caused by the joint action of water pressure $(p)$ and surrounding rock stresses $\left(\sigma_{1}\right.$ and $\left.\sigma_{3}\right)$. The hydraulic fracturing principle can be expressed by using the following formula: 


$$
p_{c}=\frac{K_{I c} \sqrt{\pi a}-\left(\sigma_{1}-\sigma_{3}\right) a \sin 2 a F_{\tau}\left(\frac{a \sin \alpha}{a \sin \alpha+H}\right)}{\lambda \pi a F_{\sigma} \frac{a \sin \alpha}{a \sin \alpha+H}}+\frac{\sigma_{1}+\sigma_{3}}{2}-\frac{\sigma_{1}-\sigma_{3}}{2} \cos 2 \alpha
$$

Where $p_{c}$ refers to the critical water pressure, $K_{I c}$ represents the fracture toughness and $F_{\sigma}, F_{\tau}$ denote the normal and shear stresses of the fault surface.

If the water pressure exceeds a critical value, fault activation will happen by hydraulic fracture and then lead to a water inrush incident.

In addition, for understanding the strength and profile of water-conducting fracture zone, in 1989 Santos firstly proposed, using a modified Hoek-Brown rock mass strength criterion together with the introduction of the concept of the point of critical energy release, to account for the strength of floor (Santos and Bieniawski, 1989). A study conducted in Huainan coal mine (Zhang et al., 2005) found that both in strike and dip directions water-conducting fracture zone increases gradually from updip to downdip (Figure 1.2); and water-conducting fracture zone also varied with the change of the dip angle of coal seam as described in Miao’s research (2011) (see Figure 1.3). 


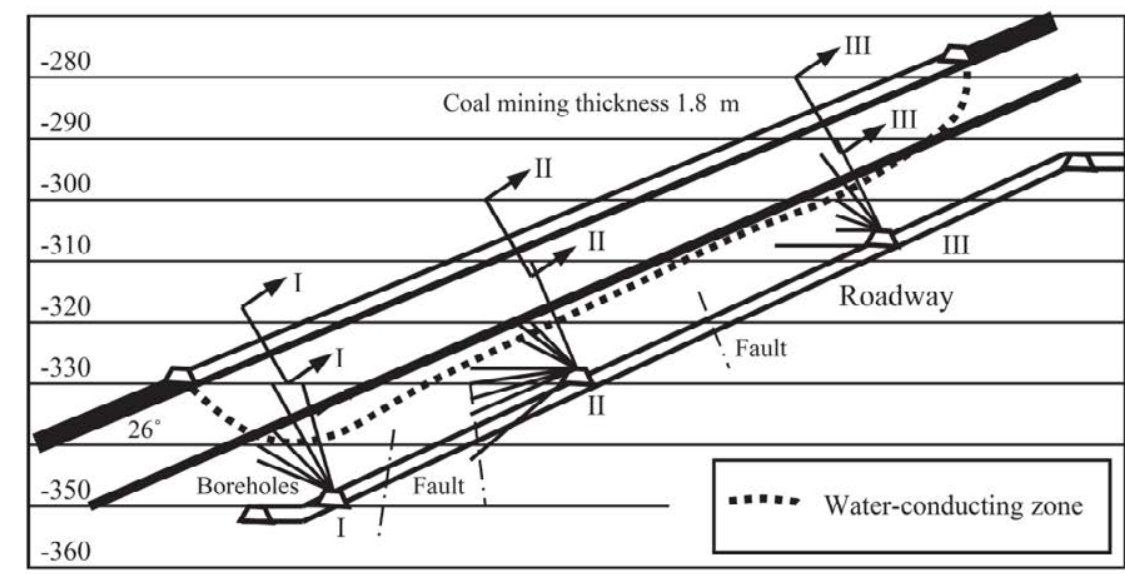

Section I-I

Section II-II

Section III-III
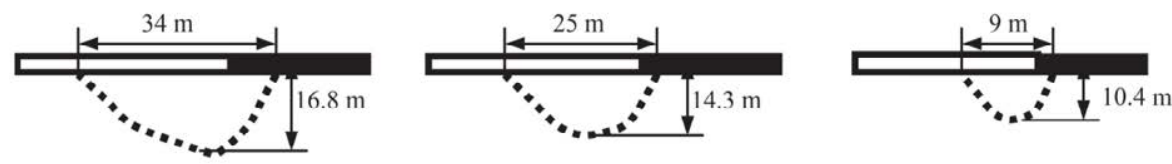

Figure 1.2. Observing borehole layout and observation section of the water-conducting fracture zone in the underlying strata for inclined coal seam in Huainan coal mines, Anhui Province. (Zhang, 2005)

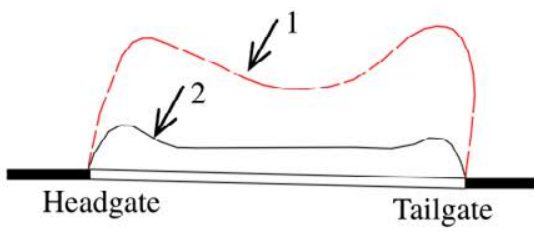

(a) Flat or slightly inclined seam

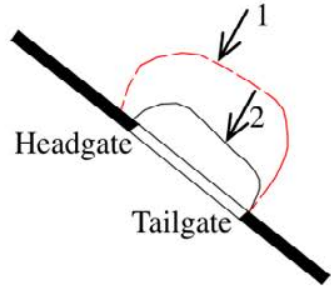

(b) Inclined seam

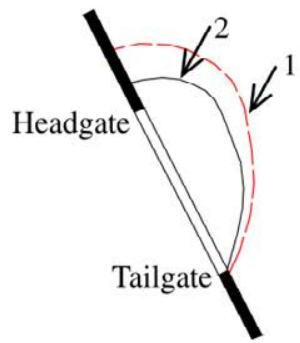

(c) Steeply inclined seam

Figure 1.3. The profile of the water-conducting fracture zone varied with the change of the dip angle of coal seam (Miao et al., 2011) 1. Water-conducting failure zone; 2. Caving zone. 


\subsubsection{Researches about the risk assessment of water inrush}

Concerning how mine water affects the quality of groundwater (Tiwary and Dhar, 1994; Sfikas et al., 2016; Cathy et al., 2002; Wright and Ryan, 2016; Annandale et al., 2002; Wisotzky, 2001; Caraballo et al., 2016), a lot of efforts have also been done in the field of assessing the risk of water inrush. Although there were many previous studies on the mechanisms of water inrush, as it has been described in the last section, it is still far from clearly knowing all the precise mechanisms of water inrush, and so far it is still impossible to accurately predict when and where the inrush disaster will happen in the mining process. For this reason, before planning to mine a coal seam, the use of risk assessment methods to determine the most water-threatening region in advance is the most effective way to control the water hazards.

For the risk assessment of water inrush in underground engineering, the research directions taken in recent years mainly focus on two branches, the risk assessment in tunnel engingeering and in mining engineering, although the researches of tunnellingrelated water issues (Goodman,1965; Li et al., 2009; Marechal and Perrochet, 2003; Park et al., 2008; Schwarz et al., 2006; Shin et al., 2002; Tseng et al., 2002; Hou et al., 2016; Hamid et al., 2012) certainly can provide some help in approaching the mining-related water issues. As in this thesis we mainly concern the mining-related water issues, so in the following paragraphs the primary aim is to disscuss and review the previous studies about the risk assessment of mining-related water inrushes.

From the very beginning, without using any specific approaches, scholars have just put forward some concepts of how to carry out risk assessment. According to a study conducted in the Kotredez coal mine (Dusan, 1991) it is possible to obtain some earlier inferences before the occurrence of a water inrush through years of ground-water level observations. Earlier studies from Italy (Sammarco, 1986, 1988) even indicated that water inrushes in mines are certainly accompanied by clear warning signals linked with changes in the water regime or mine gases, so the gas flow rates can be correlated to the hydrodynamics activities around the mine. Thereby possible inrushes can be forecasted by means of the gas flow rates. 
In China, the most simple way of assessing the risk of water inrush is to use a waterinrush index to represent the inrush degree, by selecting water pressure of the aquifer and the thickness of aquifuge as two primary parameters affecting water inrush. An empirical formula was developed by researchers to evaluate the risk of water inrush (Ministry of coal industry of PRC 1984; Meng et al., 2012), which can be written as follows:

$$
T_{c}=\frac{P}{h}
$$

Where $T_{c}$ is the water inrush index, $P$ is the water pressure of aquifer and $h$ is the thickness of aquifuge.

Considering that such index actually does not include the influences of mining-induced stresses and the lithology of aquifuge, this method has been modified to obtain another much more appropriate expression in two aspects (Zheng et al., 1999; Zhang et al., 1994), first considering that a water-conducting fracture zone will be generated under the action of mining-induced stresses, so the thickness of the fracture zone caused by mining-induced stresses should be subtracted from the thickness of aquifuge, and second considering the water-resistant difference between different rock strata, so the concept of equivalent thickness of aquifuge was introduced to modify the original expression. The modified water inrush index thereby can be written as:

$$
T_{c}=\frac{P}{\sum h_{i} c_{i}-h_{p}}
$$

Where $h_{i}$ is the thickness of the $i$-th stratum of the aquifuge, $c_{i}$ represents the converting coefficient of the equivalent aquifuge thickness and $h_{p}$ is the thickness of the mininginduced fracture zone (water-conducting fracture zone).

Despite the modified water inrush index is easy to be implemented in practice, and to some degree improve the ability in characterizing the inrush risk, it is still just a simple concept and does not really reflect the actual conceptual model of water inrush from floor because there are only few factors that are considered in this approach. A more recent study (Wu et al. 2009a) even showed that such approach had great deviations between 
prediction results and actual situations. For this reason, some more new appropriate approaches were proposed to deal with the issue of characterizing the inrush risk.

Through coupling the Analytic Hierarchy Process (AHP) (Saaty, 1980) and the use of an Geographic Information System (GIS), a method named the GIS-based AHP Vulnerable Index Method was proposed by Professor Wu (Wu et al. 2006; Wu et al. 2007; Wu and Zhou 2008; Wu et al. 2009b; Wu et al. 2011a; Wu et al. 2011b) to evaluate the water inrush vulnerability index. This method combines the advantages of AHP and GIS in processing the spatial data and allows complex superimposition of information with regard to all the controlling factors related to water inrush. The AHP in this method is used for establishing a hierarchal structure model and thus for determining the weights or contributions of the different controlling factors. After obtaining the weights of controlling factors, the vulnerability index relative to a water inrush then can be calculated and the results can be mapped visually with the function of GIS.

Bayesian networks (BN), which is a sort of probabilistic network based on a graphical network of probabilistic reasoning, is another useful tools used to conduct water-inrush assessment (Dong et al. 2012; Wu et al. 2016), through establishing a topology structure (see Figure 1.4). BN method also can deal with water-inrush hazard assessment by considering all the main controlling factors related to water inrush.

Broadly speaking, no matter whether it is an AHP-based or BN-based method, the critical step is to calculate the weight of each corresponding factor. From this perspective, fuzzy method is also another option for conducting water-inrush hazard assessment (Wang et al. 2012; Shi et al. 2015). 


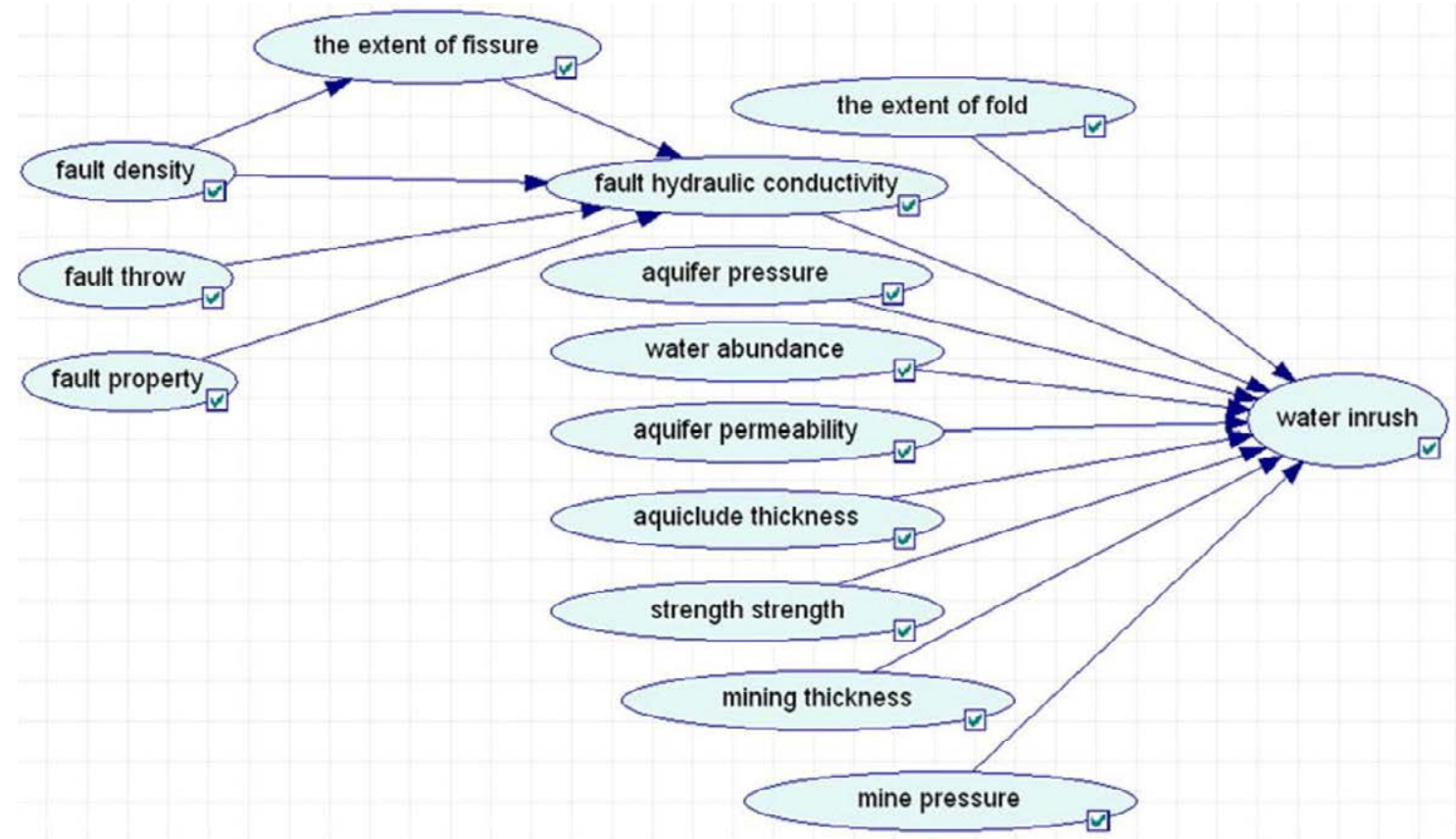

Figure 1.4. A BN topology structure of floor water-inrush hazard assessment (Dong et al. 2012)

Using numerical simulation methods to develop a common approach for water-inrush risk assessment actually is unpractical, but it should be acknowledged that in some cases, using numerical analysis techniques better results in water hazard assessment can be achieved. In Zhang's research paper (2009), by applying the flow-rock failure process analysis approach (F-RFPA) into an improved flow-stress-damage (FSD) model, a coupling analysis was conducted to analyze the permeability variation of the four stages of rock failure (elastic, damaged, cracked, and crack closure), and he believed that the most dangerous stage for water inrushes is the stage which the rock strata have the highest permeability induced by mining disturbances. Through applying FLAC ${ }^{3 \mathrm{D}}$, a numerical simulation case study was conducted in the Zhaogezhuang coal mine (Zhu et al. 2014), and an approach named 'time window' was proposed in this study for the risk assessment of the lagging water inrush.

In addition to the approaches described above, some other special risk evaluation approaches are also used for those special situations. For example, a 3-D visualization model of the southern part of the South Nottinghamshire Coalfield (Dumpleton et al. 2001) was constructed to determine potential mine water flowpaths and to identify areas at risk from future mine water pollution. An event-based stochastic forecasting approach (Istvan 
et al. 2001, 1980) is developed to assess water inrushes into underground works under karstic water hazard; in the Upper Silesian Coal Basin in Poland (Przemysław, 2011), an analytical and empirical approach was conducted to evacuate the risk of water inrush in shaft by considering six controlling factors: the inflow intensity, the amount of suspended material contained in the water flowing into the shaft, the proportion of water-bearing formations in the vertical profile, the condition of the shaft lining, the safety pillar and the history of the shaft.

\subsubsection{Research on the recognition of water-inrush sources}

Several studies (Rapantova et al. 2012; Stetzenbach et al. 2001; Sun, 2014; Sun et al. 2012; Sui et al. 2011) about how to use hydrogeological analysis methods to identify the mine water-inrush sources have been achieved. Research methods ranged from the simplest way of water temperature or water level observation (Sena and Molinero, 2009) to the complex forms of using non-linear mathematical models or numerical analysis methods.

Identifying of mine water-inrush sources through water temperature or water level observation is the most traditional and obvious way (Yuan and Gui, 2005), by measuring the water temperature or by observing the change of water level of every aquifer, waterinrush sources could be obtained without establishing any mathematical models. It is easy and efficient, especially under good hydrogeological conditions, and it can also be commonly adopted because the temperatures of the aquifers are different as a result of the impact of the geothermal gradient. In addition, the water level of the aquifers will fall rapidly in the case of water flowing out continually, so if a mine water inrush occurs, those aquifers with rapid water level falling can be identified as inrush sources. This is the so-called water level identifying method.

For the use of non-linear mathematical models, grey-system theory and fuzzy mathematics are two of the methodologies commonly used. The grey-system method is applied to identify the water sources by calculating the weighted measures of water quality between those potential water-inrush aquifers and the water-inrush point ( $\mathrm{Hu}$ and 
Zheng, 1996; Liang, 1993). Since the correlation coefficient of water quality, which can be obtained by comparing the weighted measures, reflects the water quality similarity between the potential aquifers and the water-inrush point, those aquifers which have similar water quality to the water-rush point (have greater correlation coefficient) can be regarded as reasonable inrush sources. Sometimes, water quality differences between aquifers are not obvious and various factors have to be integrated to recognize the water sources, under this case, fuzzy mathematics method is the best choice (Qian et al. 2010).

In fact, from a broader view, the process of identifying water sources is a process for assessing water quality and finding out which underground aquifer or surface water body has the similar water quality to the water bursting point. From this perspective, any pattern recognition approach or any numerical analysis method that can perform effective water quality identification can be also used for water source identification. Summarizing the past researches, the clustering analysis (CA) and the principal component analysis (PCA) are two of the numerical analysis methods commonly applied for conducting water quality evaluation in the past two decades.

CA is a kind of exploratory data analysis referred to grouping similar objects (samples) into groups (clusters) so that objects within a group are similar and different from other groups. From the perspective of machine learning, clustering analysis is an unsupervised learning process for searching clusters, so it does not depend on pre-defined groups or training samples marked with groups. It is not yet a statistical technique and the results obtained are justified according to their value in interpreting data and indicating patterns (Massart, 1983; Johnson and Wichern, 1992). To date, many studies about using CA for assessing water quality have been reported (Graca and Coimbra, 1998; Day et al., 1998; Berzas et al., 2000; Wunderlin et al., 2001; Simeonova et al., 2003; Singh et al., 2005; Astel et al., 2007; Andrade et al., 2008; Mahbub et al., 2008).

PCA, also known as a technique for variable reduction, aims to use the idea of reducing dimension to extract the most important variables from correlated variables and to transform multiple variables into a few more representative variables, and each of the principal variables is able to reflect most of the information of the original correlated variables (Dillon, 1984). Because of the wide application of analysis software such as SPSS (Statistical Product and Service Solutions) in recent years, the PCA analysis method 
has been widely used in water quality evaluation by many scientists (Librando et al., 1995; Da silva and Sacomani, 2001; Parinet et al., 2004; Ougang, 2005; Lourenco et al., 2006; Sotelo et al., 2007; Nakano et al., 2008; Homa et al., 2010) using PCA to conduct water quality assessment.

\subsection{Remaining issues}

Despite the high quantities of studies that have been done, some issues still remain to be addressed:

- To obtain more accurate fault-tip stress fields by using a more appropriate numerical simulation approach to explain and to understand the mechanisms of fault-induced water inrush more clearly.

- To directly predict the risk level of water inrush caused by a specific fault encountered during the mining process.

- To assess the fault-induced water inrush risk for a whole coalfield with consideration of all the main related parameters and all the interacting actions between parameters.

- To use a better pattern recognition technique to achieve water source identification if there is an inrush incident occurred.

As mentioned above in section 1.1.2, according to existing statistical data, up to a $79.5 \%$ of the water inrushes produced in underground mining is actually caused by faults, so this is the reason why most of the current researches focus on the study of figuring out what are the specific mechanisms of fault-induced water inrush. From the previous researches it can be concluded that the traditional FEM (also including FEM-based simulation softwares such as RFPA, COMSOL multiphysics, FLAC et al.) are the most used approaches for analyzing the fault-induced inrush mechanisms, but the fact is that these approaches actually are not appropriate for such issue for the following reason: the fault activation, which directly leads to fault propagation to form a water-flowing passageway to cause water inrush incidents, is completely determined by the stress concentration at the fault tip. However, the traditional FEM or FEM-based approaches have not advantages in addressing tip stress fields and their computing results of tip stress fields 
largely depend on the density of the splitting elements. Certainly in some cases we can relatively obtain accurate tip stress fields by increasing the element density but the computing results are still unreliable. Therefore, applying a more appropriate numerical simulation approach to get more accurate fault-tip stress fields is an indispensable way of understanding how the fault-tip stress fields are affected by the inrush-related factors such as water pressure, mining-induced stresses, fault attitude, etc., which will help to understand the mechanisms of fault-induced water inrush more clearly.

In the process of mining, it is common to encounter faults, especially in those mining areas where lots of geologic structures are distributed. On the one hand, it is necessary to design special mining or excavating methods to go through these faults safely, but on the other hand, every fault encountered in mining operations has a huge possibility of triggering a serious water hazard. Up to present, no references have been found on how to evaluate the inrush possibility for every fault encountered.

Ahead of mining a coal seam, using risk assessment methods to determine in advance the most water-threatening area is the most effective way to prevent the water hazards. Here the risk assessment covers the whole coalfield rather than just a specific fault. As can be seen from the literature review in the section 1.2.2, actually there are a lot of studies about how to use different techniques to conduct such assessment, but through careful analysis of these previous studies, it has been found that there are significant disadvantages in these techniques that the previous studies used. The traditional water inrush index (or the modified water inrush index) approach is a backward approach in which only a limited number of inrush-related factors are considered. More inrush-related factors are considered by the techniques (AHP-based methods, BN-based methods, Fuzzy method etc..) developed in recent years, but they fail to consider the interactions between factors. For underground water systems, interacting actions between factors always exist and the state of each factor is, to some degree, determined by the interactions between factors. For example, water output of aquifer impacts on aquifer pressure and it is affected by water supplement conditions, so actually the underground water system is a dynamic system and interactions between factors cannot be neglected. For this reason, the risk assessment method not only needs to consider all the main inrush-related factors but also needs to consider all the interactions between these factors. 
Using the water temperature method to determine inrush sources has the advantages of simplicity and high efficiency, but it will get into a trouble if the change of geothermal gradient is not very obvious, so it cannot be applied in situations where the lithological characteristics are homogeneous in the same coalfield or where the hard and compact rock has a high heat conductivity. Using a hydrochemical analysis as a way to identify water-inrush sources is too subjective for the reason that we often subjectively hypothesize which aquifer or surface water body is associated with the inrush incident with our previous experiences when an incident happened, and then only those hypothesized aquifers are analyzed.

The use of non-linear mathematical models is more objective but the process is complex and each of them has inherent disadvantages. For example, the fuzzy method cannot be used in every mine area because the weight distribution of evaluating indicators should consider the special circumstances of each mining region; the grey-system method also has its weakness as its theory determines that it can only be applied for positively correlated analysis. The CA and PCA approaches are better in the aspects of accuracy and objectivity, but their calculation steps are too cumbersome and not conducive to computer programming. In summary, all the described above suggest that an objective, efficient and universal pattern recognition technique should be found to realize inrush source identification. 



\section{Chapter 2 Research Objectives, Methods and Thesis Organization}

\subsection{Research Objectives}

For the research of geological hazards such as earthquakes, landslides, volcanoes, mudrock flow, etc., the accumulated experiences of previous researchers and engineers over the past few hundred years tell us that we mainly will face two kinds of problems, the scientific problems and the engineering problems. The former requires to answer problems and the latter requires to solve problems. For the research of geological hazards, the scientific problems that need to be answered include: Why does it happen? What are the mechanisms of its occurrence? Which factors are associated with its occurrence? And how each of the corresponding factors affects its occurrence? After answering these problems, then it's possible to turn into the engineering aspects: How to prevent it from happening? How to evaluate the risk of its occurrence? If it occurs, what measures are needed to be taken to minimize the damages?

In this thesis, the research targeted is another sort of underground geological hazard, the water inrush. As described in the Introduction, water inrush is a common issue for mining engineering, tunnel engineering and even urban underground construction engineering in some geographical areas, but this thesis mainly concerns are the inrush issues in mining engineering and, more specifically, water hazards in mines caused by faults (faultinduced water inrush).

In the light of the methodologies used for answering the scientific problems and solving the engineering problems, there are three main objectives in this thesis:

(1) To answer what are the mechanisms of fault-induced water inrush and to research how each of the corresponding related factors affects the occurrence of water inrush. 
(2) To evaluate the risk of fault-induced water inrush with the use of the computerassisted approaches. What needs to be emphasized here is that there are two aims involved in the risk assessment of fault-induced water inrush, on a macroscale the aim is to evaluate the risk of water inrush for a whole coalfield, and on a microscale, the aim is to evaluate the risk of water inrush for a specific area (caused by a specific fault).

(3) To research what needs to be done in order to minimize the casualties and economic losses if a fault-induced water inrush occurred, as rapidly and accurately identifying water-inrush sources after water-inrush occurring plays a critical role in taking further measures to control water volumes and reduce damages, hence in this part the thesis mainly focus on the study of water-inrush sources recognition.

\subsection{Research methods}

In this thesis, in order to comprehensively study the underground fault-induced water inrush from all aspects, several state-of-the-art approaches are applied for reaching the research objectives.

Extended finite element method (XFEM), which is a powerful approach in dealing with discontinuous issues, is applied for computing and analyzing the established faultinduced water inrush model; Rock engineering systems (RES), a systemic device for characterizing and listing and assessing all associated main factors and interactions between factors, is used for establishing a comprehensive method for the safety preassessment of fault-induced water inrush to a whole coalfield; Two types of artificial neural networks (ANN) are applied to solve our problems, the adaptive neural network (specifically the adaptive neuro-fuzzy inference system (ANFIS) ) is used for evaluating the risk of water inrush for a specific fault, and the back-propagation neural network (BPNN) is used for identifying water-inrush sources. 


\subsection{Outline of the thesis}

The thesis comprises three major parts. The first part is covered by Chapter 3 and mainly gives the theories and the fundamentals of the corresponding applied methods (XFEM, RES and ANN). The second part is developed from Chapter 4 to Chapter 7 and is a contribution of the fault-induced water inrush modeling and evaluating. The third part is developed in Chapter 8 and presents a summary of the work developed and outlinessome perspectives of future researches. The contents of each Chapter are detailed in the following.

In Chapter 3 the theories and the fundamentals of each applied research method will be outlined, algorithms about each method will be introduced and why the elected methods are better choices than other methods also will be discussed. Certainly, for any kind of methods, theories and algorithms are one thing, but how to apply them into practical problems is another matter, so in this chapter only a description of the basic knowledge of the applied methods is made. The practical implementation issues are conducted in each of the corresponding chapters (Chapters 4 to 7 ).

Chapter 4 mainly concerns the mechanisms of fault-induced water inrush. Numerical studies have shown that the occurrence of fault-related water inrush is mainly determined by the stress concentration magnitude of fault-tip. If the stress concentration magnitude is greater than the fracture toughness, then the fault will be activated and propagated and an inrush accident could occur if the propagated fault is just connected to the waterconducting fractured zone of the floor. So in this chapter, by assuming that there is one fault below an underground stope and then considering the roof, the stope, the floor and the fault as a whole computing domain, a geological discontinuity model is established to compute the fault-tip stress fields. By means of the XFEM's advantage of tackling discontinuities, the Stress Intensity Factors (SIFs), which are applied to represent the stress concentration magnitude, are computed by the method of interaction integral to evaluate the tip fields quantitatively and also to evaluate the possibility of fault activation. In addition, in this chapter how the related factors (the mining depth, aquifer pressure, fault dip, fault length) impact on the stress fields of the fault tip are discussed. 
Chapter 5 deals with the problem of predicting the probability of fault-induced water inrush. In the mining process, faults located below the stope or in front of the working face widely exist, and it is unrealistic to predict the inrush risk through assessing the activation possibility of every fault with XFEM (as the way used in Chapter 4). Since there have already been so many inrush accidents reported over the past years, in this chapter the problem of predicting the risk of water inrush will be solved from a new perspective, and a new way of using the reported historical accidents to predict the new situations will be proposed. ANN is the approach applied in this part because it can learn knowledge (or experiences) from the training samples (historical accidents). A more specifically, an approach of predicting the probability of fault-induced water inrush with ANFIS (the combination of ANN and FIS) will be developed in this chapter, and all the main parameters related to the hydraulic properties of the aquifer, the water-resisting prosperities of the aquifuge and the mining-induced stresses are considered.

Chapter 6 is an extension of chapter 5 . Both of them deal with the problem of inrush risk prediction. The difference is that chapter 6 aims to evaluate the inrush risk for a whole coalfield rather than just a specific area (a specific fault). When the problem is extended to a whole coalfield, only considering the fault itself is not enough, taking in account differences in geological structures and hydrogeological conditions, interacting actions between parameters is indispensable. For this reason, RES is introduced in this chapter to list and address all the corresponding factors and interacting actions between the related geological and hydrogeological factors, and based on RES approach a new method for safety pre-assessment of water inrush will be developed in this chapter. All the related factors including the fault density, the water yield property of aquifer, the aquifer pressure, the aquifuge thickness, the aquifuge strength, the depth of coal seam and the recharging conditions of water sources will be considered in the proposed method.

Chapter 7 proposes an ANN method to rapidly and accurately identify water-inrush sources after the occurrence of water-inrush accidents. The study about water source recognition is conducted in this chapter because no matter how advanced is the method used to predict the risk of water accident and no matter how much researches have been done, we can not guarantee that we can predict every water hazard risk with $100 \%$ accurate, so on the one hand, except for developing new predicting approaches for improving prediction accuracy, on the other hand methods about how to minimize the 
casualties and economic losses if a fault-induced water inrush occurred is also very necessary. For inrush accidents in mines, the first step and also the most important step of controlling the water disaster is to find out the inrush sources, accurately identifying which aquifer or which water body is directly related to inrush is very critical for estimating the volume of inrush water and taking further pumping measures. In this Chapter, based on the hydrochemical characteristics differences between aquifers, another ANN method (BPNN) will be proposed to achieve the identification of inrush sources.

The thesis finishes with a summary of the present work developed and advances some perspectives on further research in chapter 8. Future research trends in water hazards in mines and the computer-assisted water inrush prediction as a whole are discussed. 



\section{Chapter 3 Theories and Fundamentals of the Applied Methods}

\subsection{Introduction}

As indicated previously, in this thesis the main research objects are about all the aspects of fault-induced water inrush in mine, including research, risk assessment and source recognition. As we mentioned in 2.2, a total of three state-of-the-art methodologies will be applied in later Chapters for reaching our research objectives, the XFEM, the RES and the ANN. Before modeling and analyzing our problems with these three methodologies, a description of each methodology should be given. So this chapter will give a basic description of each methodology, including basic theories, fundamentals and algorithms. Here it should be noted that this chapter only gives the most basic knowledge of each methodology. More complex algorithms and theories will continue to be given later in each corresponding Chapter when each of these methodologies is specifically implemented.

\subsection{XFEM}

\subsubsection{Brief introduction of XFEM}

There is no doubt that finite element method (FEM) is an effective numerical method to solve scientific and engineering problems. Compared with other numerical methods, FEM has the advantages of being applicable to any geometric shapes, boundary conditions, materials and linear or nonlinear problems. However, when FEM is applied to some special situations like discontinuous problems, some of its inherent defects are exposed. For example, as FEM uses continuity approximation function to estimate displacement, so for those strong discontinuities (cracks) or even weak discontinuities (material interfaces), higher calculation accuracy only can be obtained by mesh refinement, with which usually a huge amount of calculating works are needed. Moreover, for solving problems with localized features (e.g. local large-deformation problems), the 
computing mesh may be seriously distorted and then result in a sharp decrease in terms of calculation accuracy, and sometimes the calculation even cannot be continued if there is no constantly mesh reconstruction.

In view of all these shortcomings of the FEM, a modified numerical method coupled the generalized finite element method (GFEM) and the partition of unity method (PUM) was proposed and developed by Ted Belytschko and his collaborators (1999), which is XFEM. Applying the concept of PUM, XFEM modified the displacement approximation function of FEM by adding some enriched displacement items to describe the discontinuous boundaries, with such adding items the displacement approximation function then can be more suitable to reflect the actual discontinuity characteristics. A more detailed description on the development process of XFEM shows that in 1999, aiming at twodimensional crack issues, Belytschko and Black firstly suggested using asymptotic field function to describe crack-tip elements and using signed distance function to describe crack geometrical properties so as to solve the problem of reducing mesh reconstruction. On the basis of Belytschko's work, the "jump” function then was introduced (Nicolas, et al., 1999; Moes et al., 1999) to describe crack surfaces so that to reflect the discontinuity characteristics of crack. So in fact XFEM is an extension of FEM, it can solve problems involving singularities, material interfaces and localized features with just simple grid meshing. This is why it inherits all the advantages of FEM and also has a unique aspect in dealing with discontinuities.

\subsubsection{The basic formulation of XFEM}

By means of PUM, which was firstly proposed by Melenk and his collaborators (Melenk and Babuska, 1996; Duarte and Oden, 1996; Babuska and Melenk, 1997), XFEM describes the cracks through enriching the shape functions of the elements which are involved with cracks. For linear elastic problems, when an element is involved with crack, its displacement approximation can be represented as the sum of the displacement of classical FEM $\boldsymbol{u}^{F E}$ and the enriched displacement $\boldsymbol{u}^{e n}$ as follows:

$$
\boldsymbol{u}(\boldsymbol{x})=\boldsymbol{u}^{F E}+\boldsymbol{u}^{e n}=\sum \underbrace{N_{i}(\boldsymbol{x}) \boldsymbol{u}_{i}}_{i \in N}+\sum \underbrace{N_{i}(\boldsymbol{x}) \phi(\boldsymbol{x}) \boldsymbol{a}_{i}}_{i \in N_{\Gamma} \cup N_{\Lambda}}
$$


Here $u_{i}$ is the classical FEM nodal displacement approximation; $N$ is the total number of the nodes of elements; $N_{i}$ refers to the shape function of corresponding node $i ; N_{\Gamma}$ is the set of nodes in elements cut by crack surface (nodes shown in Figure 3.1 with circles); $N_{\Lambda}$ is the set of nodes in elements cut by crack tip (nodes shown in Figure 3.1 with rectangles); $\phi(\boldsymbol{x})$ represents the form of the associated enrichment function and $\boldsymbol{a}_{i}$ represents the enriched degree of freedom (DOF) of the displacement.

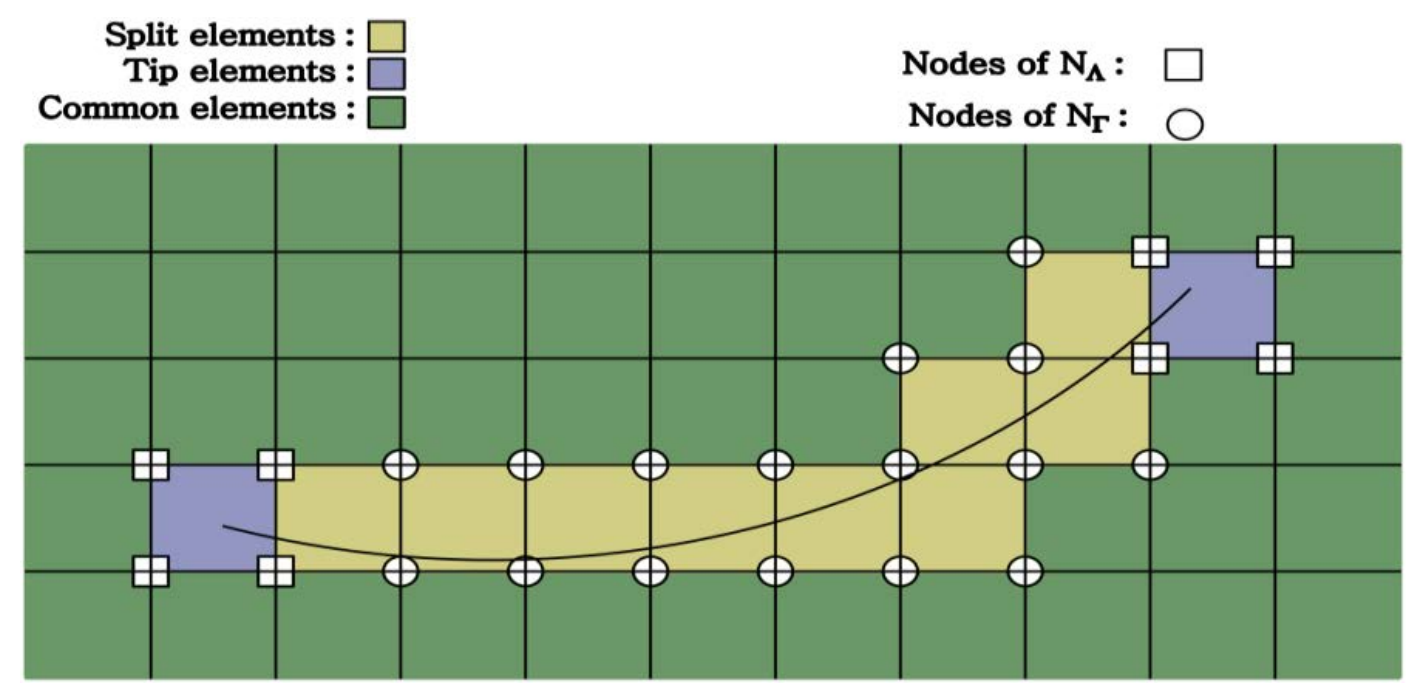

Figure 3.1.

Elements and nodes enrichment scheme for quadrilateral elements crossed by a crack, squares show the crack tip enrichment, and circles are related to the heaviside enrichment.

Eq. 3.1 can be further written as:

$$
\boldsymbol{u}(\boldsymbol{x})=\boldsymbol{u}^{F E}(\boldsymbol{x})+\boldsymbol{u}^{H}(\boldsymbol{x})+\boldsymbol{u}^{t i p}(\boldsymbol{x})
$$

Here $\boldsymbol{u}^{H}(\boldsymbol{x})$ refers to the DOF of the nodes associated with the crack surfaces and $\boldsymbol{u}^{\text {tip }}(\boldsymbol{x})$ refers to the DOF of the nodes associated with the crack tips, it can be fully expressed as (Mohammadi, 2008): 


$$
\boldsymbol{u}(\boldsymbol{x})=\sum \underbrace{N_{i}(\boldsymbol{x}) \boldsymbol{u}_{i}}_{i \in N}+\sum \underbrace{N_{i}(\boldsymbol{x}) H(\boldsymbol{x}) \boldsymbol{a}_{i}}_{i \in N_{\Gamma}}+\sum \underbrace{N_{i}(\boldsymbol{x})\left(\sum_{l=1}^{4} F_{l}(\boldsymbol{x}) \boldsymbol{b}_{i}^{l}\right)}_{i \in N_{\wedge}}
$$

Where $\boldsymbol{a}_{i}$ and $\boldsymbol{b}_{i}^{l}$ represent the enriched DOFs associated with crack surfaces and crack tips; $H(\boldsymbol{x})$ refers to the Heaviside "jump" function and takes the values +1 and -1 on different side of crack:

$$
H(\epsilon)= \begin{cases}1 & \forall \varepsilon>0 \\ -1 & \forall \varepsilon \leq 0\end{cases}
$$

$F_{l}(\boldsymbol{x})$ is a set of functions which are obtained from asymptotic displacement field near crack tip, it reflects the singularity of tip fields and can be expressed as the linear combination of the following functions:

$$
F(r, \theta)=\left\{\sqrt{\mathrm{r}} \sin \left(\frac{\theta}{2}\right), \sqrt{\mathrm{r}} \cos \left(\frac{\theta}{2}\right), \sqrt{\mathrm{r}} \sin (\theta) \sin \left(\frac{\theta}{2}\right), \sqrt{\mathrm{r}} \sin (\theta) \cos \left(\frac{\theta}{2}\right)\right\}
$$

The parameters $r$ and $\theta$ defined in polar coordinates as shown in Figure 3.2.

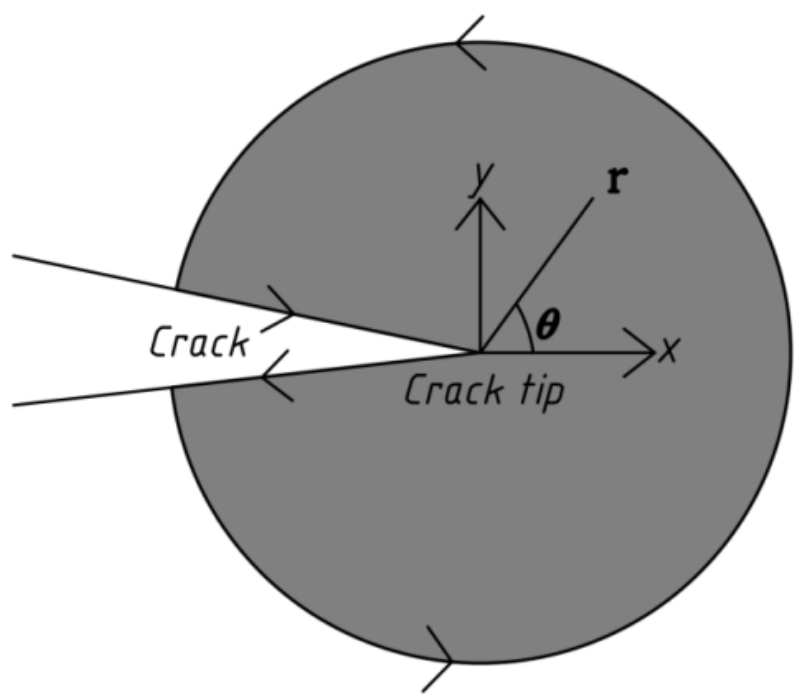

Figure 3.2. Location coordinates system at the crack tip. 
In the following, a two-dimensional crack model (Figure 3.3) will be taken as an example to describe the basic concepts and algorithms of XFEM. Considering the domain $\Omega \subset \mathcal{R}^{2}$ with a crack represented as $\Gamma_{c}$, assuming there is no surface loading imposed on the crack surfaces and the computing domain is constrained by prescribed displacements on the boundary $\Gamma_{u}$ and traction $\boldsymbol{t}$ is imposed on the boundary $\Gamma_{f}$.

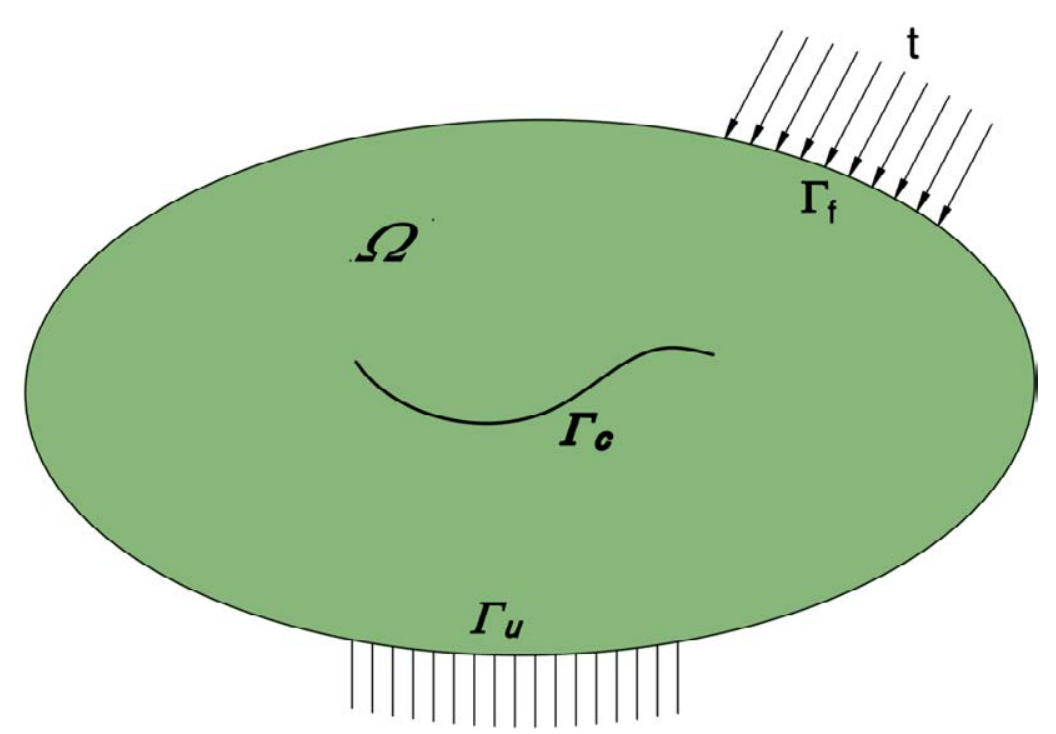

Figure 3.3. A two-dimensional crack model.

Based on the linear elastic material laws, the equilibrium equations and the boundary conditions can be expressed as the following:

$$
\left\{\begin{array}{l}
\nabla \boldsymbol{\sigma}+\boldsymbol{b}=\mathbf{0}, \quad \text { on } \Omega \\
\boldsymbol{\sigma} \cdot \boldsymbol{n}=\boldsymbol{t}, \quad \text { on } \Gamma_{f} \\
\boldsymbol{\sigma} \cdot \boldsymbol{n}^{-}=-\boldsymbol{\sigma} \cdot \boldsymbol{n}^{+}=0, \quad \text { on } \Gamma_{c} \\
\boldsymbol{\varepsilon}=\boldsymbol{\varepsilon}(\boldsymbol{u}) \\
\boldsymbol{u}=\overline{\boldsymbol{u}}, \quad \text { on } \Gamma_{u} \\
\boldsymbol{\sigma}=\boldsymbol{C}: \boldsymbol{\varepsilon}
\end{array}\right.
$$

Here $\boldsymbol{\sigma}$ is stress tensor, $\boldsymbol{\varepsilon}$ is strain tensor, $\boldsymbol{u}$ denotes displacement vector, $\boldsymbol{C}$ represents the elastic tensor and $\boldsymbol{b}$ is the body force, $\boldsymbol{t}$ and $\overline{\boldsymbol{u}}$ are boundary traction and prescribed displacement respectively. 
With the use of the constitutive laws and the principle of virtual work, the following equation can be obtained:

$$
\int_{\Omega} \boldsymbol{\sigma}: \boldsymbol{\varepsilon}\left(\boldsymbol{u}^{*}\right) \boldsymbol{d} \Omega=\int_{\Omega} \boldsymbol{b} \cdot \boldsymbol{u}^{*} d \Omega+\int_{\Gamma_{f}} \boldsymbol{t} \cdot \boldsymbol{u}^{*} d S
$$

Where $\boldsymbol{u}^{*}$ denotes the virtual displacement.

\subsubsection{The Governing Equations of XFEM}

Substituting the XFEM displacement approximation (Eq. 3.3) into the virtual work principle (Eq. 3.7), the following discrete system is obtained (Wang and Zhang, 2015; Ren, et al., 2009):

$$
\boldsymbol{K} \boldsymbol{U}=\boldsymbol{F}
$$

Where $\boldsymbol{U}$ is the vector of nodal unknowns, for every element, the corresponding vector of nodal unknowns can be expressed as:

$$
\boldsymbol{U}^{e}=\left\{u_{i}, a_{j}, t_{k}^{1}, t_{k}^{2}, t_{k}^{3}, t_{k}^{4}\right\}^{T} \quad\left(i \in N, j \in N_{\Gamma} \in N, k \in N_{\wedge} \in N\right)
$$

$\boldsymbol{K}, \boldsymbol{F}$ are the global stiffness matrix and external force vector, respectively. Both of them are computed on an element-by-element basis and then assembled by the counterparts of every element through the usual assembly procedure. The corresponding element stiffness matrix $\boldsymbol{K}^{\boldsymbol{e}}$ and element force vector $\boldsymbol{F}^{\boldsymbol{e}}$ are expressed as follows:

$$
\begin{aligned}
& \boldsymbol{K}_{i j}^{e}=\left[\begin{array}{lll}
k_{i j}^{u u} & k_{i j}^{u a} & k_{i j}^{u t} \\
k_{i j}^{a u} & k_{i j}^{a a} & k_{i j}^{a t} \\
k_{i j}^{t u} & k_{i j}^{t a} & k_{i j}^{t t}
\end{array}\right] \\
& \boldsymbol{F}^{\boldsymbol{e}}=\left\{\boldsymbol{f}_{i}^{u}, \boldsymbol{f}_{i}^{a}, \boldsymbol{f}_{i}^{t 1}, \boldsymbol{f}_{i}^{t 2}, \boldsymbol{f}_{i}^{t 3}, \boldsymbol{f}_{i}^{t 4}\right\}^{T}
\end{aligned}
$$


The sub-matrices and vectors in Eq. 3.10 and Eq. 3.11 are defined as:

$$
\begin{aligned}
k_{i j}^{r s} & =\int_{\Omega}\left(\boldsymbol{B}_{i}^{r}\right)^{T} \boldsymbol{D} \boldsymbol{B}_{j}^{s} d \Omega \quad(r, s=u, a, t) \\
\boldsymbol{f}_{i}^{u} & =\int_{\Omega} N_{i} \boldsymbol{b} d \Omega+\int_{\Gamma_{f}} N_{i} \boldsymbol{t} d s \\
\boldsymbol{f}_{i}^{a} & =\int_{\Omega} N_{i} H \boldsymbol{b} d \Omega+\int_{\Gamma} N_{i} H \boldsymbol{t} d s \\
\boldsymbol{f}_{i}^{t l} & =\int_{\Omega} N_{i} F_{l} \boldsymbol{b} d \Omega+\int_{\Gamma} N_{i} F_{l} \boldsymbol{t} d s \quad(l=1,2,3,4)
\end{aligned}
$$

Where $i, j$ are node number of element and $\Omega, \Gamma$ are the action domains of body force and external force respectively, matrices $\boldsymbol{B}_{i}^{u}, \boldsymbol{B}_{i}^{a}, \boldsymbol{B}_{i}^{t l}$ appear in Eq. 3.12 are the derivative matrix of shape functions which are given by:

$$
\boldsymbol{B}_{i}^{u}=\left[\begin{array}{cc}
\frac{\partial N_{i}}{\partial x} & 0 \\
0 & \frac{\partial N_{i}}{\partial y} \\
\frac{\partial N_{i}}{\partial y} & \frac{\partial N_{i}}{\partial x}
\end{array}\right], \boldsymbol{B}_{i}^{a}=\left[\begin{array}{cc}
\frac{\partial N_{i} H}{\partial x} & 0 \\
0 & \frac{\partial N_{i} H}{\partial y} \\
\frac{\partial N_{i} H}{\partial y} & \frac{\partial N_{i} H}{\partial x}
\end{array}\right], \boldsymbol{B}_{i}^{t l}=\left[\begin{array}{cc}
\frac{\partial N_{i} F_{l}}{\partial x} & 0 \\
0 & \frac{\partial N_{i} F_{l}}{\partial y} \\
\frac{\partial N_{i} F_{l}}{\partial y} & \frac{\partial N_{i} F_{l}}{\partial x}
\end{array}\right](l=1,2,3,4)
$$




\subsection{Rock Engineering Systems (RES)}

\subsubsection{Brief introduction of RES}

In Professor Hudson's book "Rock engineering systems: theory and practice” (Hudson, 1992), before presenting all his systems approach of RES, he quoted a poem first: “All things by immortal power, near or far, hiddenly, to each other linked are, that thou canst not stir a flower without troubling of star”. A poem suggesting that there could be relations between all things. Unlike many other methodologies only address a specific engineering aspect, his approach (Hudson, 1990, 1993; Mazzoccola and Hudson, 1996) focus on the relations between things, focus on solving the fully coupled problem with all the elements, rock mechanics, engineering parameters, structures, constructions and their interactions, for complicated and changeable rock engineering problems. RES is a powerful systematic approach.

To date, RES has already been used all over the world more than 20 years, and it almost comes to all the areas related to rock engineering. In slope engineering, researchers (Reza and Masoud, 2012; Rozos et al., 2008, 2011; Nurcihan and Sener, 2008; Masoud et al., 2013) from Iran, Turkey and Greece used it to rank the instability potential of rock slopes, and what factors have more impact on the stability of rock slopes also achieved (Masoud et al., 2011).In mining engineering, RES has been used for ranking rock cavability index in a block caving mines (Rafiee et al., 2015), for predicting the level of risk due to outof-seam dilution in longwall faces (Ali et al., 2014), for the risk assessment of floor failures (Sajjad et al., 2015), for the prediction of backbreak in bench blasting (Faramarzi et al., 2013) and for the determination of parameters influence on rock mass cavability (Rafiee et al., 2015). In underground space and tunnel engineering, RES was mainly applied to the analysis of potential damaged zones (Fattahi et al., 2013A, 2013B), the prediction of TBM performance (Omid and Seyed, 2013) and for the tunnel rock mass classification (Huang et al., 2013; Kim et al., 2008). Besides, other applications of RES included flyrock risk analysis (Farhad et al., 2014), rock blastability analysis (Latham and Lu, 1999), rockfall hazard analysis (Zhang et al., 2004), rock fragmentation prediction 
(Faramarzi et al., 2013), wellbore stability analysis (Younessi and Rasouli, 2010) and even the assessment of earthquake-induced surface effects (Castaldini et al., 1998).

\subsubsection{Interaction matrix and its coding methods}

Interaction matrix, which is the basic analytical technique of RES, is a good device for characterizing and listing all associated main parameters and interactions between parameters. In the interaction matrix for a specific engineering system (e.g. for a water inrush system), the main parameters (or factors) influencing the system are always located along the leading diagonal (top left to bottom right), called the diagonal terms; and the influence of each individual parameter on any other parameter (also called the interaction between parameters) is generally placed in the off-diagonal boxes, and they are named the off-diagonal terms. An engineering system only with two parameters is the simplest interaction matrix (see Figure.3.4); in this $2 \times 2$ interaction matrix (also named as binary interaction matrix), parameter $\mathrm{A}$ and parameter $\mathrm{B}$ placed in the leading diagonal are the main parameters, and the influence of parameter A on parameter B is placed in the top right-hand off-diagonal box. The influence of B on A is located in the bottom left-hand off-diagonal box. In Figure 3.5, by considering rock support, depth of excavation, excavation methods, rock mass quality and discontinuity geometry as five main parameters, we give an example to show how to establish an interaction matrix for generic underground excavations in practical projects. 


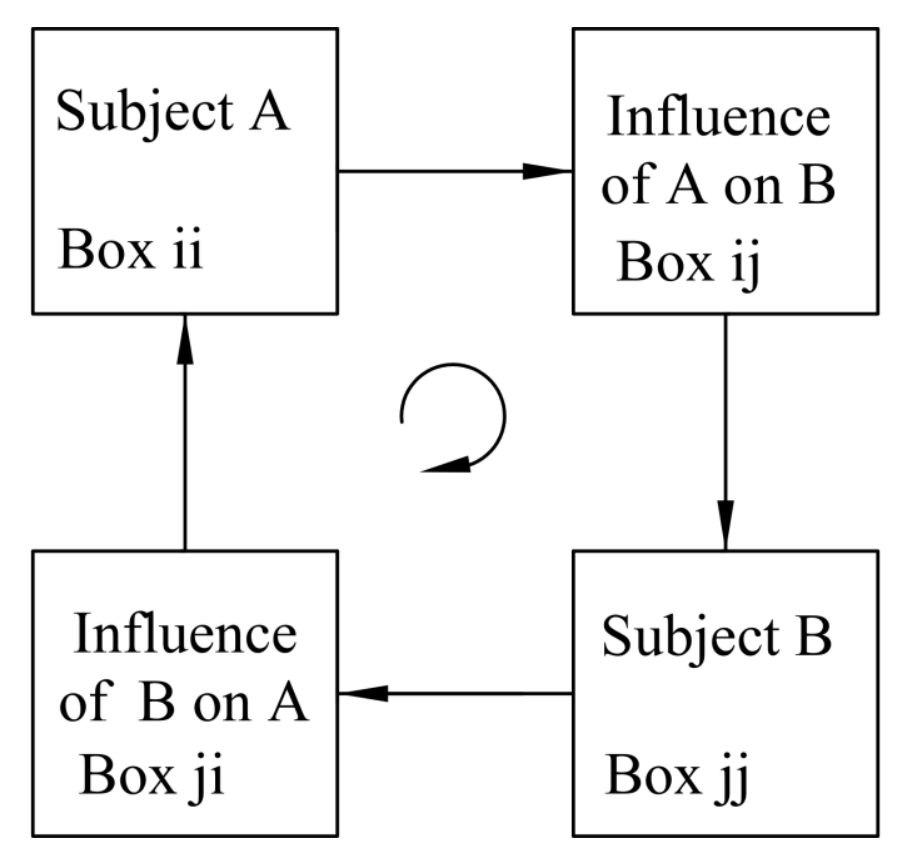

Figure 3.4. Simple binary interaction matrix.

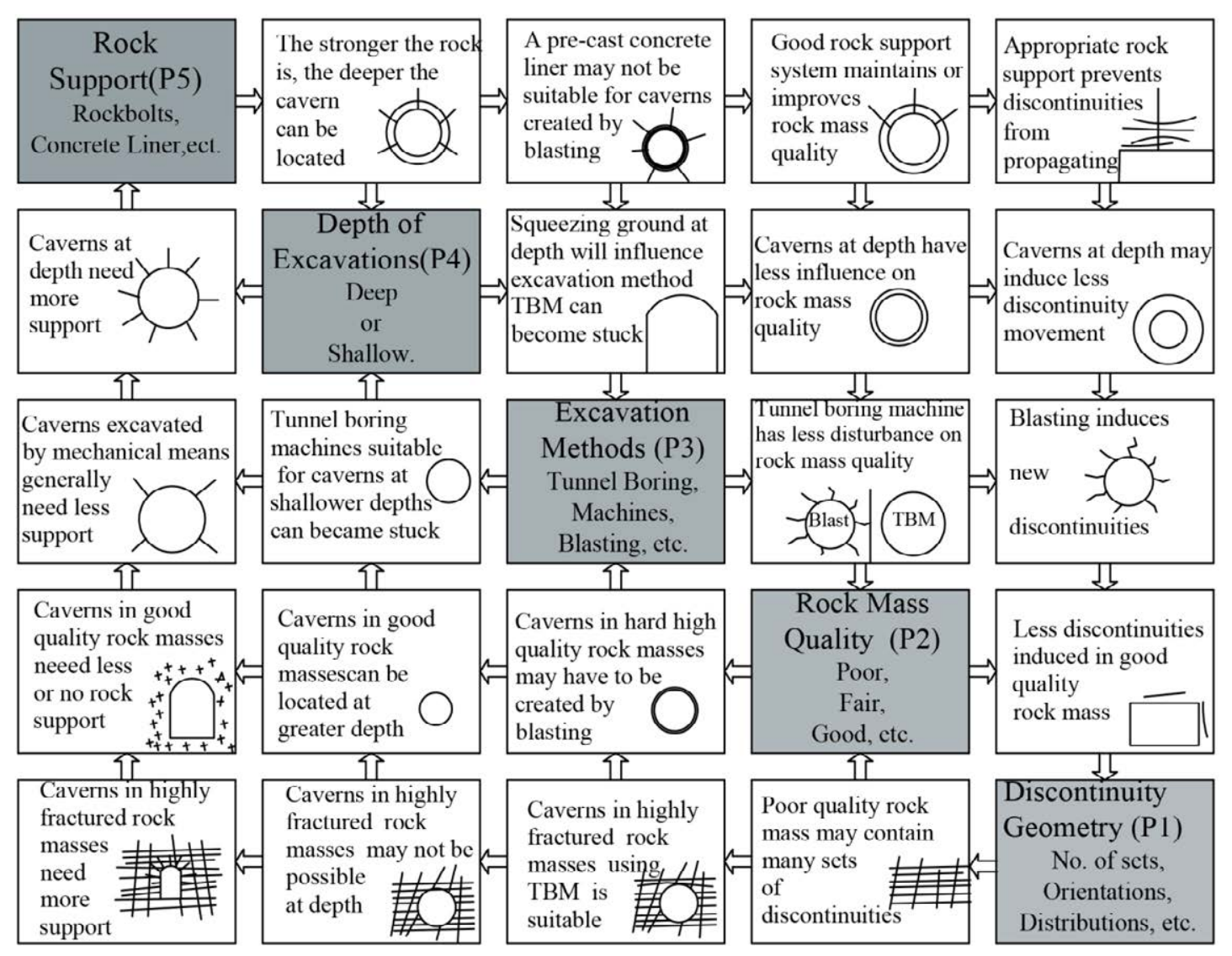

Figure 3.5. Interaction matrix of generic underground excavations. (An example for showing how to construct an interaction matrix in practical projects). 
In Figure 3.6, four main matrix coding methods are shown. These include almost all the common coding methods of interaction matrix.

The first one is the binary approach. The mechanism is either considered to be switched on or off: if it is switched on, coding the off-diagonal component with a value of unity; if it is switched off, we code the box with a value of zero. The second method is 'expert semi-quantitative' (ECQ) approach, it is an extension from the first coding approach except that the interaction intensities between parameters are classified into five categories ranging from zero to four, corresponding to 'no interaction', 'weak interaction', 'medium interaction', ‘strong interaction' and ‘critical interaction' respectively. (Because this coding method is applied in Chapter 5, so more details about this method will be given in the next section 3.2.3). The third one is slope of the $P_{i}$ and $P_{j}$ plot. If the graph of $P_{j}$ as a function of $P_{i}$ is a horizontal line, parameter $P_{j}$ dose not impact $P_{i}$, on the contrary, if there is some linear relationship between $P_{j}$ and $P_{i}$, then the interacting mechanism between these two parameter can be coded by the slope of the line. The fourth method is the most complex approach, this method needs us to represent all the interacting mechanisms between parameters by partial differential equations and estimate the constants associated with the solutions, it is a considerable potential approach but is very difficult to conduct in practical situations. 


\subsubsection{More details about the ESQ coding method}

\begin{tabular}{|l|l|}
\hline \multicolumn{2}{|c|}{ Matrix Coding Method } \\
\hline 1. Binary-Mechanisms are switched on or off: 1 (interaction) or 0 (no interaction) \\
\hline 2. Expert Semi-Quantitative (ESQ): \\
0. & No Interaction \\
1. & Weak Interaction \\
2. & Medium Interaction \\
3. & Strong Interaction \\
4. & Critical Interaction
\end{tabular}

Figure 3.6. Coding methods for interaction matrix (Hudson and Harrison, 1992).

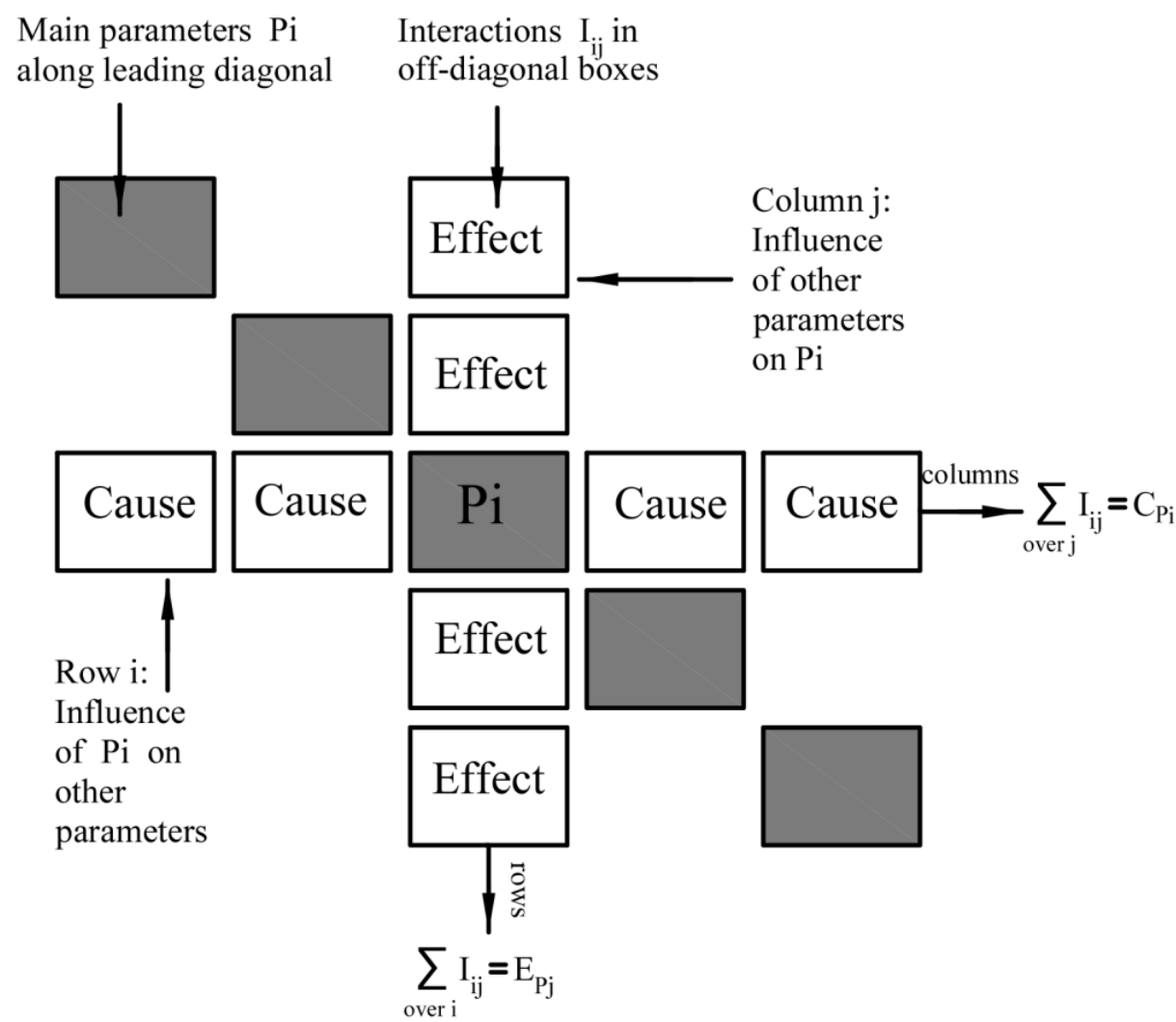

Figure 3.7. Summations of coding values in the row and column through each parameter to establish the cause and effect co-ordinates 


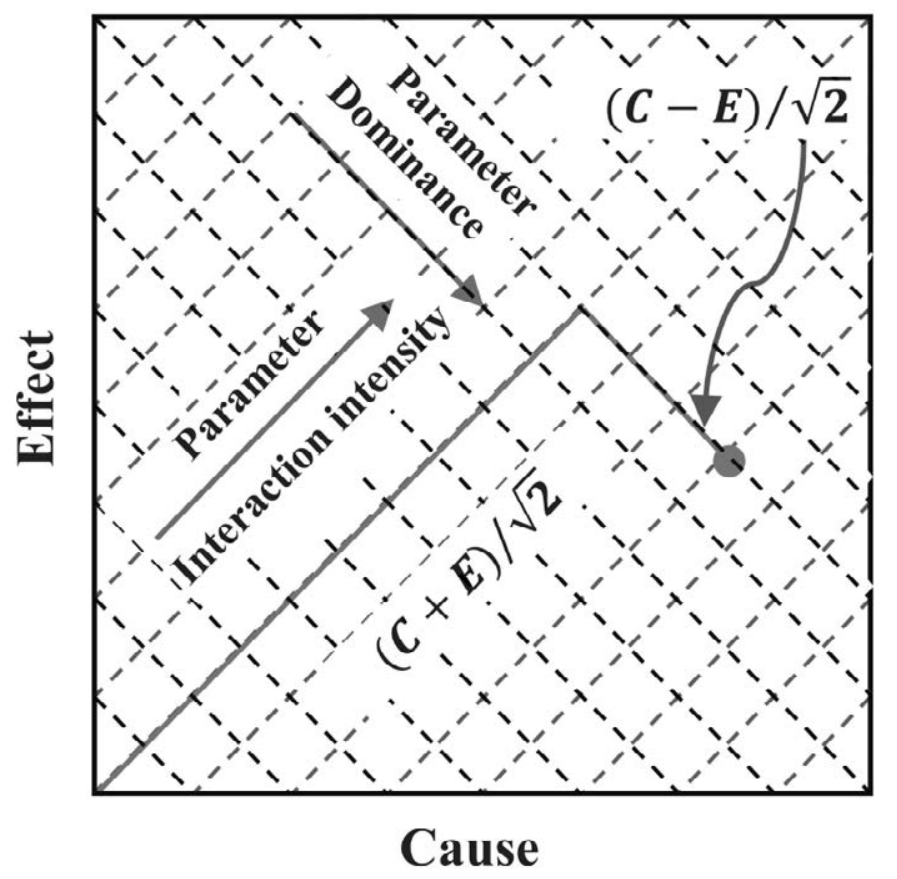

Figure 3.8. Cause-Effect plot: parameter interaction intensity and dominance. 


\subsection{Artificial Neural Networks (ANN)}

\subsubsection{Brief introduction of ANN}

More than half a century since the advent of the first computer in 1946, humans have already become more and more accustomed to use computer programs to deal with different problems. Using computer to process information has become very common in the past decades. But nevertheless, no matter how powerful the computer's ability in processing information, it is just a machine and lack of capabilities in subjective recognition and judgment. A one-year-old child can accurately identify who is his mother, but a state-of-the-art computer cannot do that. So since the 1940s, scientists began to boldly imagine whether the computer can be used for simulating the human brain so as to reach the purpose of pattern recognition, then concept of ANN is proposed.

At present, the development of the science and technology is still not advanced enough to completely replace the human brain with computers, so currently ANN actually is a sort of transition from traditional information processing to electronic human brain. On the one hand, ANN partly realizes cognitive function by simulating the structure and functionalities of biological neural networks of brain, but on the other hand it is still not a real human brain and too many assumptions contained in its algorithms, in fact, it is a mathematical model which simulates the working principles of the brain to achieve the purpose of information processing.

With the deepening of research in recent years, as an advanced tool for pattern recognition, dozens of different mature ANN models such as Hopfield network, Boltmznna network, Kohonen network, BP network, RBF network have been developed, each of these models has their own characteristics and has already been widely applied in different fields.

\subsubsection{The structure of biological neuron and neural network}

An artificial neuron is a basic unit of ANN, and it is a basic information processing unit which is established based on the imitation of the function and structure of the real biological neuron. So understanding the structure of real biological neuron will help us to better understand the artificial neuron. Figure 3.9 shows a real biological neuron with all the components, among all these components the Dendrite, the Cell body (Soma) and the 
Axon are three of the most important components for processing electrical signals. A Dendrite is a dendritic network of nerve fibers that conveys electrical signals to the Cell body, and then after the synthetizing function of the Cell body, the resultant electrical signals are sent along the axon to be distributed to other neurons, and neurons are connected by synapses.

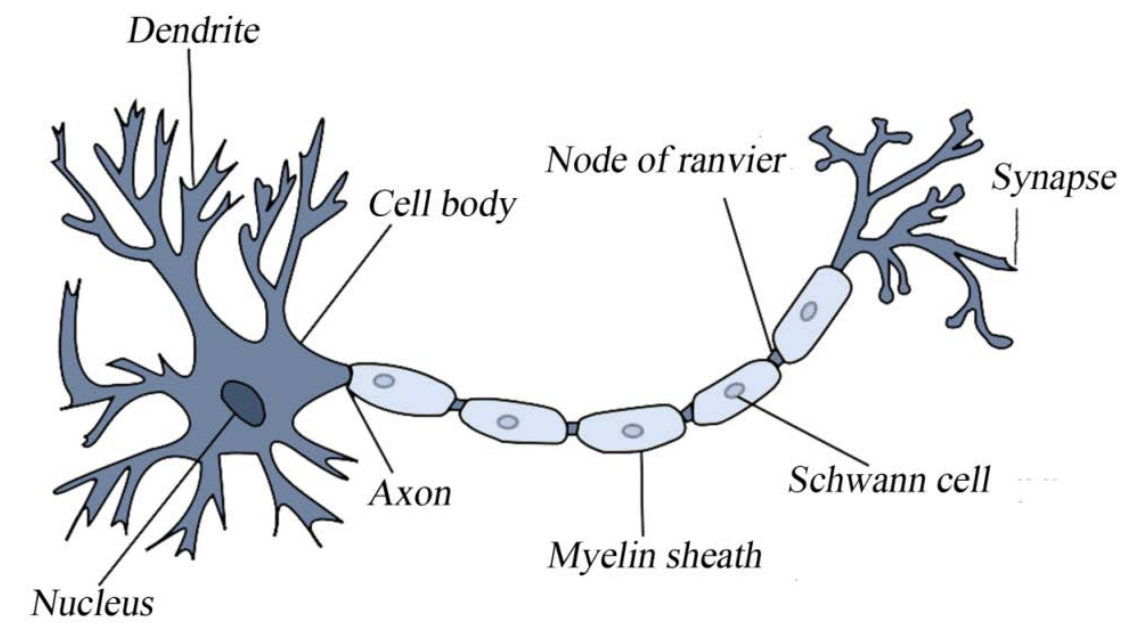

Figure 3.9. Illustration of a biological neuron with the components (Modified from David, 2005)

Neurons receive signals at synaptic junctions, on the receiving side of the synapse the signal is transmitted into the cell body along the dendrites. Some signals act as a stimulus and some act as inhibitors. When the sum of the received signals in the cell body exceeds a threshold, the cell body will be stimulated and it will send a signal through the axon to other neurons.

The neural network of brain consists of many neurons, or in other words each neuron is connected with many other neurons through synapses, the same neuron sends the same signals to other receiving neurons but will have different effects on them, which is determined by the corresponding synapse. The stronger the "connection strength" of the synapses, the stronger the received signal or on the contrary, the smaller the connection strength, the weaker the received signal. It also should be noted that the strength of synaptic connections is not changeless, which can be changed according to the acquired training or learning.

To sum up, the neural network of human brain has the following characteristics: 
- Consists of a large number of neurons and a large number of connections between neurons.

- The connection strengths between neurons determine the strengths of signal transmission.

- The connection strength between any two neurons can be changed according to the training or learning degree of the network.

- Every neuron has a 'threshold'.

- Whether the received signals act as a stimulus or as a repressor is determined by whether or not a cell body is stimulated.

\subsubsection{Artificial neuron and artificial neural network}

On the basis of the structure of biological neuron, scientists established the artificial neuron model as Figure 3.10. As can be seen in this figure, a neuron has many input signals $x_{1}, x_{2}, \cdots, x_{m}$ (because a neuron has many dendrites) and one output $y_{k}$ (a neuron has just only one axon). Assuming that the neuron has connection strengths (synaptic weights) $w_{k 1}, w_{k 2}, \cdots, w_{k m}$ with other neurons, then the signal synthesis (protein synthesis) process of the cell body can be expressed as $\sum_{i=1}^{m} w_{k i} x_{i}$. A bias $\left(b_{k}\right)$ can be used for representing the 'threshold' of the neuron and an activation function $\varphi$ can be applied for determining whether or not a cell body is stimulated.

From mathematical point of view, the signal transmission process actually is a process of implementing a mapping from input signals to output, the mathematical expressions of the mapping process can be written as:

$$
y_{k}=\varphi\left(v_{k}\right)=\varphi\left(\sum_{i=1}^{m} x_{i} w_{k i}+b_{k}\right)
$$




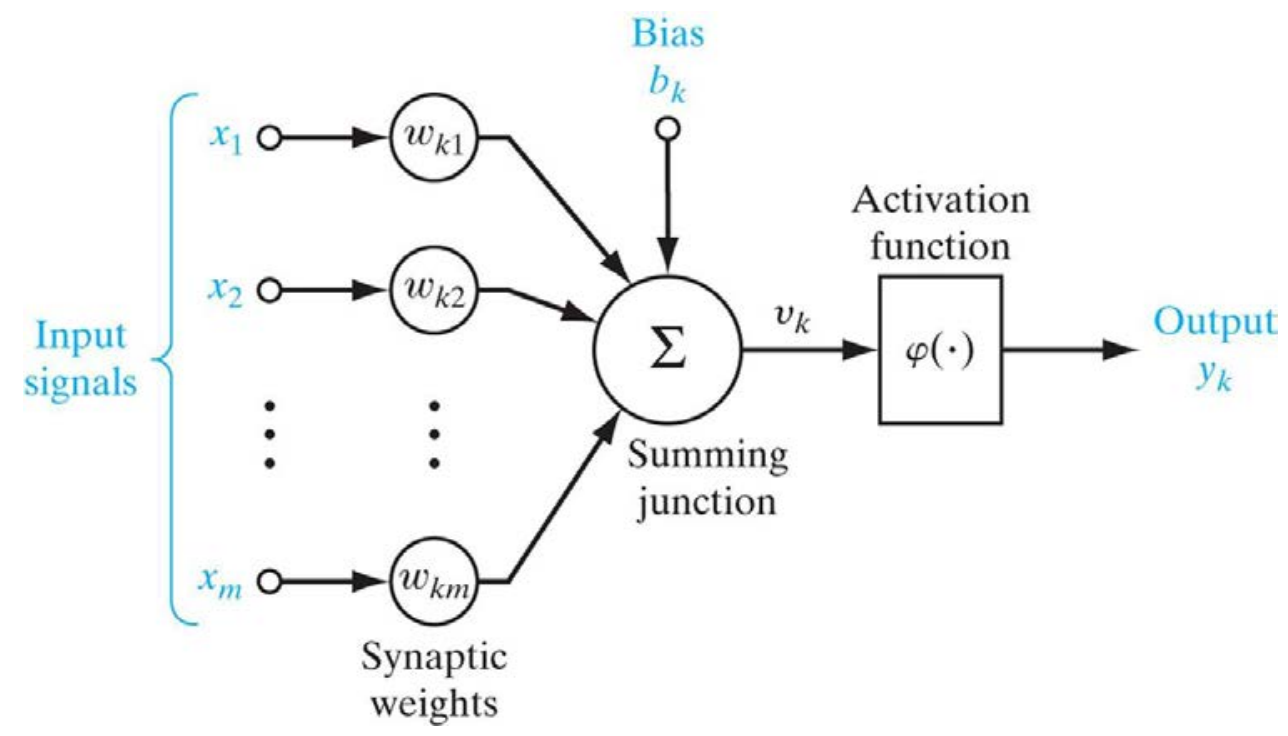

Figure 3.10 The structure of an artificial neuron.

An artificial neuron is a basic unit of ANN. With the establishment of the artificial neuron we can construct any form of ANN according to the requirement of processing information. For example, in Figure 3.11 a simple ANN consisting of multiple neurons with three layers is shown (the input layer, the hidden layer and the output layer), the first layer is the input layer and the input signals can be expressed as a column vector:

$$
\boldsymbol{x}=\left(x_{1}, x_{2}, \cdots, x_{m}\right)^{T}
$$

In the hidden layer, assuming that the connection weight of the k-th neuron to the i-th input is $w_{k i}^{1}$, then the connection weights between the $\mathrm{j}$-th neuron and the total m inputs can also be expressed as a row vector:

$$
\boldsymbol{w}_{\boldsymbol{k}}^{\mathbf{1}}=\left(w_{k 1}^{1}, w_{k 2}^{1}, \cdots, w_{k m}^{1}\right), \quad \boldsymbol{k}=1,2, \cdots, n
$$

Assuming $b_{k}^{1}$ is the bias of the $k$-th neuron of the hidden layer and $\varphi^{1}$ is its activation function, then its output can be written as:

$$
y_{k}^{1}=\varphi^{1}\left(w_{k}^{\mathbf{1}} x+b_{k}^{1}\right)
$$


Then all outputs can be written as a vector $\boldsymbol{y}^{\mathbf{1}}=\left(y_{1}^{1}, y_{2}^{1}, \cdots, y_{n}^{1}\right)^{T}$, all the weights can be written as a matrix $\boldsymbol{W}^{\mathbf{1}}=\left(\left(\boldsymbol{w}_{\mathbf{1}}^{\mathbf{1}}\right)^{\boldsymbol{T}},\left(\boldsymbol{w}_{2}^{\mathbf{1}}\right)^{\boldsymbol{T}}, \cdots,\left(\boldsymbol{w}_{\boldsymbol{n}}^{\mathbf{1}}\right)^{\mathbf{T}}\right)^{\mathbf{T}}$, together with the bias vector $\boldsymbol{b}^{\mathbf{1}}=$ $\left(b_{1}^{1}, b_{2}^{1}, \cdots, b_{n}^{1}\right)^{T}$ and the activation function matrix $\boldsymbol{\varphi}^{1}=\operatorname{diag}\left(\varphi^{1}, \varphi^{1}, \cdots, \varphi^{1}\right)$, the total output of the hidden layer thus can be derived as:

$$
y^{1}=\varphi^{1}\left(W^{1} x+b^{1}\right)
$$

Using the same algorithm, the output of the output layer can be obtained as:

$$
y^{2}=\varphi^{2}\left(W^{2}\left(\varphi^{1}\left(W^{1} \mathbf{x}+b^{1}\right)\right)+b^{2}\right)
$$

Here $\boldsymbol{W}^{\mathbf{2}}$ is the weight matrix between the hidden layer and output layer, $\boldsymbol{b}^{\mathbf{2}}$ is the bias vector and $\boldsymbol{\varphi}^{2}$ denotes the corresponding activation function matrix.

According to such derivation form, the final output of any multilayer ANN can be easily obtained. For example, the output of a three-layer ANN can be written as:

$$
y^{3}=\varphi^{3}\left(\varphi^{2}\left(W^{2}\left(\varphi^{1}\left(W^{1} \mathbf{x}+b^{1}\right)\right)+b^{2}\right)+b^{3}\right)
$$

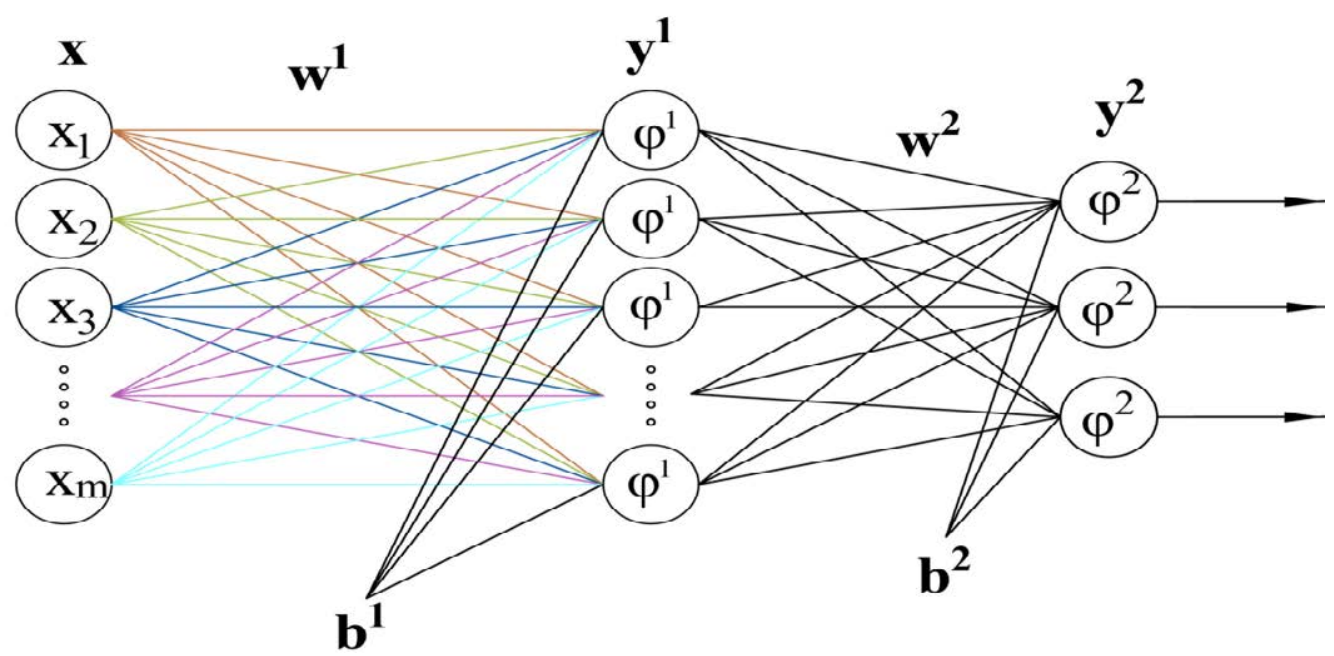

Figure 3.11 A typical ANN with three layers. 


\subsubsection{Learning process of ANN}

The learning process of ANN is also called the training process, through inputting all the training sets (training samples) into the ANN and then gradually adjusting weights according to the errors between the inputs and outputs, here the weight adjusting process actually is the learning process of ANN, after this process the ANN obtain all the knowledge contained in the training samples, and all these knowledge are stored in the adjusted weights. So after the training process, with the adjusted weights the ANN can give an appropriate output when a new sample is input into the network, this is called sample recognition.

For ANN, there are two forms of learning: one is unsupervised learning and the other is supervised learning. As in this thesis, we mainly use the latter so in the following some basic knowledge of supervised learning will be given.

Supervised learning requires the user to give the input vectors and the corresponding expected output vectors, so that the ANN can conduct its learning process based on the errors between input vectors and corresponding target vectors. This algorithm mainly includes the following steps:

(1) For each input vector of the training sets, computing its output vector;

(2) Computing the error between the output vector and the target vector;

(3) Accumulating the error and adjusting weights according to the error;

(4) Repeating steps (1)-(3) until finishing all the training sets;

(5) Judging whether the accumulating error meet the requirements of sample training, if the error is less than or equal to the preset value, the learning process finished, if not, repeating steps (1)-(4).

Here what needs to be emphasized is that so far, many new mathematical methods have been applied to the ANN and making ANN learning process has already been far different from its original method, the new developed neural network models such as fuzzy neural network (FNN), radial basis function network (RBFN) and convolutional neural network (CNN) have their own unique learning algorithms. So the detailed description of the learning process of the applied neural network model of this thesis will be given in the 
corresponding Chapters (FNN in Chapter 6 and Back-Propagation (BP) neural network in Chapter 7). 


\section{Chapter 4 Modeling and Analysis of Fault-Induced Water Inrush with XFEM}

\subsection{Introduction}

There are two situations that a fault may cause a sudden water inrush in underground mining process. The first situation is that a working face suddenly meet a large fault which is directly connected to an aquifer or a surface water body, in such case the large fault directly act as a passageway for water inrush. Another situation is water inrush caused by a small fault, in this situation the fault does not cut through the coal seam but connect to aquifers or surface water bodies under or above a stope, this type of fault also can lead to a water inrush since under the action of mining-induced stresses the fault could be activated and extended and then turned into a water-conducting passageway. For the first situation, because the geological features of those large visible faults are usually recorded in detail through geological survey before mining operations thereby in generally a lot of measures will be taken in advance to prevent water incidents, so actually in mining process the probability of sudden water inrush caused by large faults is very low. For this reason, in this Chapter we main concern the second situation about inrush caused by small fault, a computational model will be established to analyze the relations between the fault's stress fields (mainly concern the fault-tip stress fields) and the mining operations (the advancing of working face), and how the associated factors such as mining depth, water pressure, fault attitude affect the fault stress fields also will be given. The numerical modeling in this Chapter on the one hand will help to understand the mechanism of how a small fault can be turned into a water-conducting inrush passageway, and on the other hand will help to predict in which condition the fault is the most dangerous in causing water inrush incident. 


\subsection{Establishment of a computational model}

\subsubsection{Water-conducting property of fault}

Why can fault lead to water inrush? The first reason is fault itself has a good water-conducting property. Generally there are two main reasons associated with this. First, as a result of the strong relative movements and frictions among strata, in the process of fault formation there was a fault zone formed (see Figure 4.1), in which two main hydromechanical units are included: the fault core (FC) and the damage zones (DZ) (Sian et al., 2012; Caine et al., 1996; Gudmundsson et al., 2010); high-permeability structure elements such as fault gouge and fault breccia within the FC make the fault zone act as a conduit for fluid flow (Rawling et al., 2001; Bense et al., 2003), in the DZ, numerous sets of fractures may further enhance fault zone's permeability relative to the core and the undeformed protolith (Goddard and Evans, 1995). In the second, except for the feature of high permeability, the fault zone itself is a water-bearing structure filled with fluid, especially when it is connected to an aquifer (Sameh et al., 2012).

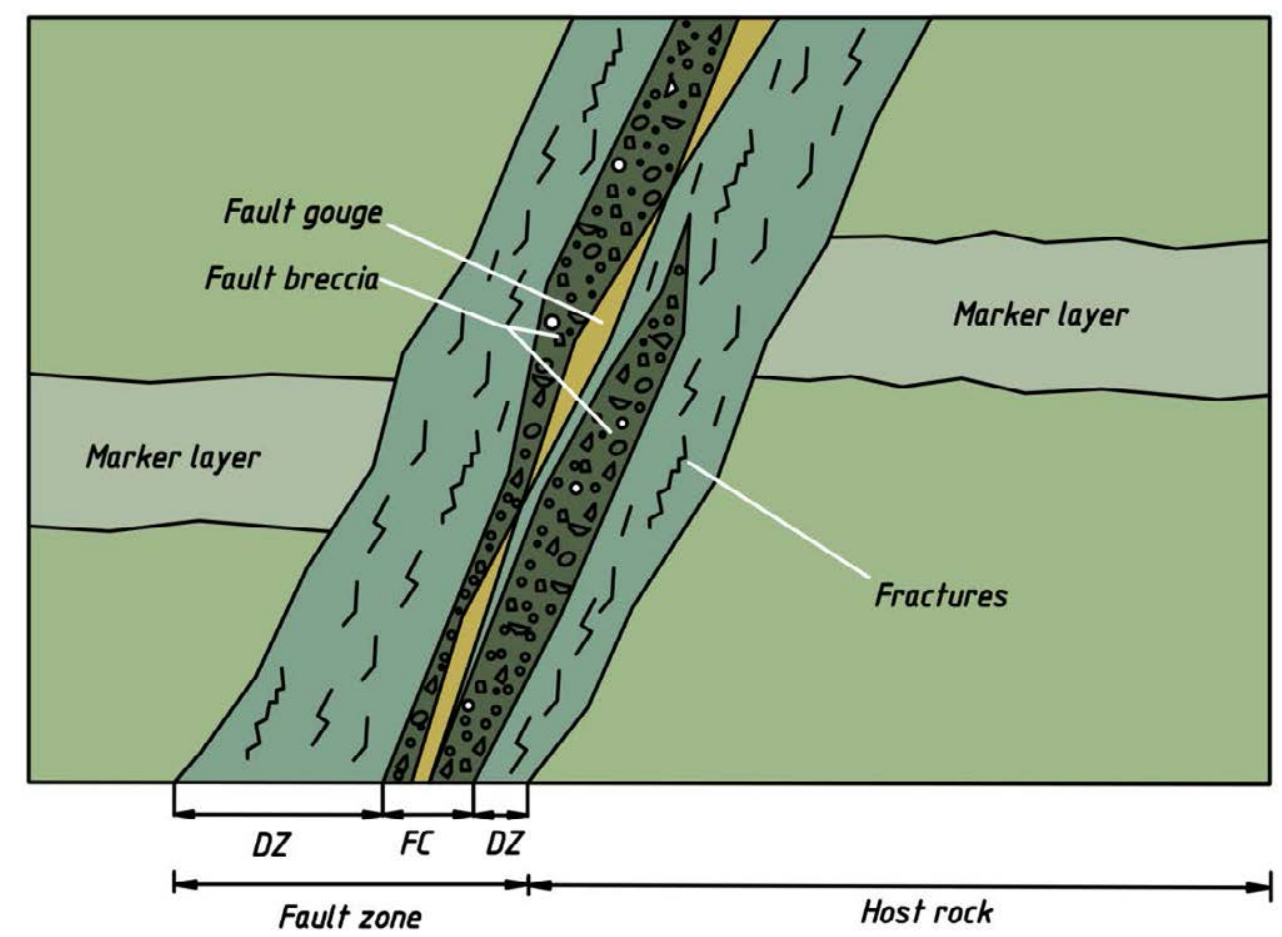

Figure 4.1 Typical structural elements of a fault zone, generally it consists of two parts: damage zone (DZ) and fault core (FC), fault gouge and fault breccia are structure elements within the fault core and sets of fractures are subsidiary structures in damage zones. Modified from (Gudmundsson, 2005) 


\subsubsection{Establishment of a fault-induced water inrush model}

As mentioned in section 4.1, for large visible faults, as usually careful measures are planned in advance for preventing inrush accidents, actually they have low possibility in leading to water hazards. On the contrary, the most dangerous threats are those small hidden faults, either we do not know of their existence or we do not have enough attention to them due to technical limitations or human negligence, these hidden faults invariably have the hidden danger of unpredicted inrush accidents.

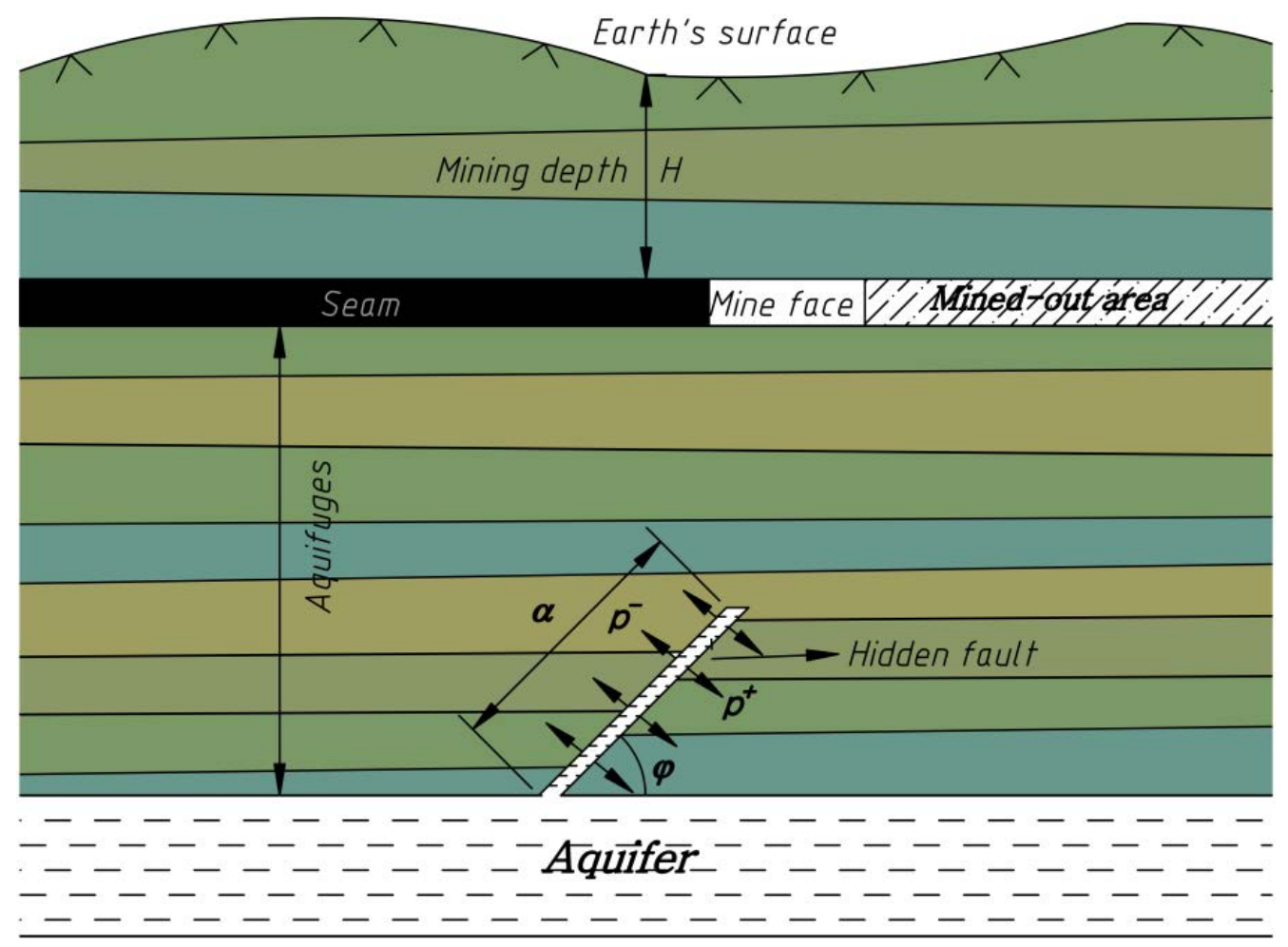

Figure 4.2 A simplified stope model of coal mining.

In mining process, with the advancing of working face, water gush out from floor and from roof are two of the common inrush types. In this Chapter we target at the former one. Figure 4.2 is a typical stope model of coal mining. In this simplified model a small hidden fault is connected to an aquifer located in the floor strata, $a$ and $\phi$ are the length and the dip angle of the fault respectively, $p$ is the water seepage pressure and we assume all strata between the seam and the aquifer are aquifuges. The model is a typical one in which the hidden fault has the potentiality of turning into an inrush passageway to cause water hazards, so it will be the 
computing model of this Chapter and all the numerical simulations in the following sections will based upon this model.

\subsubsection{Brief description of computational fracture mechanics}

As some knowledge of fracture mechanics will be used in the analysis of the fault stress fields, so in this part a basic description of computational fracture mechanics will be given.

In fracture mechanics, mathematically, a crack is understood as a line of discontinuity in two dimensions and a surface of discontinuity in three dimensions, and which may be loaded in three independent ways (Bodas, 2003; Kanninen and Popelar, 1985): opening mode (mode I), shearing mode (mode II) and tearing mode (mode III), and the stress and strain fields of the crack tip can be represented as a linear combination of each independent mode. For each loading mode, a scalar coefficient called SIF can be applied to represent the stress concentration magnitude of tip field, $K_{I}$ and $K_{\Pi}$ and $K_{\text {III }}$ refer to the SIF of modes I, II and III respectively. Certainly, if a crack is loaded in two or three modes, then the corresponding two or three SIFs needed to represent the crack tip fields.

Considering the hidden fault in Figure 4.2, we assume that geostatic pressure acts on the vertical direction and tectonic pressure acts on the horizontal direction in the model, due to the dip angle of the fault, components of these two pressures will act as both compressive stress and shear stress to the fault, thereby the crack simplified in this study is not the simple mode I, mode II or mode III, which is a kind of mixed mode compressive-shear crack. For such crack, computing the crack tip fields directly by using the traditional method of fracture mechanics is very difficult because we have to calculate the SIFs for each mode through decomposing the loads. This is why the XFEM is introduced in this chapter. In the next section, a detailed description of how to apply the XFEM to achieve the computation of crack tip fields and how to apply the interaction integral method based on XFEM to realize the SIFs computation will be given. 


\subsection{Formulation of XFEM with consideration of surface loading}

\subsubsection{Principle of virtual work when considering fluid pressure}

In Chapter 3, we have briefly described the basic formation of XFEM, but it is just the formation without considering surface loading, and in the case of our model the situation is different. The difference is that water pressure on the fault surfaces must be considered because it plays an important role in the fault growth and stability. For solving surface loading issue by means of XFEM, some works have been done by scholars in recent years (Zi and Belytschko, 2003; Asferg et al., 2007; Dolbow et al., 2001), their works are briefly described below.

Considering the domain $\Omega \subset \mathcal{R}^{2}$ with a crack described by $\Gamma_{c}\left(\Gamma_{c}=\Gamma_{\mathrm{c}}^{+} \cup \Gamma_{\mathrm{c}}^{-}\right)$as shown in Figure 4.3, assuming that $\boldsymbol{p}\left(\boldsymbol{p}=\boldsymbol{p}^{+} \cup \boldsymbol{p}^{-}\right)$is the surface loading (expressed as fluid pressure) imposed on the crack surfaces, represented by $\boldsymbol{p}^{+}$and $\boldsymbol{p}^{-}$on $\Gamma_{\mathrm{c}}^{+}$and $\Gamma_{\mathrm{c}}^{-}$, respectively. $\boldsymbol{n}^{+}$and $\boldsymbol{n}^{-}$refer to the corresponding outward normal vectors and we assume $\boldsymbol{n}=\boldsymbol{n}^{-}=-\boldsymbol{n}^{+}$. Assuming the domain is constrained by prescribed displacements on the boundary $\Gamma_{u}$ and traction $\boldsymbol{t}$ is imposed on the boundary $\Gamma_{f}$.

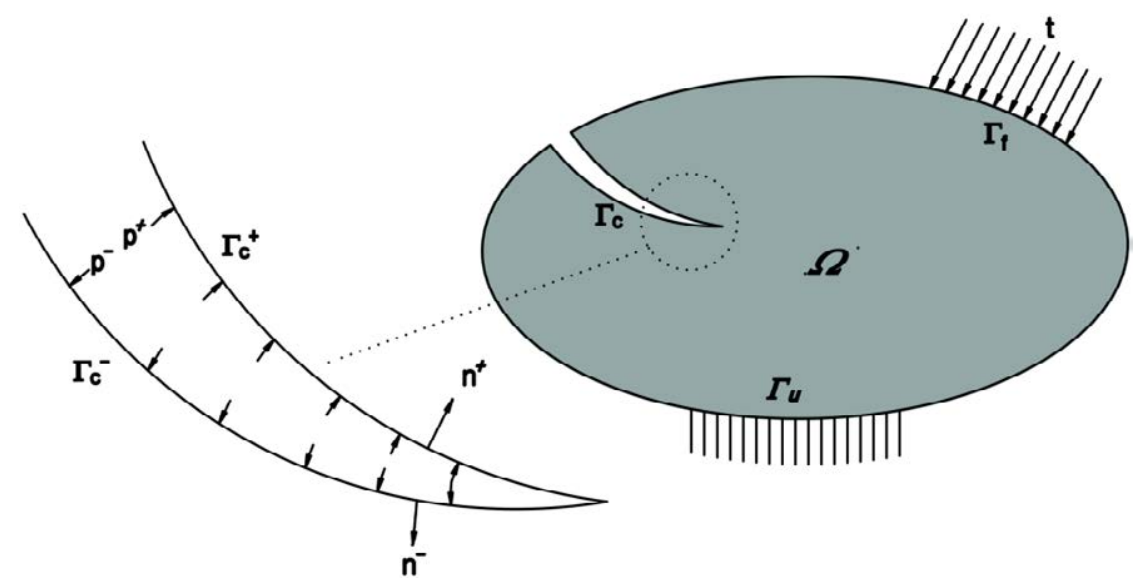

Figure 4.3. A solid domain $\Omega$ with a crack $\Gamma_{c}$ subjected to a pair of internal pressures $\left(\boldsymbol{p}^{+}\right.$and $\left.\boldsymbol{p}^{-}\right)$on crack surfaces

On the basis of Eq. 3.6, under the condition of considering the fluid pressure, a set of equations can be used for describing the equilibrium relations among the stress field $\boldsymbol{\sigma}$ of the domain, the external traction $\boldsymbol{t}$ and the surfaces loading $\boldsymbol{p}$ as: 


$$
\left\{\begin{array}{l}
\nabla \sigma+b=0, \quad \text { on } \Omega \\
\sigma . n=t, \text { on } \Gamma_{f} \\
\sigma . n^{-}=-\sigma \cdot n^{+}=p^{+}=-p^{+}=p, \quad \text { on } \Gamma_{c}
\end{array}\right.
$$

Here $\boldsymbol{b}$ is the body force.

By using the constitutive law and the principle of virtual work, two more integral terms are added to represent the surface loading when compare to Eq. 3.7, as shown in the the following equation:

$$
\int_{\Omega} \boldsymbol{\sigma}: \boldsymbol{\varepsilon}\left(\boldsymbol{u}^{*}\right) d \Omega=\int_{\Omega} \boldsymbol{b} \cdot \boldsymbol{u}^{*} d \Omega+\int_{\Gamma_{f}} \boldsymbol{t} \cdot \boldsymbol{u}^{*} d S+\int_{\Gamma_{\mathrm{c}}^{+}} \boldsymbol{p}^{+} \cdot \boldsymbol{u}^{+*} d S+\int_{\Gamma_{\mathrm{c}}^{-}} \boldsymbol{p}^{-} \cdot \boldsymbol{u}^{-*} d S
$$

Where $\boldsymbol{u}^{*}$ denotes the virtual displacement. Since on the crack surfaces we have $\boldsymbol{p}=\boldsymbol{p}^{+}=-\boldsymbol{p}^{-}$, so Eq. 4.2 can also be written as:

$$
\int_{\Omega} \boldsymbol{\sigma}: \boldsymbol{\varepsilon}\left(\boldsymbol{u}^{*}\right) d \Omega=\int_{\Omega} \boldsymbol{b} \cdot \boldsymbol{u}^{*} d \Omega+\int_{\Gamma_{f}} \boldsymbol{t} \cdot \boldsymbol{u}^{*} d S+\int_{\Gamma_{\mathrm{c}}} \boldsymbol{p} \cdot\left(\boldsymbol{u}^{+*}-\boldsymbol{u}^{-*}\right) d S
$$

\subsubsection{Governing equations when considering surface loading}

Through substituting the XFEM displacement approximation (Eq. 3.3) into the new virtual work principle (Eq. 4.3), we have:

$$
\boldsymbol{K} \boldsymbol{U}=\boldsymbol{F}
$$

As the same we mentioned in Chapter 3, where $\boldsymbol{U}, \boldsymbol{K}$ and $\boldsymbol{F}$ are the vector of nodal unknowns, the global stiffness matrix and external force vector, respectively. For every element, they can be written as:

$$
\boldsymbol{U}^{e}=\left\{u_{i}, a_{j}, t_{k}^{1}, t_{k}^{2}, t_{k}^{3}, t_{k}^{4}\right\}^{T} \quad\left(i \in N, j \in N_{\Gamma} \in N, k \in N_{\wedge} \in N\right)
$$




$$
\begin{gathered}
\boldsymbol{K}_{i j}^{e}=\left[\begin{array}{ccc}
k_{i j}^{u u} & k_{i j}^{u a} & k_{i j}^{u t} \\
k_{i j}^{a u} & k_{i j}^{a a} & k_{i j}^{a t} \\
k_{i j}^{t u} & k_{i j}^{t a} & k_{i j}^{t t}
\end{array}\right] \\
\boldsymbol{F}^{e}=\left\{\boldsymbol{f}_{i}^{u}, \boldsymbol{f}_{i}^{a}, \boldsymbol{f}_{i}^{t 1}, \boldsymbol{f}_{i}^{t 2}, \boldsymbol{f}_{i}^{t 3}, \boldsymbol{f}_{i}^{t 4}\right\}^{T}
\end{gathered}
$$

Here what needs to be noted is that the sub-matrices and vectors in Eq. 4.6 and Eq. 4.7 are different form which in Eq. 3.10 and Eq. 3.11:

$$
\begin{gathered}
k_{i j}^{r s}=\int_{\Omega}\left(\boldsymbol{B}_{i}^{r}\right)^{T} \boldsymbol{D} \boldsymbol{B}_{j}^{s} d \Omega \quad(r, s=u, a, t) \\
\boldsymbol{f}_{i}^{u}=\int_{\Omega} N_{i} \boldsymbol{b} d \Omega+\int_{\Gamma_{f}} N_{i} \boldsymbol{t} d s \\
\boldsymbol{f}_{i}^{a}=\int_{\Omega} N_{i} H \boldsymbol{b} d \Omega+\int_{\Gamma} N_{i} H \boldsymbol{t} d s+2 \int_{\Gamma} \boldsymbol{n} N_{i} \boldsymbol{p} d s \\
\boldsymbol{f}_{i}^{t l}=\int_{\Omega} N_{i} F_{l} \boldsymbol{b} d \Omega+\int_{\Gamma} N_{i} F_{l} \boldsymbol{t} d s+2 \int_{\Gamma} \boldsymbol{r}^{2 / 3} \boldsymbol{n} N_{i} \boldsymbol{p} d s \quad(l=1,2,3,4)
\end{gathered}
$$

As the same, matrices $\boldsymbol{B}_{i}^{u}, \boldsymbol{B}_{i}^{a}, \boldsymbol{B}_{i}^{t l}$ appear in Eq. 4.8 are the derivative matrix of shape functions which are given by:

$$
\boldsymbol{B}_{i}^{u}=\left[\begin{array}{cc}
\frac{\partial N_{i}}{\partial x} & 0 \\
0 & \frac{\partial N_{i}}{\partial y} \\
\frac{\partial N_{i}}{\partial y} & \frac{\partial N_{i}}{\partial x}
\end{array}\right], \boldsymbol{B}_{i}^{a}=\left[\begin{array}{cc}
\frac{\partial N_{i} H}{\partial x} & 0 \\
0 & \frac{\partial N_{i} H}{\partial y} \\
\frac{\partial N_{i} H}{\partial y} & \frac{\partial N_{i} H}{\partial x}
\end{array}\right], \boldsymbol{B}_{i}^{t l}=\left[\begin{array}{cc}
\frac{\partial N_{i} F_{l}}{\partial x} & 0 \\
0 & \frac{\partial N_{i} F_{l}}{\partial y} \\
\frac{\partial N_{i} F_{l}}{\partial y} & \frac{\partial N_{i} F_{l}}{\partial x}
\end{array}\right](l=1,2,3,4)
$$




\subsection{Fracture criterion and stress intensity factors (SIFs) for mixed mode crack}

\subsubsection{Fracture Criterion}

In section 4.2.3, we have already discussed that because of the dip angle of the fault, the geostatic pressure and the tectonic pressure will act as both compressive stress and shear stress to the fault surfaces, therefore the fault in our model actually can be regards as a kind of mixed mode crack. In this section, fracture criterion about such crack will be given. The maximum circumferential stress criterion, which was proposed by Erdogan and Sih in 1963 (Erdogan and Sih, 1963), is very powerful in solving crack extension problems. It is based on the assumption that crack will grow in the direction normal to the maximum circumferential stress $\sigma_{\theta \theta}$, according to elastic fracture mechanics, the circumferential stress and the tangential stress $\sigma_{r \theta}$ at crack tip can be expressed as:

$$
\left\{\begin{array}{l}
\sigma_{\theta \theta} \\
\sigma_{r \theta}
\end{array}\right\}=\frac{K_{I}}{4 \sqrt{2 \pi r}}\left\{\begin{array}{c}
3 \cos \left(\frac{\theta}{2}\right)+\cos \left(\frac{3 \theta}{2}\right) \\
\sin \left(\frac{\theta}{2}\right)+\sin \left(\frac{3 \theta}{2}\right)
\end{array}\right\}+\frac{K_{\Pi}}{4 \sqrt{2 \pi r}}\left\{\begin{array}{c}
-\sin \left(\frac{\theta}{2}\right)-3 \sin \left(\frac{3 \theta}{2}\right) \\
\cos \left(\frac{\theta}{2}\right)+3 \cos \left(\frac{3 \theta}{2}\right)
\end{array}\right\}
$$

By assuming $\sigma_{r \theta}=0$, the circumferential stress reaches the maximum and the crack will be in a state of instability and will grow from its tip, by combining with Eq. 4.13 we can get the further expression as follows:

$$
\tan \left(\frac{\theta}{2}\right)=\frac{1}{4}\left[\frac{K_{I}}{K_{\Pi}} \pm \sqrt{\left(\frac{K_{I}}{K_{\Pi}}\right)^{2}+8}\right]
$$

According to the hypothesis that the crack will grow in the direction perpendicular to the largest tension at the crack tip (Erdogan and Sih, 1963), we can judge whether a crack is stable by the following expression:

$$
K_{e q}=\frac{1}{2} \cos \frac{\theta_{0}}{2}\left[K_{I}\left(1+\cos \left(\theta_{0}\right)-3 K_{\Pi} \sin \left(\theta_{0}\right)\right] \geq K_{I c}\right.
$$


Where $K_{e q}$ is the equivalent stress intensity factor; $K_{I c}$ denotes the fracture toughness, which is a quantitative way of expressing a material's resistance to brittle fracture and has no relationship with the state of stress. Its value can be determined only by the material properties; $\theta_{0}$ refers to the crack propagation angle which is derived from Eq. 4.14.

$$
\theta_{0}=2 \arctan \left\{\frac{1}{4}\left[\frac{K_{I}}{K_{\Pi}} \pm \sqrt{\left(\frac{K_{I}}{K_{\Pi}}\right)^{2}+8}\right]\right\}
$$

By analyzing the expression of the fracture criterion Eq. 4.15, conclusion can be reached that the stability of a crack is directly related to its SIFs at tip. In the next section, method of computing SIFs based on XFEM will be given.

\subsubsection{Computing SIFs}

Among all methods of computing SIFs, the interaction integral method (Yau and Wang, 1984), proposed by Yau in 1984 for solving mixed mode problems, was shown to have the highest accuracy by Nagashima in his study in 2003 (Nagashima et al., 2003).

According to Yan's study, the interaction integral $I^{(1,2)}$ for two states of a crack body can be expressed as:

$$
\begin{gathered}
I^{(1,2)}=\frac{2}{E^{*}}\left(K_{I}^{(1)} K_{I}^{(2)}+K_{\Pi}^{(1)} K_{\Pi}^{(2)}\right) \\
=\int_{A}\left[\sigma_{i j}^{(1)} \frac{\partial u_{i}^{(2)}}{\partial x_{1}}+\sigma_{i j}^{(2)} \frac{\partial u_{i}^{(1)}}{\partial x_{1}}-W^{(1,2)} \delta_{1 j}\right] \frac{\partial q}{\partial x_{j}} d A \\
W^{(1,2)}=\sigma_{i j}^{(1)} \varepsilon_{i j}^{(2)}=\sigma_{i j}^{(2)} \varepsilon_{i j}^{(1)} \\
E^{*}= \begin{cases}E & \text { For plane stress } \\
\frac{E}{1-v^{2}} & \text { For plane strain }\end{cases}
\end{gathered}
$$


Where $\sigma_{i j}^{(1)}, \varepsilon_{i j}^{(1)}, u_{i}^{(1)}$ refer to the real state (state 1$)$ which are obtained from the present XFEM calculation, $\sigma_{i j}^{(2)}, \varepsilon_{i j}^{(2)}, u_{i}^{(2)}$ refer to the auxiliary state (state 2) which are obtained from the asymptotic fields for mode I or mode $\Pi ; E$ is the Young's modulus and $v$ is the Poisson's ratio; $\mathrm{A}$ is the integral domain; $q$ is the weight function which takes a value of unity on an open set containing the crack tip and vanished on an outer prescribed contour (Li et al., 1985).

Once the value of the interaction integral $I^{(1,2)}$ is obtained from Eq. 4.17, by making the state 2 as the pure Mode $I$ asymptotic fields with $K_{I}^{(2)}=1, K_{\Pi}^{(2)}=0$, and then we can get the stress intensity factor for Mode $I$ as:

$$
K_{I}^{(1)}=\frac{2}{E^{*}} I^{(1, \text { modeI })}
$$

Using the similar way we can determine the stress intensity factor for Mode $\Pi$.

As described before, in this paper, our situation is that we must consider the fluid pressure on crack surfaces, but the interaction integral showed in Eq. 4.17 is only to the situation when the crack surfaces are traction-free, in views of this, Dolbow (2001) improved the interaction integral method by adding a integral term about crack surfaces loading to compute the SIFs, the complete expression of his study is:

$$
\begin{gathered}
\mathrm{I}^{(1,2)}=\int_{\mathrm{A}}\left[\sigma_{\mathrm{ij}}^{(1)} \frac{\partial \mathrm{u}_{\mathrm{i}}^{(2)}}{\partial \mathrm{x}_{1}}+\sigma_{\mathrm{ij}}^{(2)} \frac{\partial \mathrm{u}_{\mathrm{i}}^{(1)}}{\partial \mathrm{x}_{1}}-\mathrm{W}^{(1,2)} \delta_{1 \mathrm{j}}\right] \frac{\partial \mathrm{q}}{\partial \mathrm{x}_{\mathrm{j}}} \mathrm{dA}+ \\
\int_{\Gamma_{\mathrm{c}}^{+}+\Gamma_{\mathrm{c}}^{-}}\left[\sigma_{\mathrm{i} 2}^{(1)} \frac{\partial \mathrm{u}_{\mathrm{i}}^{(2)}}{\partial \mathrm{x}_{1}}+\sigma_{\mathrm{i} 2}^{(2)} \frac{\partial \mathrm{u}_{\mathrm{i}}^{(1)}}{\partial \mathrm{x}_{1}}\right] \mathrm{qmdS}
\end{gathered}
$$

Where $m$ is the unit outward normal; $\Gamma_{\mathrm{c}}^{+}+\Gamma_{\mathrm{c}}^{-}$are the crack surfaces. 


\subsection{Numerical implementation and computational results}

The numerical implementation of the model (Figure 4.2) established in section 4.2.2 firstly requires splitting it as a XFEM computational mesh (Figure 4.4). As shown in Figure 4.4, the whole computational domain is split as 1802 four-node elements and 1890 nodes. The computational size is $80 \mathrm{~m}$ (width) in the horizontal direction and $45 \mathrm{~m}$ (height) in the vertical direction. Geostatic pressure $\sigma_{1}=\gamma H$ acts on the vertical direction and tectonic pressure $\sigma_{2}=\sigma_{3}=\lambda \gamma H$ act on the horizontal direction, and both of them act as compressive stress. $\gamma$ is the specific weight of the strata and $\lambda$ is the lateral pressure coefficient, $H$ represents the mining depth. In addition, in this computational model, we assume that the mining depth is $H=300 \mathrm{~m}$ in the underground, $a=15 \mathrm{~m}$ and $\varphi=45^{\circ}$ are the length and the dip angle of the fault respectively, and $p=5 \mathrm{Mpa}$ is the fluid pressure.

Based on XFEM and the knowledge of fracture mechanisms, a Matlab code was written to perform the numerical calculations. Under the assumptions of $\mathrm{H}=300 \mathrm{~m}, \mathrm{a}=15 \mathrm{~m}$, $\varphi=45^{\circ}$ and $\mathrm{p}=5 \mathrm{MPa}$, the stress distribution of the whole computational domain is given in Fig. 7; note that the stress is the von Mises equivalent stress $\sigma_{\mathrm{v}}$. For general plane stress condition $\left(\sigma_{3}=0, \sigma_{31}=\sigma_{23}=0\right), \sigma_{v}$ can be obtained by Eq. 4.22:

$$
\sigma_{\mathrm{v}}=\sqrt{\sigma_{11}^{2}-\sigma_{11} \sigma_{22}+\sigma_{22}^{2}+3 \sigma_{12}^{2}}
$$

As can be seen from Fig. 7, there are two main areas where the stress distributions are significant. In the first area, the mining-induced stresses distribute symmetrically around the mine face and the stress concentration occurs in front of the face. The second area is the area surrounding the fault, where significant stress concentration occurs at the fault tip. 


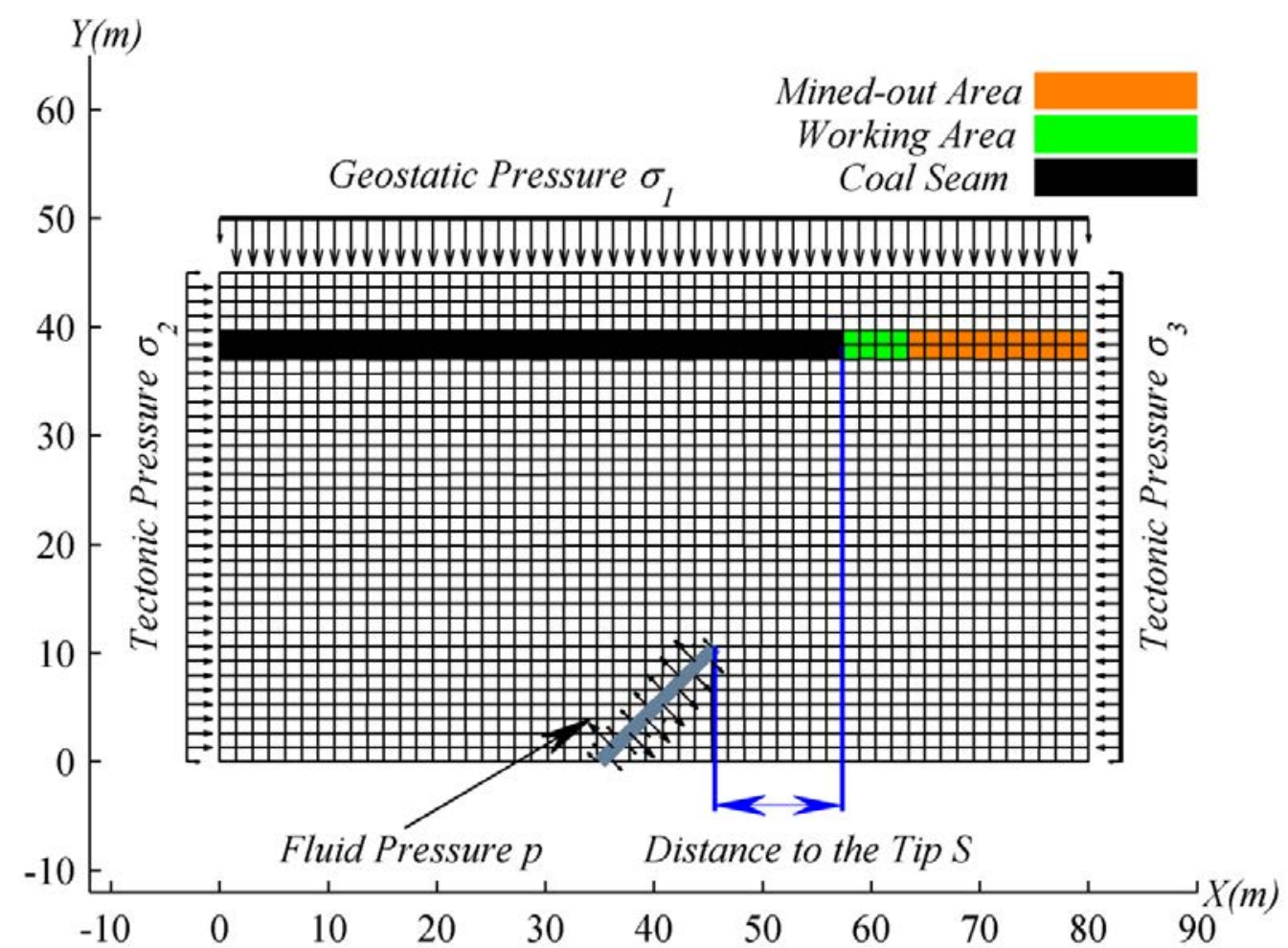

Figure 4.4. Computational mesh generated based on the established model shown in Figure 4.2 .

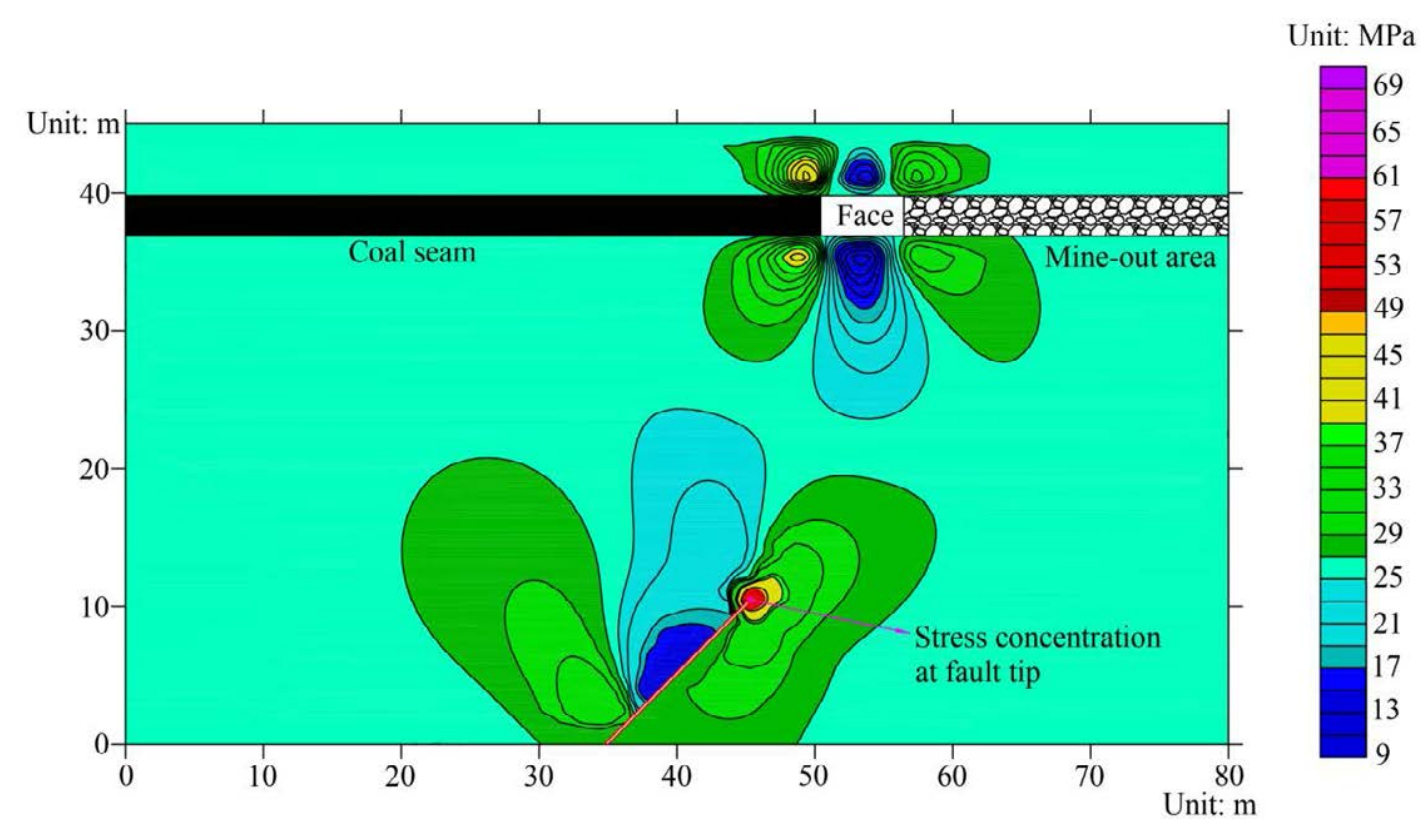

Figure 4.5. Von-Mises stress contours of the whole computational domain. 


\subsubsection{How the associated factors affect the fault's stress fields}

In the computing process of XFEM, the mining depth, the fault length, the fault dip and the fluid pressure are four of the direct parameters that we used to calculate the stress field of the fault tip. The corresponding SIFs $\left(K_{I}\right.$ and $\left.K_{\Pi}\right)$ are applied to represent the stress concentration magnitude of the tip field and $K_{e q}$ (Eq. 4.15) is the equivalent SIF which combined $K_{I}$ and $K_{\Pi}$ to evaluate stress concentration magnitude collectively. If the equivalent SIF is greater than the fracture toughness $K_{I c}$ of the strata, the fault will be activated at tip and extend to the floor of working area to cause water inrush. We can summarize this process as Figure 4.6.

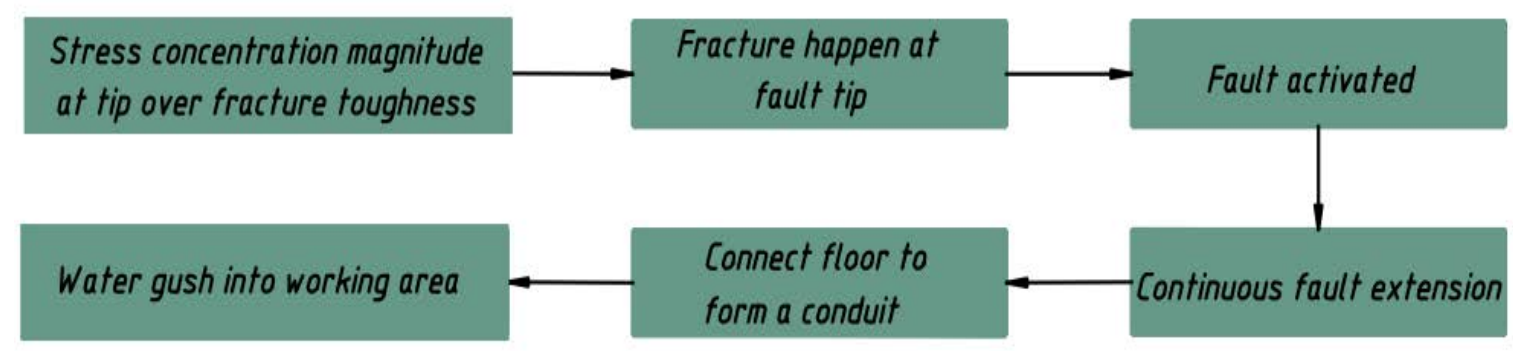

Figure 4.6. The whole process of how a fault-induced water inrush accident caused in a mine face.

In order to analyze how the variation of these four corresponding parameters ( $H, a, \varphi$,and $p$ ) influence the tip fields which is directly related to water inrush, different values of the mining depth $H$, the fault length $a$, the fault dip $\varphi$ and the fluid pressure $p$ are taken to run the Matlab code to get the corresponding SIFs. In the following paragraphs, the calculation results of how each of these four parameters affects the stress fields of the fault tip will be given in detail, which will provide us a quantitative way to understand in which condition the fault has the greatest possibility to be activated and the mining face has the greatest risk of water inrush accident.

Assuming that $\mathrm{a}=15 \mathrm{~m}, \varphi=45^{\circ}$ and $\mathrm{p}=5 \mathrm{MPa}$, and varying $\mathrm{H}$ from $50 \mathrm{~m}$ to $300 \mathrm{~m}$, Figure 4.7 shows how the SIFs vary with value of $\mathrm{H}$. The figure can be analyzed more clearly by considering two regions. When the value of $\mathrm{H}$ is less than $147 \mathrm{~m}$, the value of $\mathrm{K}_{\mathrm{I}}$ is positive, which means that the stress field of the fault tip in this case is tension stress and that the effects of the geostatic and tectonic pressures are weaker than that of the fluid pressure. Therefore, in this situation, the tension stress caused by the fluid pressure is the main driving force of fault activation. In the second region, where $\mathrm{H}$ exceeds $147 \mathrm{~m}$, both $\mathrm{K}_{\mathrm{I}}$ and $\mathrm{K}_{\mathrm{eq}}$ are negative, and 
the tip field becomes compressive stress. $\mathrm{K}_{\mathrm{I}}, \mathrm{K}_{\Pi}$ and $\mathrm{K}_{\mathrm{eq}}$ increase as $\mathrm{H}$ increases, which indicates that the probability of fault activation rises and the possibility of water inrush increases as the mining depth increases.

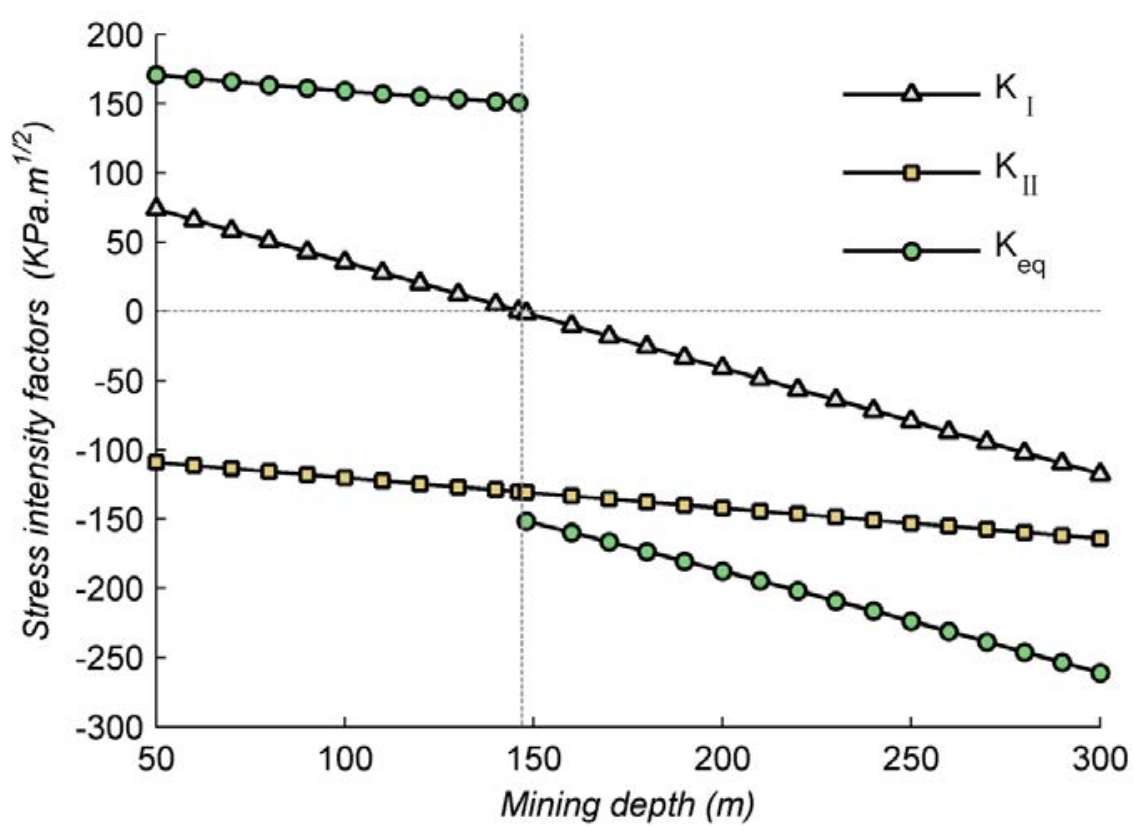

Figure 4.7. How the variation of the mining depth affects the stress field of the fault tip.

Assuming that $\mathrm{a}=15 \mathrm{~m}, \varphi=45^{\circ}$, and $\mathrm{H}=300 \mathrm{~m}$ and the fluid pressure $\mathrm{p}$ ranges from 0.5 to $5 \mathrm{MPa}$, the SIFs vary due to the change of p. As can be seen in Figure 4.8, with the increase of $\mathrm{p}, \mathrm{K}_{\Pi}$ gradually decreases, which indicates that the degree of shear stress concentration continually weakens at the fault tip, and the value of $\mathrm{K}_{\mathrm{I}}$ increases with the raise of $p$, this is representative of the compressive stress concentration constantly increasing. From the overall trend of $\mathrm{K}_{\mathrm{I}}, \mathrm{K}_{\Pi}$ and based on the small changes of $\mathrm{K}_{\mathrm{eq}}$, it can be concluded that the higher the fluid pressure, the greater the likelihood of a compressive fracture occurring at the fault tip and the greater the possibility that water inrush will be induced by fault activation. In addition, at a low fluid pressure, a fault can also be activated at the fault tip, causing water inrush by shear stresses, because under low fluid pressure, $K_{\Pi}$ is much greater than $K_{I}$. 


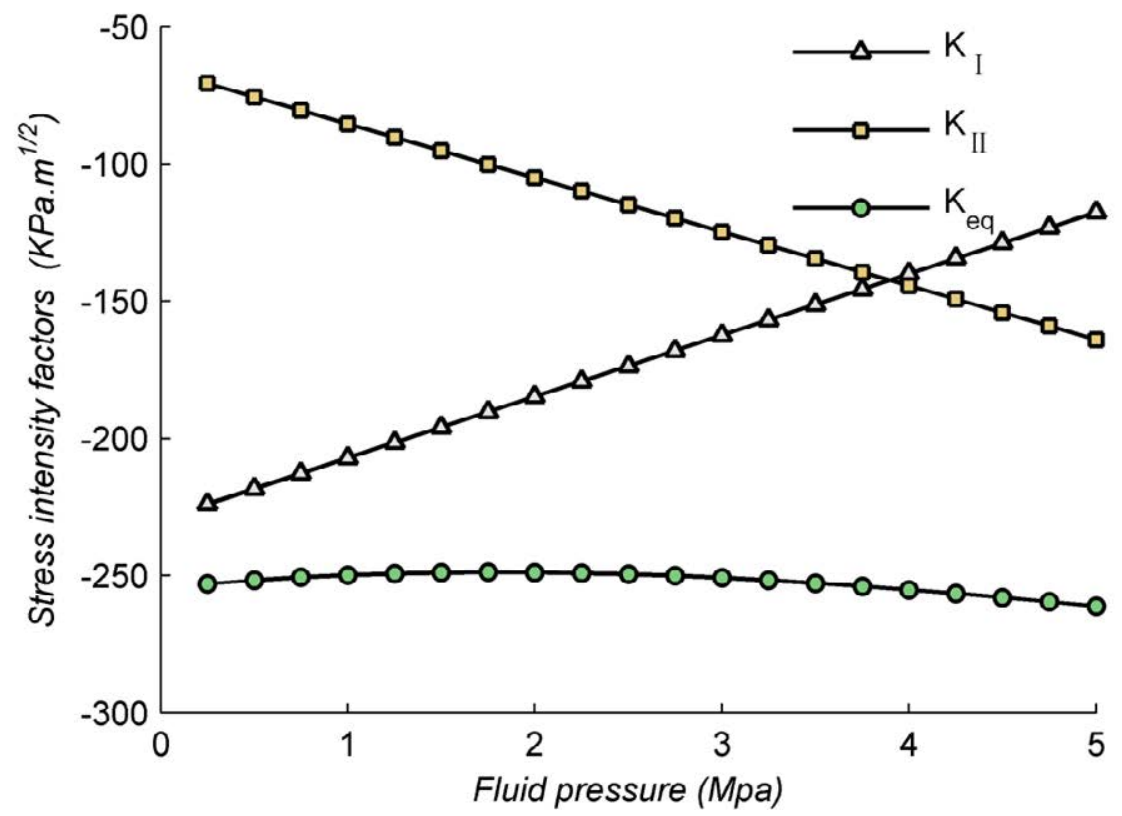

Figure 4.8. How the variation of the fluid pressure impacts on the stress field of the fault tip.

At a mining depth, $\mathrm{H}$, of $300 \mathrm{~m}, \mathrm{p}=5 \mathrm{MPa}$, changing the fault dip from $10^{\circ}$ to $90^{\circ}$ and the fault length from $5 \mathrm{~m}$ to $20 \mathrm{~m}$ to see how these two parameters impact the stress fields of the fault tip. Figure 4.9 shows that below $57^{\circ}$, the compressive stress concentration weakens as $\varphi$ increases, but above $57^{\circ}$, the concentration degree increases gradually until reaching $90^{\circ} . \mathrm{K}_{\Pi}$ is reduced as the fault dip increases, which indicates that the concentration of shear stress is continually abated. When the angle approaches $90^{\circ}$, the concentration of the shear stress does not exist. Figure 4.10 shows how the SIFs vary with the value of a. In summary, the three SIFs have the same variation trend, namely increasing as fault length grows. This results in stronger compressive and shear stress concentrations at the fault tip as the fault length increases. Therefore, there is a higher probability of fault activation and a greater possibility of water inrush accidents. 


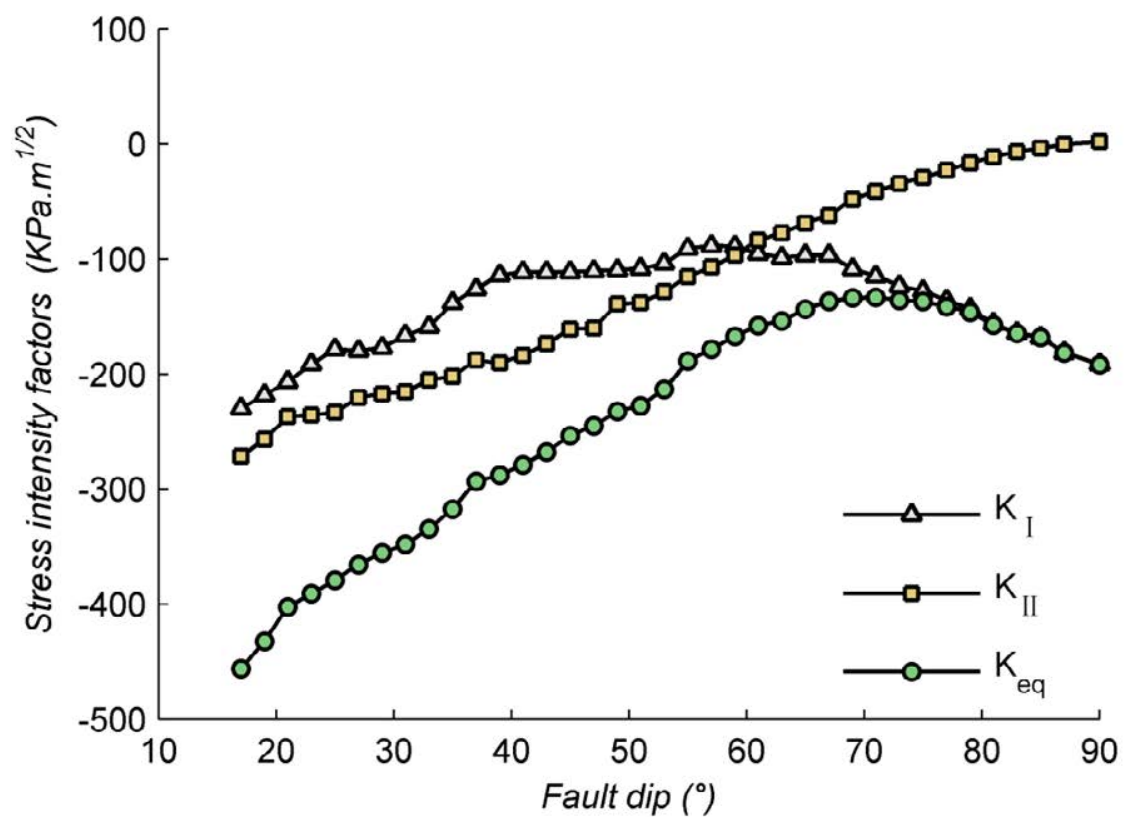

Figure 4.9. How the variation of the fault dip impacts on the stress field of the fault tip.

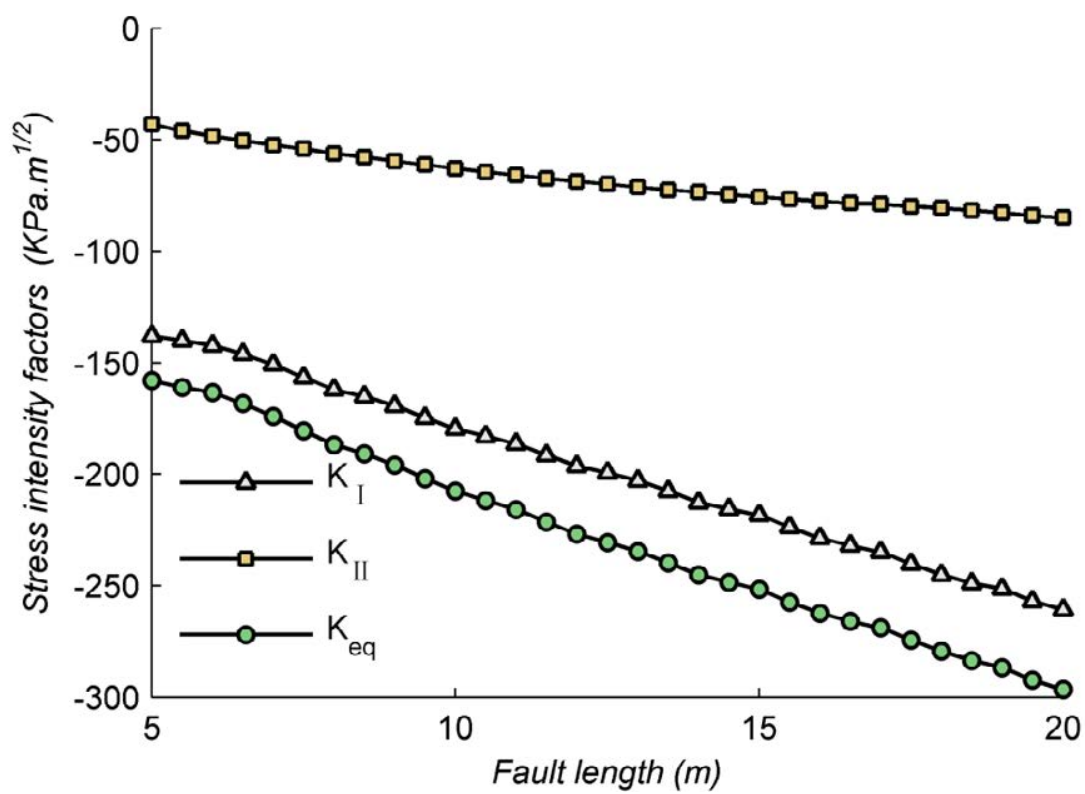

Figure 4.10. How the variation of the fault length impacts on the stress field of the fault tip. 


\subsubsection{Whether the advancing of mining face could result in fault activation}

Cases of sudden water inrush often occur when a mine face advances to a certain location. This is generally explained by faults under the mine face being activated by mining-induced stress. A numerical simulation was used to verify this explanation. The same quadrilateral mesh model was used as in the previous sections (Figure 4.4), and H, a, $\varphi$, and p were set as fixed values, $\mathrm{H}=300 \mathrm{~m}, \mathrm{a}=15 \mathrm{~m}, \varphi=45^{\circ}$, and $\mathrm{p}=5 \mathrm{MPa}$. The advancing process of a mine face was simulated from right to left (Figure 4.11). Different elastic modulus values were used to simulate the material properties of different elements. For example, the working area was set as air elements and the elastic modulus was set as a value that approaches zero. For the minedout area, the elastic modulus was set as two orders of magnitude less than the coal seam because in the actual mining situation, the mined-out area is typically filled with unconsolidated and crushed rock.

When mine face advancement from right to left was simulated, the computation results of the SIFs corresponded to where the working area was in different locations. By setting the horizontal distance S (Figure 4.4) as the abscissa, Figure 4.12 shows how SIFs vary as the mine face advances. Note that in this figure, the abscissa is positive when the mine face is on the right side of the fault tip. The results (Figure 4.12) indicate that as the face gets closer to the fault tip, $K_{I}$ gradually increases and $K_{\Pi}$ gradually decreases, which indicates that the degree of compressive stress concentration is increased and the shear stress concentration is gradually abated. The $\mathrm{K}_{\mathrm{eq}}$, which combines $\mathrm{K}_{\mathrm{I}}$ and $\mathrm{K}_{\Pi}$ to evaluate the magnitude of the overall stress concentration, continually increases as the face approaches the fault tip. These results show that when the mining face gradually approaches a fault tip, stress concentration is elevated, which creates a greater possibility of fault activation and water hazards. 
A: Working area is located before the fault tip

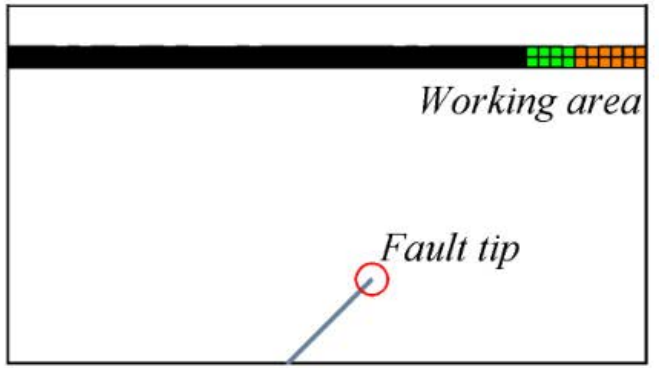

B: Working area is located on the fault tip

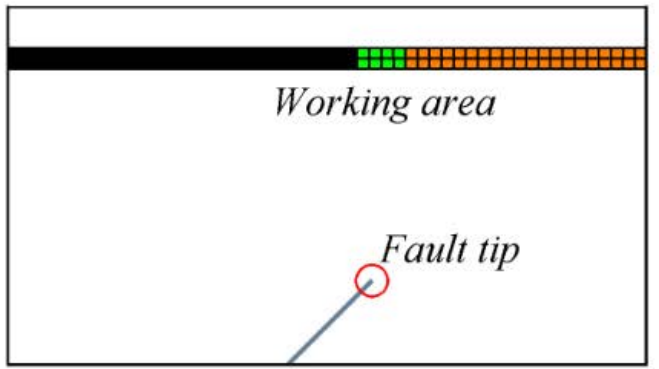

C: Working area is located behind the fault tip

\begin{tabular}{|c|}
\hline Working area \\
\hline \\
\hline \\
\end{tabular}

Figure 4.11. The advancing process of a mining face from right to left. 

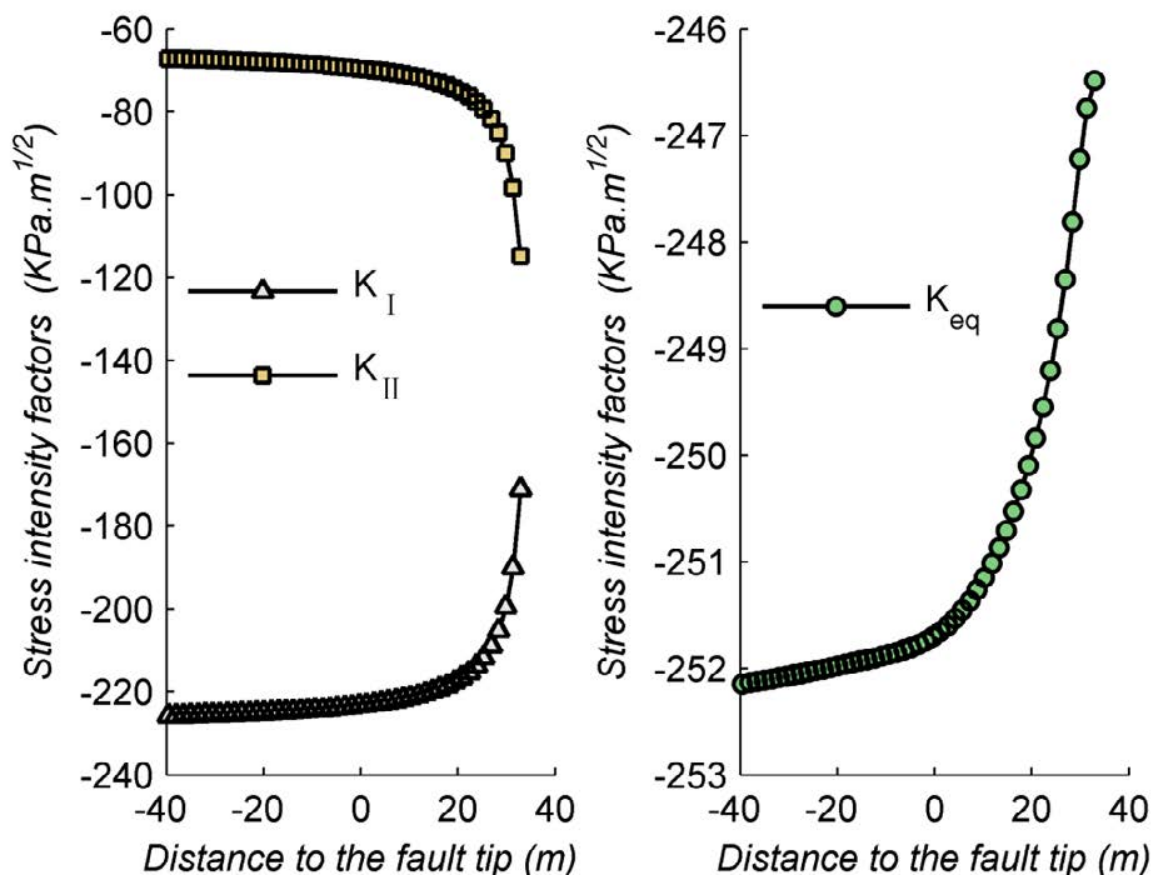

Figure 4.12. How the advancing of the mining face influences the stress field of the fault tip. 


\subsection{Summary of the chapter}

In this Chapter, in order to analyze the relationship between water inrush and hidden faults in underground mining engineering, a hidden fault under a mining face was simplified as an extensible crack. By means of this simplification, a calculation model has been established and the application of XFEM and fracture mechanics have been introduced for solving the discontinuity issues of the established computing model. Combining with the interaction integral method, the SIFs have been calculated to evaluate the stress concentration magnitude at fault tip. According to our final simulation results, the following conclusions can be summed up:

(1) In general, if the effect of geostatic pressure and tectonic pressure is stronger than fluid pressure, the possibility of water inrush increases with the increase of mining depth.

(2) Water inrushes can be induced by compressive fracture at fault tip when fluid pressure is low or by shear fracture at fault tip when fluid pressure is high.

(3) The variation trend of $K_{I}$ is shaped like a parabola, indicating that shear stress concentration is abated with the increase of dip angle, although compressive stress concentration is stronger for larger and smaller angles. Both the compressive stress concentration and the shear stress concentration are enhanced with the growth of fault length.

(4) In addition to the factors discussed above directly related to water inrush, computing results in this Chapter also illustrate that the advancement of mining face in underground engineering also can lead to a water accident, the reason is that the overall stress concentration magnitude increase gradually as the mining face gets closer to the fault tip. 


\section{Chapter 5 Risk Assessment of Fault-Induced Water Inrush: Application to a Specific Fault}

\subsection{Introduction}

As illustrated in Chapter 4, in the process of mining, if there is a fault located just right below a stope, then an inrush incident could be occur when the working face advances close to the fault. Although in Chapter 4 how each of the associated parameters impacts on the inrush risk has been theoretically analyzed, it just provide us a qualitative way to understand in which condition the working face has the danger of occurring water hazards.

In actual mining engineering, qualitative knowledge is not enough, if there is a fault located just right below the working face, we need to know exactly how much the risk degree of this fault will lead to a water inrush accident, in other words, a quantitative way to evaluate the fault-induced water inrush risk is better than a qualitative one in actual mining engineering.

Therefore, in this Chapter, the aim is to develop a quantitative way to assess the risk of faultinduced water inrush. A new state-of-the-art method, the adaptive neuro-fuzzy inference system (ANFIS), is introduced to develop our assessment approach. Here what needs to be emphasized is that as the ANFIS used in this Chapter incorporates the knowledge of the original ANN (the relevant basic knowledge has already been given in Chapter 3) and the fuzzy inference system (FIS), so in this Chapter some basic knowledge of FIS will also be given.

\subsection{Two typical fault-induced inrushes in underground mining}

As described in Chapter 4 (section 4.2.1), fault has a good water-conducting property because the high-permeability structure elements within the fault zone can act as a conduit for fluid flow and moreover the fault zone itself is a water-bearing structure filled with fluid, especially 
when it is connected to an aquifer. So this kind of property makes fault become the most common passageway of inrushes.

In general, there are two kinds of typical fault-induced inrushes in underground mining. The first type are the inrushes caused by large visible faults. In this case, a coal seam and an aquifer can be cut simultaneously by a large fault (see Figure 5.1), as a fault generally acts as a water-conducting structure to make the aquifer and the coal seam directly connected, hence a water inrush accident may occur suddenly when a working face is close to the fault. The second type are the inrushes caused by small hidden faults. In this case, a small hidden fault is connected to an aquifer but not to a coal seam, but this does not represent that mining activities will be able to stay away from fault-induced water inrush accidents. With the coupled actions of mining-induced stresses and fluid pressure the fault may be reactivated and then gradually propagated to connect with the fractured zone to form a water-conducting pathway (see Figure 5.2), here it should be emphasized that both the formation of the fractured zone (Palchik, 2003; Liang et al., 2015) and the fault reactivation (Jonny et al., 2015; Isiam et al., 2009) are directly associated with the mining-induced stresses. Whether or not a fault is activated on the one hand is related to the fault-tip stress concentration scale caused by mining-induced stresses, and on the other hand related to the relative position between the fault and the working face. As for the fractured water-conducting zone in the floor caused by mining-induced stresses, according to Li's work (Li et al., 2015), by means of conducting a correlation analysis between the related mining parameters and the size of fractured zone in 16 working faces, he came to the following regression formula:

$$
h=0.0175 H+0.1463 \alpha+3.3817 M+0.0508 L-7.76695
$$

Where $\mathrm{h}$ is the depth of water-conducting fractured zone, $\mathrm{H}$ is the mining depth; $\alpha$ is the dip angle of the coal seam; $M$ is the mining height; $\mathrm{L}$ is the length of working face. As it can be seen from this formula, the correlation coefficient of the mining height is the largest, which means the mining height has the most significant influence on the size of fractured zone, followed by dip angle of coal seam, more investigations about how the fractured zone is affected by dip angle of coal seam also can be seen from Miao and Zhang's works (Miao et al., 2011; Zhang, 2005). 


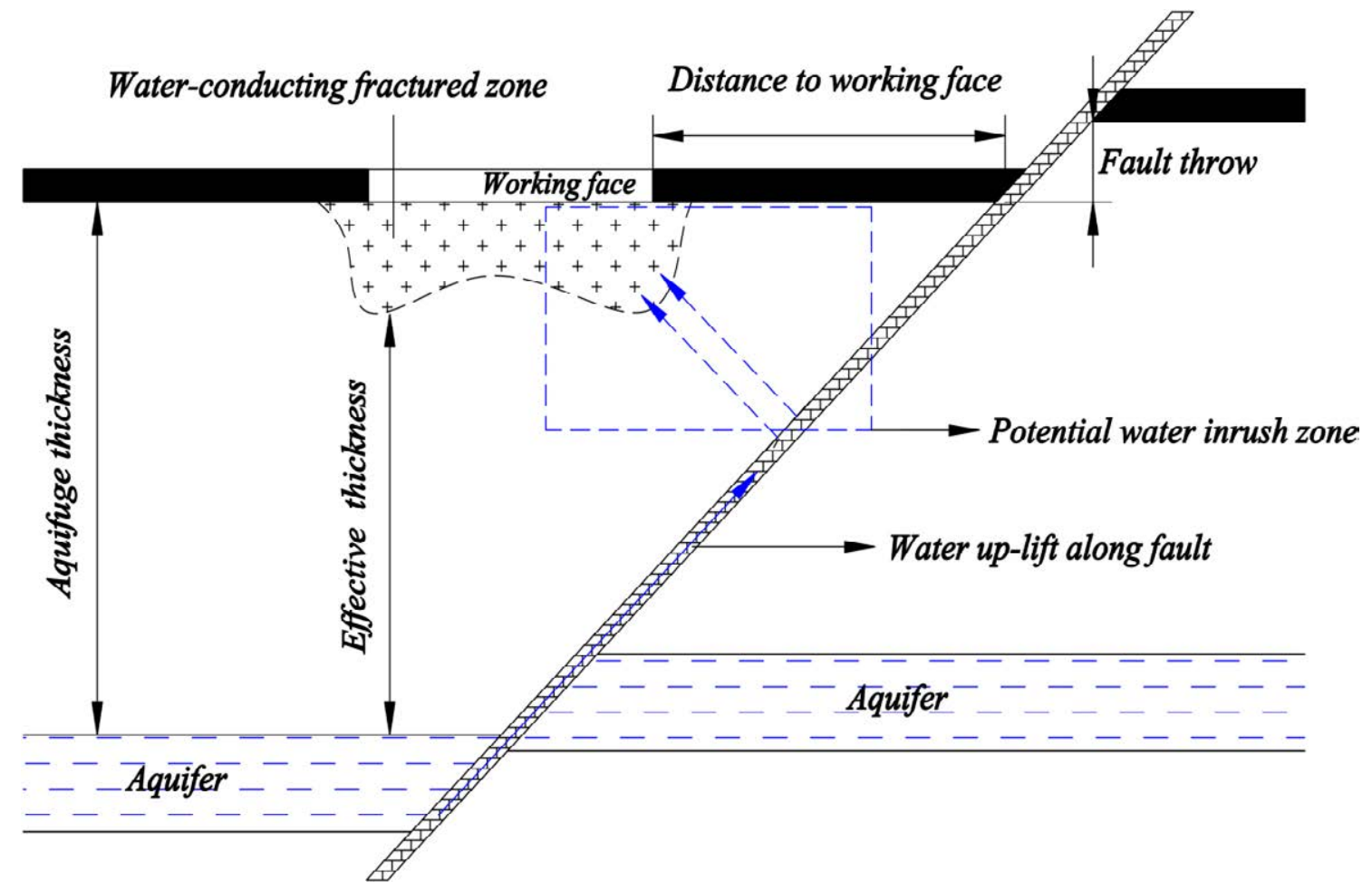

Figure 5.1. The coal seam and the aquifer are connected by a large fault.

In the process of mining, a water-conducting fault mainly affects water inrush in the following aspects. Groundwater in the aquifer can rise to a certain height by the water-conducting fault, thus reducing the effective thickness of the aquifuge. In some cases, groundwater may even directly rising to a coal seam with the aquifuge completely losing its water-resisting function. Sometimes a large fault may cut through multiple aquifers and that these cut aquifers are thus hydraulically linked, if water inrush occurs in such case, there will be a large volume of groundwater related. 


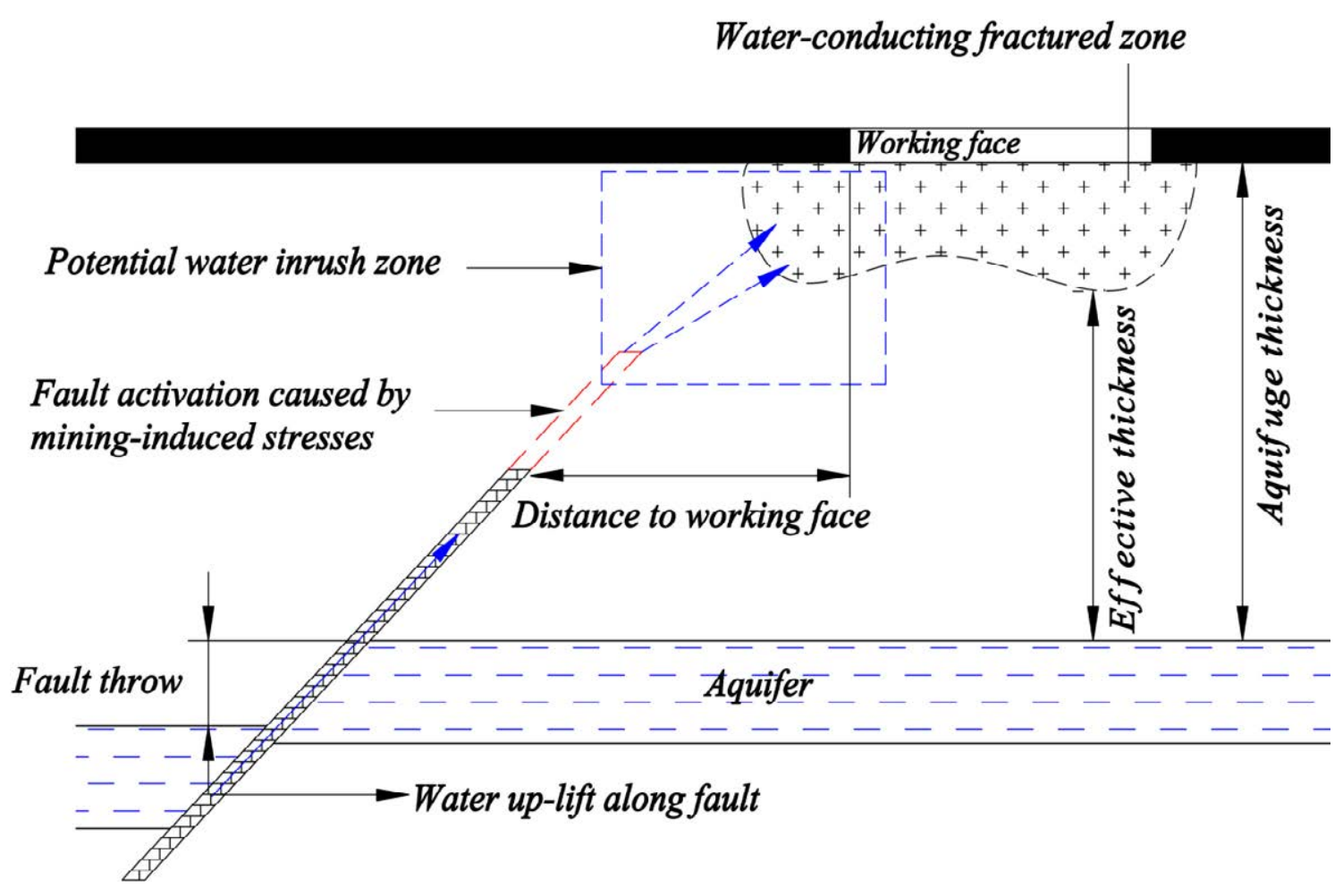

Figure.5.2. A small fault is connected to an aquifer but not to a coal seam.

The above analysis of the two typical types of inrush gives a conclusion that water inrush in underground mining is a hazard caused by multiple factors. All the related factors including the aquifer pressure, the fault throw, the aquifuge thickness and the mining-induced stresses play equal role in the final inrush if there are no interacting actions between these factors. If a method is introduced to predict the risk of the inrush, all the related factors should be considered. In the following sections in this chapter, with the use of ANFIS, a novel method will be developed to achieve such kind of risk assessment by considering all the associated factors. 


\subsection{Methodology of ANFIS}

Based on the fuzzy theory, the fuzzy linguistic variables and the fuzzy logic inference, the FIS (fuzzy inference system) can mimic the process of human reasoning and decision-making (Zadeh, 1978) to solve some of those reasoning problems described in the language of uncertainty, which has taken a major step in the aspects of the simulation of human brain, but it is still far from reaching the realm of the human brain in terms of data processing and selforganized learning. Comparing with the fuzzy control system, ANN also can achieve human intelligence by simulating the working mechanism of the brain (Fukushima, 1980; Mcculloch and PIitts, 1990), and as it consists of a large number of interconnected processing units, it can mimic the nervous system of brain to process data in parallel.

By integrating the self-learning mechanism of the ANN into the FIS, using the self-learning process of the ANN to adjust the membership functions and fuzzy rules, the ANFIS combines the advantages of the ANN and the FIS. In the ANFIS, the input and output nodes of the neural network are used to express the input and output signals of fuzzy systems, and the membership functions and fuzzy rules of fuzzy systems are represented by the hidden notes of the neural network (Jang, 1991, 1993, 1996).

\subsubsection{Architecture of ANFIS}

In Figure 5.3, a typical ANFIS model with two inputs $x, y$ and an output $f$ is shown, for the first-order Sugemo fuzzy model, two rules were employed:

$$
\begin{gathered}
\text { Rule }^{1}: \text { if } x \text { is } A_{1} \text { and } y \text { is } B_{1} \text {, then } f_{1}=p_{1} x+q_{1} y+r_{1} \\
\text { Rule }^{n}: \text { if } x \text { is } A_{2} \text { and } y \text { is } B_{2} \text {, then } f_{2}=p_{2} x+p_{2} y+r_{2}
\end{gathered}
$$

In Eq. 5.2, the input part is fuzzy but the output part is a certain linear function (sometimes it also could be a constant), and where $A_{1}, B_{1}, A_{2}, B_{2}$ represent the membership functions for $x$ and $y ; p_{1}, q_{1}, r_{1}, p_{2}, q_{2}, r_{2}$ are the parameters for the whole fuzzy systems. 
The process of fuzzy reason is illustrated in Figure 5.3, as can be seen from the figure that an ANFIS consists of five layers. Layers marked by squares represent that they are adaptive layers, which means that their node values are adjustable, on the contrary, layers marked with circles represent their parameter sets are fixed.

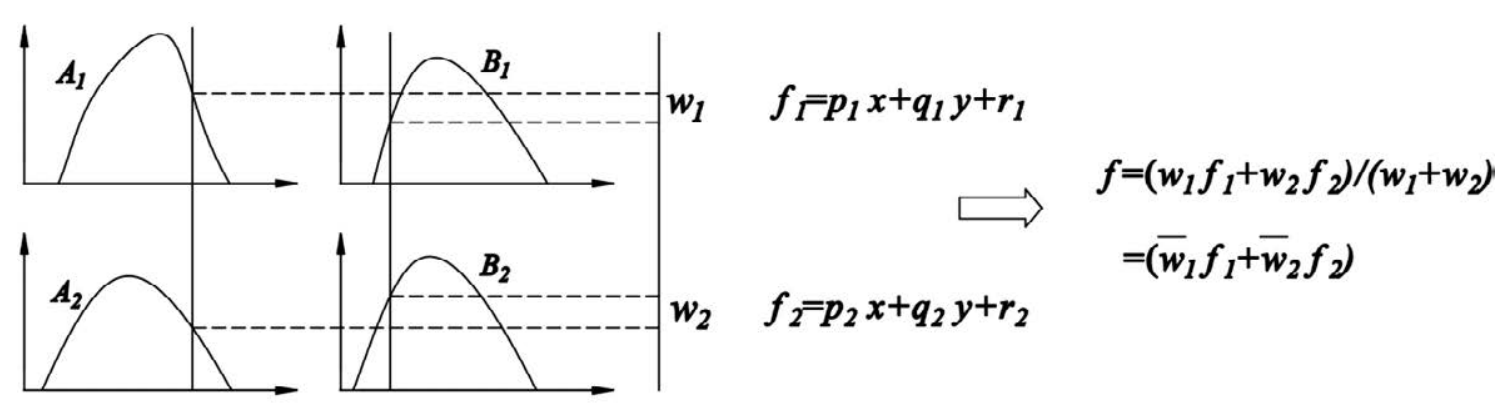

Premise part

Consequent part

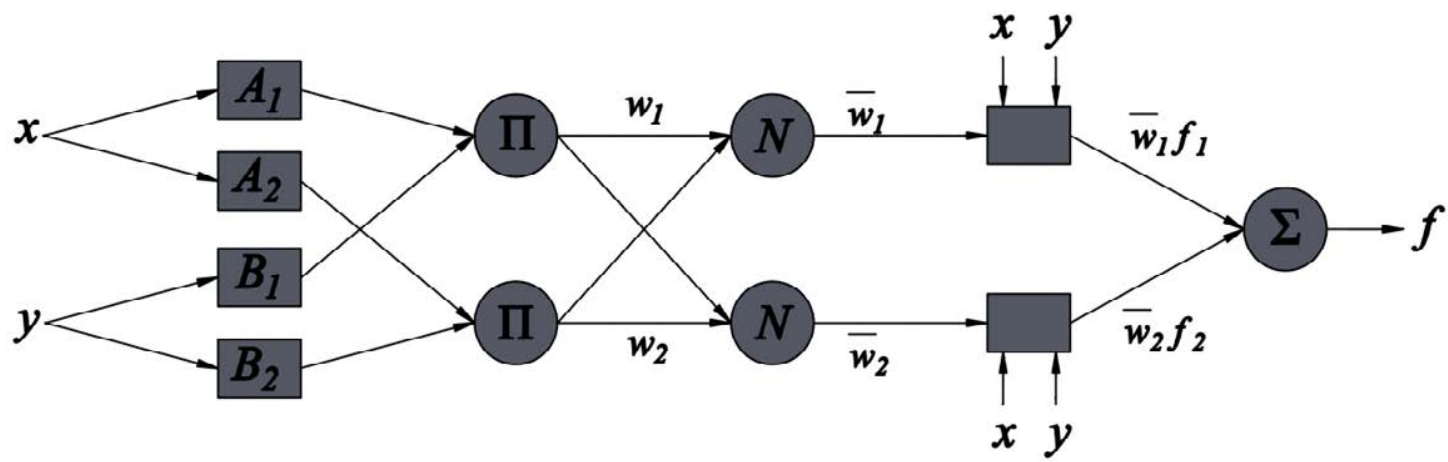

\section{Layer $1 \quad$ Layer $2 \quad$ Layer $3 \quad$ Layer $4 \quad$ Layer 5}

Figure.5.3. A typical ANFIS model with two inputs and one output.

Layer 1: The first layer of this system is the fuzzy layer, and each node of this layer is an adaptive node and represents a fuzzy linguistic variable. If we choose a Gaussian function as the membership function, membership grade of every element of the inputs could be calculated as follows:

$$
\begin{aligned}
& O_{1, i}=\mu_{A_{i}}(x)=\left(\exp \left(-\left(x-c_{i}\right)\right)^{2} / \sigma_{i}\right)(i=1,2) \\
& O_{1, i}=\mu_{B_{i}}(y)=\left(\exp \left(-\left(y-c_{i}\right)\right)^{2} / \sigma_{i}\right)(i=1,2)
\end{aligned}
$$

Where $c_{j}$ and $\sigma_{j}$ are two premise parameters that could change the shape of the membership function, $\mathrm{c}_{\mathrm{j}}$ denotes the center of the membership function and $\sigma_{j}$ represents its width. 
Layer 2: Labeled as $\Pi$, each node of layer 2 is a fixed node which represented by a circle, and the output of each node is calculated by means of the 'product' of all the incoming signals of the first layer:

$$
O_{2, i}=w_{i}=\mu_{A_{i}}(x) u_{B_{i}}(y) \quad(i=1,2)
$$

The output $w_{i}$ is the firing strength of the corresponding rule.

Layer 3: each node of this layer is also a fixed node marked with circle and labeled as $\mathrm{N}$, denoting the normalized firing strengths of every rule. The outputs for this layer are computed by using Eq. 5.6 as:

$$
O_{3, i}=\bar{w}_{i}=w_{i} /\left(w_{1}+w_{2}\right) \quad(i=1,2)
$$

Where $\bar{w}_{i}$ is the normalized firing strengths.

Layer 4: For this layer, every node represent a node function (see Eq.5.7), and each adaptive node of this layer representing the contribution of the $i$-th rule to the overall output.

$$
O_{4, i}=\bar{w}_{i} f_{i}=\bar{w}_{i}\left(p_{i} x+q_{i} y+r_{i}\right) \quad(i=1,2)
$$

Corresponding to the above mentioned premise parameters, here $p_{i}, q_{i}, r_{i}$ are called the consequent parameters.

Layer 5: in this layer, the overall outputs, which are the sum of all incoming signals of the previous layers, are calculated through the sum operation $(\Sigma)$ :

$$
O_{5, i}=f=\sum_{i} \bar{w}_{i} f_{i}=\frac{\sum_{i}\left(w_{i} f_{i}\right)}{\sum_{i} w_{i}}(i=1,2)
$$




\subsubsection{Hybrid learning rule of ANFIS}

The learning process of the ANFIS actually is a process of learning knowledge from the training samples by adjusting the premise parameters and the consequent parameters, which is achieved by using the gradient method and the least squares method (Takagi and Segeno, 1985; Mamdani and Assilian, 1999; Larsen, 1980). For the above described ANFIS model, if we rewrite Eq. 5.8 as Eq. 5.9, clearly we can see from the Eq. 5.9 that the overall output of the model can be expressed as a linear combination of the consequent parameters. Supposing $t$ is the target value and $f$ is the actual output, the target of the learning process thereby is to find the optimal consequent parameters that could minimize the error function $e$ between $t$ and $f$ (see Eq. 5.10).

$$
\begin{gathered}
f=\sum_{i} \bar{w}_{i} f_{i}=\left(\bar{w}_{1} x\right) p_{1}+\left(\bar{w}_{1} y\right) q_{1}+\left(\bar{w}_{1}\right) r_{1}+\left(\bar{w}_{2} x\right) p_{2}+\left(\bar{w}_{2} y\right) q_{2}+\left(\bar{w}_{2}\right) r_{2} \\
e=(f-t)^{2}
\end{gathered}
$$

As discussed in Jang's research (Jang, 1993), the learning process includes a forward process and a backward process. In the forward process, the functional signals go forward until layer 4 and the consequent parameters (in the layer 4) are determined by means of the least squares estimate; in the backward pass, the errors are propagated backward and at the same time the premise parameters are updated by using the gradient decent. 


\subsection{Risk assessment of fault-induced water inrush with ANFIS}

As mentioned in section 5.2, fault-induced water inrushes are affected by multiple factors. The aquifer pressure is the most important factor since it always acts as a dynamic factor to trigger an inrush accident. The fault, which is like a bridge that connects the aquifer and the seam, often acts as a conduit to allow water flow from an aquifer to a coal seam. The aquifuge, on the contrary, has a restraining role to resist water flow from an aquifer to a coal seam.

Corresponding to the above mentioned factors, water pressure (WP), distance to working face (DWF) (detailed representation can be seen in Figure 5.1 and Figure 5.2), fault throw (FT), mining height (MH), dip angle of coal seam (DACS) and aquifuge thickness (AT) are therefore regarded as the six main parameters to assess the risk of water inrush. Here, the WP is used for representing the hydraulic property of aquifer, the DWF and the FT are used for indicating the relative position between the fault and the working face, the size of the mining-induced fractured zone is mainly determined by the MH and DACS and we use AT to indicate the water-resisting capability of the aquifuge.

\subsubsection{ANFIS training}

To train the ANFIS, the first step is the determination of the input parameters and the desired output. The six main parameters mentioned above are selected as the input parameters. If using 1 and -1 (named as the water inrush index) to represent water inrush occurring and not occurring respectively, then 1 and -1 can be used as the numerical desired outputs to implement ANFIS training. The ANFIS structure implemented is illustrated in Figure 5.4 with input and output parameters: 


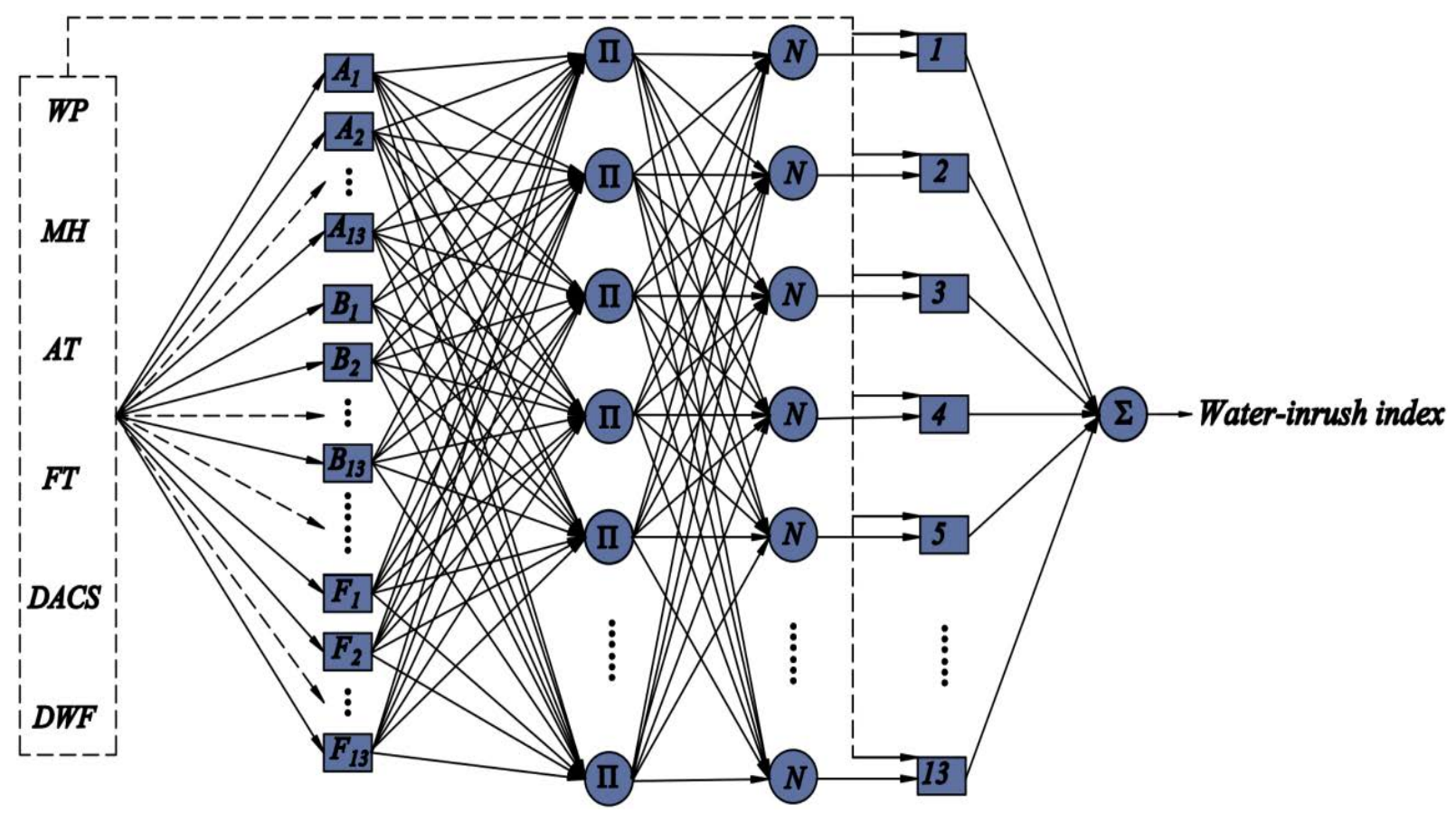

Figure.5.4. ANFIS structure used for the assessment of water inrush index.

For the ANFIS, its prediction is based on the training and learning from known samples, which means that use the knowledge (or experiences) learned from the historical cases to predict the new cases. In this thesis real water inrush cases reported by Shi (2015) from China were selected as training samples (see Table 5.1).

Table 5.1

Real water inrush cases used for ANFIS training (reported by Shi (2015))

\begin{tabular}{|c|c|c|c|c|c|c|c|}
\hline Mines & $\begin{array}{l}(\mathrm{WP}) \\
\text { /MPa }\end{array}$ & $\underset{/ \mathrm{m}}{(\mathrm{MH}}$ & $\begin{array}{c}(\mathrm{AT}) \\
/ \mathrm{m}\end{array}$ & $\begin{array}{l}(\mathrm{FT}) \\
/ \mathrm{m}\end{array}$ & $\begin{array}{c}\text { (DACS } \\
)^{\circ}\end{array}$ & $\begin{array}{c}(\mathrm{DWF}) \\
/ \mathrm{m}\end{array}$ & $\begin{array}{c}\text { Whether water } \\
\text { inrush accident } \\
\text { occurred in actual } \\
\text { situation }\end{array}$ \\
\hline $\begin{array}{l}\text { Xiazhuang coal mine } \\
\text { case } 1\end{array}$ & 1.82 & 0.8 & $\begin{array}{c}26.3 \\
9\end{array}$ & 4 & 12 & 16 & Yes \\
\hline $\begin{array}{l}\text { Xiazhuang coal mine } \\
\text { case } 2\end{array}$ & 1.65 & 1.6 & $\begin{array}{c}25.8 \\
5\end{array}$ & 50 & 17 & 90 & Yes \\
\hline $\begin{array}{l}\text { Xiazhuang coal mine } \\
\text { case } 3\end{array}$ & 1 & 0.9 & $\begin{array}{c}22.3 \\
3\end{array}$ & 2 & 13 & 16 & Yes \\
\hline $\begin{array}{l}\text { Xiazhuang coal mine } \\
\text { case } 4\end{array}$ & 2.88 & 1 & $\begin{array}{c}17.6 \\
8\end{array}$ & 1.3 & 20 & 0 & Yes \\
\hline Jingxing coal mine case1 & 2.01 & 8 & 28 & 0.6 & 18 & 10 & Yes \\
\hline Jingxing coal mine case 2 & 1.91 & 8 & 43 & 1.5 & 11 & 2 & Yes \\
\hline $\begin{array}{l}\text { Hongshan coal mine case } \\
1\end{array}$ & 1.33 & 0.85 & $\begin{array}{c}36.3 \\
8\end{array}$ & 0.8 & 7 & 62 & No \\
\hline
\end{tabular}




\begin{tabular}{|c|c|c|c|c|c|c|c|}
\hline $\begin{array}{l}\text { Hongshan coal mine case } \\
2\end{array}$ & 0.95 & 1.45 & $\begin{array}{c}26.8 \\
9\end{array}$ & 1 & 6 & 55 & No \\
\hline $\begin{array}{l}\text { Hongshan coal mine case } \\
3\end{array}$ & 0.92 & 1.4 & $\begin{array}{c}33.6 \\
1\end{array}$ & 0.5 & 8 & 0 & No \\
\hline $\begin{array}{l}\text { Hongshan coal mine case } \\
4\end{array}$ & 0.34 & 0.9 & $\begin{array}{c}32.6 \\
5\end{array}$ & 22 & 6 & 6 & No \\
\hline Heishan coal mine case 1 & 1.06 & 2 & $\begin{array}{c}27.7 \\
9\end{array}$ & 0.46 & 7 & 21 & No \\
\hline Heishan coal mine case 2 & 0.83 & 2.85 & $\begin{array}{c}26.5 \\
6\end{array}$ & 0.7 & 12 & 6 & No \\
\hline Xieyi coal mine & 2 & 2.81 & 30 & 1.5 & 18 & 12 & Yes \\
\hline Jiulishan coal mine & 1.87 & 1.9 & 23 & 0.5 & 15 & 17 & Yes \\
\hline Pandong coal mine & 1.7 & 2.8 & 10 & 5 & 17 & 10 & Yes \\
\hline Taoyang coal mine & 0.6 & 1.1 & 17 & 8 & 19 & 6 & Yes \\
\hline Huatai coal mine & 2.1 & 1.6 & 59.5 & 3.5 & 10 & 39 & No \\
\hline Panxi coal mine case 1 & 2.8 & 2.75 & $\begin{array}{c}69.1 \\
7\end{array}$ & 11.7 & 12 & 36 & No \\
\hline Panxi coal mine case 2 & 2.8 & 2.55 & $\begin{array}{c}66.1 \\
1\end{array}$ & 16 & 12 & 29 & No \\
\hline Xiezhuang coal mine & 1.3 & 1.7 & 30 & 4.9 & 5 & 21 & Yes \\
\hline
\end{tabular}

WP: water pressure; MH: mining height; AT: aquifuge thickness; FT: fault throw; DACS: Dip angle of coal seam; DWF: distance to working face;

Before starting the training process, first of all, the initial FIS need to be generated. The key to this step is to determine the number of membership functions for each of corresponding input parameters, and the shape of the membership functions of the premise part. For the shape of the membership functions, in this study Gaussian shaped membership function was selected. In general, the grid partition and the subtractive clustering are the two ways which have been widely applied for generating the initial FIS. By setting all initial water inrush indexes as 0 and by choosing subtractive clustering approach to generate the initial FIS, 13 if-then rules thereby were generated as can be seen in Figure 5.5A. The advantage of the subtractive clustering technique is that a large data set can by automatically distilled into several natural groups, thus resulting in a concise representation of the behavior of a system (Chiu, 1994) .More detailed description of the subtractive clustering technique can be seen in Chiu's further work (Chiu, 1997). In this study, for generating the initial FIS, the corresponding system parameter values are set as follows: range of influence is 0.65 , squash factor is 1.25 , accept ratio is 0.5 and reject ratio is 0.15 . 
1. If (WP is A10) and (MH is B1) and (AT is C1) and (FT is D1) and (DACS is E1) and (DWF is F1) then (Water-inrush index is 0) 2. If (WP is A4) and (MH is B2) and (AT is C2) and (FT is D2) and (DACS is E2) and (DWF is F2) then (Water-inrush index is 0) 3. If (WP is A12) and (MH is B3) and (AT is C13) and (FT is D3) and (DACS is E3) and (DWF is F3) then (Water-inrush index is 0$)$ 4. If (WP is A8) and (MH is B4) and (AT is C4) and (FT is D4) and (DACS is E4) and (DWF is F4) then (Water-inrush index is 0)

5. If (WP is A6) and (MH is B5) and (AT is C5) and (FT is D5) and (DACS is E5) and (DWF is F5) then (Water-inrush index is 0 ) 6. If (WP is A2) and (MH is B6) and (AT is C6) and (FT is D6) and (DACS is E6) and (DWF is F6) then (Water-inrush index is 0$)$ 7. If (WP is A7) and (MH is B7) and (AT is C7) and (FT is D7) and (DACS is E7) and (DWF is F7) then (Water-inrush index is 0) 8. If (WP is A1) and (MH is B8) and (AT is C8) and (FT is D8) and (DACS is E8) and (DWF is F8) then (Water-inrush index is 0$)$ 9. If (WP is A9) and (MH is B9) and (AT is C9) and (FT is D9) and (DACS is E9) and (DWF is F9) then (Water-inrush index is 0$)$

10. If (WP is A13) and (MH is B10) and (AT is C10) and (FT is D10) and (DACS is E10) and (DWF is F10) then (Water-Inrush index is 0) 11. If (WP is A5) and (MH is B11) and (AT is C11) and (FT is D11) and (DACS is E11) and (DWF is F11) then (Water-inrush index is 0)

12. If (WP is A11) and (MH is B12) and (AT is C12) and (FT is D12) and (DACS is E12) and (DWF is F12) then (Water-inrush index is 0) 13. If (WP is A3) and (MH is B13) and (AT is C13) and (FT is D13) and (DACS is E13) and (DWF is F13) then (Water-inrush index is 0)

$$
\begin{gathered}
\text { Before } \\
\text { ANFIS training } \\
\text { After }
\end{gathered}
$$

1. If (WP is A10) and (MH is BI) and (AT is Cl) and (FT is DI) and (DACS is E1) and (DWF is F1) then (Water-inrush index is 1.04) 2. If (WP is A4) and (MH is B2) and (AT is C2) and (FT is D2) and (DACS is E2) and (DWF is F2) then (Water-inrush index is -2.949) 3. If (WP is A12) and (MH is B3) and (AT is C13) and (FT is D3) and (DACS is E3) and (DWF is F3) then (Water-inrush index is -1.09)

4. If (WP is A8) and (MH is B4) and (AT is C4) and (FT is D4) and (DACS is E4) and (DWF is F4) then (Water-inrush index is 1.091)

5. If (WP is A6) and (MH is B5) and (AT is C5) and (FT is D5) and (DACS is E5) and (DWF is F5) then (Water-inrush index is -1.054)

B. If (WP is A2) and (MH is B6) and (AT is C6) and (FT is D6) and (DACS is E6) and (DWF is F6) then (Water-inrush index is 1.002)

B

7. If (WP is A7) and (MH is B7) and (AT is C7) and (FT is D7) and (DACS is E7) and (DWF is F7) then (Water-inrush index is 1.02)

8. If (WP is Al) and (MH is B8) and (AT is C8) and (FT is D8) and (DACS is E8) and (DWF is F8) then (Water-inrush index is -1.001)

9. If (WP is $A 9$ ) and (MH is B9) and (AT is C9) and (FT is D9) and (DACS is E9) and (DWF is F9) then (Water-inrush index is 1.016)

10. If (WP is A13) and (MH is B10) and (AT is C10) and (FT is D10) and (DACS is E10) and (DWF is F10) then (Water-Inrush index is 1.001)

11. If (WP is A5) and (MH is B11) and (AT is C11) and (FT is D11) and (DACS is E11) and (DWF is F11) then (Water-inrush index is 2.819)

12. If (WP is A11) and (MH is B12) and (AT is C12) and (FT is D12) and (DACS is E12) and (DWF is F12) then (Water-inrush index is -1.041)

13. If (WP is A3) and (MH is B13) and (AT is C13) and (FT is D13) and (DACS is E13) and (DWF is F13) then (Water-inrush index is 1.01)

Figure.5.5. The initial FIS rules before training and after training.

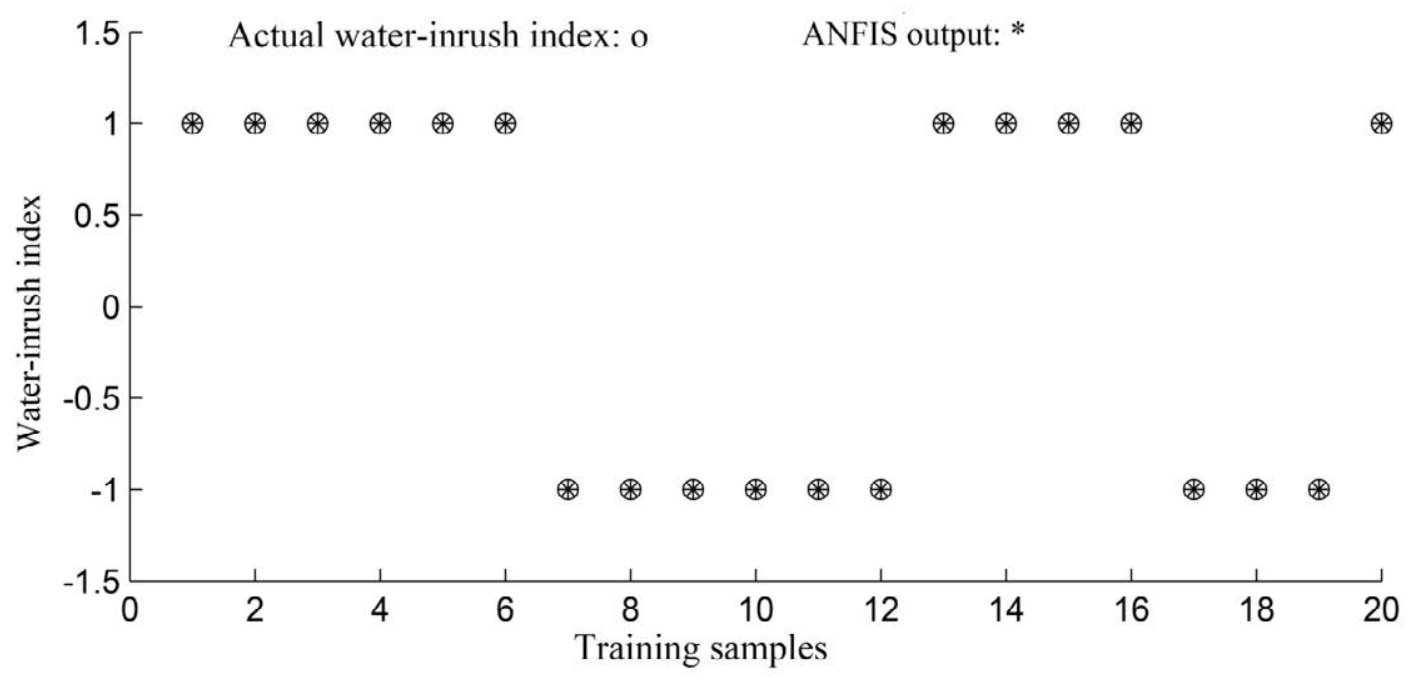

Figure.5.6. The training results of the ANFIS. 
The ANFIS was trained by using the hybrid training algorithm. The shapes of the membership functions, which are determined by the initial FIS rules, were constantly adjusted by the ANFIS training process. In this study, after 18 epochs of training, training accuracy meets the requirements and the outputs of ANFIS were exactly consistent with the desired outputs (see Figure 5.6). After the training process, the 13 initial FIS rules were modified as it can been seen in Figure 5.5B and the final shapes of the membership functions correspond to the six main parameters as shown in Figure 5.7 and Figure 5.8.
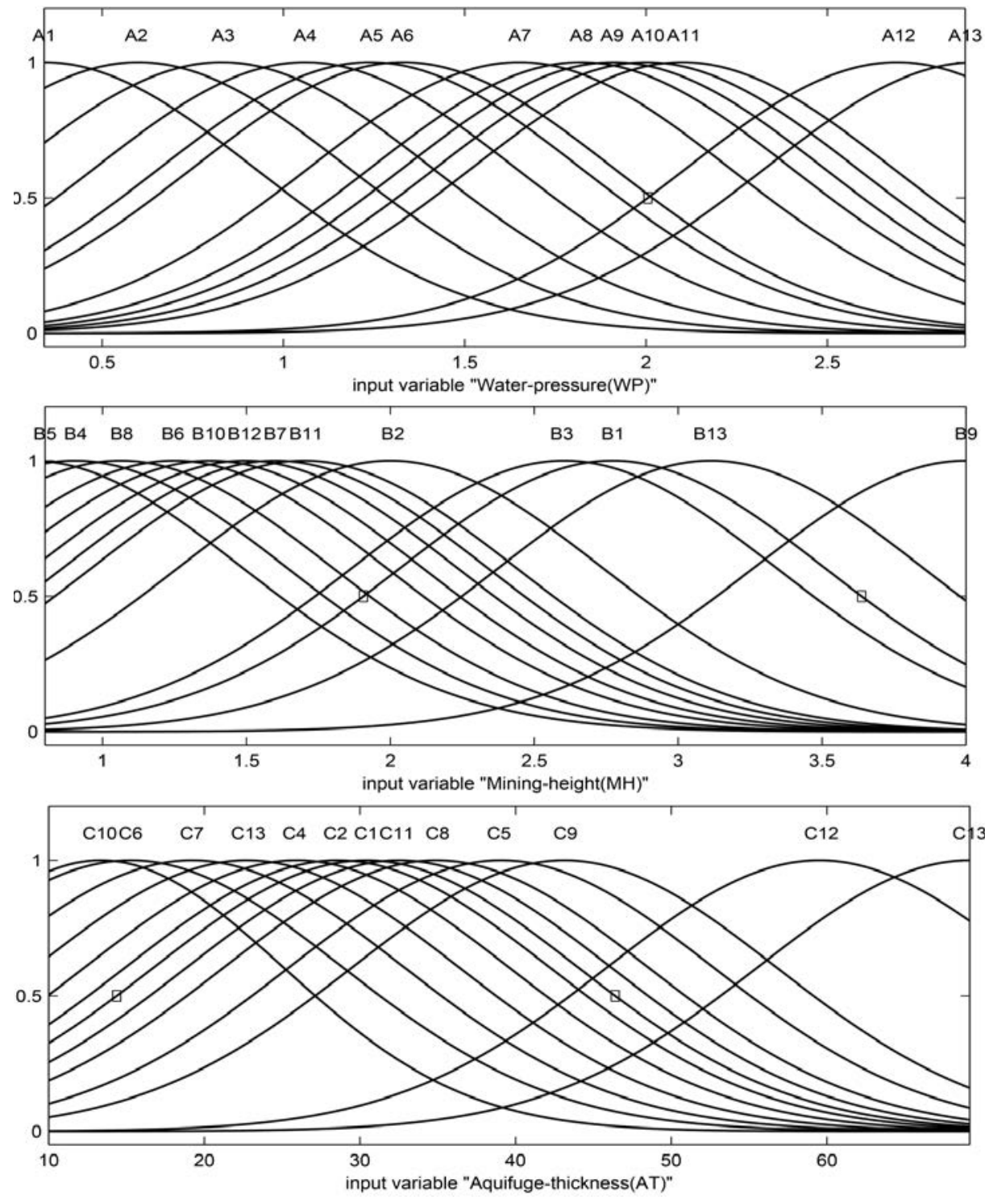

Figure.5.7. the shape of the membership functions after training (for parameters WP, MH and AT). 

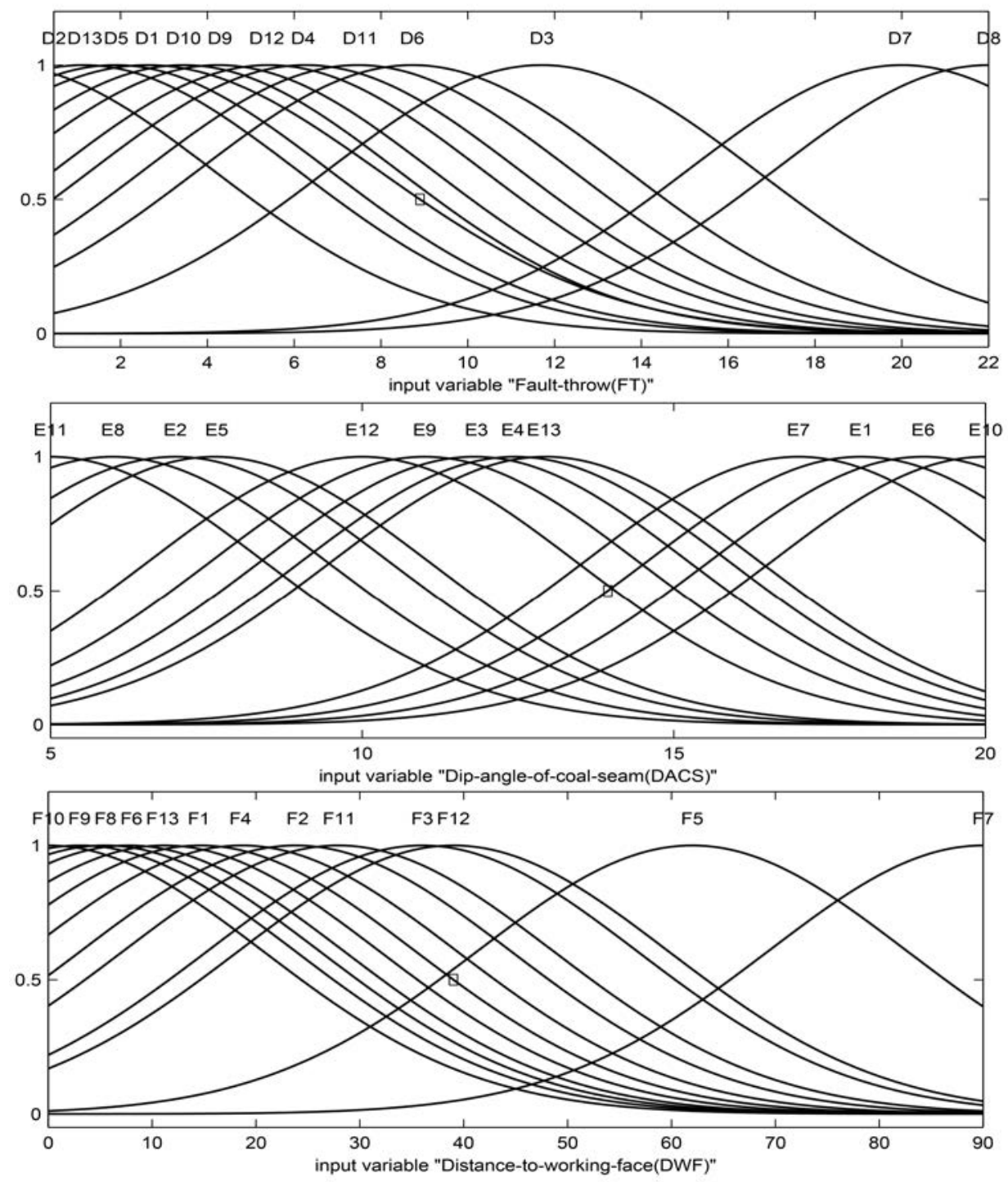

Figure.5.8. The shape of the membership functions after training (for parameters FT, DACS and DWF).

\subsubsection{Using the trained rules to infer water inrush index}

Actually, the training process of ANFIS is the process of learning knowledge from the samples. Without doubt, the randomly generated initial FIS rules cannot be used to accurately infer the outputs from the sample inputs, but through sample training, the ANFIS can constantly learn knowledge from training samples, modify the shape of the membership functions and thus gradually adjust the initial FIS rules. Therefore, the trained FIS rules are the optimized rules corresponding to the input-output pairs of the training samples. 
With all the trained FIS rules, which imply all the knowledge learned from the training samples, fuzzy reasoning can thereby be conducted by using these FIS rules to predict the water inrush indexes for any new samples.

In order to test the usability and accuracy of the established ANFIS, another five real water inrush cases are used to test the developed ANFIS.

In Table 5.2, geological data of another five working faces are given. By using the 13 trained rules (Figure 5.5B) obtained from the previous ANFIS training, the inference results of the water inrush indexes corresponding to the five working faces are obtained (see Figure 5.9Figure 5.13).

Table 5.2

Geological data of the five working faces used for predicting

\begin{tabular}{lcccccc}
\hline Working faces & $\begin{array}{c}(\mathrm{WP}) \\
\text { (MPa }\end{array}$ & $\begin{array}{c}(\mathrm{MH}) \\
/ \mathrm{m}\end{array}$ & $\begin{array}{c}(\mathrm{AT}) \\
/ \mathrm{m}\end{array}$ & $\begin{array}{c}(\mathrm{FT}) \\
/ \mathrm{m}\end{array}$ & $\begin{array}{c}\text { (DACS) } \\
/{ }^{\circ}\end{array}$ & $\begin{array}{c}(\mathrm{DWF}) \\
/ \mathrm{m}\end{array}$ \\
\hline $\begin{array}{l}31503 \text { working face in Huatai coal mine } \\
51302 \text { working face in Liangzhuang }\end{array}$ & 1.08 & 0.90 & 16.50 & 3.2 & 7 & 7 \\
$\begin{array}{l}\text { coal mine } \\
6194 \text { working face in Panxi coal mine }\end{array}$ & 4.06 & 2.75 & 65.86 & 10.0 & 10 & 11 \\
$\begin{array}{l}9602 \text { working face in Baizhuang coal } \\
\text { mine }\end{array}$ & 3.11 & 2.61 & 44.30 & 3.5 & 11 & 12 \\
$\begin{array}{l}\text { 61106 working face in Huahen coal } \\
\text { mine }\end{array}$ & 2.70 & 2.55 & 66.97 & 16.0 & 12 & 31 \\
\hline
\end{tabular}

WP: water pressure; MH: mining height; AT: aquifuge thickness; FT: fault throw; DACS: distance to working face; 

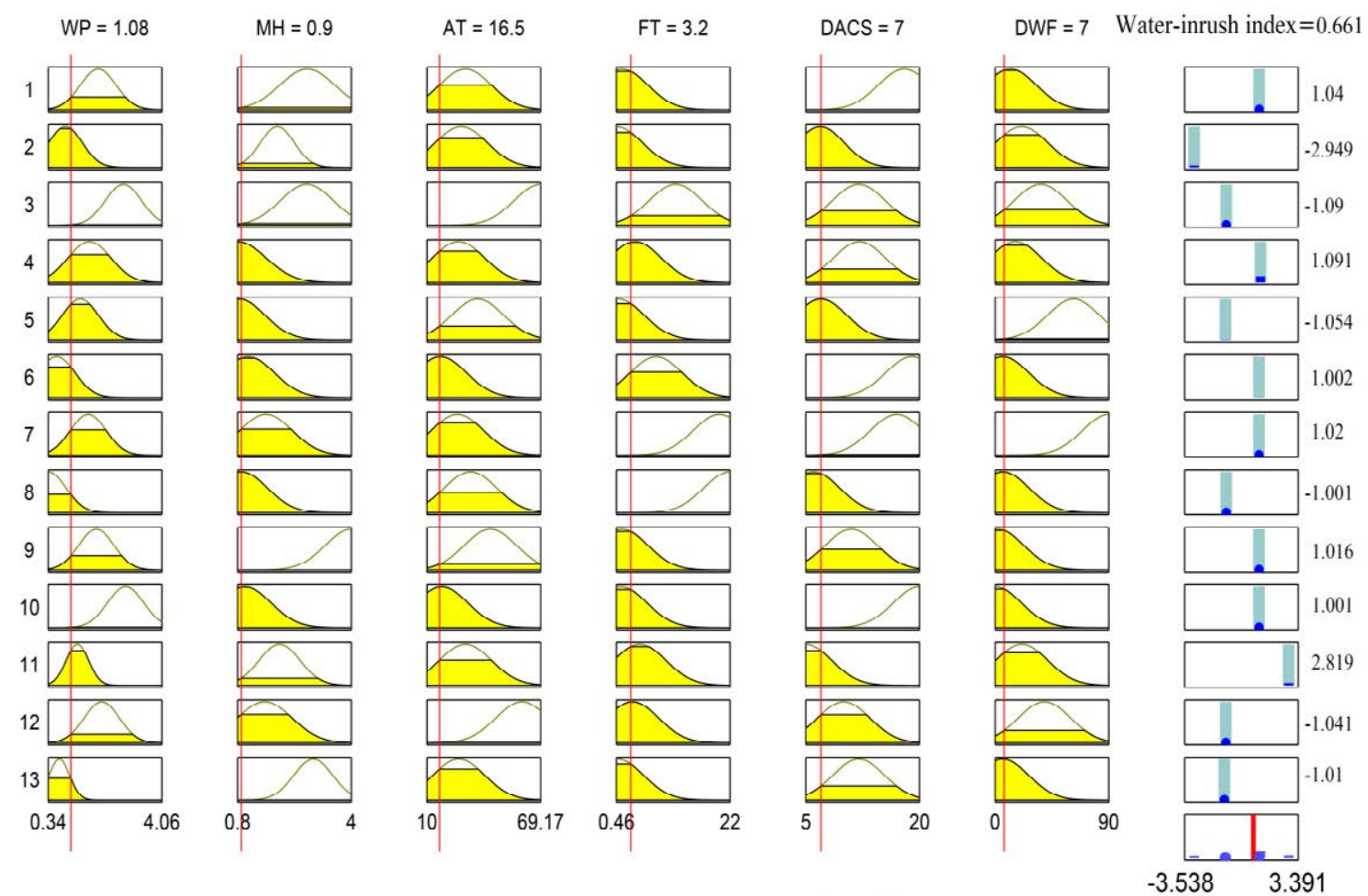

Figure.5.9. The inference process and result of the water inrush index for 31503 working face in Huatai coal mine by using the 13 trained rules.
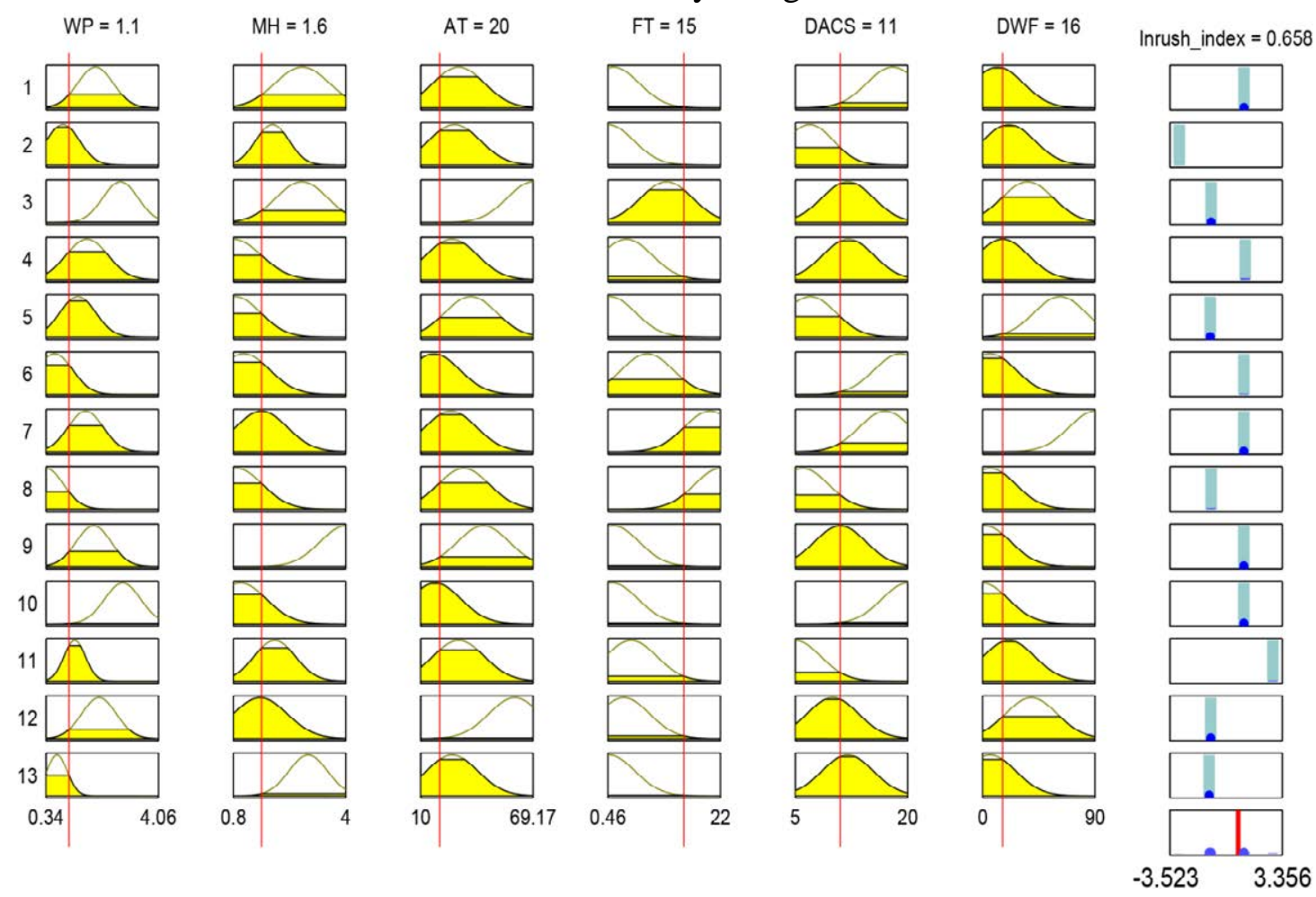

Figure.5.10. The inference process and result of the water inrush index for 51302 working face in Liangzhuang coal mine by using the trained rules. 


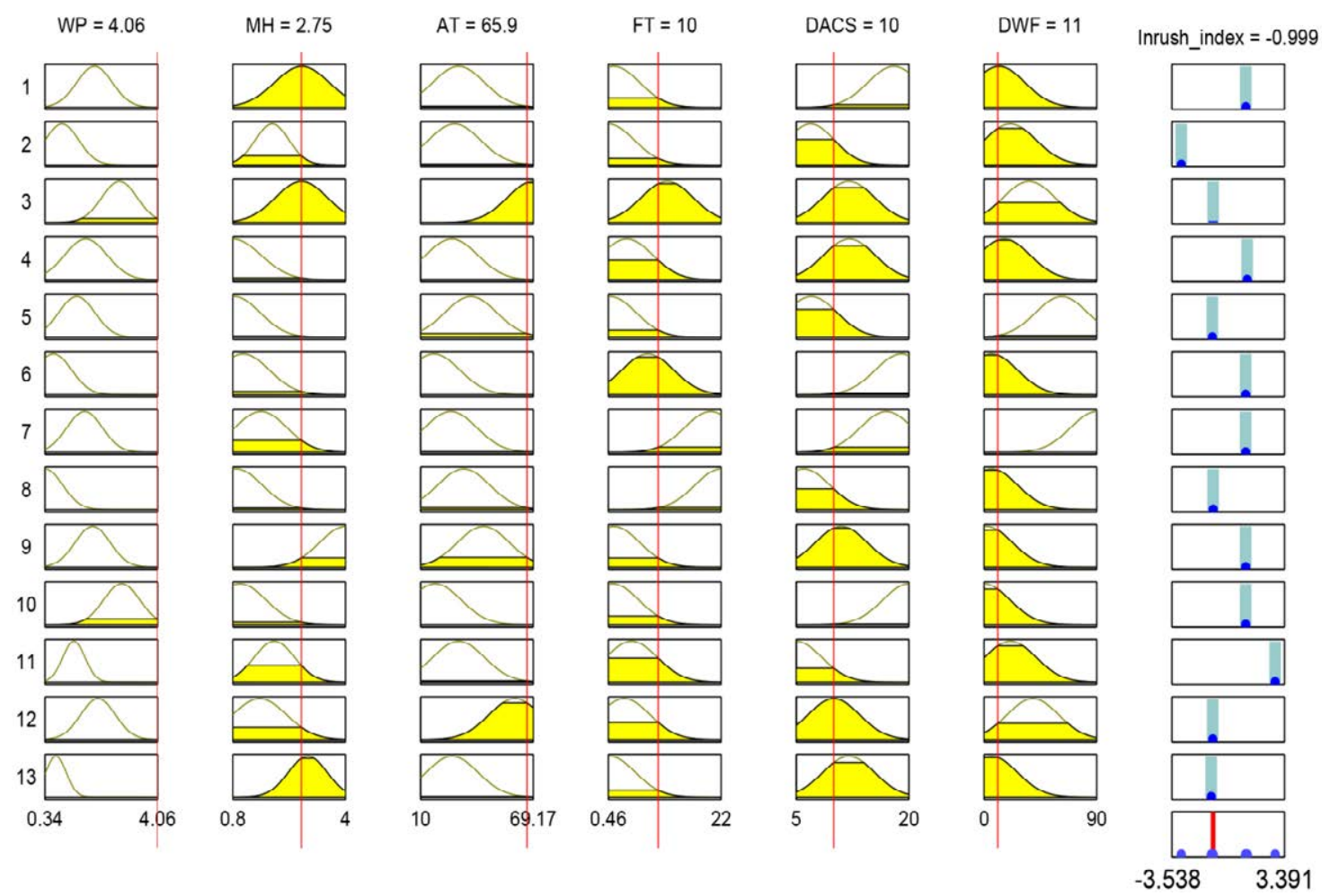

Figure.5.11. The inference process and result of the water inrush index for 6194 working face in Panxi coal mine by using the 13 trained rules.
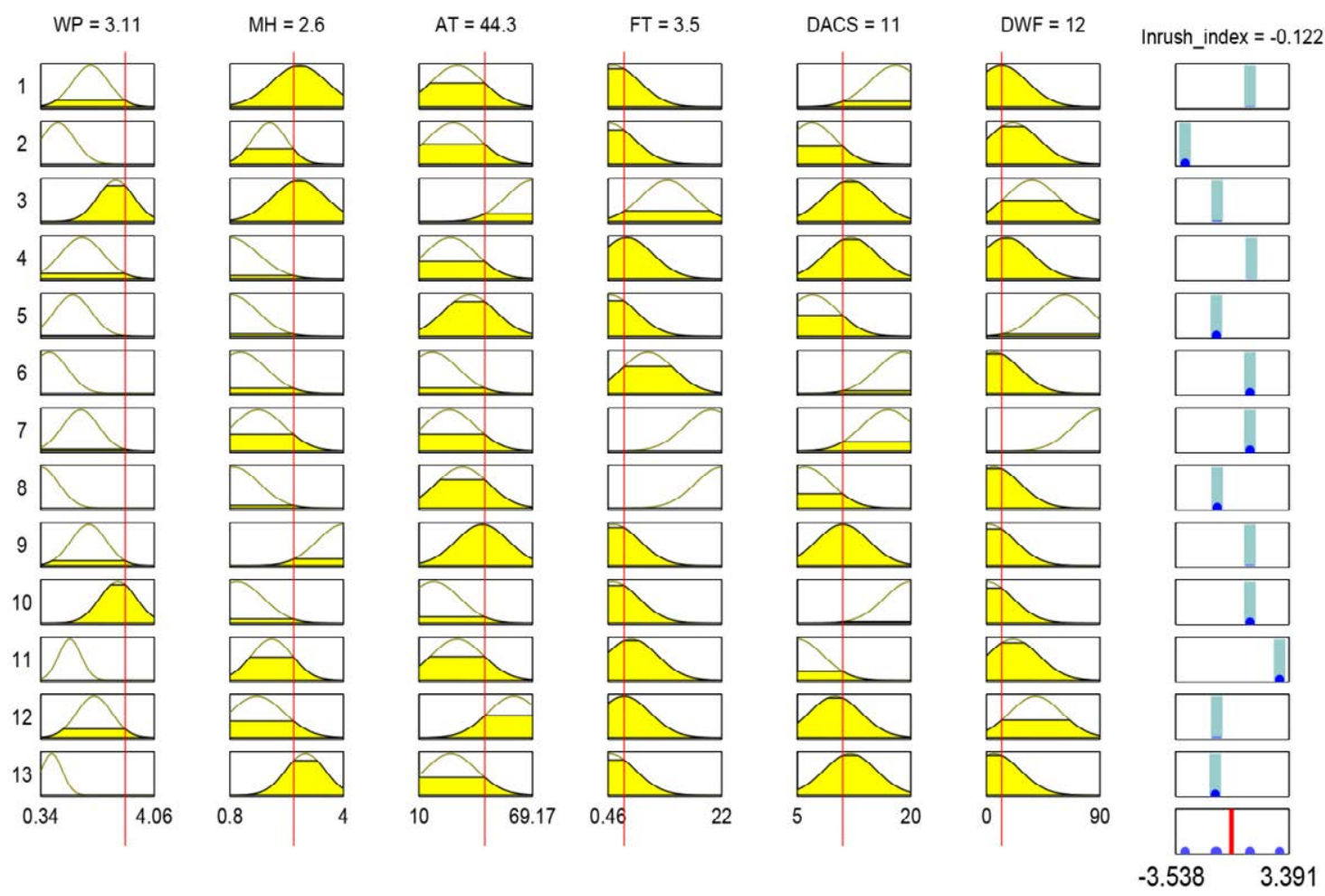

Figure.5.12. The inference process and result of the water inrush index for 9602 working face in Baizhuang coal mine by using the 13 trained rules. 

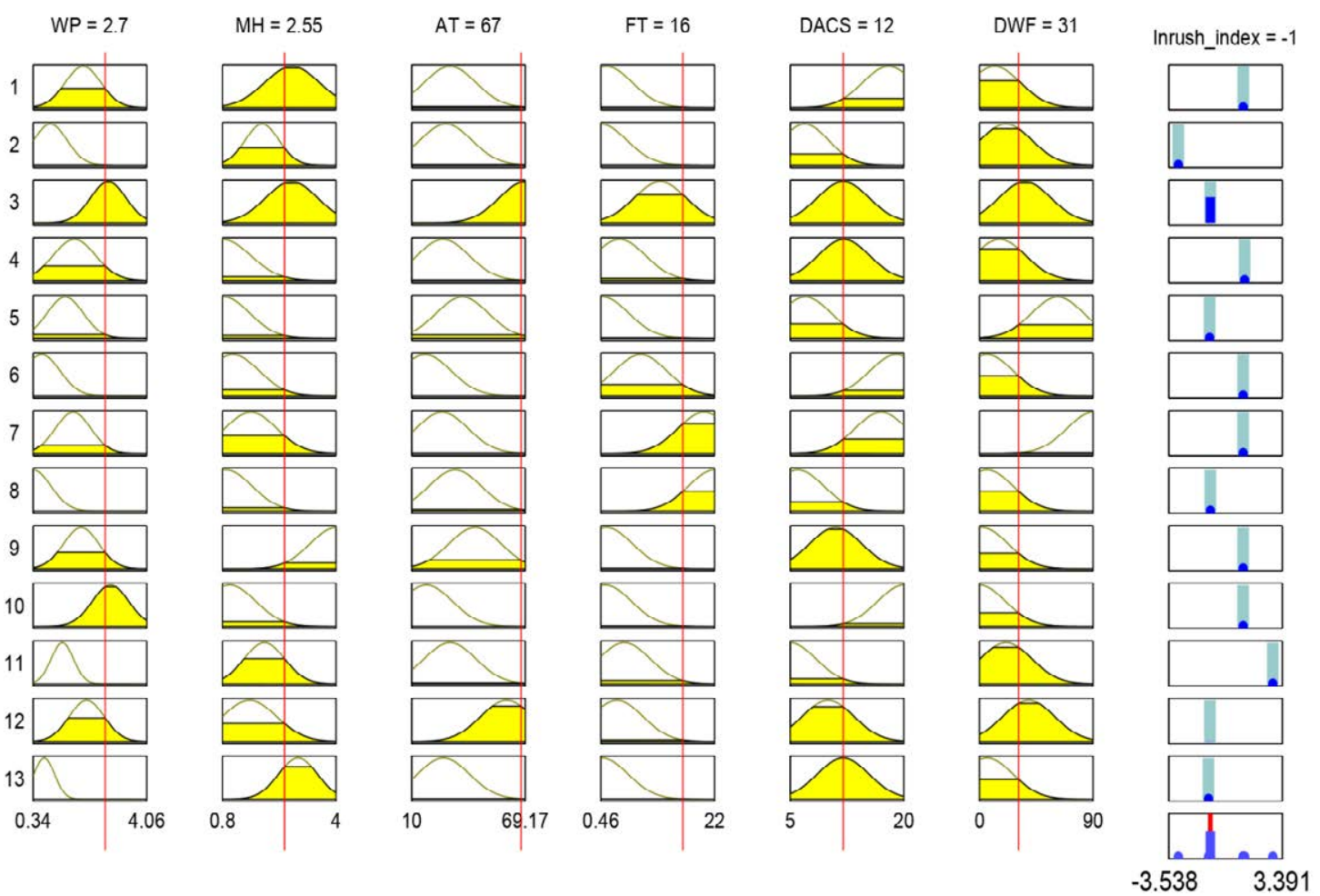

Figure.5.13. The inference process and result of the water inrush index for 61106 working face in Huahen coal mine by using the 13 trained rules.

\subsubsection{Using the water inrush index to predict the inrush risk}

In section 5.4.1, when training the ANFIS rules, 1 and -1 were used to represent water inrush occurring and not occurring respectively, so here 1 and -1 once again are used for establishing the membership function of water inrush, the discourse domain of the membership function is [-3.5 3.4] (see Figure 5.9-Figure 5.13), and there are two fuzzy subsets included within the discourse domain, the subset of water inrush occurring (Eq. 5.11) and the subset of water inrush not occurring (Eq. 5.12). Now with the established membership function of water inrush, the probability of water inrush occurring or not occurring for any new cases can then be calculated. For example, for 31503 working face, the water inrush index inferred by the trained rules is 0.661 , through substituting 0.661 into the membership function of water inrush occurring, the calculated result is 0.8305 , so the probability of water inrush occurring is 0.8305 , by using the same way, getting the probability of water inrush not occurring is 0.1695 . In Figure 5.14- Figure 5.18, the corresponding assessment results of the five working faces are shown. 


$$
\begin{aligned}
& y_{1}=\left\{\begin{array}{lr}
1 & x \geq 1 \\
\frac{1+x}{2} & -1<x<1 \\
0 & x \leq-1
\end{array}\right. \\
& y_{2}=\left\{\begin{array}{lr}
1 & x \leq-1 \\
\frac{1-x}{2} & -1<x<1 \\
0 & x \geq 1
\end{array}\right.
\end{aligned}
$$

Where $y_{1}$ represents the membership function of water inrush occurring; $y_{2}$ represents the membership function of water inrush not occurring; $x$ denotes the water inrush index inferred by the trained rules.

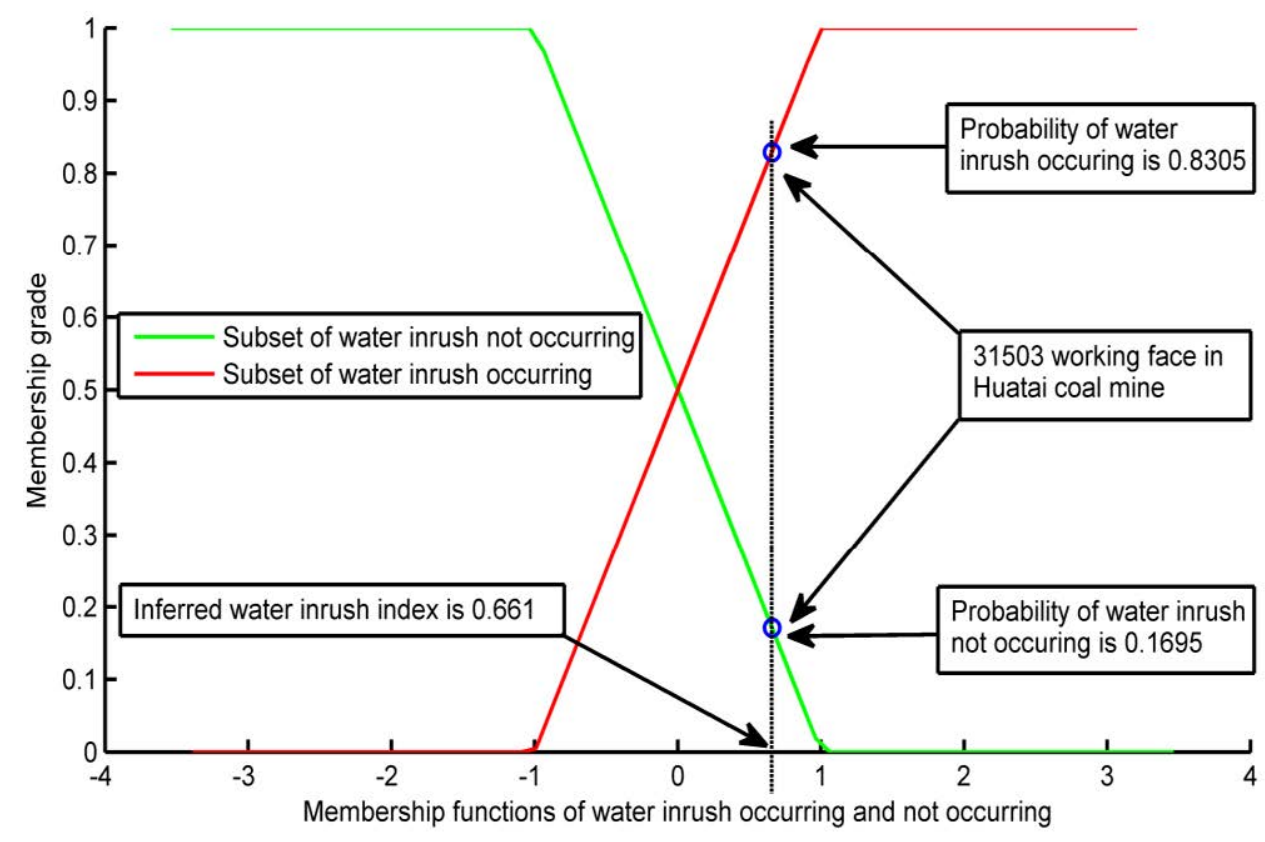

Figure.5.14. The assessment result of 31503 working face in Huatai coal mine. 


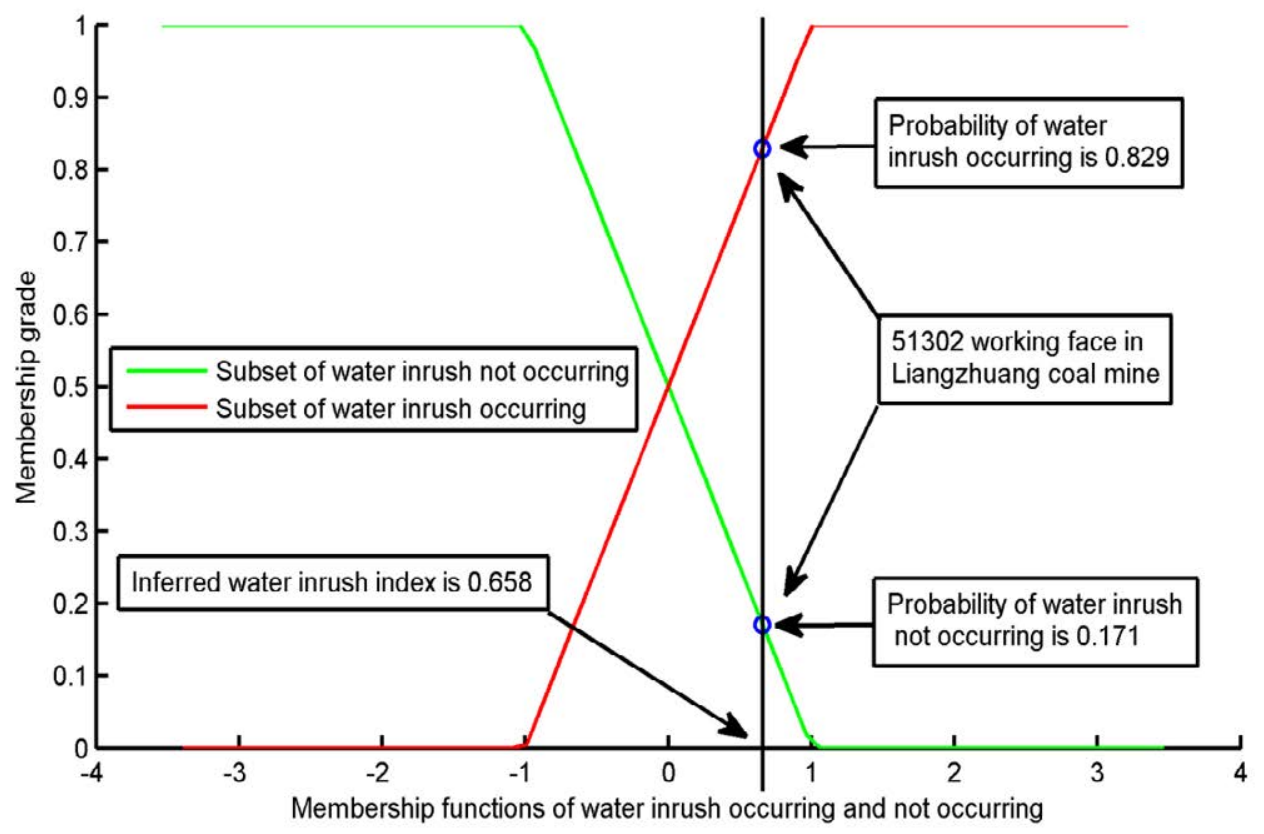

Figure.5.15. The assessment result of 51302 working face in Liangzhuang coal mine.

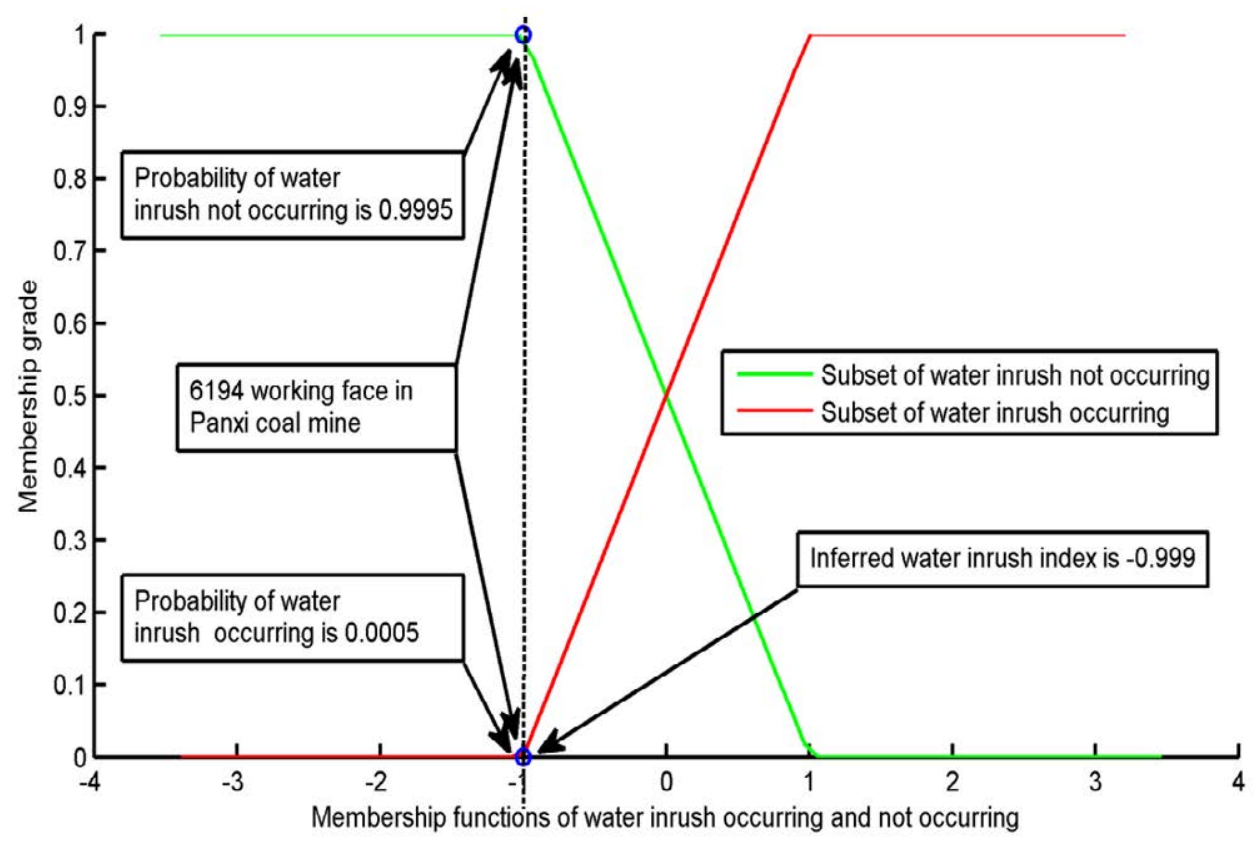

Figure.5.16. The assessment result of 6194 working face in Panxi coal mine. 


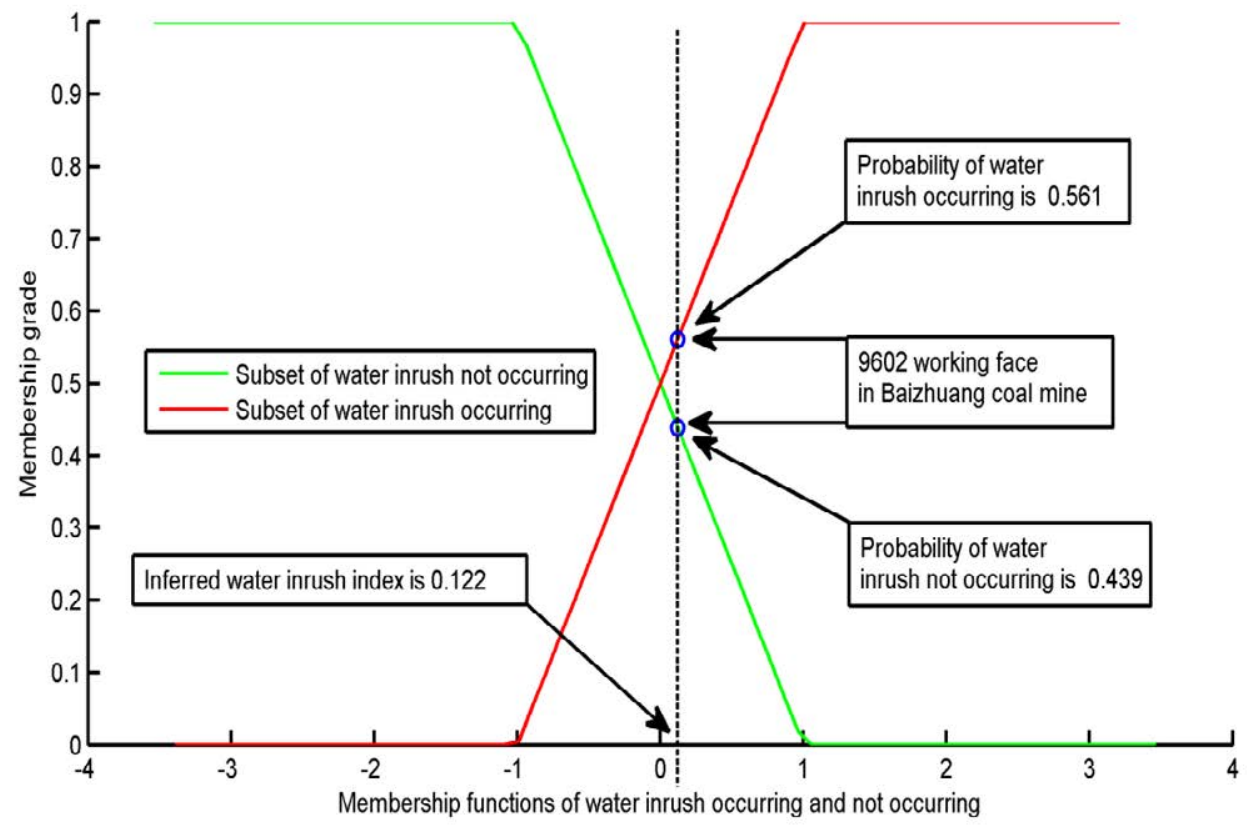

Figure.5.17. The assessment result of 9602 working face in Baizhuang coal mine.

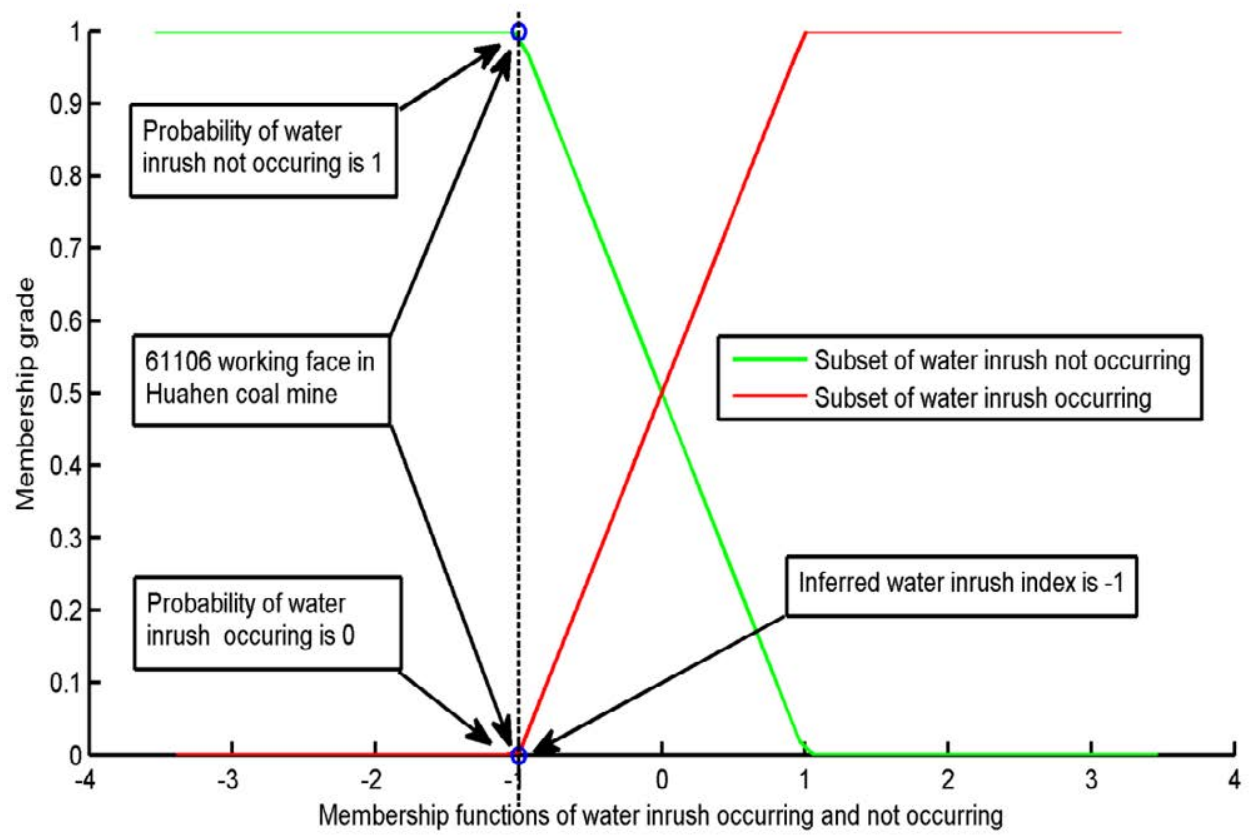

Figure.5.18. The assessment result of 61106 working face in Huahen coal mine. 
As detailed listed in Table 5.3, among the five cases, water inrush accidents actually happened at 31503 working face in Huatai coal mine, 51302 working face in Liangzhuang coal mine and 9602 working face in Baizhuang coal mine. The predicted results obtained in this study show that the probabilities of water inrush occurring in these three working faces are greater than the probabilities of not occurring, which are consistent with the actual situations and also mean ANFIS is a realizable technique for fault-induced water inrush prediction.

Table 5.3

Predicting results of the five testing working faces

\begin{tabular}{lccccc}
\hline & $\begin{array}{c}\text { Water inrush } \\
\text { index } \\
\text { inferred by } \\
\text { post-training } \\
\text { rules }\end{array}$ & $\begin{array}{c}\text { Probability } \\
\text { of water } \\
\text { inrush } \\
\text { occurring }\end{array}$ & $\begin{array}{c}\text { Probability } \\
\text { of water } \\
\text { inrush not } \\
\text { occurring }\end{array}$ & $\begin{array}{c}\text { Whether } \\
\text { water inrush } \\
\text { occurred in } \\
\text { actual } \\
\text { situation }\end{array}$ & $\begin{array}{c}\text { Whether the } \\
\text { prediction } \\
\text { consistent } \\
\text { with the } \\
\text { actual }\end{array}$ \\
\hline $\begin{array}{l}\text { 31503 working face } \\
\text { in Huatai coal mine }\end{array}$ & 0.661 & 0.8305 & 0.1695 & Yes & Yes \\
$\begin{array}{l}51302 \text { working face } \\
\text { in Liangzhuang coal } \\
\text { 6194 working face in }\end{array}$ & 0.658 & 0.829 & 0.171 & Yes & Yes \\
$\begin{array}{l}\text { Panxi coal mine } \\
\text { 9602 working face in } \\
\text { Baizhuang coal mine }\end{array}$ & -0.999 & 0.0005 & 0.9995 & No & Yes \\
$\begin{array}{l}\text { 61106 working face } \\
\text { in Huahen coal mine }\end{array}$ & -1 & 0.561 & 0.439 & Yes & Yes \\
\hline
\end{tabular}

\subsection{Summary of the chapter}

In order to provide a better way to assess the risk of mine water inrushes, reducing the occurrence of a large number of ongoing water inrush accidents in mining working face. In this chapter, the technique ANFIS to predict the probability of the fault-induced water inrush was used. All the main parameters related to the hydraulic properties of the aquifer, the waterresisting properties of the aquifuge and the mining-induced stresses were considered in the developed method. With these main parameters an ANFIS model was constructed and the subtractive clustering method was used to generate the initial FIS rules, in the training step, 20 real water inrush cases were used to train the initial rules and the membership functions. 
The advantage of ANFIS is that after the training process, the trained FIS rules and the adjusted membership functions actually imply all the knowledge learned from the training samples, so these rules and membership functions actually can be used for predicting new cases. In this chapter, with five real water inrush cases selected from different mines, their water inrush probabilities by using the trained FIS rules and membership functions were calculated, the final predicted results are totally consistent with the actual situation, this means ANFIS is a reliable and accurate technique for assessing fault-induced water inrushes. 



\section{Chapter 6 Risk Assessment of Fault-Induced Water Inrush: Application to a Whole Coalfield}

\subsection{Introduction}

In Chapter 5, how to evaluate the risk of water inrush caused by a specific fault was under research and an effective approach was developed. However, in mining engineering, conducting an inrush risk assessment to a whole coalfield is also very necessary. This kind of risk assessment will suggest us which part of the mining region has high risk of water inrush and which part is risk free, this will help engineers to take effective measures to prevent water inrush occurrence before mining or excavating in those regions where the water inrush possibility is high.

Unlike the previous chapter, the research objective of this chapter is an entire coalfield. By means of the RES and by considering the water yield property of aquifer, the aquifer pressure, the aquifuge thickness, the aquifuge strength, the depth of coal seam, the fault density and the recharging conditions of water sources as the seven main parameters relating to water inrush. A new systematic approach for evaluating the risk of fault-induced water inrush for a whole coalfield will be developed in this chapter, and a water inrush index (range from 0 to 100) will be proposed and this index will enable us to understand which part of the mining region has high risk of water inrush and which part is risk free.

\subsection{Factor analysis}

As mentioned in Chapter $\mathbf{4}$ and Chapter 5, water inrush is a complex dynamical system, which is composed of four main elements: aquifer properties (water output, hydraulic pressure, water supplement conditions etc.), aquifuge properties (lithology type, thickness), mining-induced stresses and inherent geological structures (such as water conducting faults, fractures etc.). 


\subsubsection{Aquifer properties}

Among these factors, aquifer properties are the most important factors in the mine water inrush system. Water output of aquifer and water supplement conditions are very crucial in determining the hydrogeological complexity of a mine and in determining to what extent a mine has waterhazard threatening. In China, according to the "Provisions on Prevention and Control of Water in Coal Mines” provided by The State Administration of Work Safety in 2009, mine hydrogeological complexity is classified into four grades based on water output of aquifer, surrounding goaf water and water supplement conditions. The detailed classification is given in Table 6.1. As can be seen from this table, this is a very fundamental classification and it just provides very preliminary criterions to evaluate the risk of mine water inrush hazard.

The impact of hydraulic pressure of aquifer (hereinafter referred to as aquifer pressure) on water inrush is mainly reflected in two aspects. First, aquifer pressure and mining-induced stresses are two of the main factors of inducing fault and fracture reactivation (Odintsev and Miletenko, 2015; $\mathrm{Bu}$ and Mao, 2009; Islam and Shinjo, 2009), especially for those faults and fractures that are directly connected with an aquifer, their tip-stress fields (represented by stress intensity factors (SIFs)) are directly affected by aquifer pressure. If the SIFs magnitude exceeds the fracture toughness of the faults and fractures, then these faults and fractures will be reactivated and gradually extended as potential water conduits to cause water inrush incidents. Second, according to the hypothesis of 'three zones' (Qian and Liu, 1983), there are three characteristic zone existing in floor strata, the fracture zone beneath the coal seam induced by mining, the waterproof zone in the intermediate layer and the hydraulic fracture zone induced by the aquifer pressure at the bottom (Wang and Park, 2003). So from this perspective aquifer pressure actually affects the effective water-resisting thickness of aquifuge because it directly determines the range of the hydraulic fracture zone in the aquifuge. 
Table 6.1

Classification of mine hydrogeological complexity.

\begin{tabular}{|c|c|c|c|}
\hline $\begin{array}{l}\text { Hydrogeolo- } \\
\text { gical } \\
\text { complexity }\end{array}$ & $\begin{array}{l}\text { Aquifer type and water } \\
\text { source recharge }\end{array}$ & $\begin{array}{c}\text { Water } \\
\text { output of } \\
\text { aquifer q } \\
\left(\mathrm{L} \cdot \mathrm{s}^{-1} \cdot \mathbf{m}^{-1}\right)\end{array}$ & Surrounding goaf water \\
\hline Simple & $\begin{array}{l}\text { Porous aquifer or fissured } \\
\text { aquifer or karst aquifer is } \\
\text { affected by mining } \\
\text { operations, very poor water } \\
\text { source recharge. }\end{array}$ & $\mathrm{q} \leq 0.1$ & $\begin{array}{l}\text { No surrounding goaf } \\
\text { water }\end{array}$ \\
\hline Medium & $\begin{array}{l}\text { Porous aquifer or fissured } \\
\text { aquifer or karst aquifer is } \\
\text { affected by mining } \\
\text { operations, medium water } \\
\text { source recharge. }\end{array}$ & $0.1<\mathrm{q} \leq 1.0$ & $\begin{array}{l}\text { Small volumes of } \\
\text { surrounding goaf water, } \\
\text { locations and volumes of } \\
\text { the goaf water are clear. }\end{array}$ \\
\hline Complex & $\begin{array}{l}\text { Karst aquifer or gravel } \\
\text { aquifer or surface water is } \\
\text { affected by mining } \\
\text { operations, abundant water } \\
\text { source recharge. }\end{array}$ & $1.0<\mathrm{q} \leq 5.0$ & $\begin{array}{c}\text { Small volumes of } \\
\text { surrounding goaf water, } \\
\text { locations and volumes of } \\
\text { the goaf water are not } \\
\text { clear. }\end{array}$ \\
\hline Very Complex & $\begin{array}{l}\text { Karst aquifer or surface water } \\
\text { or surrounding goaf water is } \\
\text { affected by mining } \\
\text { operations, very abundant } \\
\text { water source recharge }\end{array}$ & $q>5.0$ & $\begin{array}{c}\text { Large volumes of } \\
\text { surrounding goaf water, } \\
\text { locations and volumes of } \\
\text { the goaf water are not } \\
\text { clear. }\end{array}$ \\
\hline
\end{tabular}

\subsubsection{Aquifuge properties}

Contrary to an aquifer that acts as motivations for inducing water inrushes, an aquifuge acts as a resisting role in water inrushes, and its resisting ability mainly depends on its lithology type and thickness.

According to Meng's research (Meng et al., 2012), the resistance capability to aquifer pressure of an aquifuge vary with its lithologic features. For coal-bearing sedimentary rock, the lithology of aquifuge is mainly mudstone, siltstone and sandstone. According to Meng's experiment results conducted in Fangezhuang coalmine, he suggested that aquifuges can be classified into 
three types: the mudstone type, the sandstone type and the mudstone-sandstone or mudstonesiltstone compound type. The mudstone type has the weakest capability in resisting aquifer pressure and the sandstone type is just the contrary. The determination of the lithology type of an aquifuge is mainly based on the proportion of mudstone in the aquifuge, if using a letter $\mathrm{K}$ (given by Eq. 6.1) to represent the percentage of mudstone content in the aquifuge, the aquifuge's capability in resisting aquifer pressure decreases with the increase of $\mathrm{K}$ because the mechanical strength of the aquifuge decreases with the increase of mudstone proportion

$$
\mathrm{K}=\frac{\mathrm{h}}{\mathrm{H}} \times 100 \%
$$

where $\mathrm{h}$ is the total thickness of mudstone in the aquifuge and $\mathrm{H}$ is the total thickness of the aquifuge.

In addition to the mechanical strength of aquifuge, the thickness of aquifuge also plays an important role in determining capability of the aquifuge in resisting aquifer pressure. According to the empirical value obtained from many water inrush cases (Zhang et al., 1997), most water inrushes take place under the condition that the aquifuge thickness is less than $40 \mathrm{~m}$. Over the past few decades, by using aquifuge thickness and aquifer pressure, a traditional water inrush index $I_{t}$ (see Eq. 6.2) has been defined and applied for assessing the water inrush risk in China and it refers to the limit aquifer pressure that unit impermeable aquifuge can afford.

$$
I_{t}=\frac{P}{H}
$$

Where $\mathrm{P}$ is the aquifer pressure and $\mathrm{H}$ is the aquifuge thickness. According to the previous studies (Wang and Park, 2003; Sun et al., 2013), water inrushes occur if $I_{t}$ is greater than 0.05-0.1 $\mathrm{Mpa} / \mathrm{m}$, in Table 6.2 critical values of $\mathrm{I}_{\mathrm{t}}$ in several mining areas are given. So if we takeH $\leq$ $40 \mathrm{~m}$ as the safe aquifuge thickness, the safe aquifer pressure is $\mathrm{P}=\mathrm{H} \times \mathrm{I}_{\mathrm{t}}=40 \times 0.05=$ 2 Mpa. 
Table 6.2

Empirical and critical value of $I_{t}$ in several mining areas (Meng et al., 2012).

\begin{tabular}{lr}
\hline Mining area & Critical value of $\mathrm{I}_{\mathrm{t}}$ \\
\hline Fengfeng mining area & $0.066-0.076$ \\
Handan mining area & $0.066-0.100$ \\
Jiaozuo mining area & $0.060-0.100$ \\
Zibo mining area & $0.06 .-0.140$ \\
Jingxing mining area & $0.060-0.150$ \\
\hline
\end{tabular}

\subsubsection{Mining-induced stresses}

Mining-induced stresses, which are mainly affected by mining depth, mining width and lithology of roof and floor, may act as a trigger for water inrush. In the process of mining, under the disturbance of mining-induced stresses faults and fractures in aquifuge may be reactivated and propagated to form interconnected water conduits and thereby to cause water inrush incidents. Moreover, according to studies conducted by Lu, Miao and Singh (Lu and Wang, 2015; Miao et al., 2011; Singh et al., 1986), water-conducting fracture zones caused by mining-induced stresses in the seam floor even reduce the effective aquifuge thickness and increase the probability of water inrush. Among all the mining-stresses related factors, mining depth is the dominant one (Brown and Hoek, 1978 ) and has a significant impact on underground water hazards (Zhang and Peng, 2005; Hill and Price, 1983; Hu, 2010), so in this study mining depth is considered as a key factor to evaluate water inrush risk.

\subsubsection{Geological structures}

Geological structures such as faults, joints, and collapse columns are directly related to mine water inrushes mainly for two reasons (Bu and Mao, 2009). Firstly high density of geological structures may decrease floor integrity and strength and hence may lead to a wider range of water-conducting fracture zone in floor when there is a mining disturbance; secondly geological 
structures such as faults and collapse columns themselves are potential water conduits with good water conductivity, therefore high density of geological structures will increase floor waterconducting property.

Among all the geological structures, geological faults are the most common structures that cause water inrush accidents. In China, up to $79.5 \%$ of inrush events in mines are associated with geological faults (Bu and Mao, 2009). Therefore, for a coalfield, its fault distribution complexity directly determines the possibility of water inrush accidents. Currently the most advanced way to assess the fault distribution complexity is by using fractal analysis method (Aviles et al., 1987; Koukouvelas et al., 1999; Matsumoto et al., 1992; Pérez-López et al., 2005). This method can be conducted by using a two-dimensional geological map with all fault traces and a numerical value named fractal dimension (FD) is used to quantitatively characterize the complexity of the fault distribution. According to Xu's research (Xu et al., 1996) on the fault distribution in Xuzhuang and Yaoqiao coal mines, he suggested that the use of FD to replace the fault density to describe the fault distribution complexity is more appropriate, and in Table 6.3 the suggested classification of fault distribution complexity in his study is listed.

Table 6.3

Suggested classification of fault distribution complexity in Xuzhuang and Yaoqiao mines (Xu et al., 1996).

\begin{tabular}{lccccc}
\hline Classification & $\begin{array}{c}\text { Very } \\
\text { simple }\end{array}$ & Simple & Medium & Complex & Very complex \\
\hline $\begin{array}{l}\text { Fractal } \\
\text { Dimension }\end{array}$ & $<1.15$ & $1.15-1.25$ & $1.25-35$ & $1.35-1.45$ & $>1.45$ \\
\hline
\end{tabular}

Apart from the fault distribution complexity, according to Wu's study (Wu et al., 2011), fault intersections and endpoints (I+E) also have an impact on water inrush. At interactions and endpoints of faults where mining-induced stresses and in-situ stresses tend to concentrate, rock is more crushed and fracture is more developed. So the number of fault intersections and endpoints influence the performance of the aquifuge in resisting water inrush.

In practical applications, in order to describe the fault distribution complexity of each part of a coalfield in greater detail, a coalfield generally needs to be divided into many small elements, and 
then using box-counting method to compute the FD of each element and counting the number of interactions and endpoints of each element. Using box-counting method to compute FD and thereby to characterize the complexity of the fault distribution has already well-established by several previous studies (Zhao et al., 2011; Pérez-López et al., 2005; Walsh and Watterson, 1993).

\subsection{Formulating the risk assessment by using RES}

\subsubsection{Formulating the interaction matrix}

In Chapter 3, basic knowlege about the RES and the coding method RES have already been given, so here developing a risk assessment system for fault-induced water inrush will be directly given. In section 6.2, the aquifer properties, aquifuge properties, mining-induced stresses and inherent geological structures were recognized as four of the main factors directly related to water inrush. Thereby here seven main parameters are further extracted from the four main factors as the main terms to construct the interaction matrix. The seven main parameters are water output of aquifer, aquifer pressure, aquifuge thickness, lithology type of aquifuge, depth of coal seam (mining depth), fault distribution complexity and supplement conditions of water sources. According to the constructing rules of the interaction matrix described in Chapter 3, the 7 main parameters are located along the diagonal elements and the interacting action between each two parameters is placed in the corresponding off-diagonal element, thus a $7 \times 7$ square interaction matrix including 7 diagonal terms and 42 off-diagonal terms is constructed (see Figure.6.1) to represent the water inrush system. 


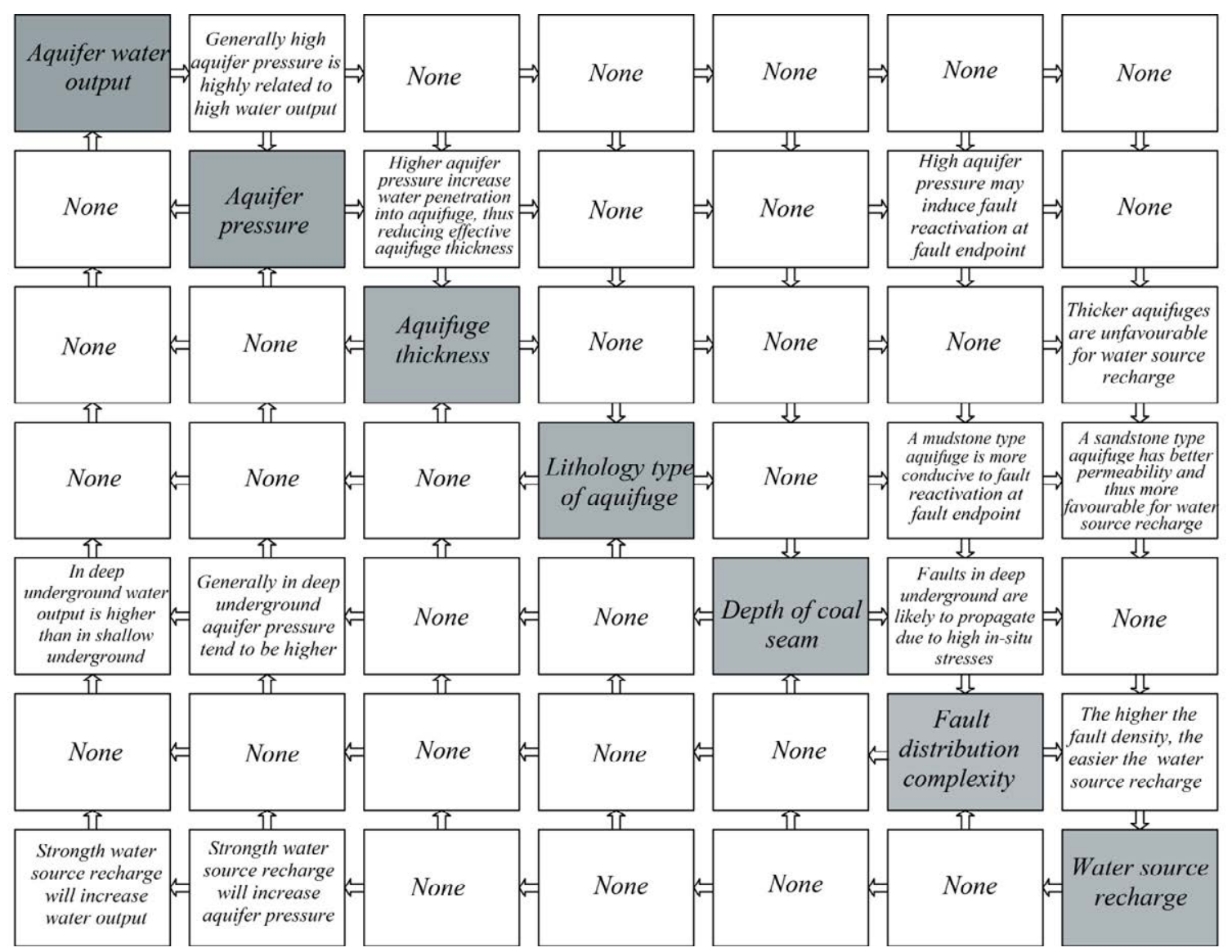

Figure.6.1. The constructed interaction matrix of the water inrush system.

\subsubsection{Interaction matrix coding and C-E plot}

With the established interaction matrix of water inrush system, traditional ESQ method suggested by Hudson (1992) is applied to code it (as shown in Table 6.4). In this coding system numbers from 0 (no interaction) to 4 (critical interaction) are used for representing the interacting intensities between each two parameters, and numbers 1, 2 and 3 refer to weak, medium and strong interactions, respectively. The complete coding results of the interaction matrix corresponding to Figure 6.1 are shown in Table 6.5. With this coding matrix, as described in section Chapter 3, the cause value $\mathrm{C}$ and the effect value $\mathrm{E}$ with respect to each corresponding parameter can then be computed as the sum of the off-diagonal rows and the sum of the offdiagonal columns, respectively, and by plotting each parameter in a cause and effect space then the C-E plot can be obtained for the established water inrush system, which is shown in Figure 
6.2. Note that in this $\mathrm{C}-\mathrm{E}$ plot the parameter interactive intensity $(\mathrm{C}+\mathrm{E})$ can be measured along the $\mathrm{C}=\mathrm{E}$ line and the parameter dominance $(\mathrm{C}-\mathrm{E})$ can be measured by the perpendicular distance of the parameter point from this line, the two sets of $45^{\circ}$ lines in the plot indicate contour of equal value for the cause and effect value.

Table 6.4

ESQ coding value suggested by Hudson (1992)

\begin{tabular}{lc}
\hline Significance & Coding value \\
\hline No interaction & 0 \\
Weak interaction & 1 \\
Medium interaction & 2 \\
Strong interaction & 3 \\
Critical interaction & 4 \\
\hline
\end{tabular}

Table 6.5

The results of the interaction matrix coding corresponding to Figure 6.1 using the ESQ coding system

\begin{tabular}{|c|c|c|c|c|c|c|c|c|}
\hline \multicolumn{9}{|c|}{ Interaction matrix coding } \\
\hline P1 & 4 & 0 & 0 & 0 & 0 & 0 & 4 & \multirow{7}{*}{ 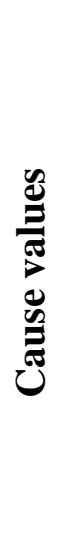 } \\
\hline 0 & $\mathbf{P 2}$ & 2 & 0 & 0 & 3 & 0 & 5 & \\
\hline 0 & 0 & P3 & 0 & 0 & 0 & 3 & 3 & \\
\hline 0 & 0 & 0 & P4 & 0 & 2 & 2 & 4 & \\
\hline 3 & 3 & 0 & 0 & P5 & 2 & 0 & 8 & \\
\hline 0 & 0 & 0 & 0 & 0 & P6 & 3 & 3 & \\
\hline 4 & 4 & 0 & 0 & 0 & 0 & P7 & 8 & \\
\hline 7 & 11 & 2 & 0 & 0 & 7 & 8 & \multicolumn{2}{|c|}{$\sum_{\square} \square=35$} \\
\hline \multicolumn{7}{|c|}{ Effect values } & \multicolumn{2}{|c|}{$\sum_{\square} \square=35$} \\
\hline
\end{tabular}




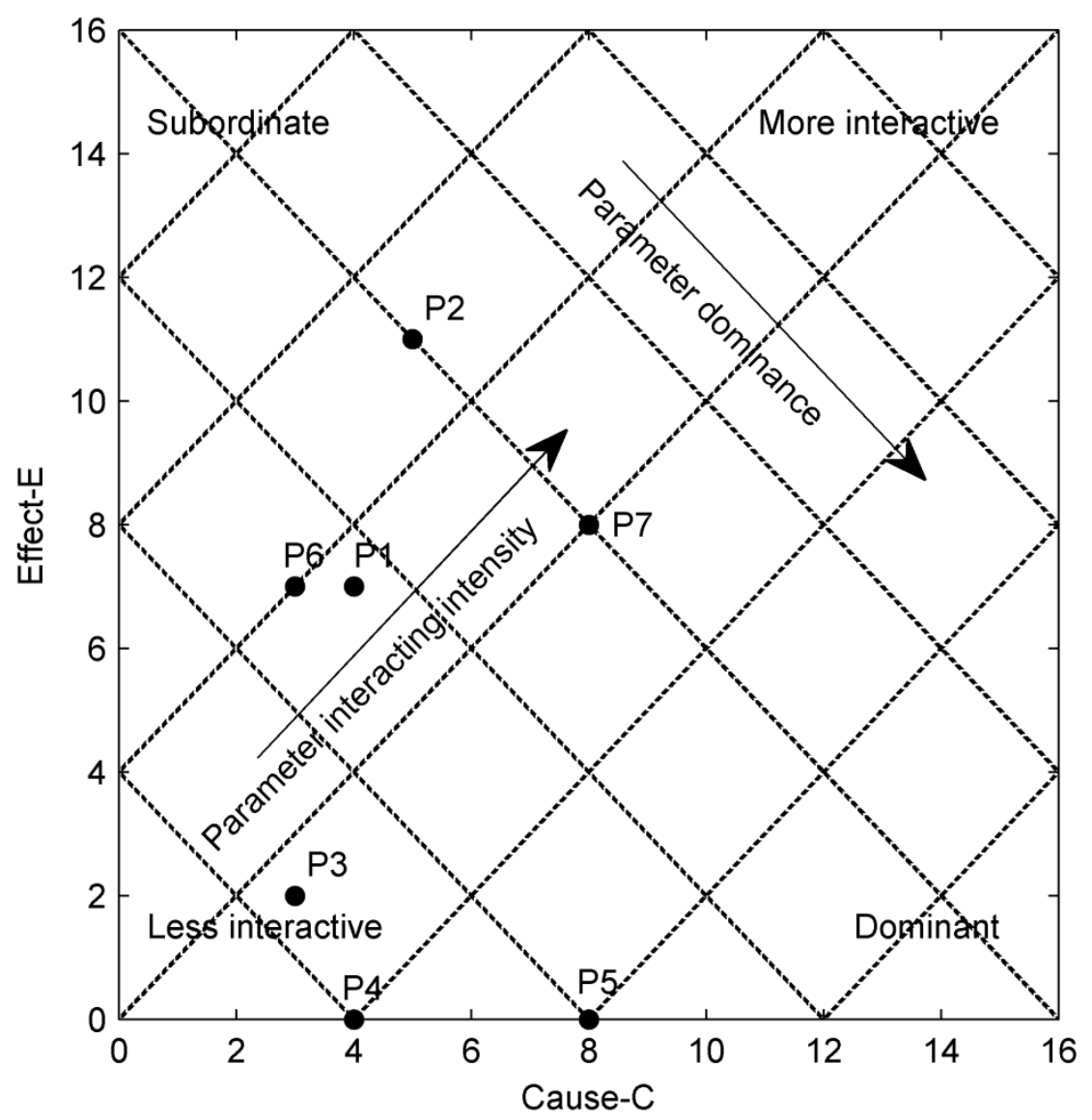

Figure.6.2. Parameter interaction intensity and dominance.

According to Hudson's research (1992), the C-E plot also can be illustrated like that: parameters located in the top right portion of the diagram are more interactive than the parameters placed in the bottom left portion. Parameters located in the bottom right portion of the diagram are 'dominant' in the system, and those 'subordinate' parameters which are highly dominated by the system are located in the top left portion.

By means of the C-E plot a visually understand of the performance of each parameter to the whole water inrush system can be achieved, as it can be seen from Figure 6.2 that the aquifer pressure (P2) and water source supplement (P7) are the most interactive parameters to the water inrush system and the lithology type of aquifuge (P4) is the lest interactive one; and the plot also shows that the depth of coal seam (P5) is the most dominant parameter in the water inrush system and the aquifer pressure (P2), on the contrary, is the most subordinate parameter which is highly influenced by all other parameters in the water inrush system. 


\subsubsection{Computing water inrush index}

According to the theory of rock engineering systems, the parameter interacting intensity $(\mathrm{C}+\mathrm{E})$ also represents the parameter importance to the system, the greater the parameter interacting intensity, the greater the impact of the parameter on the system. In Figure 6.3, the histogram of parameter interacting intensity corresponding to parameters considered in the water inrush system is shown. For the reason of getting a weighting coefficient for each parameter, these $\mathrm{C}+\mathrm{E}$ values are transformed into percentage values (see Eq. 6.3 and Table 6.6), which represent the proportional share of each parameter in the water inrush system.

$$
w_{i}=\frac{C_{i}+E_{i}}{\sum_{i=1}^{n}\left(C_{i}+E_{i}\right)} \times 100
$$

Where $C_{i}$ represents the cause value of the $i$-th parameter; $E_{i}$ represents the effect value of the $i$ th parameter; $i$ denotes the number of parameter and $n$ refers to the total number of selected parameters.

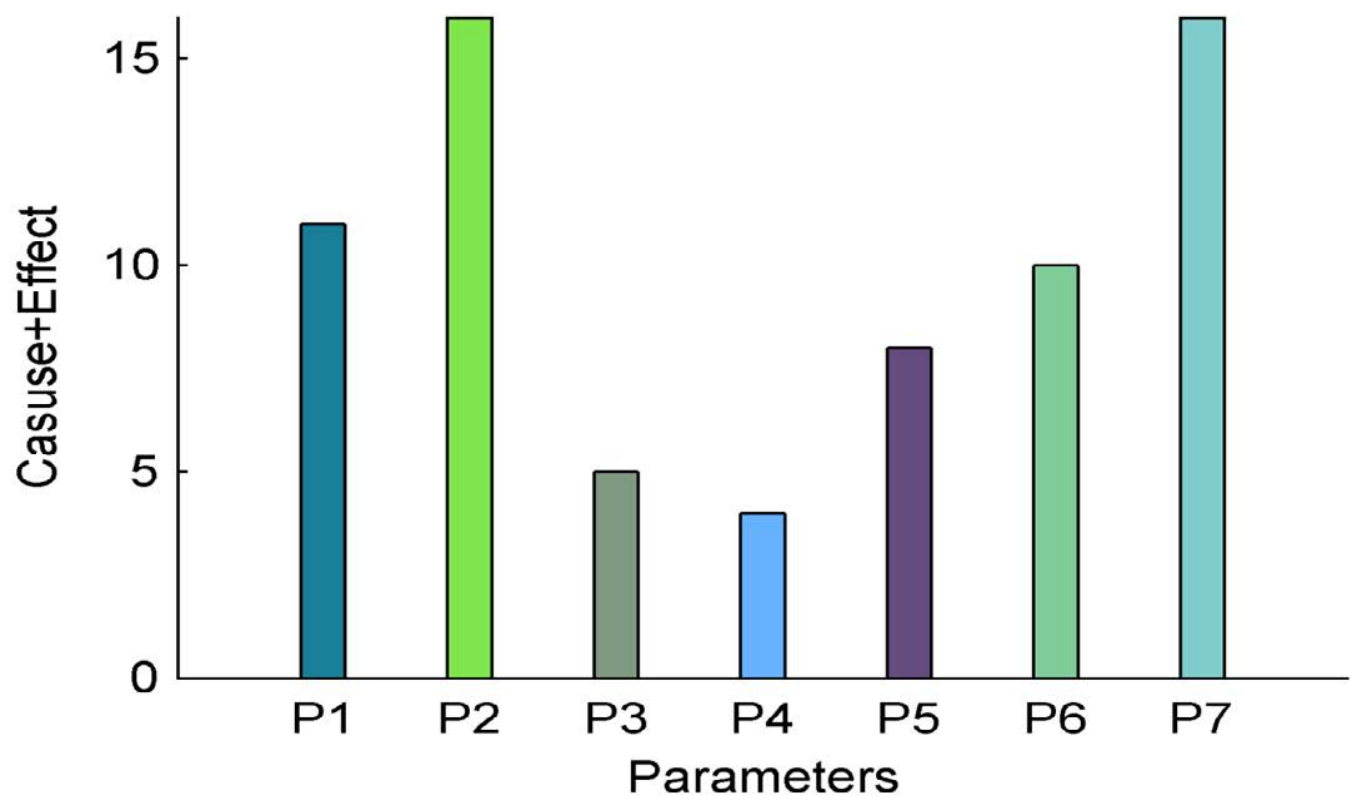

Figure.6.3. The histogram of parameter interactive intensity. 
Table 6.6

The weighted coefficients of the selected parameters

\begin{tabular}{lccccc}
\hline Parameters & $\mathrm{C}_{i}$ & $E_{i}$ & $C_{i}+E_{i}$ & $w_{i}$ & $s_{i}$ \\
\hline Water output of aquifer(P1) & 4 & 7 & 11 & 15.71 & 5.238 \\
Aquifer pressure(P2) & 5 & 11 & 16 & 22.86 & 7.619 \\
Aquifuge thickness(P3) & 3 & 2 & 5 & 7.14 & 2.381 \\
Lithology type of aquifuge (P4) & 4 & 0 & 4 & 5.71 & 1.905 \\
Depth of coal seam(P5) & 8 & 0 & 8 & 11.43 & 3.810 \\
Fault distribution complexity & 3 & 7 & 10 & 14.29 & 4.762 \\
Water source supplement(P7) & 8 & 8 & 16 & 22.86 & 7.619 \\
\hline
\end{tabular}

The next step is to compute the water inrush index $(I)$, which can be calculated by using the following equation.

$$
I=\sum_{i=1}^{n} s_{i} p_{i}
$$

Where $p_{i}$ is the rating value of the $i$-th parameter (see Table 6.7); and $s_{i}$ is the normalized weighting coefficients of the $i$-th parameter in the outburst system, which is obtained by using $w_{i}$ to divide with the maximum rating value (See Eq.6.5).

$$
s_{i}=\frac{w_{i}}{3}
$$

\section{Table 6.7}

Suggested rating values of the selected parameters

P1- Water output of aquifer (L/s.m)

$<0.1$

$0.1-1$

P2- Aquifer pressure (MPa) 


\begin{tabular}{|c|c|}
\hline$<2$ & 0 \\
\hline $2-4$ & 1 \\
\hline 4-6 & 2 \\
\hline$>6$ & 3 \\
\hline \multicolumn{2}{|l|}{ P3-Aquifuge thickness (m) } \\
\hline$>60$ & 0 \\
\hline $50-60$ & 1 \\
\hline $40-50$ & 2 \\
\hline$<40$ & 3 \\
\hline \multicolumn{2}{|l|}{ P4- Lithology type of aquifuge } \\
\hline Sandstone type I: K<15\% & 0 \\
\hline Sandstone type II: Ke(15\%, 35\%) & 1 \\
\hline Mudstone-sandstone or Mudstone-siltstone type: $\mathrm{K} \in(35 \%, 65 \%)$ & 2 \\
\hline Mudstone type: $K \geq 65 \%$ & 3 \\
\hline \multicolumn{2}{|l|}{ P5- Depth of coal seam ( $m$ ) } \\
\hline$<200$ & 0 \\
\hline $200-400$ & 1 \\
\hline $400-800$ & 2 \\
\hline 800 & 3 \\
\hline \multicolumn{2}{|l|}{ P6- Fault distribution complexity } \\
\hline Low complexity: FD $\leq 1.25$ and $\mathrm{I}+\mathrm{E} \leq 5$ & 0 \\
\hline Medium complexity: $\mathrm{FD} \in(1.25,1.35)$ and $\mathrm{I}+\mathrm{E} \leq 5$ & 1 \\
\hline High complexity: $\mathrm{FD} \in(1.35,1.45)$ and $\mathrm{I}+\mathrm{E} \in(5,25)$ & 2 \\
\hline Very high complexity: FD $\geq 1.45$ and $\mathrm{I}+\mathrm{E} \geq 15$ & 3 \\
\hline \multicolumn{2}{|l|}{ P7- Water source supplement } \\
\hline No water source supplement & 0 \\
\hline Weak water source supplement & 1 \\
\hline Medium water source supplement & 2 \\
\hline Strong water source supplement & 3 \\
\hline
\end{tabular}




\subsection{A case study from Liyazhuang coal mine}

Located in Huozhou district of Southern Shanxi Province, Liyazhuang coalfield is a large-scale base for producing coking coal, and the production capacity is 1.5 million tons of raw coal per year. The No.2 coal seam, with the average thickness of $2.75 \mathrm{~m}$ (range from $0.65 \mathrm{~m}$ to $4.27 \mathrm{~m}$ ), is the main seam being mined currently in this coalfield. The longwall top coal caving is the applied mining method. In the floor of No.2 coal seam, there is a water-rich Limestone aquifer that threatening the coal seam mining, and several small-scale water inrush events have occurred in recent years. So in this section our aim is to zone the water inrush safety for the No.2 coal seam throughout the entire coalfield.

For completely surveying the hydrogeological conditions for the entire coalfield, from April 2010 to April 2011 a number of boreholes distributed throughout the entire coalfield have been constructed by China National Administration of Coal Geology aim to get the detailed geological data of the aquifers and aquifuges in Liyazhuang mine. Therefore here the water inrush assessment for No.2 coal seam is based on these geological data and the assessment step is like that: firstly evaluating the water inrush index for each borehole, and next through the interpolation of water inrush indexes of all boreholes the water inrush safety maps for the whole coalfield is achieved.

Corresponding to the parameter rating value in Table 6.7, the surveyed geological data for the 12 boreholes are listed in Table 6.8, and in this table some parameters such as the water output of aquifer (P1) (see water output contour map of the Carboniferous Limestone aquifer in Figure 6.4), the aquifer pressure (P2), the aquifuge thickness (P3) and the depth of coal seam (P5) are four of the parameters that can be represented numerically based on the geological survey results. But for the other three parameters, the lithology type of aquifuge (P4), the fault distribution complexity (P6) and the supplement conditions of water sources (P7), they belong to the nonnumerical parameters and cannot be obtained directly from the geological survey results, therefore some subjective judgments are needed to classify them. In the next, how these three parameters are classified will be given.

For the lithology type of aquifuge, as described in section 6.2.2, its classification is mainly based on the proportion of mudstone in the aquifuge. In Table 6.9 the proportion of each lithology in 
the aquifuge for all the 12 boreholes are listed and the classification standard (Table 6.10) is based on Meng's research (Meng et al., 2012).

Table 6.8

Surveyed geological data for the 12 boreholes

\begin{tabular}{|c|c|c|c|c|c|c|c|}
\hline $\begin{array}{c}\text { Borehole } \\
\text { s }\end{array}$ & P1 & $\mathbf{P} 2$ & P3 & P4 & P5 & P6 & P7 \\
\hline LK1 & $\begin{array}{l}0.1- \\
0.5\end{array}$ & 2.797 & 43.40 & Mudstone type & 208.95 & $\begin{array}{c}\text { High } \\
\text { complexity }\end{array}$ & $\begin{array}{c}\text { Medium } \\
\text { supplemen }\end{array}$ \\
\hline LK2 & $<0.1$ & 1.300 & 41.87 & Sandstone type I & 358.229 & $\begin{array}{l}\text { Very high } \\
\text { complexity }\end{array}$ & $\begin{array}{c}\text { Strong } \\
\text { supplemen }\end{array}$ \\
\hline LK3 & $\begin{array}{c}0.1- \\
0.5\end{array}$ & 1.509 & 63.95 & $\begin{array}{c}\text { Mudstone- } \\
\text { siltstone }\end{array}$ & 360.747 & $\begin{array}{l}\text { Very high } \\
\text { complexity }\end{array}$ & $\begin{array}{c}\text { Strong } \\
\text { supplemen }\end{array}$ \\
\hline LK4 & $\begin{array}{l}0.1- \\
0.5\end{array}$ & 1.202 & 28.87 & $\begin{array}{l}\text { Mudstone- } \\
\text { sandstone }\end{array}$ & 362.199 & $\begin{array}{l}\text { Very high } \\
\text { complexity }\end{array}$ & $\begin{array}{c}\text { Strong } \\
\text { supplemen }\end{array}$ \\
\hline LK5 & $\begin{array}{l}0.5- \\
1.0\end{array}$ & 2.191 & 56.59 & $\begin{array}{l}\text { Mudstone- } \\
\text { sandstone }\end{array}$ & 305.008 & $\begin{array}{c}\text { High } \\
\text { complexity }\end{array}$ & $\begin{array}{c}\text { Strong } \\
\text { supplemen }\end{array}$ \\
\hline LK6 & $<0.1$ & 2.656 & 40.41 & $\begin{array}{l}\text { Mudstone- } \\
\text { sandstone }\end{array}$ & 247.94 & $\begin{array}{c}\text { Medium } \\
\text { complexity }\end{array}$ & $\begin{array}{c}\text { Strong } \\
\text { supplemen }\end{array}$ \\
\hline LK7 & $<0.1$ & 0.000 & 49.44 & Sandstone type I & 510.611 & $\begin{array}{c}\text { Medium } \\
\text { complexity }\end{array}$ & $\begin{array}{c}\text { Strong } \\
\text { supplemen }\end{array}$ \\
\hline LK8 & $\begin{array}{c}0.1- \\
0.5\end{array}$ & 1.626 & 63.95 & Sandstone type II & 350.174 & $\begin{array}{l}\text { Very high } \\
\text { complexity }\end{array}$ & $\begin{array}{c}\text { Strong } \\
\text { supplemen }\end{array}$ \\
\hline LK9 & $>1.0$ & 2.602 & 43.49 & Mudstone type & 248.112 & $\begin{array}{c}\text { High } \\
\text { complexity }\end{array}$ & $\begin{array}{c}\text { Medium } \\
\text { supplemen }\end{array}$ \\
\hline LK10 & $\begin{array}{l}0.5- \\
1.0\end{array}$ & 2.394 & 43.76 & $\begin{array}{l}\text { Mudstone- } \\
\text { sandstone }\end{array}$ & 276.483 & $\begin{array}{c}\text { High } \\
\text { complexity }\end{array}$ & $\begin{array}{c}\text { Strong } \\
\text { supplemen }\end{array}$ \\
\hline LK11 & $<0.1$ & 1.940 & 36.05 & Mudstone type & 328.691 & $\begin{array}{c}\text { High } \\
\text { complexity }\end{array}$ & $\begin{array}{c}\text { Strong } \\
\text { supplemen }\end{array}$ \\
\hline LK12 & $<0.1$ & 2.825 & 43.55 & Mudstone type & 204.925 & $\begin{array}{c}\text { High } \\
\text { complexity }\end{array}$ & $\begin{array}{c}\text { Medium } \\
\text { supplemen }\end{array}$ \\
\hline
\end{tabular}


Table 6.9

The proportion of each lithology in the aquifuge

\begin{tabular}{lccc}
\hline Boreholes & $\begin{array}{c}\text { Proportion of sandstone } \\
\text { in the aquifuge }\end{array}$ & $\begin{array}{c}\text { Proportion of mudstone } \\
\text { in the aquifuge }\end{array}$ & $\begin{array}{c}\text { Proportion of siltstone in } \\
\text { the aquifuge }\end{array}$ \\
\hline LK1 & $27.47 \%$ & $67.43 \%$ & $5.10 \%$ \\
LK2 & $75.44 \%$ & $13.07 \%$ & $11.48 \%$ \\
LK3 & $10.51 \%$ & $54.88 \%$ & $34.61 \%$ \\
LK4 & $52.39 \%$ & $36.99 \%$ & $10.62 \%$ \\
LK5 & $57.44 \%$ & $38.74 \%$ & $3.82 \%$ \\
LK6 & $34.90 \%$ & $45.16 \%$ & $19.96 \%$ \\
LK7 & $66.67 \%$ & $5.20 \%$ & $28.13 \%$ \\
LK8 & $54.00 \%$ & $25.42 \%$ & $20.58 \%$ \\
LK9 & $13.86 \%$ & $65.62 \%$ & $20.52 \%$ \\
LK10 & $13.27 \%$ & $41.51 \%$ & $45.22 \%$ \\
LK11 & $4.17 \%$ & $66.58 \%$ & $29.24 \%$ \\
LK12 & $13.35 \%$ & $66.24 \%$ & $20.41 \%$ \\
\hline
\end{tabular}

Table 6.10

Lithology type of aquifuge and its resistance to water pressure (Meng et al., 2012)

\begin{tabular}{|c|c|c|c|c|}
\hline $\begin{array}{l}\text { Lithology } \\
\text { type }\end{array}$ & $\begin{array}{l}\text { Mudstone } \\
\text { content K } \\
(\%) \\
\end{array}$ & Main lithology & Main lithofacies & $\begin{array}{c}\text { Resistance } \\
\text { to water } \\
\text { pressure } \\
\end{array}$ \\
\hline Mudstone & $\geq 65$ & $\begin{array}{l}\text { Sand-shale, silty } \\
\text { mudstone and coal } \\
\text { seam }\end{array}$ & $\begin{array}{c}\text { Floodplain, swamp facies, peat } \\
\text { swamp facies and lagoon bay } \\
\text { facies }\end{array}$ & Weak \\
\hline $\begin{array}{l}\text { Mudstone- } \\
\text { sandstone }\end{array}$ & $35-65$ & $\begin{array}{l}\text { Siltstone, silty } \\
\text { mudstone and } \\
\text { mudstone }\end{array}$ & $\begin{array}{l}\text { Interdistributary, floodplain } \\
\text { and natural levee facies }\end{array}$ & Medium \\
\hline Sandstone & $<35$ & $\begin{array}{l}\text { Sandstone, siltstone } \\
\text { and limestone }\end{array}$ & $\begin{array}{l}\text { Distributary channel, crevasse } \\
\text { splay and miniature channel } \\
\text { facies or shallow sea deposits }\end{array}$ & Strong \\
\hline
\end{tabular}




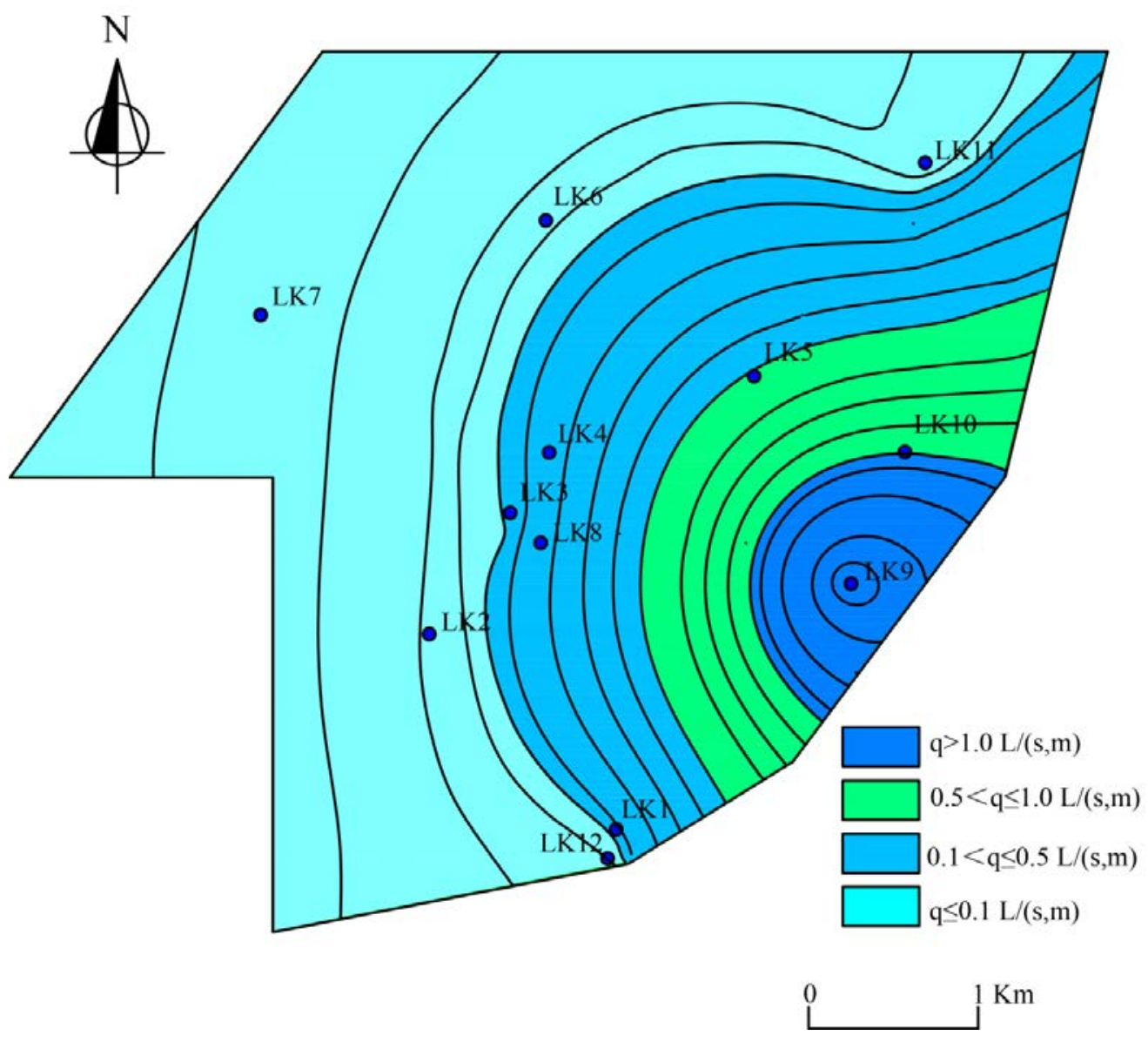

Figure 6.4 The water output contour map of the Carboniferous Limestone aquifer in Liyazhuang coal mine.

As mentioned in section 6.2.4, currently fractal analysis method has already successfully applied by several previous studies to characterize the complexity of the fault distribution, so in this thesis this method is used for characterizing the fault distribution complexity in Liyazhuang coal mine. By dividing the two-dimensional fault distribution map (Figure 6.5) into 30 elements ( $1 \mathrm{~km} \times 1 \mathrm{~km}$ for each element), the box-counting method (Liebovitch and Toth 1989; Foroutan-pour et al., 1999) is used for computing the FD of each element and counting the number of interactions and endpoints (I+E) of each element, and the final results are displayed in Figure 6.6. The classification standards to FD and I+E here are mainly based on Xu's research (1996) and Wu's research (2011) respectively. Groundwater supplement in Liyazhuang coal mine mainly depends on rainfall infiltration and sometimes together with the infiltration of surface water bodies. In the surface of Liyazhuang coal mine there are some seasonal rivers 
which with water flow in rainy seasons. In Figure 6.7, the distribution of these small rivers are showed. As can be seen from this figure, the entire coalfield is almost completely covered by these small rivers, for this reason, we consider all boreholes in the coalfield as strong water supplement and medium water supplement.

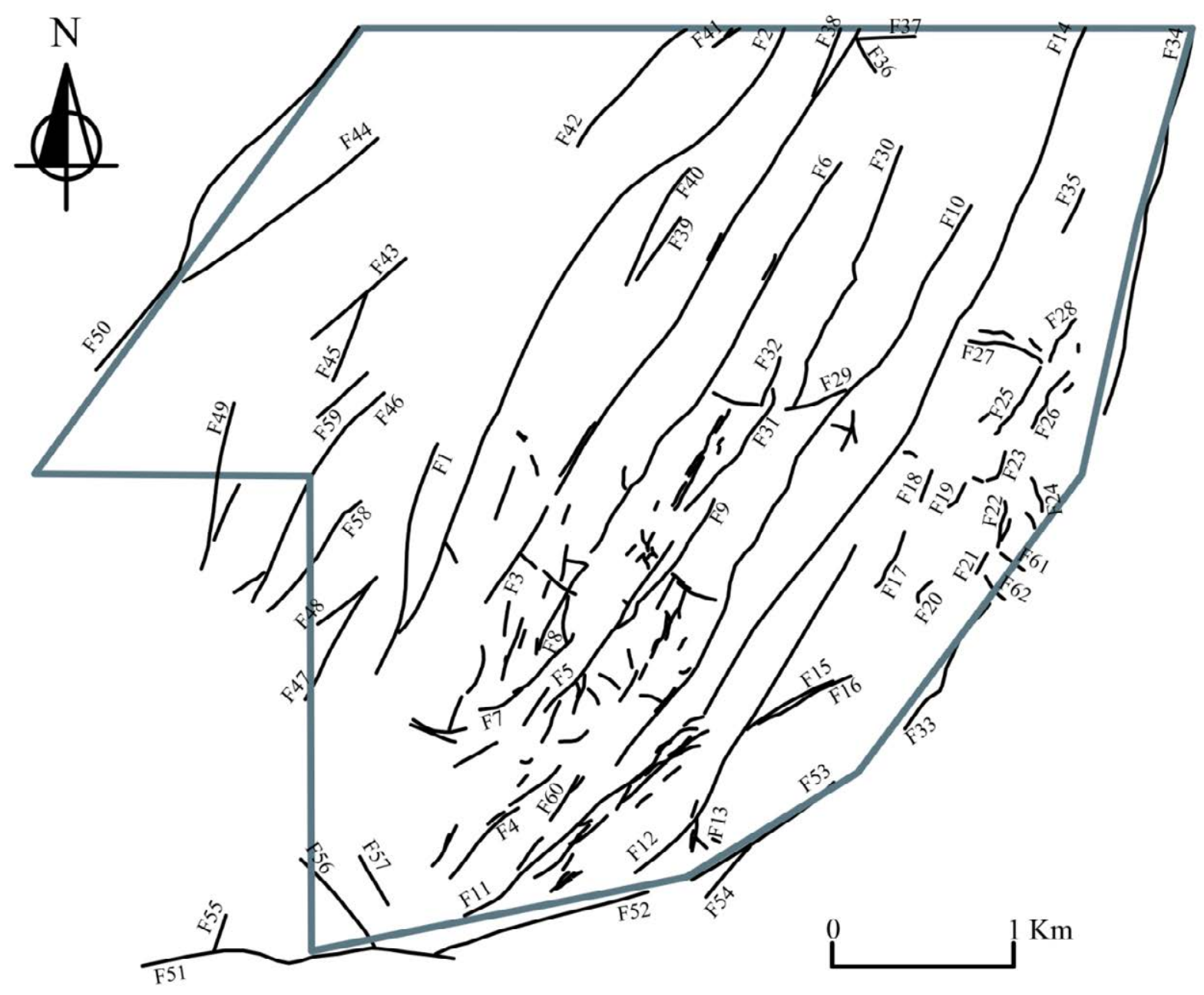

Figure 6.5 The two-dimensional fault traces of Liyazhuang coal mine 

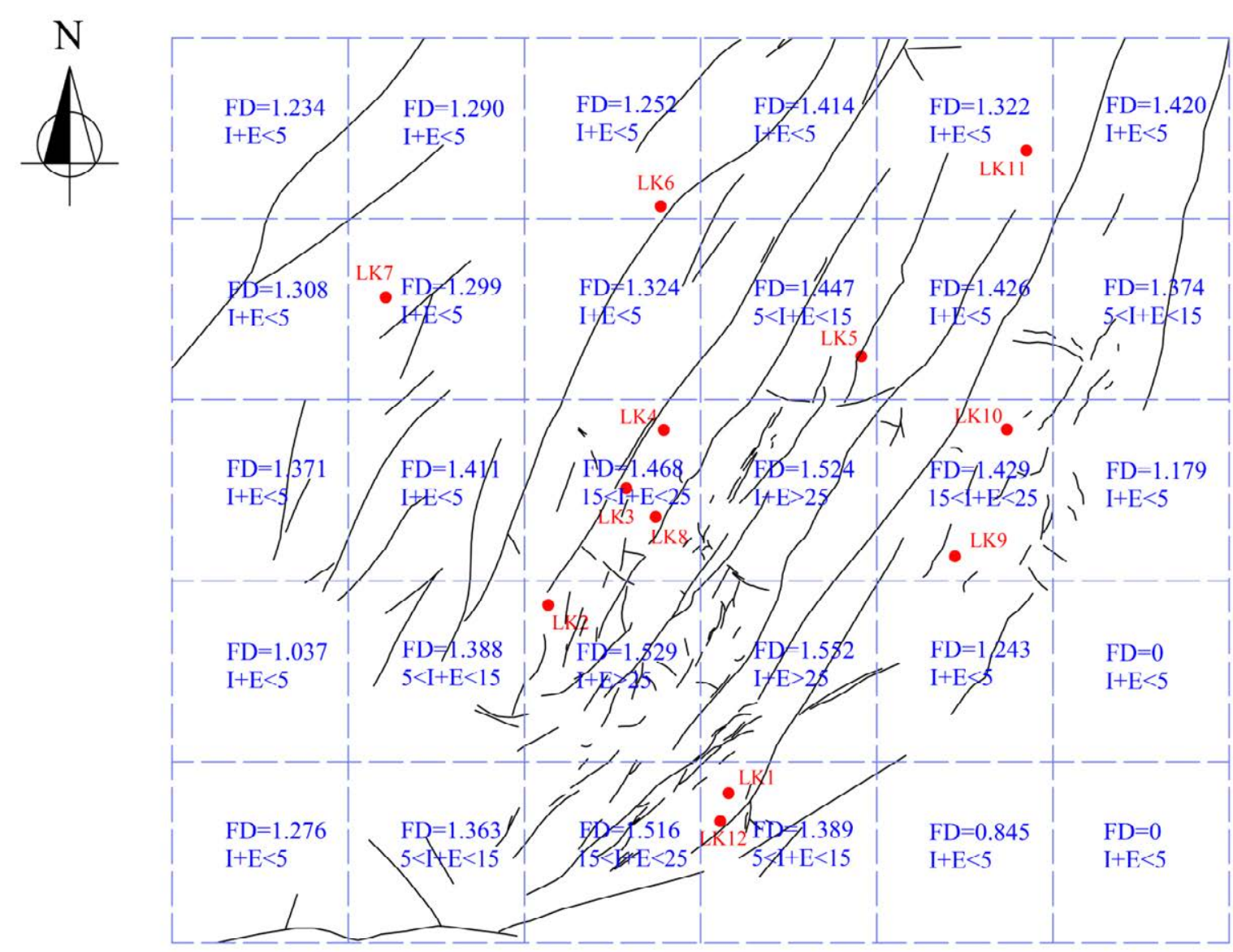

0 $1 \mathrm{Km}$

Figure 6.6 The final calculation results of the FD and I+E based on the two-dimensional fault traces. 


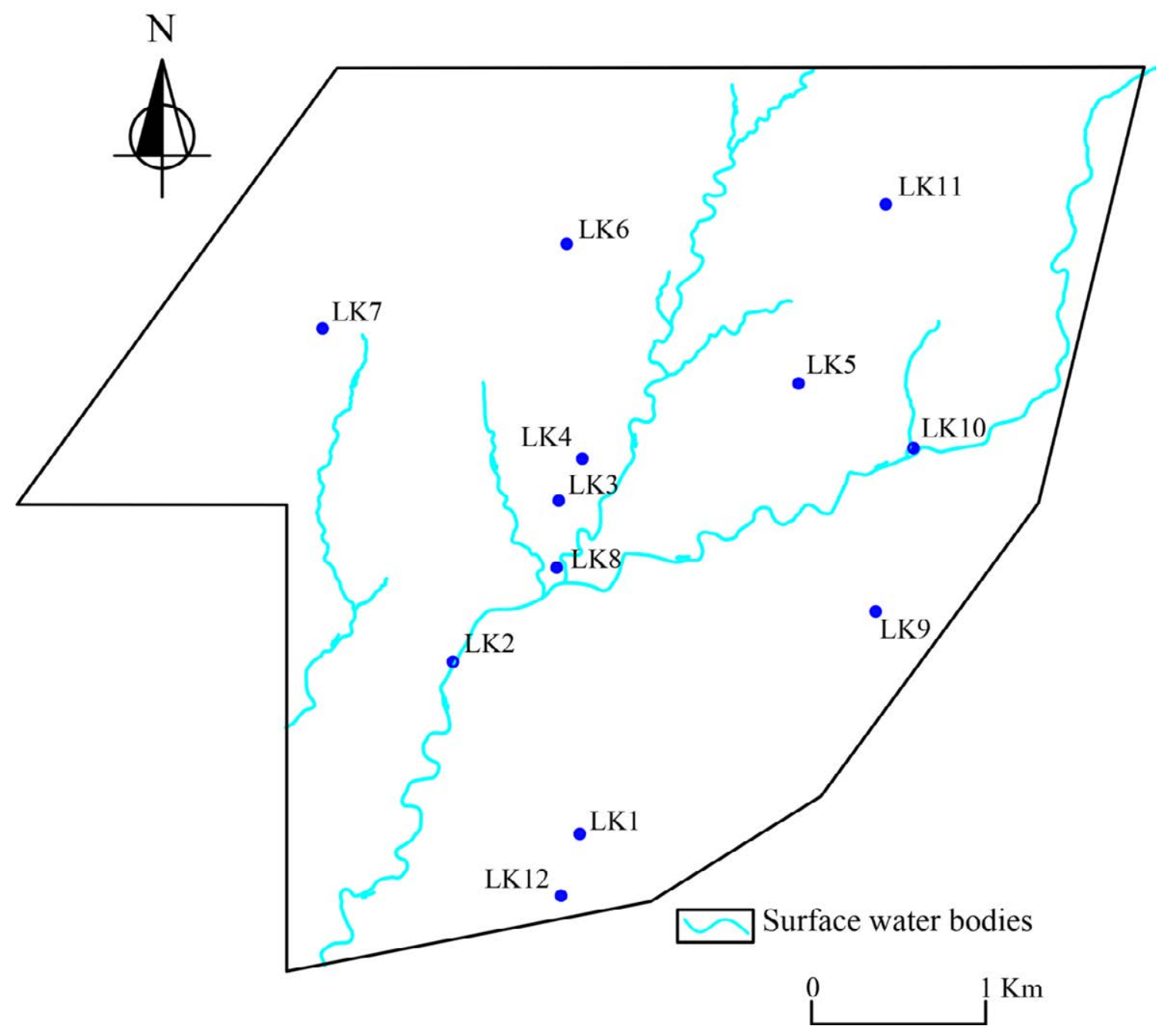

Figure 6.7 The distribution of surface water bodies in Liyazhuang coal mine.

With all the geological data of boreholes as listed in Table 6.8, water inrush index for each borehole can then be calculated by using the above developed method. The calculation steps are as follows: firstly, rating each corresponding parameter of Table 6.8 according to Table 6.7, together with the normalized weighting coefficients obtained in Table 6.6 we then can compute water inrush index of each borehole by means of Eq. 6.4. The final computing results are listed in Table 6.11. Finally through the interpolation of all calculated water inrush indexes at all the 12 boreholes then the water inrush risk contour map for the whole mining district is obtained, which is shown in Figure 6.8.

As it can be seen from Figure 6.8, the risk contour map shows that, in general, No.2 coal seam has a moderate risk of water inrush because all the water inrush indices are between 40 and 60 . 
To view Liyazhuan coalfield as a whole, the eastern part is more risky than the western part. So the assessment result suggests that more water-inrush prevention measures should be taken in the eastern coalfield in the process of mining practices.

Table 6.11

The evaluation results of the 12 boreholes

\begin{tabular}{lllllllll}
\hline \multirow{2}{*}{ Boreholes } & \multicolumn{7}{c}{ Parameter rating value } & Water \\
\cline { 2 - 7 } & P1 & P2 & P3 & P4 & P5 & P6 & P7 & $\begin{array}{c}\text { inrush } \\
\text { index }\end{array}$ \\
\hline LK1 & 1 & 1 & 2 & 3 & 1 & 2 & 2 & 51.906 \\
LK2 & 1 & 0 & 2 & 0 & 1 & 3 & 3 & 50.953 \\
LK3 & 1 & 0 & 0 & 2 & 1 & 3 & 3 & 50.001 \\
LK4 & 1 & 0 & 3 & 2 & 1 & 3 & 3 & 57.144 \\
LK5 & 1 & 1 & 1 & 2 & 1 & 2 & 3 & 55.239 \\
LK6 & 0 & 1 & 2 & 2 & 1 & 1 & 3 & 47.62 \\
LK7 & 0 & 0 & 2 & 0 & 2 & 1 & 3 & 40.001 \\
LK8 & 1 & 0 & 0 & 1 & 1 & 3 & 3 & 48.096 \\
LK9 & 1 & 1 & 2 & 3 & 1 & 2 & 2 & 51.906 \\
LK10 & 1 & 1 & 2 & 2 & 1 & 2 & 3 & 57.62 \\
LK11 & 0 & 0 & 3 & 3 & 1 & 2 & 3 & 49.049 \\
LK12 & 0 & 1 & 2 & 3 & 1 & 2 & 2 & 46.668 \\
\hline Maximum rating value & 3 & 3 & 3 & 3 & 3 & 3 & 3 & 100 \\
\hline Weighted coefficients & 5.23 & 7.61 & 2.38 & 1.90 & 3.81 & 4.76 & 7.61 & \\
\hline
\end{tabular}



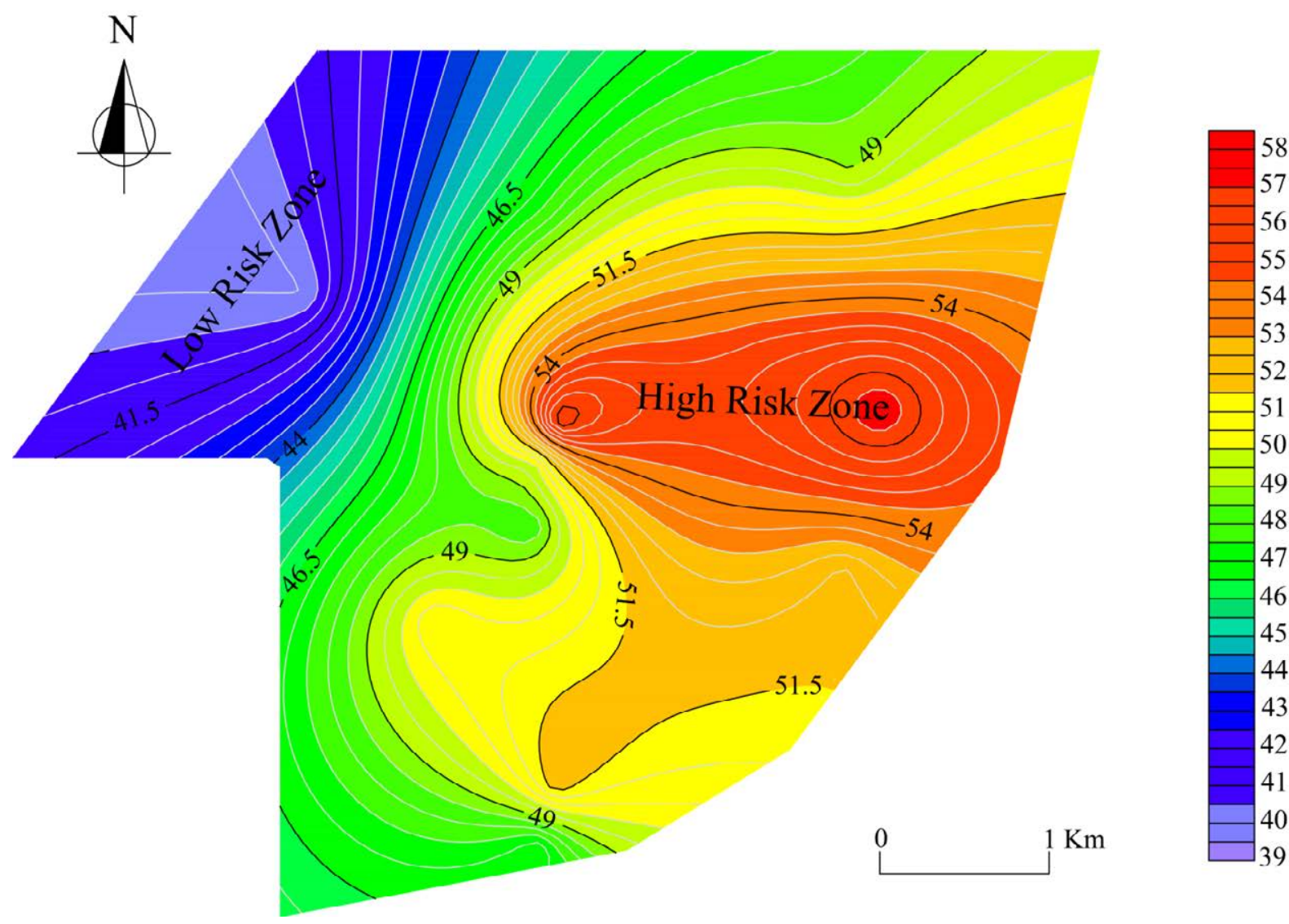

Figure 6.8 The water inrush risk contour map of Liyazhuang coal mine. 


\subsection{Summary of the chapter}

In this chapter, by means of the RES, a new method for safety pre-assessment of floor water inrush was developed. By selecting the water output of aquifer, the aquifer pressure, the aquifuge thickness, the lithology type of aquifuge, the depth of coal seam, the fault distribution complexity and the water source supplement as seven main parameters, an interaction matrix was constructed to analyze the floor water inrush system. The constructed matrix was coded through the ESQ method and the coded results indicate that in the water inrush system the aquifer pressure and the water source supplement are two of the most interactive parameters, which means these two parameters have the most impact on the water inrush system. In addition, the coded results also indicate that the depth of coal seam is the most dominant parameter and its variation will has the most influence on the other parameters.

In order to show how the developed method can be applied in real mining practices, a safety preassessment of floor water inrush was conducted in Liyazhuang coal mine. Through calculating the water inrush indices of the 12 boreholes that distributed in the whole coalfield, a water inrush safety map for the whole coalfield was obtained by using the method of interpolation, and in such a map which part of the coalfield has the highest risk of occurring water inrush hazards was clearly displayed. 



\section{Chapter 7 Solving the Problem of Identifying Water Sources Rapidly After an Inrush Accident}

\subsection{Introduction}

In the previous chapters (Chapter 4 - Chapter 6), the thesis mainly focus on the research on what are the mechanisms of the fault-induced water inrush and how can we conduct an effective risk assessment for such a kind of water hazard. However, as it has been discussed in the previous chapters, water inrush in underground mining is a complex geological hazard and so many factors and interactions between factors are related. No matter how accurate a risk assessment approach is, it can not $100 \%$ guarantee that every water inrush accident can be accurately predicted. So far, inrush accidents still occur every year all over the world, especially in developing countries. For inrush accidents in underground mining, the first and also the critical step of controlling the accident is to find out the related inrush sources, accurately identifying which aquifer or which water body is directly related to the inrush accident can help to estimate the inrush scale and then to take further pumping measures.

In this chapter, an ANN-based approach about how to indentify water sources will be proposed and developed.

\subsection{The basis of using hydrochemical characteristics to identify water sources}

In present water source identification technology, using hydrochemical characteristics to recognize water source has been widely used. To find out the water types (compounds, isotopes, trace elements and hydrochemical types) that characterize the characteristics of each aquifer is the basis of water source identification.

In general, different underground aquifers have different chemical and isotopic compositions mainly for two reasons. First of all water movements and exchanges between aquifers will 
result in corresponding chemical and isotopic compositions changes; second, in the process of movements and water exchanges, the corresponding physical and chemical interactions between water and surrounding strata will also lead to the change of chemical and isotopic compositions. Of course, the water exchanges between underground aquifers are not unlimited, When the dynamic equilibrium is formed, the hydrochemical characteristics of each aquifers remain stable. Therefore, under different geological and hydrogeological conditions, generally every underground aquifer has different hydrochemical characteristics, which provides a basis for identifying the water sources.

Compared with the surface water bodies, groundwater flow is quite slow, which leads to a long time of mutual contact and interaction between water and surrounding rocks. Coupled with the different causes of groundwater often have different original chemical composition, so actually aquifers in different environmental geologies could have great differences in hydrochemical characteristics. There are six most widely distributed ions in groundwater including $\mathrm{Na}^{+}+\mathrm{K}^{+}, \mathrm{Ca}^{2+}, \mathrm{Mg}^{2+}, \mathrm{Cl}^{-}, \mathrm{SO}_{4}{ }^{2-}$ and $\mathrm{HCO}_{3}{ }^{-}$. They are commonly referred to as conventional ions or conventional components, which account for more than $90 \%$ of all dissolved salts and also determine the chemical type of water.

\subsection{The limitations of traditional used methodologies}

As in this chapter a new approach is attempted to be used for water source recognition, so it is necessary to analyze why a new approach is needed and what are the limitations of the traditional used methodologies.

Using water temperature way to identify the water sources has the advantages of simplicity and high efficiency, but it will get into trouble if the change of geothermal gradient is not very obvious. Therefore, it cannot be applied in the situation where the lithological characteristics are homogeneous in the same coalfield or where the hard and compact rock has a high heat conductivity.

For hydrogeological analysis approaches, subjective judgments often affect the final identification results. Engineers often subjectively hypothesize, according to their previous 
experiences when accidents happened, which aquifers associated with the water inrush should be analyzed. This is why it is difficult to make an objective recognition considering all the possible aquifers.

Non-linear mathematical methods are more objective but the process is so complex and each of them has inherent disadvantages. For example, the methodology of fuzzy mathematics cannot be used in every mine area in common because the weight distribution of evaluating indicators should consider the special circumstances of each region, no matter the over standard weight, standard deviation weight or even the differential weighting method cannot resolve the problem. The grey-system method has also its weakness since its theory determines that it can only be applied for positively correlated analysis.

Clustering method is an unsupervised learning method, which is more suitable for cluster analysis with large samples. For water source recognition problem, it is a small sample problem, and there will be a high misjudgment rate if we use clustering method.

\subsection{Methodology of ANN}

\subsubsection{Back propagation neural network}

Among all neural networks, the BP neural network, independently discovered by Rumelhart, Hinton and Williams (1986) and David Parker (1985) has been widely used after a detailed description by James McClelland and David Rmelhar (1985). It is a kind of forward neural network with multi-layer neurons. Each layer contains a number of neurons, and neurons between the layers interconnected through weights and thresholds. It belongs to the supervised learning algorithm, and the essence of the algorithm is by constantly comparing the network outputs with target vectors to adjust the network weights and thresholds to achieve the minimization of the mean square error (MSE).

The network training process starts by giving a random set of weights and thresholds, then the output is calculated in feed-forward way. Of course, the MSE is relatively big in the first step, that will force the weights and thresholds of the output layer to be changed gradually by means 
of gradient descent method, and then the change propagate back forward until the input layer over the network to update the weights and thresholds. When all the weights and thresholds are updated, the first iteration is completed and network will proceed to the second one with a new input. Computing process like this is repeated until the convergence of system error.

\subsubsection{Detailed algorithm}

In order to ensure the network has strong capability of forecasting, establishing an appropriate neural network based on the actual project is required. Once the structure of the network of a practical project is determined, by training the neural network with training sample sets and then the network will be able to establish a mapping from input to output, after the training, the trained network then can be applied to realize pattern recognition. Description in detail about the algorithm as the following steps (also illustrated in Figure 7.1):

Step one: according to the input vector $\boldsymbol{p}=\left(p_{1}, p_{2}, \cdots, p_{n}\right)$ and the target vector $\boldsymbol{t}=$ $\left(t_{1}, t_{2}, \cdots, t_{q}\right)$ to determine the nodes of the input layer, the hidden layer and the output layer, supposing they are $\mathrm{n}, \mathrm{m}$ and q respectively. Initializing the connection weights and the thresholds as $w_{i j}, w_{j k}, \boldsymbol{a}$ and $\boldsymbol{b}$, all of them are tiny numbers, which can be obtained by randomizer of the computer.

Step two: according to the input vector $\boldsymbol{p}$, the output of the hidden layer $y_{\mathrm{j}}$ can be calculated by Eq.7.1 as:

$$
y_{j}=f\left(\sum_{i=1}^{n} w_{i j} p_{i}-a_{j}\right) j=1,2,3, \cdots, m
$$

In this formula: $w_{i j}$ denotes the connection weights from the input layer to the hidden layer, and $a_{j}$ is the threshold of the hidden layer, $f$ represents the activation function of the hidden layer whose mathematical expression is $f(x)=\left(1+e^{-x}\right)^{-1}$.

Step three: according to $y_{j}$, outputs of the output layer can be calculated by Eq. 7.2 as: 


$$
h_{k}=\mathrm{g}\left(\sum_{j=1}^{m} w_{j k} y_{\mathrm{j}}-b_{k}\right) k=1,2,3, \cdots, q
$$

In Eq. 7.2, $w_{j k}$ denote the weights from the hidden layer to the output layer, $b_{k}$ is the threshold of the output layer, $g$ is the activation function of the output layer and the mathematical expression is $\mathrm{g}(\mathrm{x})=\mathrm{x}$.

Step four: supposing that $\boldsymbol{e}=\frac{1}{2} \sum_{k=1}^{q}\left(t_{k}-h_{k}\right)^{2}$ is defined as the error function of the network, then the increments of the weights and the thresholds can be calculated by Eq. 7.3.

$$
\begin{gathered}
\Delta w_{i j}=-\eta \frac{\partial e}{\partial w_{i j}} \\
\Delta w_{j k}=-\eta \frac{\partial e}{\partial w_{j k}} \\
\Delta a_{j}=-\eta \frac{\partial e}{\partial a_{j}} \\
\Delta b_{k}=-\eta \frac{\partial e}{\partial k}
\end{gathered}
$$

Where $\eta$ denotes the rate of network learning, which is established as a small number in interval $[0,1]$.

Step five: by means of increments obtained from Eq. 7.3, the weights and thresholds then can be updated as Eq. 7.4- Eq. 7.7.

$$
\begin{gathered}
w_{i j}=w_{i j}-\eta \Delta w_{i j}=w_{i j}-\eta y_{j}\left(1-y_{j}\right) p_{i} \sum_{k=1}^{q} w_{j k} e_{k} \\
w_{j k}=w_{j k}-\eta \Delta w_{j k}=w_{j k}-\eta y_{j} e_{k} \\
a_{j}=a_{j}-\eta \Delta a_{j}=a_{j}-\eta y_{j}\left(1-y_{j}\right) \sum_{k=1}^{q} w_{j k} e_{k} \\
b_{k}=b_{k}-\eta \Delta b_{k}=b_{k}-e_{k}
\end{gathered}
$$

Where $e_{k}=t_{k}-h_{k}$ denotes the single error of iteration. 
Step six: Through Eq. 7.8 the global error is calculated to know whether the global error reaches the accuracy requirement. If it does not reach the minimum mean square error, coming back to step (2).Of course, iteration will come to end if it does.

$$
E=\frac{1}{2 n} \sum_{i=1}^{n} \sum_{k=1}^{q}\left(t_{k}-h_{k}\right)^{2}
$$

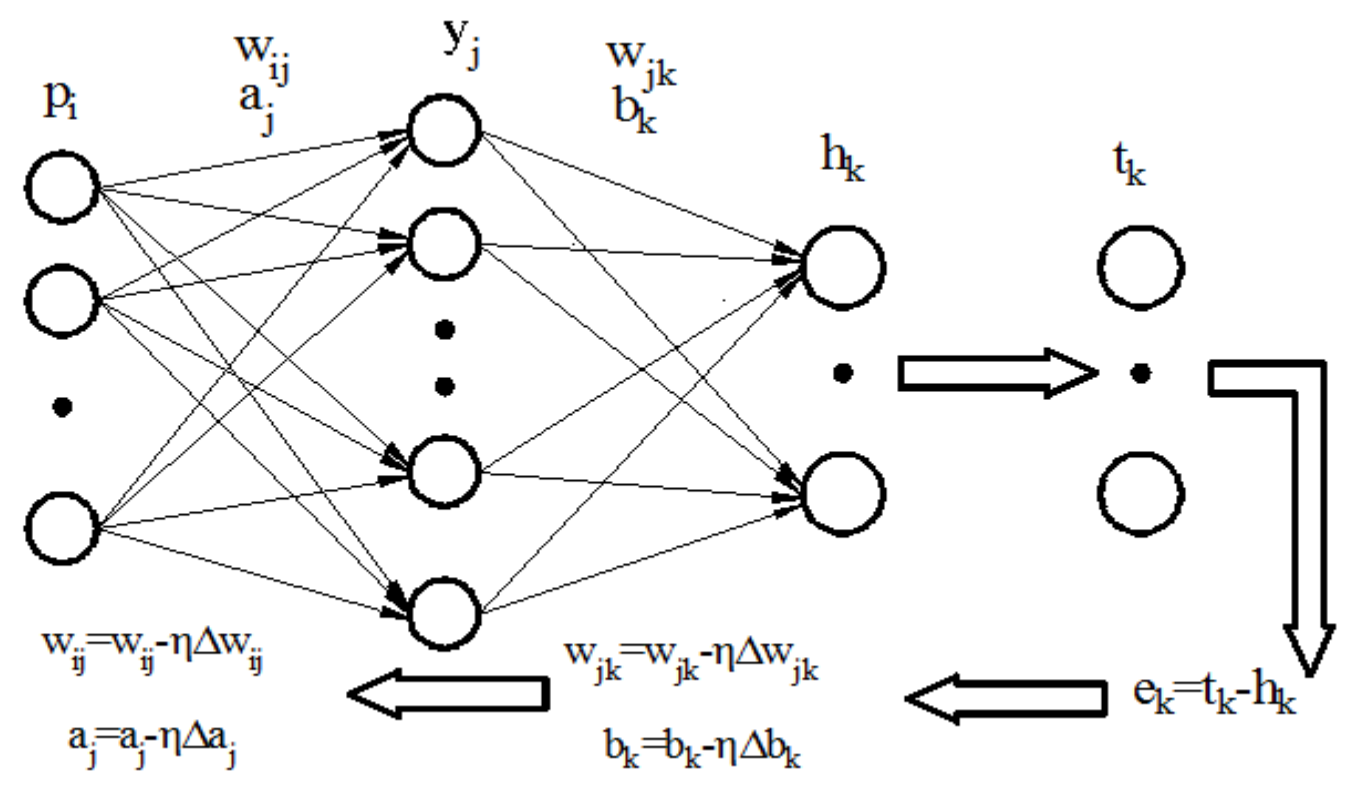

Figure.7.1. The structure of BP neural network and its algorithm in detail.

\subsection{A case study from Jiaozuo mine area}

\subsubsection{The establishing and training of ANN}

Groundwater in aquifers usually has distinct hydrochemical characteristics because each of them is supplied by different sources or their draining conditions are significant differences. For example, aquifers belonging to the coal floor always have high concentration of $\mathrm{Ca}^{2+}$, $\mathrm{Na}^{+} \mathrm{K}^{+}, \mathrm{Mg}^{2+}$ and $\mathrm{HCO}^{-}$, sandstone strata in coal roof mainly have $\mathrm{Na}^{+}, \mathrm{K}^{+}$, and $\mathrm{SO}_{4}{ }^{2-}$, in mined-out areas, its content of $\mathrm{SO}_{4}{ }^{2-}$ always in a high level because it is a long 
time in a state of closing. Therefore, by analyzing the concentration of characteristic ions of water samples, which aquifer is connected with the water inrush could be identified.

In this thesis, Jiaozuo mine area, which is located in Henan province in China, has been selected as the research object. In this mine area, nine of the major producing mines are frequently threatened by water-inrush accidents and a total of more than 700 times of water inrushes have happened in the coal production history. Among them, there were 61 times the inrush-water volume was greater than $10 \mathrm{~m}^{3} / \mathbf{m i n}$ and the maximum inrushing volume up to $320 \mathbf{m}^{3} / \mathbf{m i n}$. the Quaternary sandstone aquifer, the Permian shale aquifer, the Ordovician limestone aquifer and the Carboniferous limestone aquifer are four of the major aquifers related to water inrush. In 2003, based on 39 water samples collected from four major aquifers in this mine area, a complex mathematical model was established by Zhang (2003) to achieve water-inrush sources recognition, but the model was so complicated and also involved a lot of manual calculations. Therefore, in this thesis, we try to establish a BP neutral network (Figure 7.2) to replace his model and to make sources recognition easier.

The neural network model used in this paper consists of three layers, and the number of neurons in each layer is 6,20 and 4 respectively. Where the 6 neurons in input layer denote the concentrations of $\mathrm{Na}^{+}+\mathrm{K}^{+}, \mathrm{Ca}^{2+}, \mathrm{Mg}^{2+}, \mathrm{Cl}^{-}, \mathrm{SO}_{4}{ }^{2-} \mathrm{HCO}_{3}^{-}, 20$ is the number of neurons of the hidden layer and the 4 neurons in output layer represents the 4 elements of the output vector which is expressed as $\mathrm{X}=(\mathrm{X} 1, \mathrm{X} 2, \mathrm{X} 3, \mathrm{X} 4)$.

Selecting 35 sample (Table 7.1) sets as training data from all of the 39 water samples and choosing the remaining 4 as the forecasting objects. In addition, 35 samples that belong to 4 aquifers are divided into 4 different vectors in the form of $\mathrm{T}=(\mathrm{T} 1, \mathrm{~T} 2, \mathrm{~T} 3, \mathrm{~T} 4)$, which are the target vectors of neural network. For example, vector $(1,0,0,0)$ is used for representing the 6 water samples which belong to the Ordovician limestone aquifer (Aquifer I ). In the same way, vector $(0,1,0,0)$ indicates the 12 samples of the Carboniferous limestone aquifer (Aquifer II), vector $(0,0,1,0)$ denotes the 9 water samples which belong to the Permian shale aquifer in the roof (Aquifer III) and vector ( 0 , $0,0,1)$ is used for representing the 8 water samples of the Quaternary sandstone aquifer (AquiferIV). After establishing the structure of the network and determining the training samples, combined with MATLAB software to program it for network testing and forecasting. 
Table 7.1

The training sample sets and their vector representation.

\begin{tabular}{|c|c|c|c|c|c|c|c|c|c|c|c|}
\hline \multirow{2}{*}{$\begin{array}{c}\text { Sample } \\
\text { No. }\end{array}$} & \multicolumn{6}{|c|}{ Ions (Mg/L) } & \multirow{2}{*}{ Aquifer } & \multicolumn{4}{|c|}{ Vector representation } \\
\hline & $\mathrm{Na}^{+}+\mathrm{Ka}^{+}$ & $\mathrm{Ca}^{2+}$ & $\mathbf{M g}^{2+}$ & $\mathrm{Cl}^{-}$ & $\mathrm{SO}_{4}{ }^{2-}$ & $\mathrm{HCO}_{3}{ }^{-}$ & & $\mathbf{T 1}$ & $\mathbf{T} 2$ & T3 & T4 \\
\hline 1 & 11.98 & 76.15 & 15.56 & 8.5 & 26.9 & 292.84 & I & 1 & 0 & 0 & 0 \\
\hline 2 & 19.34 & 65.73 & 18.48 & 10.64 & 67.24 & 239.19 & I & 1 & 0 & 0 & 0 \\
\hline 3 & 11.5 & 84.57 & 24.81 & 19.86 & 82.61 & 253.83 & I & 1 & 0 & 0 & 0 \\
\hline 4 & 19.78 & 52.5 & 16.29 & 9.93 & 37.66 & 229.43 & I & 1 & 0 & 0 & 0 \\
\hline 5 & 35.1 & 46.2 & 17.6 & 35.8 & 43.2 & 219.9 & I & 1 & 0 & 0 & 0 \\
\hline 6 & 44.88 & 73.24 & 24.8 & 24.07 & 85.97 & 303.56 & I & 1 & 0 & 0 & 0 \\
\hline 7 & 10.29 & 61.23 & 29.33 & 12.16 & 47.46 & 309.85 & II & 0 & 1 & 0 & 0 \\
\hline 8 & 10.64 & 59.3 & 28.4 & 12.59 & 34.7 & 291.68 & II & 0 & 1 & 0 & 0 \\
\hline 9 & 8.0 & 69.3 & 26.39 & 10.96 & 43.88 & 295.24 & II & 0 & 1 & 0 & 0 \\
\hline 10 & 6.45 & 63.43 & 24.1 & 9.24 & 41.9 & 266.34 & II & 0 & 1 & 0 & 0 \\
\hline 11 & 8.3 & 63.5 & 26.9 & 11.19 & 43.85 & 282.52 & II & 0 & 1 & 0 & 0 \\
\hline 12 & 7.1 & 63 & 24.7 & 7.35 & 37.8 & 266.13 & II & 0 & 1 & 0 & 0 \\
\hline 13 & 7.7 & 67.1 & 39 & 8.82 & 46.5 & 281.57 & II & 0 & 1 & 0 & 0 \\
\hline 14 & 7 & 68.7 & 24.9 & 11.7 & 43.77 & 282.16 & II & 0 & 1 & 0 & 0 \\
\hline 15 & 17.85 & 62.96 & 17.28 & 6.68 & 23.31 & 284.57 & II & 0 & 1 & 0 & 0 \\
\hline 16 & 13.59 & 61.59 & 18.85 & 6.68 & 23.57 & 276.69 & II & 0 & 1 & 0 & 0 \\
\hline 17 & 10 & 63.87 & 32.83 & 4.06 & 65.09 & 295.87 & II & 0 & 1 & 0 & 0 \\
\hline 18 & 12.69 & 69.39 & 29.38 & 13.64 & 34.54 & 325.08 & II & 0 & 1 & 0 & 0 \\
\hline 19 & 98.1 & 3.1 & 1.1 & 23.5 & 43.84 & 638.7 & III & 0 & 0 & 1 & 0 \\
\hline 20 & 207.35 & 34.75 & 11.16 & 23.78 & 46.54 & 558.82 & III & 0 & 0 & 1 & 0 \\
\hline 21 & 311.75 & 16.25 & 2.04 & 33.58 & 20.56 & 736.76 & III & 0 & 0 & 1 & 0 \\
\hline 22 & 303.12 & 10.24 & 8.55 & 32.84 & 17.47 & 773.45 & III & 0 & 0 & 1 & 0 \\
\hline 23 & 304.82 & 5.77 & 3.61 & 40.77 & 53 & 628.96 & III & 0 & 0 & 1 & 0 \\
\hline
\end{tabular}


$\begin{array}{llllllllllll}24 & 257.23 & 0 & 0 & 27.22 & 12.24 & 428.71 & \text { III } & 0 & 0 & 1 & 0\end{array}$ $\begin{array}{llllllllllll}25 & 502.45 & 0 & 2.48 & 29.04 & 9.79 & 1105.8 & \text { III } & 0 & 0 & 1 & 0\end{array}$ $\begin{array}{llllllllllll}26 & 309.33 & 0 & 0 & 29.03 & 0 & 562.17 & \text { III } & 0 & 0 & 1 & 0\end{array}$ $\begin{array}{llllllllllll}27 & 358.58 & 10.22 & 3.72 & 32.68 & 14.69 & 691.17 & \text { III } & 0 & 0 & 1 & 0\end{array}$ $\begin{array}{llllllllllll}28 & 9.1 & 86.5 & 31.8 & 22.4 & 57.8 & 348.31 & \text { IV } & 0 & 0 & 0 & 1\end{array}$

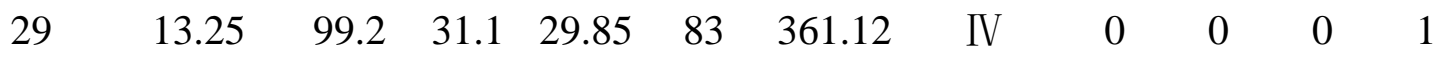
$\begin{array}{llllllllllll}30 & 9.2 & 106.7 & 39.1 & 40.1 & 69.8 & 402.1 & \text { IV } & 0 & 0 & 0 & 1\end{array}$

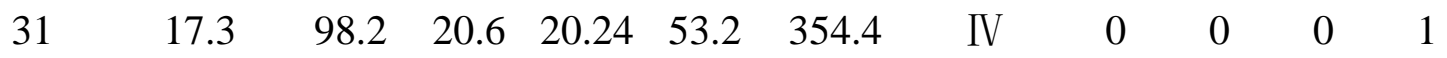

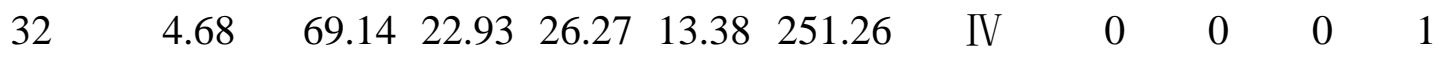

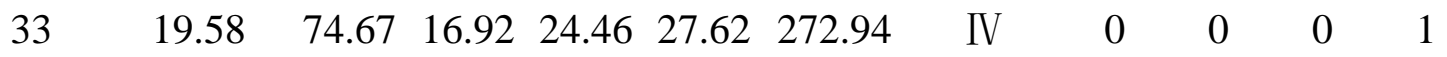

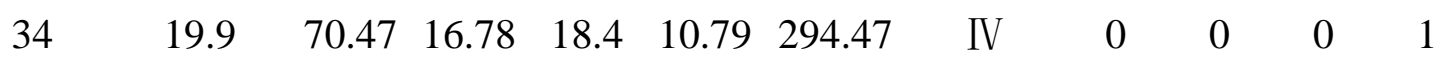

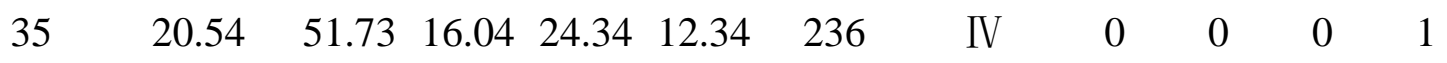

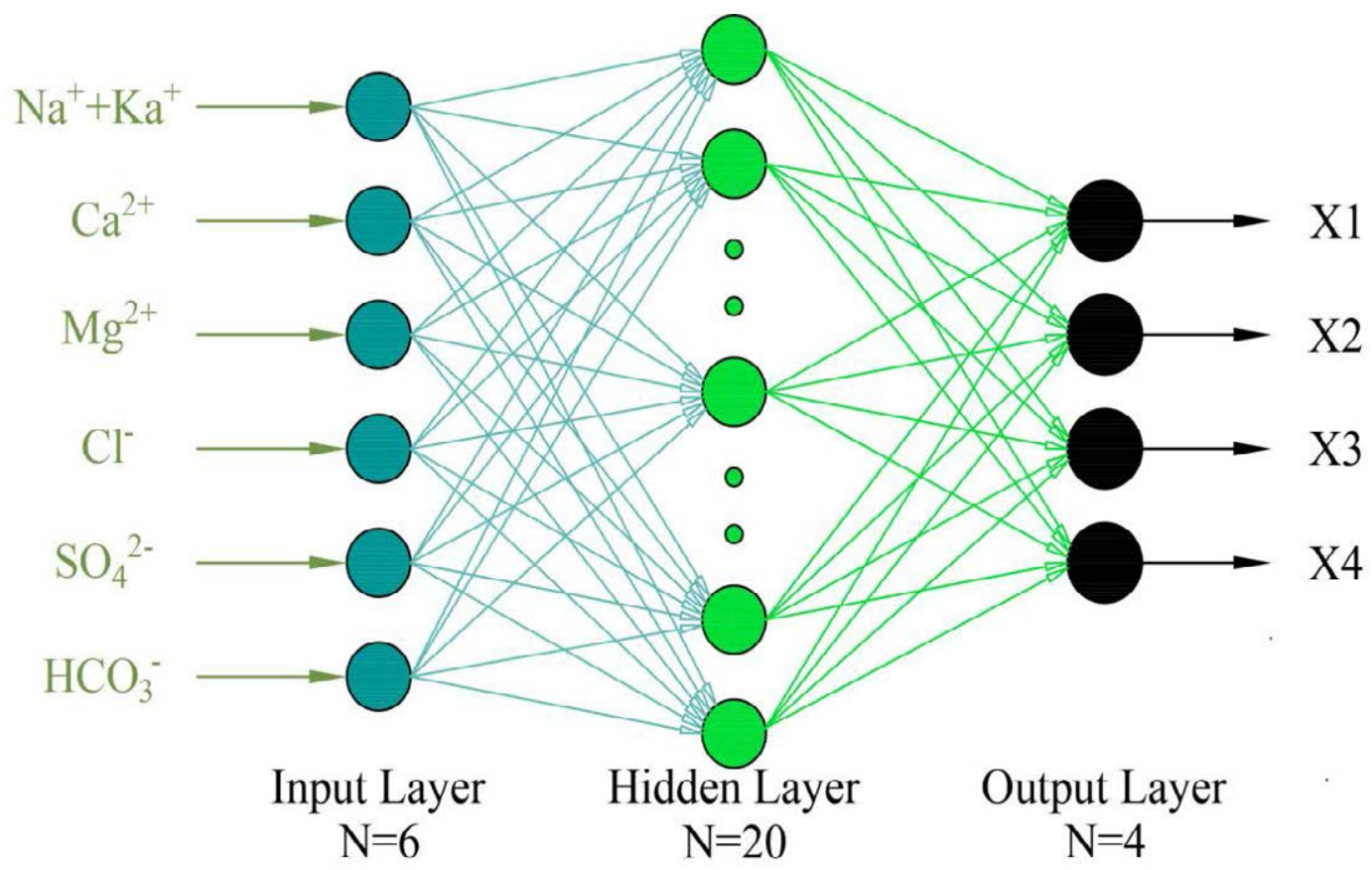

Figure.7.2. BP neural network model of water sources recognition. 


\subsubsection{The testing and forecasting processes}

Setting the goal of the minimum mean square error of the network as $1 \times 10^{-7}$, debugging the program to train the samples, the training process as shown in Figure.7.3, the network has converged to the minimum mean square error at $2.3 \times 10^{-8}$ after 17 training cycles, that is to say, the network has completed the learning and training of all samples with 17 iterations.

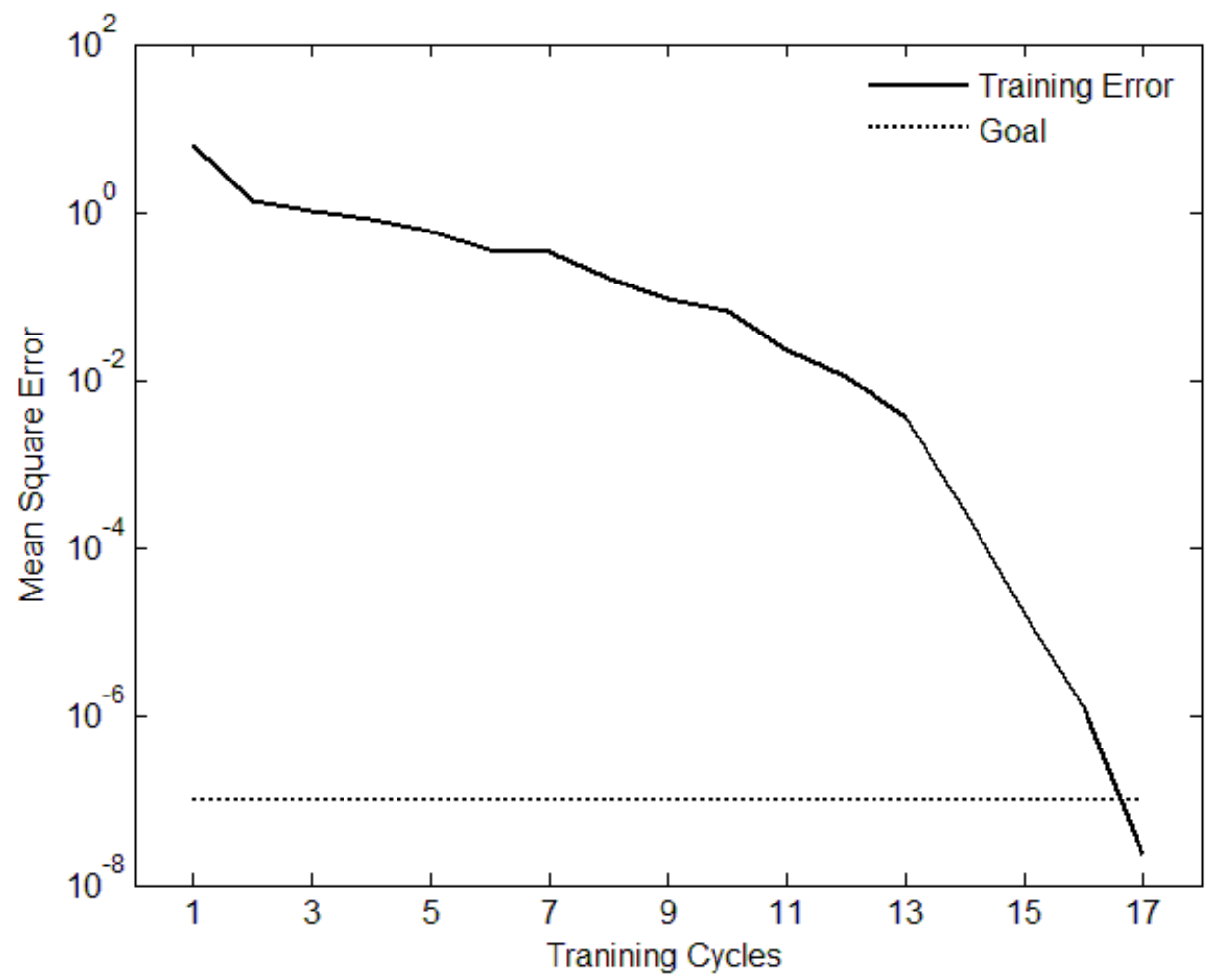

Figure.7.3. Neural network training performance

After the training process is finished, in order to test whether the trained network meets the requirements, the samples in Table 1 once again are used for testing the network, 3 samples of each aquifer are randomly selected for network testing, and the testing results are shown in Table 7.2. Comparing every element of the output vectors with elements of that 4 target vectors, the output vectors then can be classified as corresponding aquifer. The final results indicate that the correct rate of the recognition is $100 \%$. All of the 12 selected aquifers were correctly identified, which indicates that the trained network has reached the requirements. 
Table 7.2

The testing results with samples randomly selected from training samples.

\begin{tabular}{|c|c|c|c|c|c|c|c|c|c|c|c|c|c|}
\hline \multicolumn{2}{|c|}{ Samples } & 1 & 3 & 4 & 8 & 11 & 17 & 21 & 22 & 26 & 29 & 32 & 35 \\
\hline \multicolumn{2}{|c|}{ Actual aquifer } & I & I & I & II & II & II & III & III & III & IV & IV & IV \\
\hline & $\mathrm{X} 1$ & 1.00 & 1.00 & 1.00 & 0.00 & 0.00 & 0.00 & 0.00 & 0.00 & 0.00 & 0.09 & 0.01 & 0.00 \\
\hline Output & $\mathrm{X} 2$ & 0.00 & 0.00 & 0.00 & 1.00 & 1.00 & 1.00 & 0.00 & 0.00 & 0.00 & 0.01 & 0.01 & 0.00 \\
\hline \multirow[t]{2}{*}{ Vectors } & X3 & 0.00 & 0.00 & 0.00 & 0.00 & 0.00 & 0.00 & 1.00 & 1.00 & 1.00 & 0.02 & 0.00 & 0.00 \\
\hline & $\mathrm{X} 4$ & 0.00 & 0.00 & 0.00 & 0.00 & 0.00 & 0.00 & 0.00 & 0.00 & 0.00 & 0.99 & 0.99 & 0.99 \\
\hline \multicolumn{2}{|c|}{ Aquifer identified } & $\mathrm{I}$ & I & $\mathrm{I}$ & II & II & II & III & III & III & IV & IV & IV \\
\hline \multicolumn{2}{|c|}{$\begin{array}{l}\text { Recognition } \\
\text { results }\end{array}$} & True & True & True & True & True & True & True & True & True & True & True & True \\
\hline
\end{tabular}

Table 7.3

The remaining sample sets and their vector representations.

\begin{tabular}{|c|c|c|c|c|c|c|c|c|c|c|c|}
\hline \multirow{2}{*}{$\begin{array}{c}\text { Sample } \\
\text { No. }\end{array}$} & \multicolumn{6}{|c|}{ Ions $(\mathrm{Mg} / \mathrm{L})$} & \multirow{2}{*}{ Aquifer } & \multicolumn{4}{|c|}{ Vector representation } \\
\hline & $\mathrm{Na}^{+}+\mathrm{Ka}^{+}$ & $\mathrm{Ca}^{2+}$ & $\mathrm{Mg}^{2+}$ & $\mathrm{Cl}^{-}$ & $\mathrm{SO}_{4}^{2-}$ & $\mathrm{HCO}_{3}{ }^{-}$ & & $\mathrm{T} 1$ & $\mathrm{~T} 2$ & T3 & $\mathrm{T} 4$ \\
\hline 1 & 23.76 & 66.40 & 19.59 & 18.13 & 57.26 & 255.29 & I & 1 & 0 & 0 & 0 \\
\hline 2 & 9.97 & 64.45 & 26.84 & 9.59 & 40.53 & 288.14 & II & 0 & 1 & 0 & 0 \\
\hline 3 & 294.75 & 8.93 & 3.63 & 30.27 & 24.24 & 680.51 & III & 0 & 0 & 1 & 0 \\
\hline 4 & 14.19 & 81.96 & 24.14 & 25.81 & 40.99 & 315.08 & IV & 0 & 0 & 0 & 1 \\
\hline
\end{tabular}


Table 7.4

The forecasting results of neural network with 4 remaining samples.

\begin{tabular}{|c|c|c|c|c|c|}
\hline \multicolumn{2}{|l|}{ Samples } & 1 & 2 & 3 & 4 \\
\hline \multicolumn{2}{|c|}{ Actual aquifer } & I & II & III & IV \\
\hline & $\mathrm{X} 1$ & 0.99 & 0.01 & 0.00 & 0.01 \\
\hline Output & $\mathrm{X} 2$ & 0.00 & 1.00 & 0.00 & 0.00 \\
\hline \multirow[t]{2}{*}{ Vectors } & X3 & 0.00 & 0.00 & 1.00 & 0.00 \\
\hline & $\mathrm{X} 4$ & 0.04 & 0.01 & 0.02 & 0.99 \\
\hline \multicolumn{2}{|c|}{ Aquifer identified } & I & II & III & IV \\
\hline \multicolumn{2}{|c|}{ Recognition results } & True & True & True & True \\
\hline
\end{tabular}

Among the 39 water samples, 35 of them are used for training and testing the neural network, so there are 4 samples (see Table 7.3) that are still not used to train or test the networks, in the next step, that 4 remaining samples then can be used for testing the prediction function of the network which has been trained and tested completely by those 35 samples. The first step of the prediction process is to use the 4 remaining samples as new input data of the neural network to calculate their output vectors, and then by comparing every element of the output vectors with the target vectors, we will be able to know which aquifer each of these four new samples belongs to. The final output vectors and prediction results are shown in Table 7.4. As seen from the table that the aquifers forecasted by the neural network are fully consistent with the actual aquifers, which indicates that this trained network absolutely can be utilized to water sources recognition for any new water samples collected from mine areas. Hence when water inrush occurred, the identification of water sources become faster and easier because we do not need to establish a complex mathematical model, only by entering the collected water samples into the trained network, we can predict which aquifer is related to water inrush. 


\subsection{Summary of the chapter}

Based on the problem of how to identify the water source quickly and accurately when a water inrush occurs in the process of mining to avoid more casualties and to control the disaster, this chapter proposed and developed an approach of using the BP neural network to achieve water source identification. 35 water samples selected from Jiaozuo mine area have been used for a case study in this chapter, the final testing and forecasting results indicated that BP neural network is an ideal tool to realize water source recognition, the model is simple and the recognition result is accurate. Compared with the method of hydrochemical analysis, the ANN method is more objective because the process of training and forecasting is based on objective samples rather than subjective judgement. In comparison with the nonlinear methods, the ANN method can automatically establish a nonlinear mapping between the input data and output data without setting a complex mathematical model, which can save a lot of tedious calculations.

The biggest disadvantage of the BP neural network is that it uses the traditional gradient descent method to achieve the minimum mean square error, thus resulting in the network is not very stable and sometimes the model can get stuck in local minima instead of converging to global minimum, in addition, the model is very sensitive in initial weights and thresholds, sometimes the initial weight and thresholds even affect the convergence rate of the network, so the further research should focus on improving this model by changing the iterative algorithm. 



\section{Chapter 8 Conclusions and recommendations for future work}

\subsection{Conclusions}

As it has been described in Chapter 2 (section 2.1), for the research of geological hazards, the most important aspects are to solve two kinds of problems, the scientific problems and the engineering problems. The scientific problems include: Why does it happen? What are the mechanisms of its occurrence? Which factors are associated with its occurrence and how each of the corresponding factors affects its occurrence? The engineering problems include: How to prevent it from happening and how to evaluate the risk of its occurrence? If it occurs, what measures are needed to be taken to minimize the damages?

Since the research object of this thesis is also a kind of geological hazard in underground engineering, the fault-induced mine water inrush. Therefore in this chapter, the conclusions of this thesis are just given by answering the above problems according to the studies conducted in the previous chapters (Chapter 4 to Chapter 7).

Why does fault-induced water inrush happen in underground mining?

According to the studies conducted in Chapter 4, a fault may act as a potential water passageway to cause water inrush incidents in underground mining mainly due to two reasons. First, the fault zone is a high permeability structure that facilitates water flow; second, the fault zone itself is a typical water-bearing structure.

What are the mechanisms of fault-induced water inrush?

According to the studies conducted in Chapter 4 and Chapter 5, in mining practices, typical fault-induced water inrushes mainly occur in the following two situations. In the first situation, the seam and the aquifer are simultaneously cut by a large fault. In this condition the fault actually serves as a conduit which connects the seam to the aquifer, with the advancement of working face along the seam, an unexpected inrush incident may sudden occur if the working face just approach to close the fault and at the same time the fault has a good water conductivity. 
In the second situation, a small fault is connected to the aquifer but not connected to the seam. According to the modelling and calculation results obtained in Chapter 4, under the coupled actions of mining-induced stresses and fluid pressure, a water conduit between the aquifer and the seam also can be formed to result in a water inrush incident due to fault reactivation.

Which factors are associated with the occurrence of fault-induced water inrush and how each of the corresponding factors affects its occurrence?

According to the studies conducted in Chapter 4, Chapter 5 and Chapter 6 all the factors including the aquifer pressure, the aquifuge thickness, the aquifuge strength, the fault dip, the fault throw, fault length, the mining depth, the advancement of the working face, geostatic and tectonic pressures etc. are associated with fault-induced water inrushes. Based on the numerical simulation results obtained in Chapter 4 , for water inrushes caused by a small fault due to fault reactivation, how each of the related factors affects the water inrush occurrence as follows:

(1) In general, if the combined effect of geostatic and tectonic pressures exceed the fluid pressure, the possibility of water inrush increases with the mining depth.

(2) Water inrushes can be induced by compressive fracture at the fault tip when aquifer pressure is low or by shear fracture at the fault tip when fluid pressure is high.

(3) Both the compressive stress concentration and the shear stress concentration increase as the fault length increases, which increase the possibility of water inrush occurrence.

(4) Working face advancement can also lead to a water accident due to the overall stress concentration magnitude increase at the fault tip as the mine face approaches the tip.

\section{How to evaluate the risk of fault-induced water inrush?}

This thesis addressed the risk assessment of the fault-induced water inrush from two different perspectives.

In Chapter 5 the ANFIS model was introduced to predict the fault-induced water inrush risk. Six parameters related to the aquifer, the water-resisting properties of the aquifuge and the mining-induced stresses were extracted as the major parameters to construct the ANFIS model. The constructed ANFIS was trained with 20 reported real fault- 
induced water inrush cases, and another 5 new cases were used to test the prediction performance of the trained ANFIS. The final results showed that the predicted results of the 5 cases were completely consistent with the actual situations. This indicates that using ANFIS to quantitatively predict the risk of fault-induced water inrush is possible.

In Chapter 6, the risk assessment of the fault-induced water inrush was conducted from another perspective. Unlike Chapter 5 only concerned the water inrush risk caused by a specific fault (a specific location), Chapter 6 assess the fault-induced water inrush risk for a whole coalfield with consideration of all the main related parameters and all the interacting actions between parameters. In Chapter 6, by means of the RES and by considering the water yield property of aquifer, the aquifer pressure, the aquifuge thickness, the aquifuge strength, the depth of coal seam, the fault density and the water source recharge as the seven main parameters related to fault-induced water inrush, a new systematic approach for evaluating the water inrush index (range between 0 and 100) was proposed and developed, and such index will help to understand the risk degree of water inrush.

If fault-induced water inrush occurs, what measures are needed to be taken to minimize the damages?

For a sudden inrush accident in underground, accurately recognizing which aquifer or which water body is directly associated with the accident can take a big step in estimating the inrush scale and then taking further pumping measures to manage the and control the accident. In this thesis, using the ANN method to identify the inrush sources was proposed and developed. According to the studies that were carried out in Chapter 7, the use of ANN to identify the water-inrush sources has the advantages of accuracy, objectivity and simplicity. 


\subsection{Recommendations for future work}

There are many more interesting ideas that could develop from the work presented in this thesis:

(1) In Chapter 4, a computational model was established to simulate how a small hidden fault can be activated to cause water inrushes, however, in actual mining practices, water hazards caused by a large visible fault are also very common, therefore, using numerical methods to analyze water inrushes caused by large faults are also necessary.

(2) In Chapter 5, six parameters were selected as the main controlling parameters to evaluate the risk of water inrush caused by a specific fault. In the future work, more mining-condition-related parameters need to be considered into the risk assessment model, mining-condition-related parameters such as mining width, mining speed, floor and roof strength, mining methods, etc. are also very important in determining whether a fault has the possibility in inducing a water inrush incident.

(3) In Chapter 6, a new method of using RES to assess the risk of fault-induced water inrush for a whole coalfield was proposed. But because the lack of geological data, only one case study has been carried out in that chapter and so the proposed method has not been fully verified. In the future works, more case studies need to be done to verify the proposed method.

(4) In Chapter 7, using BP neural network to identify the water inrush sources was proposed. But the biggest disadvantage of the BP model is that it uses the traditional gradient descent method to achieve the minimum mean square error, thus resulting in the network is not very stable and sometimes the model can get stuck in local minima instead of converging to global minimum. In addition, the model is very sensitive in initial weights and thresholds, sometimes the initial weight and thresholds even affect the convergence rate of the network, so the further research should focus on improving this model by changing the iterative algorithm. 
(5) As can be seen, in this thesis, in Chapter 5 and Chapter 7, two different kinds of ANN model were applied to solve the corresponding problems. The machine learning methods were used in these two chapters to learning knowledge from the collected samples or historical samples and to predict new samples by using the learned knowledge. Today's world is a big data world, and without doubt that artificial intelligence (AI) will bring a new round of technological revolution. For the research in geological hazards, many backward concepts need to be changed, a backward concept such as if we do not precisely understand the mechanisms of a geological hazard, then we cannot predict precisely its occurrence. In recent years, the welldeveloped AI provides us many new techniques to solve engineering problems. In the future works, by using more new AI techniques into the research of mine water inrush will achieve more significant achievements. 


\section{References}

Ali BN, Golam RS, Mohammad A (2014) Risk analysis and prediction of out-of-seam dilution in longwall mining. International Journal of Rock Mechanics \& Mining Sciences70:115122

Andrade EM, Queiroz PHA, Souza IH, Oliveira LRA, Guerreiro MJ (2008) Land use effects in groundwater composition of an alluvial aquifer (Trussu River, Brazil) by multivariate techniques. Environmental Research 106:170-177

Annandale JG, Jovanovic NZ, Tanner PD, Benade N, Du Plessi HM (2002) The sustainability of irrigation with Gypsiferous mine water and implications for the mining industry in south Africa. Mine water and the Environment 21 (2): 81-90

Asferg JL, Poulsen PN, Nielsen LO (2007) A consistent partly cracked XFEM element for cohesive crack growth. Int J Numer Meth Eng 72(4):464-485

Astel S, Tsakovski P, Barbieri V, Simeonov (2007) Comparison of self-organizing maps classification approach with cluster and principal components analysis for large environmental data sets. Water Research 4:4566-4578

Aviles CA, Scholz CH, Boatwright J (1987) Fractal analysis applied to characteristic segments of the San Andreas fault. J. Geophys. Res Solid Earth 92(B1):331-344

Babuska I, Melenk J M (1997) The partition of unity finite element method. International Journal for Numerical Methods in Engineering 40 (4): 727-758

Berzas JJ, Garcia LF, Rodriguesand RC, Martin-Alvarez PJ (2000) Evolution of the water quality of a managed natural wetland: tables de daimiel national park (Spain). Water Research 34 (12):3161-3170

Bense VF, Van Balen RT (2003) Hydrogeological aspects of fault zones on various scales in the Roer Valley Rift System. Journal of Geochemical Exploration 78-79:317-320.

Belytschko T, Black T (1999) Elastic crack growth in finite elements with minimal remeshing. International Journal for Numerical Methods in Engineering 45:601-620

Bordas S, (2003) Extended Finite Element and level set methods with applications to growth of cracks and biofilms. PhD thesis, Northwestern University.

Bu W, Mao X (2009) Research on effect of fault dip on fault activation and water inrush of coal floor. Chin. J Rock Mech Eng 28:386-394

Brown ET, Hoek E (1978) Trends in relationships between measured in-situ stresses and depth. Int J Rock Mech Min Sci Geomech Abstr 15(4):211-215 
Castaldini D,Genevois R,Panizza M , Puccinelli A, Berti M,Simoni A (1998) An integrated approach for analyzing earthquake-induced surface effects: A case study from the Northern Apennines, Italy. J. Geodynamics 26:413-441

Caine JS, Evans JP, Forster CB (1996) Fault zone architecture and permeability structure. Geology 24(11):1025-1028.

Caraballo MA, Macias F, Miguel NJ (2016) Long term fluctuations of groundwater mine pollution in a sulfide mining district with dry Mediterranean climate: Implications for water resources management and remediation. Science of the total environment 539:427-435

Cathy ML, Louis MM, Jeffrey GS, Paul FZ (2002). The effects of sulfate on the physical and chemical properties of actively treated acid mine drainage floc. Mine Water and the Environment 21:114-120

Chiu SL (1997) An efficient method for extracting fuzzy classification rules from high dimensional data. J. Advanced Computational Intelligence 1:1-7

Chiu SL (1994) Fuzzy model identification based on cluster estimation. J. Intell. Fuzzy Syst. 2: $267-278$

Chen ZH, Hu ZP, Li H, Chen QF (2011) Fracture mechanical model and criteria of insidious fault water inrush in coal mines. Journal of China University of Mining \& Technology 40:673-677 (In Chinese)

Coalfield Geological Central Bureau of China. Coalfield hydrogeology of China. Coal Industry Publishing House of China 2000, pp 15-59, Beijing

Day JA, Dallas HF, Wackernagel A (1998) Delineation of water management regions for South Africa rivers based on water chemistry. Aquatic Ecosystem Health and Management $1: 183-197$

Da silva, AMM, Sacomani LB (2001). Using chemical and physical parameters to define quality of Pardo river water (Botucatu sp Brazil). Water Research 35(6):1609-1616

David Kriesel (2005) A brief introduction to neural networks. http://www.dkriesel.com/ en/science/neural_networks.

Detournay E (2004) Propagation regimes of fluid-driven fractures in impermeable rocks. Int. J. Genmech 4 (1):1-11

Desroches J, Detournay E, Lenoach B, Papanastasiou P, Pearon JAR, Thiercelin M (1994) The crack tip region in hydraulic fracturing. Proc. R. Soc. Lond. Ser 447:39-48

Detlef B (2012) Inrush and mine inundation-A real threat to Australian coal mines. International Mine Water Association, In: Annual Conference. 
Dillon WR, Goldstein M (1984) Multivariate analysis methods and application. John and Wiley and Sons.

Dolbow J, Moës N, Belytschko T (2001) An extended finite element method for crack growth with frictional contact. Comput Method Appl M 190(51-52): 6825-6846.

Dong D, Sun W, Xi S (2012) Water-inrush assessment using a GIS-based bayesian network for the 12-2 coal seam of the Kailuan Donghuantuo coal mine in China. Mine Water Environ 31:138-146

Dumpleton S, Robins SN, Walker JA, Merrin PD (2001) Mine water rebound in South Nottinghamshire: risk evaluation using 3-D visualization and predictive modelling. Quarterly Journal of Engineering Geology and Hydrogeology 34:307-319

Duarte CA, Oden JT (1996) H-p clouds: A h-p meshless method. Numerical Methods for Partial Differential Equations 12: 673-705

EDI (2010) Fatalities in Queensland coal mines 1882-2010. The State of Queensland, Department of Employment, Economic Development and Innovation, Australia.

Erdogan F, Sih GC (1963) On the Crack Extension in Plates Under Plane Loading and Transverse Shear. Journal of Basic Engineering 85(4):519-527.

Faramarzi F, Ebrahimi FMA, Mansouri H (2013) An RES-based model for risk assessment and prediction of backbreak in bench blasting. Rock Mechanics \& Rock Engineering 46:877-887

Faramarzi F, Mansouri H, Ebrahimi Farsangi MA (2013) A rock engineering systems based model to predict rock fragmentation by blasting. International Journal of Rock Mechanics and Mining Sciences 60:82-94

Fattahi H, Shojaee S, Ebrahimi Farsangi MA (2013) Application of adaptive neuro-fuzzy inference system for the assessment of damaged zone around underground spaces. Int. J. Optim. Civil Eng. 3(4):673-693

Fattahi H, Shojaee S, Ebrahimi Farsangi MA, Hamid M (2013) Hybrid Monte Carlo simulation and ANFIS-subtractive clustering method for reliability analysis of the excavation damaged zone in underground spaces. Computers and Geotechnics 54:210 221

Farhad F, Hamid M, Ebrahimi Farsangi MA (2014) Development of rock engineering systems-based models for flyrock risk analysis and prediction of flyrock distance in surface blasting. Rock Mechanics \& Rock Engineering 47:1291-1306

Foroutan-pour K, Dutilleul P, Smith DL (1999) Advances in the implementation of the boxcounting method of fractal dimension estimation. Appl Math Comput 105(2):195-210 
Fukushima K (1980) Neocognitron a Self-Organizing Neural Network Model for a Mechanism of Pattern-Recognition Unaffected by Shift in Position. Biological cybernetics 36(4):193-202

Francis SK (2004) Problem in "Void” detection in coal mine water hazards. 23rd International Conference on Ground Control in Mining Morgantown, West Virginia, USA.

Garagash D, Detourmay E (2000) The tip region of a fluid-driven fracture in an elastic medium. J. Appl. Mech 67 (1):183-192

Goodman R (1965) Groundwater inflows during tunnel driving. Eng Geol 2:39-56

Goddard JV, Evans JP (1995) Chemical changes and fluid-rock interaction in faults of crystalline thrust sheets. Northwestern Wyoming, U.S.A. Journal of Structural Geology $17: 533-547$

Graca MAS, Coimbra CN (1998) The elaboration of indices to assess biological water quality. A case study. Water Research 32:380-392

Gudmundsson A (2005) Effects of mechanical layering on the development of normal faults and dykes in Iceland. Geodinamica Acta 18:11-30

Gudmundsson A, Simmenes TH, Larsen B, Philipp SL (2010) Effects of internal structure and local stresses on fracture propagation, deflection, and arrest in fault zones. Journal of Structural Geology 32: 1643-1655

Hamid RZ, Ali U, Mostafa S (2012) Identifying geological hazards related to tunneling in carbonate karstic rocks-Zagros, Iran. Arab J Geosci 5:457-464

Hill J G, Price D R (1983) The impact of deep mining on an overlying aquifer in western Pennsylvania. Ground Water Monit R 3(1):138-143

Hou TX, Yang XG, Xing HG, Huang KX, Zhou JW (2016) Forecasting and prevention of water inrush during the excavation process of a diversion tunnel at the Jinping II Hydropower Station, China. SpringerPlus 5(1):1-19

Homa R, Ahmad A, Ayoob T (2010) Evaluation of spatial and temporal variation in water quality by pattern recognition techniques: A case study on Jajrood River (Tehran, Iran). Journal of Environmental Management 91:852-860

Hu Y, Zheng S (1996) Application of grey related degree method in identifying mine water inrush sources in Xinhe. Coal Geology of China 4:50-51

Hu WY (2010) The characteristics of karst and deep coal mine karst water hazards in eastern North China. Coal geology \& Exploration 38:23-27 
Huang HF, Mao XB, Yao BH, Pu H (2012) Numerical simulation on fault water-inrush based on fluid-solid coupling theory. Journal of Coal Science \& Engineering 18(3):291-296

Huang RQ, Huang J, Ju NP, Li YR (2013) Automated tunnel rock classification using rock engineering systems. Engineering Geology 156:20-27

Hudson J, Harrison J (1992 )A new approach to studying complete rock engineering problems, Quarterly Journal of Engineering Geology and Hydrogeology 25:93-105

Hudson JA, Harrison JP (1990) A new approach to studying complete rock engineering problems. Q. J. Engng Geol 25:93-105

Hudson JA (1993) Establishing potential behavioral modes of rock engineering systems by computer simulation of interaction matrix energy flux. Int. J. Rock Mech. Min Sci. \& Geomech. Abstr 30:457-468

Istvan B, Lucien D, Antal S, Ferenc S (1980) Stochastic forecasting of mine water inrushes. Advances in Water Resources 3(1):3-8

IsIam MR, Ryuichi S (2009) Mining-induced fault reactivation associated with the main conveyor belt roadway and safety of the Barapukuria Coal Mine in Bangladesh: Constraints from BEM simulations. Int. J. Coal Geol. 79(4):115-130

Jang JSR (1996) Input selection for ANFIS learning. Proceedings of the Fifth IEEE International Conference on Fuzzy Systems 3:1493-1499

Jang JSR (1991) Fuzzy modeling using generalized neural networks and Kalman filter algorithm. Proceedings Ninth National Conference on Artificial Intelligence 2:762-767

Jang JSR (1993) Anfis: adaptive-network-based fuzzy inferencesystem. IEEE Trans. Syst. Man. Cybern. 23:665-685

Jonny R, Antonio PR, Frederic C, George JM (2015). Modeling of fault activation and seismicity by injection directly into a fault zone associated with hydraulic fracturing of shale-gas reservoirs. J. Petrol. Sci. Eng. 127:377-386

Johnson RA, Wichern DW (1992). Applied multivariate statistical analysis. $3^{\text {rd }}$ ed. 642 pp. Prentice-Hall International, Englewood Cliffs, New Jersey, USA

Kanninen MC, Popelar (1985). Advanced fracture mechanics, Volume Oxford Engineering Science Series. Oxford University Press 1985

Kim MK, Yoo YI, Song JJ (2008) Methodology to quantify rock behavior around shallow tunnels by Rock Engineering Systems. Geosystem Engineering 11 (2):37-42 
Koukouvelas IK, Asimakopoulos M, Doutsos TT (1999) Fractal characteristics of active normal faults: an example of the eastern Gulf of Corinth, Greece. Tectonophysics 308(1):263-274

Krzysztof P, Kazimierz R, Piotr C (2016) Causes and effects of uncontrolled water inrush into a decommissioned mine shaft. Mine Water Environ. 35:128-135

Kuscer D (1991) Hydrological regime of the water inrush into the Kotredez Coal Mine (Slovenia, Yugoslavia). Mine Water and the Environment 10:93-102

Kurlenya MV, Baryshnikov VD, Gakhova LN (2013) Effect of partial water flooding on the stress-strain state of the crown pillar in the Aikhal Mine. J. Min. Sci. 49(4):537-543

Larsen P (1980) Industrial Applications of Fuzzy-Logic Control. Int. J. Man-Mach. Stud 12(1):3-10

Latham JP, Lu P (1999) Development of an assessment system for the blastability of rock masses. International Journal of Rock Mechanics and Mining Sciences 36:41-55

Le Cun, Yann. Une (1985) Procedure d'apprentissage pour reseau a seuil assymetrique. Cognitive 85:599-604

Li LC, Yang TH, Liang ZZ, Zhu WC, Tang CA (2011) Numerical investigation of groundwater outbursts near faults in underground coal mines. International Journal of Coal Geology 85:276-288

Li LC, Tang CA (2009) Numerical Analysis of Pathway Formation of Groundwater Inrush Form Faults in Coal Seam Floor. Chinese Journal of Rock Mechanics and Engineering 28:290-297

Li D, Li X, Li C, Huang B, Gong F, Zhang W (2009) Case studies of groundwater flow into tunnels and an innovative water-gathering system for water drainage. Tunn Undergr Space Technol 24:260-268

Li FZ, Needleman A (1985) A Comparison of Methods for Calculating Energy Release Rates. Engineering Fracture Mechanics 21(2):405-421.

Li J, Xu Y, Xie X, Yao Y, Gao Y (2015) Influence of mining height on coal seam floor failure depth. Journal of China Coal Society 40:303-310

Liang DX, Jiang ZQ, Guan YZ (2015) Field research: measuring water pressure resistance in a fault-induced fracture zone. Mine Water and the Environment 34:320-328

Liang J (1993) Application of grey relational analysis in the recognition of mine water sources. Coal Geology of China 6:42-44

Librando V, Mayazzu G, Puglisi A (1995) Multivariate micro pollutants analysis in marine waters. Journal of Science and Technology 32 (9-10):341-348 
Liebovitch LS, Toth T (1989) A fast algorithm to determine fractal dimensions by box counting. Phys Lett A 141(8-9):386-390

Liu ZJ, Hu YQ (2007) Solid-liquid coupling study on water inrush through faults in coal mining above confined aquifer. Journal of China University of Mining \& Technology 32(10):1046-1050

Lourenco ND, Chaves CL, Novais JM, Menezes JC, Pinheiro HM, Diniz D (2006) UV spectra analysis for water quality monitoring in a fuel park wastewater treatment plant. Chemosphere 65:786-791

Lu Y, Wang L (2015) Numerical simulation of mining-induced fracture evolution and water flow in coal seam floor above a confined aquifer. Computers and Geotechnics $67: 157-171$

Matsumoto N, Yomogida K, Honda S (1992) Fractal analysis of fault systems in Japan and the Philippines. Geophys Res Lett 19(4): 357-360

Masoud ZN, Rafael J, Reza K, KhalooKakaie R, Seyed-Mohammad EJ (2013) A new openpit mine slope instability index defined using the improved rock engineering systems approach. International Journal of Rock Mechanics \& Mining Sciences 61:1-14

Masoud ZN, Rafael J, Reza K, KhalooKakaie R, Seyed-Mohammad EJ (2011) A probabilistic systems methodology to analyze the importance of factors affecting the stability of rock slopes. Engineering Geology 118:82-92.

Mamdani EH, Assilian S (1999) An Experiment in Linguistic Synthesis with a Fuzzy Logic Controller. Int. J. Man-Mach. Stud. 51(2):135-147

Mazzoccola DF, Hudson JA (1996) A comprehensive method of rock mass characterization for indicating natural slope instability. Q. J. Engng Geol 29:37-56

Massart DL, Kaufman L (1983) The interpretation of analytical chemical data by the use of cluster analysis. Wiley, New York

Mahbub H, Syed Munaf A, Walid A (2008) Cluster analysis and quality assessment of logged water at an irrigation project, eastern Saudi Arabia. Journal of Environmental Management 86 (1):297-307

Marechal JC, Perrochet P (2003) New analytical solution for the study of hydraulic interaction between Alpine tunnels and groundwater. Bull Soc Geol Fr 174:441-448

Mcculloch WS, PIitts W (1990) A Logical Calculus of the Ideas Immanent in Nervous Activity (Reprinted from Bulletin of Mathematical Biophysics 1943; 5, 115-133). B. Math. Biol. 52(1-2):99-115 
Meng Z, Li G, Xie X (2012) A geological assessment method of floor water inrush risk and its application. Eng Geol 143:51-60

Melenk JM, Babuska I (1996) The partition of unity finite element method: Basic theory and applications, Comput. Method Appl. Mech 139 (1):289-314

Miao X, Cui X, Wang J, Xu J (2011) The height of fractured water-conducting zone in undermined rock strata. Engineering Geology 120:32-39

Mironenko V, Strelsky F (1993) Hydrogeomechanical problems in mining.Mine Water and the Environment 12(1):35-40

Ministry of coal industry of PRC (1984) Codes of mine hydrogeology.Coal Industry Publishing House of China, Beijing, China, pp 45-51

Mokhov AV (2007) Fissuring due to inundation of coal mines and its hydrodynamic implications. Doklady Earth Sciences 414:519-521

Motyka J, Bosch AP (1985) Karstic phenomena in calcareous-dolomitic rocks and their influence over the inrushes of water in lead-zinc mines in Olkusz region (South of Poland).International Journal of Mine Water 4:1-12

Mohammadi S. Extended finite element method for fracture analysis of structure. London: Blackwell Publishing, 2008

Moes N, Dolbow J, Belytschko T (1999) A finite element method for crack growth without remeshing. International Journal for Numerical Methods in Engineering 46: 131-150

Musa SDM, Raymond JD, Kim A AH, Nick K (2012) 3D edge detection seismic attributes used to map potential conduits for water and methane in deep gold mines in the Witwatersrand basin, South Africa. Geophysics77:133-147

Nagashima T, Omoto Y, Tani S (2003). Stress intensity factor analysis of interface cracks using XFEM, Int. J.Numer. Methods Eng 56 (8):1151-1173.

Nakano T, Tayasu I, Yamada Y, Hosono T, Igeta I, Hyodo F, Ando A, Saitoh Y, Tanaka T, Wada E, Yachi Sh (2008) Effect of agriculture on water quality of Lake Biwa tributaries, Japan. The Science of the Total Environment 389:132-148

Nicolas M, John D, Belytschko T (1999) A finite element method for crack growth without remeshing. International Journal for Numerical Methods in Engineering 46:131-150

Nurcihan C, Sener C (2008) An application of the interaction matrices method for slope failure susceptibility zoning: Dogankent settlement area (Giresun, NE Turkey). Bull Eng Geol Environ 67:375-385

Odintsev VN (2015) Miletenko MA. Water inrush in mines as a consequence of spontaneous hydrofracture. Journal of Mining Science 51:423-434 
Omid F, Seyed RT (2013) An application of rock engineering systems for estimating TBM downtimes. Engineering Geology 157:112-123

Ougang Y (2005) Evaluation of river water quality monitoring stations by principal component analysis. Water Research 39:2621-2635

Park K, Owatsiriwong A, Lee J (2008) Analytical solution for steadystate- groundwater inflow into a drained circular tunnel in a semiinfinite aquifer: a revisit. Tunn Undergr Space Technol- 23:206-209

Parinet B, Lhote A, Legube B (2004) Principal component analysis, an appropriate tool for water quality, evaluation and management-application to a tropical lake system. Ecological Modelling 178:295-311

Palchik V (2003) Formation of fractured zones in overburden due to longwall mining. Environ. Geol. 41(1):28-38

Parker DB (1985) Learning-logic: Casting the cortex of the human brain in silicon, Center for computational research in economics and management science, MIT press, Cambridge.

Przemysław B (2011) Water hazard assessment in active shafts in Upper Silesian Coal Basin Mines. Mine Water Environ. 30:302-311

Pérez-López R, Paredes C, Muñoz-Martín A (2005) Relationship between the fractal dimension anisotropy of the spatial faults distribution and the paleostress fields on a Variscan granitic massif (Central Spain): the F-parameter. J Struct Geol 27(4):663-677

Qian J, Zhang C, Fang L, Gao Z, Wang L (2010) Application of fuzzy excessive criterion model to determine source of inrush water in Xieqiao mine. Proceedings 2010 Sixth International Conference on Natural Computation 159-162

Qian MG, Liu TC (1983) Ground pressure and strata control in mine. Beijing: Coal Industry Press. (In Chinese)

Rafiee R, Ataei M, KhalooKakaie R (2015) A new cavability index in block caving mines using fuzzy rock engineering systems. International Journal of Rock Mechanics \& Mining Sciences 77:68-76

Rafiee R, Mohammad A, Khalokakaie, Seyed-Mohammad EJ, Farhang S (2015) Determination and assessment of parameters influencing rock mass cavability in block caving mines using the probabilistic rock engineering system. Rock Mechanics \& Rock Engineering 48: 1207-1220.

Rawling GC, Goodwin LB, Wilson, JL (2001) Internal architecture, permeability structure, and hydrologic significance of contrasting fault-zone types. Geology 29 (1): 43-46. 
Rapantova N, Krzeszowski, S, Grmela A. Wolkersdorfer C (2012) Quantitative assessment of mine water sources based on the general mixing equation and multivariate Statistics. Mine Water the Environment 31(4):252-265

Ren QW, Dong YW, Yu TT (2009) Numerical modeling of concrete hydraulic fracturing with extended finite element method. Sci China Ser E-Tech Sci 52:559-565

Reza K, Masoud ZN (2012) Ranking the rock slope instability potential using the Interaction Matrix (IM) technique: a case study in Iran. Arab J Geosci 5:263-273

Rozos D, Pyrgiotis L, Skias S, Tsagaratos P (2008) An implementation of rock engineering system for ranking the instability potential of natural slopes in Greek territory. An application in Karditsa County. Landslides 5:261-270

Rozos D, Bathrellos GD, Skillodimou HD (2011) Comparison of the implementation of rock engineering system and analytic hierarchy process methods, upon landslide susceptibility mapping, using GIS: a case study from the Eastern Achaia County of Peloponnesus, Greece. Environ Earth Sci 63:49-63

Rumelhart DE, Hinton GE, Williams RJ (1986) Learning representation by back-propagating errors. Nature 323: 533-536

Saaty TL (1980) The Analytic Hierarchy Process. McGraw-Hill, New York, pp 112-155

Santos CF, Bieniawski ZT (1989) Floor design in underground coalmines. Rock Mechanics and Rock Engineering 22(4):249-272

Sajjad A, Gholamreza S, Hossein J (2015) Risk analysis and prediction of floor failure mechanisms at longwall face in parvadeh-I coal mine using rock engineering systems (RES). Rock Mechanics \& Rock Engineering 49:1889-1901

Sameh WAM, Broder JM (2012) Interpretation of Groundwater Flow into Fractured Aquifer. International Journal of Geosciences 3: 357-364.

Sammarco O (1986) Spontaneous inrushes of water in underground mines. International Journal of Mine Water 1986, 5(2):27-42

Sammarco O (1988) Inrush prevention in an underground mine. International Journal of Mine Water 7(4):41-53

Schwarz L, Reichl I, Kirschner H, Robl K (2006) Risks and hazards caused by groundwater during tunneling: geotechnical solutions used as demonstrated by recent examples from Tyrol, Austria. Environ Geol 49:858-864

Sena C, Molinero, J (2009) Water resources assessment and hydrogeological modelling as a tool for the feasibility study of a closure plan for an open pit mine (La Respina Mine, Spain). Mine Water and the Environment 28(2):94-101 
Sfikas A, Angelidis, P, Petridis, DA (2016) Statistical approach for identification of potential pollution incidents due to lignite mining activity in a surface water stream. Desalination and water treatment 40:18606-18618

Simeonova V, Stratis JA, Samara C, Zachariadis G, Voutsa D, Anthemidis A, Sofoniou M, Kouimtzis Th (2003) Assessment of the surface water quality in Northern Greece. Water Research 37:4119-4124

Sian L, Victor B, Jenni T (2011) Fault architecture and deformation processes within poorly lithified rift Sediments, Central Greece. Journal of Structural Geology 33:1554-1568

Singh KP, Malik A, Sinha S (2005) Water quality assessment and apportionment of pollution sources of Gomti river (India) using multivariate statistical techniquesda case study. Analytica Chimica Acta 538:355-374

Singh RN, Hibberd S, Fawcett RJ (1986) Studies in the prediction of water inflows to longwall mine workings. Int J Mine Water 5(3):29-46

Shi LQ, Tan XP, Wang J, Ji XK, Niu C, Xu DJ (2015) Risk assessment of water inrush based on PCA_Fuzzy_PSO_SVC. Journal of China Coal Society 40(1):167-171

Shi LQ, Singh RN (2001) Study of mine water inrush from floor strata through faults. Mine Water and the Environment 20:140-147

Shin JH, Addenbrooke TI, Potts DM (2002) A numerical study of the effect of groundwater movement on longterm- tunnel behavior. Geotechnique 52:391-403

Sotelo MF, Andrade JM, Carlosena A, Tauler R (2007) Temporal characterization of river waters in urban and semi-urban areas using physico-chemical parameters and chemometric methods. Analytica Chimica Acta 583:128-137

Sun LH (2014) Statistical analysis of hydrochemistry of groundwater and its implications for water source identification: a case study. Arabian Journal of Geosciences 7(9):3417-3425

Sun L, Gui H (2012) Establishment of water source discrimination model in coal mine by using hydrogeochemistry and statistical analysis: a case study from Renlou coal mine in northern Anhui Province. Journal of Coal Science and Engineering 18(4):385-389 (in Chinese)

Sun Y, Sui W, Dong G, Liu S, Yu J (2013) Evaluation and depressurization of an ordvician limestone confined aquifer in Xingcun coal mine. In: Reliable Mine Water Technology. Colorado; pp. 893-898

Sui W, Liu J, Yang S, Chen Z, Hu Y (2011) Hydrogeological analysis and salvage of a deep coalmine after a groundwater inrush. Environmental Earth Sciences 62(4):735-749 
Stetzenbach KJ, Hodge VF, Guo C, Farnham IM, Johannesson KH (2001) Geochemical and statistical evidence of deep carbonate groundwater within overlying volcanic rock aquifers/aquitards of southern Nevada, USA. Journal of Hydrology 243(3-4):254-271

Szwedzicki T (2004) Warning signs to geotechnical failure of mining structures. Int. J. Min. Reclam. Env. 18(2):150-163

Takagi T, Sugeno M (1985) Fuzzy Identification of Systems and its Applications to Modeling and Control. IEEE Trans. Syst. Man. Cybern. 15(1):116-132

Tiwary RK, Dhar BB (1994) Environmental pollution from coal mining activities in Damodar River Basin, India. Mine Water and the Environment 13: 1-9

Tseng DJ, Tsai BR, Chang LC (2001) A case study on ground treatment for a rock tunnel with high groundwater ingression in Taiwan. Tunn Undergr Space Technol 16:175-183

Vutukuri VS, Singh RN (1995) Mine inundation-case histories. Mine Water Environ.14:107130

Wang KF, Zhang Q (2015) Analysis of hydraulic fracturing in concrete dam considering fluid-structure interaction using XFEM-FVM model. Engineering Failure Analysis 57:399-412

Wang Y, Yang W, Li M, Liu X (2012) Risk assessment of floor water inrush in coal mines based on secondary fuzzy comprehensive evaluation. International Journal of Rock Mechanics \& Mining Sciences 52:50-55

Wang JA, Park HD (2003) Coal mining above a confined aquifer. International Journal of Rock Mechanics \& Mining Sciences 40:537-55

Walsh JJ, Watterson J (1993) Fractal analysis of fracture patterns using the standard boxcounting technique: valid and invalid methodologies. J Struct Geol 15(12):1509-1512

Wisotzky F (2001) Prevention of acidic groundwater in Lignite Overburden Dumps by the addition of Alkaline Substances: Pilot-scale field experiments. Mine Water and the Environment 20 (3): 122-128

Wright IA, Ryan MM (2016) Impact of mining and industrial pollution on stream macroinvertebrates: importance of taxonomic resolution, water geochemistry and EPT indices for impact detection. Hydrobiologia 1:103-115

Wu Q, Wang M, Wu X (2004) Investigations of groundwater bursting into coal mine seam floors from fault zones. International Journal of Rock Mechanics \& Mining Sciences 41:557-571

Wu Q, Zhou W, Pan G, Ye S (2009a) Application of a discrete-continuum model to karst aquifers in North China. Ground Water 47(3):453-461 
Wu Q, Pang W, Wei Y (2006) The coupling technology of GIS and ANN of evaluation of vulnerability of groundwater inrush into coal mines from aquifers underlying the coal seams. J Chin Coal Soc 3:314-319

Wu Q, Zhou W, Wang J, Xie S (2009b) Prediction of groundwater inrush into coal mines from aquifers underlying the coal seams in China: application of vulnerability index method to Zhangcun Coal Mine, China. Environ Geol 57(5):1187-1195

Wu Q, Zhou W (2008) Prediction of groundwater inrush into coal mines from aquifers underlying the coal seams in China: vulnerability index method and its construction. Environ Geol 55(4):245-254

Wu Q, Zhang Z, Ma J (2007) The new practical evaluation method of floor water inrush. I: the establishment of the main controlling index system. J Chin Coal Soc 32(1):42-47

Wu Q, Liu Y, Yang L (2011a) Using the Vulnerable Index Method to assess the likelihood of a water inrush through the floor of a multi-seam coal mine in China. Mine Water Environ $30: 54-60$

Wu Q, Liu Y, Liu D, Zhou W (2011b) Prediction of floor water inrush: the application of GISbased AHP Vulnerable Index Method to Donghuantuo coal mine, China. Rock Mech Rock Eng 44:591-600

Wu J, Xu S, Zhou S, Qin Y (2016) Scenario analysis of mine water inrush hazard using Bayesian networks. Safety Science 89:231-239

Wunderlin DA, Pilar DM, Valeria AM, Fabiana PS, Cecilia HA, Bistoni MA (2001) Pattern recognition techniques for the evaluation of spatial and temporal variations in water quality. Water Research 35:2881-2894

Xu Z, Wang J, Zhang D, Xie H (1996) Fractal dimension description of complexity of fault network in coal mines. J China Coal Soc 21(4):359-363

Yau JF, Wang SS (1984) An analysis of interface cracks between dissimilar isotropic materials using conservation integral in elasticity, Eng. Fract. Mech 20(3):423-432

Younessi A, Rasouli V (2010) A fracture sliding potential index for wellbore stability analysis. International Journal of Rock Mechanics and Mining Sciences 47:927-939

Yuan W, Gui H (2005) The characteristics of geothermal temperature and its application in distinguishing the source of water in Renlou Mine. Journal of Anhui University of Science and Technology 4:9-12. (In Chinese)

Zadeh LA (1978) Fuzzy sets as a basis for a theory of possibility. Fuzzy Sets Syst. 1(1):3-28.

Zi G, Belytschko T (2003) New crack-tip elements for XFEM and applications tocohesive cracks. Int J Numer Meth Eng 57(15):2221-2240. 
Zhu W, Wei C (2011) Numerical simulation on mining-induced water inrushes related to geologic structures using a damage-based hydromechanical model. Environ Earth Sci 62:43-54

Zhao J, Chen S, Zuo R, Carranza EJM (2011) Mapping complexity of spatial distribution of faults using fractal and multifractal models: vectoring towards exploration targets. Comput Geosci 37(12):1958-1966

Zhang X, Zhang Z, Peng S (2003) Application of the second theory of quantification in identifying gushingwater sources of coal mines. Journal of China University of Mining and Technology 3:251-254

Zhang LZ (2013) Mechanism of water inrush for coal mine, deep exploitation-taking Wangfeng coal mine as an example. Doctor thesis, Chang’an University, Xi'an, China (In Chinese)

Zhang HQ, He YN, Tang CA, Bashir AJ, Han L (2009) Application of an improved Flowstress-damage model to the criticality assessment of water inrush in a mine: a case study. Rock Mech Rock Eng 42:911-930

Zhang LQ, Yang ZF, Liao LQ, Chen J (2004) An application of the rock engineering system(RES) methodology to rockfall hazard assessment on the Chengdu-Lhasa Highway, China International Journal of Rock Mechanics and Mining Sciences 41(3):526527

Zhang JC (2005) Investigations of water inrushes from aquifers under coal seams. International Journal of Rock Mechanics \& Mining Sciences 42:350-360

Zhang JC, Zhang YZ, Liu TQ (1997) Fluid flow in rockmass and water in-rush through coalseam floor. Beijing: Geology Press. ( In Chinese).

Zheng SH, Chen JZ, Liu HH (1999) Special applied hydrogeology. China University of Mining and Technology, Xuzhou.

Zhang D, Zheng S, Sun Y, Ji J (1994) Changping, geographic information system technology and the application in prediction of coal mine water disaster. China University of Mining and Technology, Beijing

Zhang J, Peng S (2005) Water inrush and environmental impact of shallow seam mining. Environ geol 48(8):1068-1076

Zhu B, Wu Q, Yang J, Cui T (2014) Study of pore pressure change during mining and its application on water inrush prevention: a numerical simulation case in Zhaogezhuang coalmine, China. Environ Earth Sci 71:2115-2132 
Zhu W, Wei C (2011) Numerical simulation on mining-induced water inrushes related to geologic structures using a damage-based hydromechanical model. Environ Earth Sci 62:43-54 